MARTHA CARRER CRUZ GABRIEL

\title{
ARTE TRANSMÍDIA NA ERA DIGITAL
}

Tese apresentada ao Programa de Pós-Graduação em Artes Visuais, Área de Concentração Poéticas Visuais, Linha de Pesquisa Multimeios, da Escola de Comunicação e Artes da Universidade de São Paulo, como exigência parcial para obtenção do Título de Doutor em Artes Visuais, sob a orientação da Profa. Dra. Silvia Laurentiz. 
Arte Transmídia na Era Digital 
Banca Examinadora 
Para meus pais, Roldão e Alzira, pelo eterno incentivo e torcida.

Para Pedro e Mariana, por serem a inspiração da minha vida.

Para Nilson, pela parceria, cumplicidade, incentivo e apoio, sempre, que tornam possíveis meus projetos e sonhos. 


\section{Agradecimentos}

Agradeço a Deus.

Agradeço à minha orientadora, Silvia Laurentiz,

pela competência e profissionalismo que admiro tanto, e que conduziram a orientação dessa tese, bem como pelo carinho, atenção, dedicação e amizade durante todo o processo. Muito obrigada, Silvia, querida!

Agradeço à minha família,

especialmente aos meus pais, Roldão e Alzira, que me formaram e incentivaram a estudar, pesquisar, questionar sempre, e ao meu marido, Nilson, e meus filhos, Pedro e Mariana, pelo companheirismo e paciência ao longo dos anos em que essa tese foi desenvolvida. Isto certamente nutriu e incentivou o desenvolvimento desse projeto.

Agradeço à banca de qualificação dessa tese:

Prof. Dr. Milton Sogabe e Prof. Dr. Gilbertto Prado, pelas valiosas discussões na qualificação, que muito contribuíram para o resultado final dessa tese.

Agradeço a todos professores, pesquisadores e autores, que por meio de suas obras contribuíram para essa pesquisa.

Agradeço a todos os cientistas, desenvolvedores, programadores, pessoas técnicas e comuns que com o seu trabalho ao longo da história nos trouxeram até aqui: a era transmídia. 


\section{Resumo}

Esta tese reflete sobre um processo específico: a transmídia e seu potencial de criar novas possibilidades interativas e artísticas apropriando-se dos ambientes digitais. A disseminação tecnológica no cotidiano das pessoas nas últimas décadas alavanca uma proliferação e diversidade de mídias que propiciam um ambiente fértil para desenvolvimento de processos transmidiáticos. Apesar de a transmídia não ser um fenômeno novo, as novas possibilidades que o ambiente digital hiperconectado e rico em novas mídias e interfaces traz são inúmeras, não apenas nas áreas das artes, mas também em quaisquer áreas que envolvam comunicação, informação e interação. Novos modos de interação trazem consigo novas possibilidades, tanto quanto novos desafios. 0 foco deste trabalho é o contexto atual transmidiático e as oportunidades e desafios emergentes de seu uso. 0 escopo compreende também a apresentação e análise de algumas obras de arte que se beneficiaram do uso da transmídia como processo fundamental para seu desenvolvimento, razão pela qual não seriam possíveis em outro cenário que não o transmidiático atual. Foram desenvolvidos pela autora quatro trabalhos de arte como experimentação transmídia que refletem os resultados obtidos.

Palavras-chave: Transmídia, Convergência, Mobile, Redes Sociais, Buscadores. 


\section{Abstract}

This thesis reflects about a particular process: the transmedia and its potential to create new interactive and artistic possibilities that appropriate from the digital environments. The technological dissemination in people's daily lives in the past decades leverages a media proliferation and diversification that propitiate a fertile environment for the development of transmedia processes. Although transmedia is not a new phenomenon, the new possibilities that the actual digital environment provide hiper-connected and rich in new media and interfaces - are countless, not only in the field of Arts, but also in any other areas related to communication, information and interaction. New interactive modes bring with themselves new possibilities as much as new challenges. The focus of this work is the emergent transmedia context and the opportunities and challenges that rise from its use. The scope here also involves the presentation and analysis of some artworks that take advantage from the use of transmedia as a fundamental process to their development, not being able to exist in any other scenario than the present one. It was developed by the author four artworks as transmedia experimentation that reflect the achieved results.

Keywords - Transmedia, Convergence, Mobile, Social Media, Search Engines. 


\section{LISTA DE ILUSTRAÇÕES}

Figura 1.1 - Imagem do vídeo da palestra Circuitos artísticos na era da mobilidade, proferida por Lucia Santaella ............................ 24

Figura 1.2 - TED Talk Where good ideas como from, por Steve Johnson .......... 26

Figura 1.3 - TED Talk When ideas have sex, por Matt Ridley $\ldots . \ldots \ldots \ldots \ldots \ldots . . . . .27$

Figura 1.4 - Imagem de acesso ao vídeo da TV1 sobre web semântica ............ 29

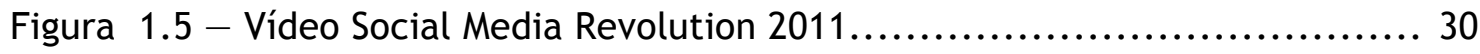

Figura 1.6 - Imagem do Hype-cycle de Gartner .............................. 37

Figura 1.7 - Imagem da página de acesso ao serviço SPOKEO ................. 41

Figura 1.8 - Imagem da página de entrada do site Please Rob Me ............... 44

Figura 1.9 - Imagem do vídeo A Arte do Cibridismo ......................... 52

Figura 1.10 - Imagem de acesso ao vídeo The Forth Screen $\quad . . . . . . . . . . . . . . . . . .53$

Figura 1.11 - Imagem de acesso ao filme EPIC 2015 ...........................54

Figura 1.12 - Imagem de acesso ao vídeo sobre futuro com Arthur Clarke ..........56

Figura 1.13 - Imagem de acesso ao vídeo do programa de TV World of Ideas, com Isaac Asimov ...............................................57

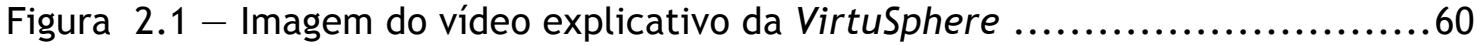

Figura 2.2 - Screenshot da entrada do campus da Universidade Anhembi Morumbi no Second Life ........................................ 62

Figura 2.3 - Imagem que mostra na metade esquerda uma foto da pessoa e na metade direita a imagem de seu avatar no Second Life ............... 65

Figura 2.4 - Screenshot do vídeo do trabalho de arte Skindoscope SL ..............68

Figura 2.5 - Diagrama da Sequência de Virtualidade (Virtuality Continuum) .......70

Figura 2.6 - Imagem da instalação de arte DE PROXÉMICA......................71

Figura 2.7 - Imagem do vídeo da We AR in MoMA................................72

Figura 2.8 - Imagem do vídeo da apresentação de Blaise Aguera y Arcas no

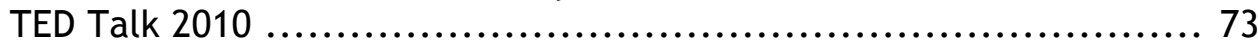

Figura 2.9 - Imagem da timeline da história da realidade aumentada .............74

Figura 2.10 - Imagem do vídeo mostrando a interação do holograma do CEO da Telstra em uma conferência ......................................76

Figura 2.11 - Holografia Tangível: vídeo de demonstração do desenvolvimento .....77 
Figura 2.12 - Foto da capa do livro Marketing na Era Digital com o marcador de realidade aumentada ..........................................78

Figura 2.13 - Foto mostrando o aplicativo de realidade aumentada Monocle, no iPhone ............................................................79

Figura 2.14 - Foto mostrando o holograma que dá informações a passageiros no aeroporto inglês de Luton ............................................8 80

Figura 2.15 - À esquerda, uma imagem de demonstração de aplicativo de rastreamento facial via webcam e à direita, exemplo de aplicação em realidade aumentada em uma ação do Burger King em 2009 que 'colocava' no rosto dos interatores máscaras digitais do filme Transformers 80

Figura 2.16 - Imagem do vídeo que apresenta o case The Real Life Like no Coca-Cola Village em Israel 86

Figura 2.17 - Imagem do vídeo de entrevista de Tim O’Reilly sobre Web 2.0, Web 3.0, Internet das Coisas .86

Figura 2.18 - Imagem do vídeo explicativo da ação Quick is Deadly da Nike para o tênis Zoom na China 89

Figura 2.19 - Imagem da loja da C\&A em campanha de 2009 90

Figura 2.20 - Imagem do cupom de desconto recebido no celular via Bluetooth na campanha da C\&A em 2009. .90

Figura 2.21 - Imagem do vídeo explicativo da ação Carefree - Interactive Vending Machine, da Unilever ....

Figura 2.22 - Imagem do outdoor eletrônico que mostrava o resultado em tempo real das participações dos torcedores na campanha Qual a Maior Torcida do RS? 92

Figura 2.23 - Fotografia do cartaz da promoção SPOLETO + FOURSQUARE .........95

Figura 2.24 - Processo de Mobile Tagging ........................................96

Figura 2.25 - Tipos de mobile tags .......................................97

Figura 2.26 - Imagem de uma Beetagg linkando para o perfil de Martha Gabriel no Twitter 97

Figura 2.27 - Imagem de uma Microsoft Tag .98

Figura 2.28 - Imagem do vídeo LabCast do MIT, demonstrando as características e funcionalidade do Bokode

Figura 2.29 - Imagem de um código de barras linear que armazena o número "123456"

Figura 2.30 - Imagem de um QR Code armazenando e linkando para a URL <http://www.martha.com.br/> 100 
Figura 2.31 - Imagem do clip Integral com o QR code para acessar o vídeo 103

Figura 2.32 - Foto de um iPhone com um cartão de embarque mobile da Swiss air usando o padrão Aztec de mobile tag ............................. 105

Figura 2.33 - Foto de um túmulo com QRcode no Japão ....................... 106

Figura 2.34 - Imagem de acesso ao vídeo sobre o NBuilding no Japão............. 108

Figura 2.35 - Imagem outdoor da Calvin Klein dando acesso à propaganda censurada 108

Figura 2.36 - Imagem do programa sobre o clima no Weather Channel, que apresenta um QRcode para download do aplicativo mobile do canal em aparelhos celulares Android

Figura 2.37 - Imagem de um QRcode com informações de contato

Figura 2.38 - Imagem do vídeo de demonstração da Stanford University Mobile Phone Orchestra

Figura 2.39 - Imagem de vídeo de demonstração do Flipboard para iPad 114

Figura 2.40 - Foto de celular mostrando a TV TIM veiculando campanha do Johnnie Walker Black Label 116

Figura 2.41 - Imagem do video do TED Talk com Nicholas Christakis: The hidden influence of social networks

Figura 2.42 - Gráfico que apresenta a proliferação das plataformas de redes sociais online 127

Figura 2.43 - Vídeo Evolution of Search.................................... 135

Figura 2.44 - Vídeo Web Semântica ........................................... 136

Figura 2.45 - Estatísticas de atividades online .............................. 137

Figura 2.46 - Comandos e operadores do Google ............................... 139

Figura 2.47 - Produtos e serviços do Google .................................. 141

Figura 2.48 - Imagem do vídeo Computing a theory of everything, com Stephen Wolpram no TED Talk 2010 150

Figura 2.49 - Imagem e QRcode de acesso ao vídeo de demonstração do banner em realidade aumentada da promoção de 1 dólar do Burguer King ... 156

Figura 2.50 - Imagem e QRcode de acesso ao vídeo de demonstração do game de realidade aumentada em 3D nas caixas de cereal Chocapic 157

Figura 2.51 - QRcode de acesso à matéria Camera-equipped digital billboards scan humans in Tokyo, serve up tailored ads

Figura 2.52 - Imagem do outdoor digital da campanha 15 Seconds of Fame no Times Square 159 
Figura 2.53 - Imagem de aplicativo vídeo imersivo que permite passear e explorar New York city.......................................... 160

Figura 2.54 - Imagens do início e final do vídeo Wario Land: Shake It! ............. 161

Figura 2.55 - Imagens do vídeo A hunter shoots a bear da Tipp-Ex .............. 162

Figura 2.56 - QRcode de acesso ao vídeo How to use YouTube annotations ........ 162

Figura 2.57 - Tabela dos Top 25 social games no Facebook, segundo a Inside Social Games.................................................... 166

Figura 3.1 - Imagem da imagem Abundance through evolution .................. 178

Figura 3.2 - Imagem do programa sobre o clima no Weather Channel, que apresenta um QRcode para download do aplicativo mobile do canal em aparelhos celulares Android

Figura 3.3 - Screenshot da entrevista em que lan Pearson fala sobre as previsões para os próximos 20 anos

Figura 3.4 - Screen shot do vídeo explicativo do ARG The Art of the Heist........ 183

Figura 3.5 - Evolução do tempo gasto no consumo de mídia por usuários de

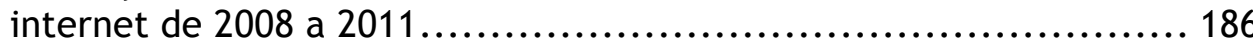

Figura 3.6 - Dispositivos usados enquanto se assiste à TV ou a vídeos ........... 187

Figura 3.7 - Dados de como as pessoas usam seus dispositivos móveis enquanto assistem à televisão ........................................... 188

Figura 4.1 - Screenshot do trabalho de arte moZaico de voSes .................. 190

Figura 4.2 - Screenshot do trabalho de arte Locative Painting.................. 192

Figura 4.3 - Screenshot do trabalho de arte SENSITIVE ROSE ................... 193

Figura 4.4 - Acesso ao vídeo do trabalho de arte SENSITIVE ROSE $\ldots \ldots \ldots \ldots \ldots \ldots \ldots 195$

Figura 4.5 - Acesso à página mobile de interação com o SENSITIVE ROSE ......... 195

Figura 4.6 - Foto do trabalho de arte Crystal Ball na exposição da Dinamize, Porto Alegre, jun.2010 196

\section{LISTA DE TABELAS}

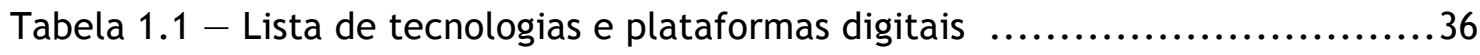

Tabela 2.1 - Tabela mostrando a capacidade máxima de um QR code para armazenamento de dados. Fonte: DENSO-WAVE, 2009 100

Tabela 2.2 - Linha cronológica dos buscadores web 


\section{SUMÁRIO}

Agradecimentos ..................................................... vii

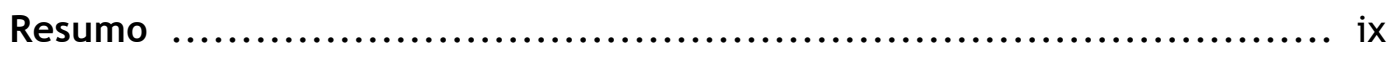

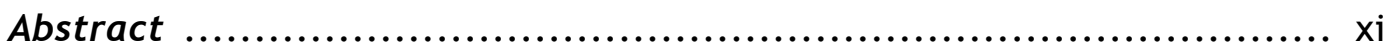

Lista de Ilustrações .............................................. xiii

Lista de Tabelas ...................................................... xvi

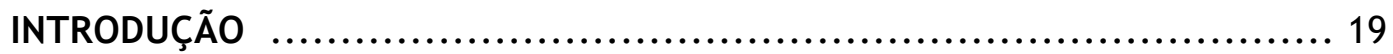

I. TRANSFORMAÇÃO DO AMBIENTE TECNO-INFO-SOCIAL ................... 23

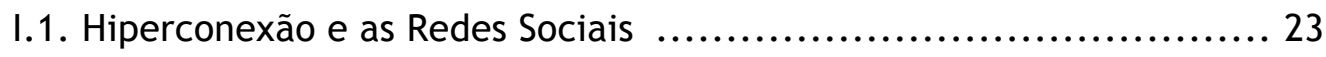

I.2. Parametrização da Mídia: Explosão do Conteúdo, Big-Data e Busca ... 31

I.3. Proliferação de Tecnologias e Plataformas .......................... 34

I.4. Era do Controle Distribuído ..................................... 40

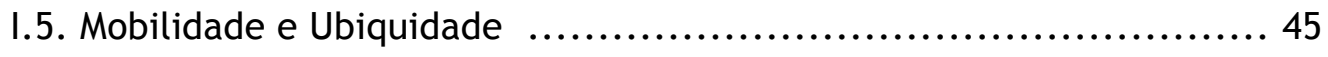

I.6. Cibridismo .................................................... 50

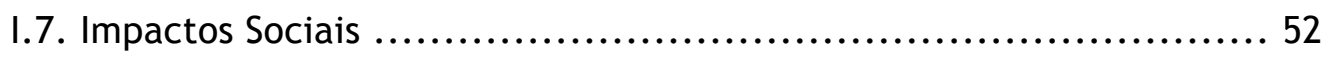

II. TECNOLOGIAS E PLATAFORMAS DIGITAIS ATUAIS E EMERGENTES ........ 59

II.1. Realidade Virtual ............................................... 59

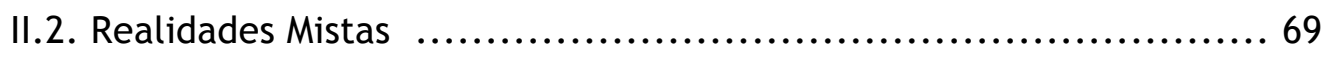

II.3. Tecnologias Mobile ........................................... 82

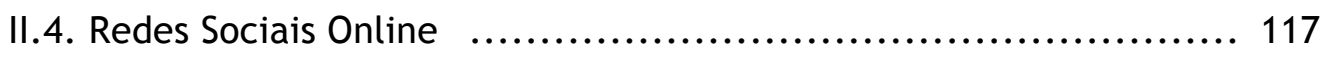

II.5. Busca Online .............................................. 130

II.6. Games, Vídeos, Conteúdos Digitais e Display ................... 155

III. TRANSMÍDIA E CONVERGÊNCIA .................................... 169

III.1. Hibridação e Convergência $\quad$..................................... 172

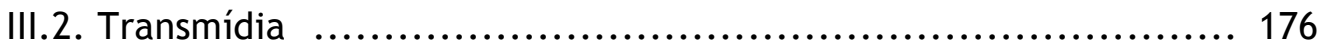

Arte Transmídia na Era Digital $\quad$ xvii 
IV. ARTE TRANSMÍDIA NA ERA DIGITAL ............................... 189

IV.1. Exemplo de aplicação 1: moZaico de voSes ....................... 190

IV.2. Exemplo de aplicação 2: Locative Painting .................... 192

IV.3. Exemplo de aplicação 3: SENSITIVE ROSE ...................... 193

IV.4. Exemplo de aplicação 4: Crystal Ball .......................... 196

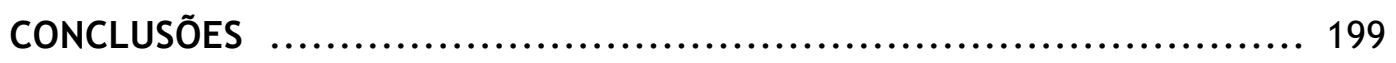

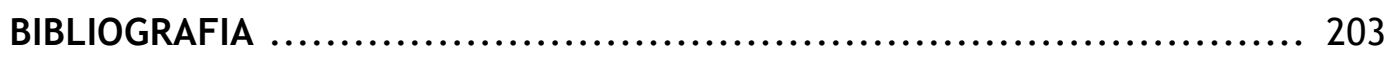

APÊNDICE A - Exemplos de Realidade Aumentada ...................... 211 


\section{INTRODUÇÃO}

A evolução das tecnologias digitais de informação e comunicação tem causado a disseminação de diversas plataformas emergentes que, somadas às tradicionais plataformas de comunicação, ampliam as possibilidades de interatividade, integração e hibridação dos meios e experimentação artística. Redes sociais online, tecnologias mobile, realidades mistas, tecnologias de voz, vídeo imersivo e games são algumas das plataformas digitais que se apresentam para ampliar o cenário de comunicação e interação. Nesse sentido, a análise e reflexão sobre as novas formas de interatividade, hibridação e convergências na web, possibilitadas pela introdução das tecnologias digitais, bem como seus possíveis impactos nas experimentações artísticas, mais especificamente no que se refere ao aumento das potencialidades de transmídia ${ }^{1}$, se fazem oportunas.

O objetivo principal deste trabalho é analisar em que medida as tecnologias digitais, que possibilitam as diversas plataformas digitais emergentes, afetam a web e/ou the acrescentam novas formas de interatividade, hibridação e convergências ${ }^{2}$, que favorecem especificamente os processos transmidia na arte.

Para a construção do quadro teórico de referência, foram utilizados os trabalhos de Lev Manovich (The Language of New Media), Frank Popper (Art of the Electronic Age), Stephen Wilson (Information Arts - intersections of art, science, and technology), Steven Johnson (A Cultura da Interface), Pierre Lévy (As tecnologias da Inteligência), Nicholas Negroponte (Vida Digital), Arlindo Machado (Máquina e Imaginário), Julio Plaza e Mônica Tavares (Processos Criativos com os Meios Eletrônicos), Lucia Santaella (Matrizes da Linguagem e Pensamento - Sonora, Visual, Verbal), Janet Murray (Hamlet no Holodeck), Henry Jenkins (Cultura da Convergência) e Guy Debord (A Sociedade do Espetáculo), bem como artigos específicos relacionados às novas tecnologias e novas mídias na arte.

\footnotetext{
${ }^{1}$ Transmídia é o processo de se utilizar mais de uma mídia para a construção de uma mensagem ou obra, de forma que cada a mensagem/obra transcenda uma única mídia e que cada mídia contribua com suas potencialidades. A transmídia é conceituada e discutida no capítulo 3.

${ }^{2}$ Hibridação e convergência serão abordadas e discutidas no capítulo 3.
} 
Desse modo, os estudos focados na evolução e proliferação de interfaces e da relação homem-computador, tal como proposto, foram essenciais ao entendimento das plataformas tecnológicas e à transformação social no estágio em que se encontra, permitindo situar no cenário atual as plataformas emergentes e suas possibilidades artísticas de transmídia.

Em decorrência do quadro teórico de referência apresentado acima, temos que: 1) a proliferação de tecnologias e plataformas digitais de comunicação e informação acrescentará novas possibilidades e complexidades à web, gerando novas formas de interatividade, hibridação e convergências entre arte e tecnologia, ampliando o cenário transmídia, de forma a possibilitar criações artísticas que antes não eram possíveis; 2) o modo de interação humano por meio das plataformas digitais emergentes é diferente do modo de interação nas mídias tradicionais, portanto requer um tratamento diferenciado para se explorar suas plenas possibilidades potenciais. Partindo dessas premissas, o presente trabalho se propõe a investigar como o cenário transmídia modifica o universo das criações artísticas, e vice-versa. A criação artística no ambiente transmídia atual, por exemplo, apresenta possibilidades distintas da criação artística na era pré-web, que contava com uma menor quantidade de plataformas, as quais eram predominantemente analógicas (como uma vídeo instalação). De onde lançamos a seguinte dúvida inicial: com a emergência e disseminação de plataformas e tecnologias digitais quais são as novas formas de criação e interação artísticas que ampliam o cenário de possibilidades criativas? Nossa tese é que há uma contribuição importante produzida pelas transmídias digitais, que criam poéticas e estéticas particulares somente possíveis no ambiente tecnológico atual.

Para a elaboração do presente trabalho foi feita uma pesquisa sobre o histórico e evolução das tecnologias e plataformas digitais de comunicação e informação até o estágio atual, e sobre as peculiaridades de cada uma delas.

A pesquisa utilizou referências relacionadas tanto com a engenharia, a computação e o marketing que dizem respeito a tecnologias de comunicação e informação, quanto com as humanidades, como comunicação e artes, que dizem respeito à linguagem e interação humana. 
Nesse sentido, são usadas tanto informações obtidas na internet sobre estado da arte em tecnologia, como livros e referências clássicas. Diversas tecnologias digitais na web ainda são recentes, e uma das principais dificuldades é encontrar textos, referências e trabalhos publicados sobre o assunto, especialmente sua aplicação no contexto da arte, mas também nas áreas comerciais e de produção.

Além da pesquisa teórica, foram desenvolvidos pela autora quatro trabalhos de arte como experimentação transmídia, afim de causar a reflexão a que o presente estudo se propõe - moZaico de voSes, Locative Painting, SENSITIVE ROSE e Crystal Ball.

Esta tese foi dividida em cinco capítulos.

O primeiro capítulo, “Transformações do Ambiente Tecno-Info-Social”, apresenta a mudança do cenário tecno-social pela introdução e proliferação de tecnologias e plataformas digitais na sociedade. A hiperconexão, o 'big-data', a mobilidade e o cibridismo são apontados como as principais tendências transformadoras do ambiente sócio-cultural que, consequentemente, afetam a arte contemporânea que nele se desenvolve e se apresenta.

O segundo capítulo, “Tecnologias e Plataformas Digitais”, traz um panorama das principais tecnologias e plataformas digitais que compõem o ambiente conectado atual, bem como das tendências emergentes, no intuito de apresentar as novas possibilidades para a criação transmídia.

O terceiro capítulo, "Convergência e Transmídia”, conceitua e analisa os processos de convergência e transmidiáticos no ambiente atual, altamente tecnológico, discutindo as possibilidades de hibridação e interação deles decorrentes.

O quarto capítulo, “Arte Transmídia na Era Digital”, é dedicado às reflexões sobre os processos transmidiáticos na arte e apresenta quatro trabalhos de arte que se apropriam de processos transmidiáticos digitais.

$\mathrm{Na}$ conclusão, analisamos as possibilidades transmídia nas criações artísticas e a maneira pela qual elas se afetam mutuamente. 


\section{CAPÍTULO I - TRANSFORMAÇÃO DO AMBIENTE TECNO-INFO-SOCIAL}

É inegável que as tecnologias digitais têm se tornado cada vez mais presentes em todos os aspectos da vida humana - social, profissional, pessoal - e têm impactado e afetado a sociedade, a cultura, o modo como vivemos e interagimos com o mundo. No entanto, vários fenômenos que se apresentam hoje categorizados como novidades, são na realidade, fenômenos antigos que foram impulsionados pelo digital e não causados por ele. Exemplo disso é o tão proclamado poder do usuário, que adquire papel central no cenário atual. Esse poder do usuário (que hoje ganha novo status, levando alguns a denominá-lo interator), foi realmente alavancado pela tecnologia digital -- tecnologias interativas de informação e comunicação, mobilidade, computação ubíqua, etc. --, mas que já se preconizava muito antes, pelo menos desde a década de 1970, quando foi inventado o controle remoto de TV, que passou a permitir que, com o movimento de apenas um dedo, o usuário mudasse de canal, 'interagindo e editando' facilmente, assim, a mídia à sua maneira.

Dos anos 70 para cá, muitas outras tecnologias vieram pouco a pouco embasando o cenário digital que se apresenta hoje e, como analisaremos a seguir, as principais transformações no ambiente tecnológico-informacional-social decorrente da disseminação e penetração das inúmeras tecnologias digitais no cotidiano das pessoas.

\section{I.1. Hiperconexão e as Redes Sociais}

Se considerarmos a evolução tecnológica, podemos dizer que desde a fala estamos caminhando para um cenário mais conectado. A evolução das tecnologias de comunicação e dos meios de transporte foi gradativamente nos libertando de limitações geográficas e temporais, e acelerando cada vez mais os processos comunicacionais. Ao mesmo tempo em que essas tecnologias diminuíam limitações (geográficas, temporais, suportes, etc.), também ampliavam possibilidades de conexão - com mais pessoas, em diversos lugares, de diversos ritmos, dispositivos e modos, inclusive simultâneos. Conforme novas tecnologias de informação, comunicação e conexão foram surgindo, fomos presenciando um colapso de tempo e espaço no planeta. 
Segundo Lucia Santaella (Figura 1.1),

o processo evolutivo das tecnologias desde a pré-história é um processo de crescimento, multiplicação e diversificação das possibilidades humanas de criar linguagem. A revolução digital se inicia na Revolução Industrial, quando se deu o surgimento de máquinas capazes de competir com a nossa capacidade de produzir e reproduzir linguagens.

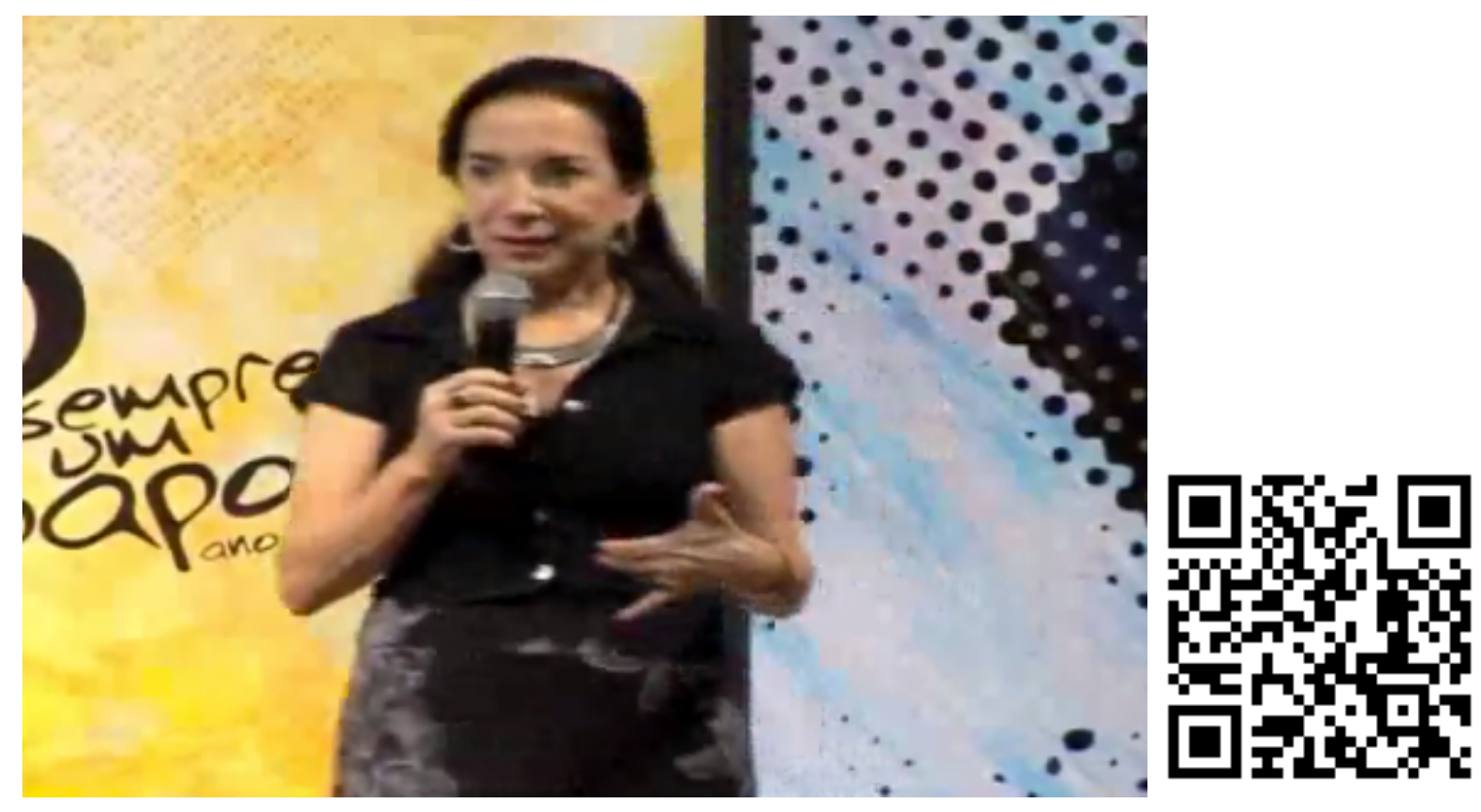

Figura 1.1 - Imagem do vídeo da palestra "Circuitos artísticos na era da mobilidade", proferida por Lucia Santaella no Projeto Sempre Um Papo, em 20/nov/2008 na Casa Fiat de Cultura, Belo Horizonte, MG. O vídeo pode ser acessado em <http://youtu.be/XhRgfLuZXNY> ou pelo QRcode na figura.

Dessa forma, podemos dizer não apenas que ficamos mais conectados de forma gradativa e rápida conforme as tecnologias digitais se disseminam, mas também que o processo de produção e reprodução de linguagens acompanha a evolução das tecnologias digitais.

Segundo Santaella (2007), estamos na $5^{\text {a }}$ geração de tecnologias digitais, a geração das “Tecnologias da Conexão Contínua". Essa geração é catalisada pelas tecnologias móveis e é constituída por "uma rede móvel de pessoas e tecnologias nômades que operam em espaços físicos contínuos". Essas tecnologias foram sendo incorporadas pelas pessoas numa interface de linguagens tão amigável que analfabetos e crianças conseguem interagir com elas. 
Incontáveis tecnologias contribuíram para o ambiente tecno-info-social em que vivemos hoje - fala, escrita, telégrafo, telefone, carro, satélite, computador pessoal, impressora, fax, internet, telefone celular, GPS -, e cada uma delas contribuiu em algum grau para a nossa conexão atual. No entanto, de todas as tecnologias que nos trouxeram até aqui, talvez a mais importante seja a banda larga computacional, que começou a se tornar disponível às pessoas por volta do ano 2000 e, desde então, se dissemina de forma ampla.

A banda larga de internet permitiu a importante mudança de 'estar conectado' para 'ser conectado'. 'Estar' conectado significa que você eventualmente entra e sai da internet, como na época das conexões discadas à rede, na década de 1990 (e ainda hoje, em muitos lugares no Brasil e no mundo e também nos telefones celulares que acessam momentaneamente a internet para navegação). 'Ser' conectado significa que parte de você está na rede - você vive em simbiose com ela. Isso só foi possível pelo barateamento da banda larga de internet, principal catalisador da tão celebrada participação do usuário na rede, a qual se tornou a fonte de seu crescente poder no cenário atual, permitindo-lhe expressar-se, publicar, atuar, escolher, opinar, criar, influenciar outras pessoas. A banda larga de internet distribui o poder entre os nós das redes (pessoas), transformando o cenário de criação, publicação e distribuição de informações e conteúdos no mundo.

O cenário de hiperconexão criado pela banda larga de internet é responsável também pelo aumento gigantesco da velocidade de introdução e disseminação de inovações no mundo. Duas apresentações do $\operatorname{TED}^{3}$ discutem a relação entre a conexão entre as pessoas e o surgimento de ideias e inovação - Where good ideas come from e When ideas have sex.

Em Where good ideas come from (De onde vêm as boas ideias) (Figura 1.2), Steve Johnson argumenta que um dos principais catalisadores do desenvolvimento e propagação de ideias e do florescimento intelectual da humanidade nos últimos 500 anos foi o surgimento dos cafés ingleses, onde as pessoas se encontravam para conversar e

3 TED (Technology, Entertainment and Design) é uma conferência que acontece desde 1990 em Monterey na Califórnia, Estados Unidos, cuja missão é disseminar ideas worth spreading. Os palestrantes normalmente são escritores, cientistas, artistas, pessoas com ideias que transformam o mundo. Mais informações podem ser obtidas no site oficial do TED, em <www.ted.com> ou na Wikipedia, <http://en.wikipedia.org/wiki/TED_> (conference). 
trocar ideias. Dessa conexão entre as pessoas surgiu uma criatividade e inovação incomum, que alavancaram e favoreceram a inovação.

\section{Steven Johnson: Where good ideas come from}
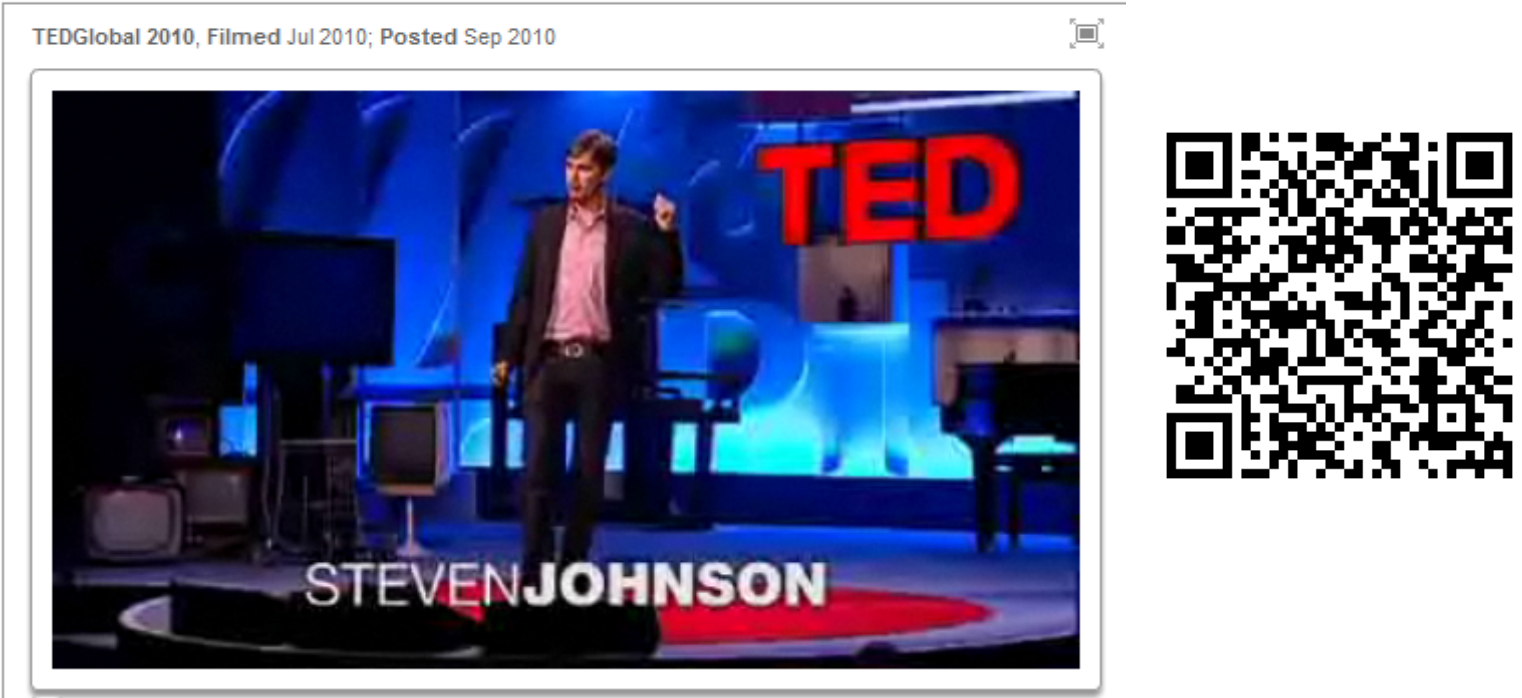

Figura 1.2 - TED Talk Where good ideas como from, por Steve Johnson, disponível em: <http://www.ted.com/talks/lang/pt-br/steven_johnson_where_good_ideas_come_from.html> ou pelo QRcode ao lado da imagem. Acesso em: 10.ago.2011.

Matt Ridley discute a velocidade da inovação em sua apresentação When ideas have sex (Quando as ideias fazem sexo), baseado no fato de que, quando as pessoas se encontram, suas ideias se acasalam, gerando novas ideias. Ele mostra que o ritmo da inovação ao longo da história da humanidade foi acelerando conforme as pessoas e comunidades aumentavam sua conexão (Figura 1.3). 


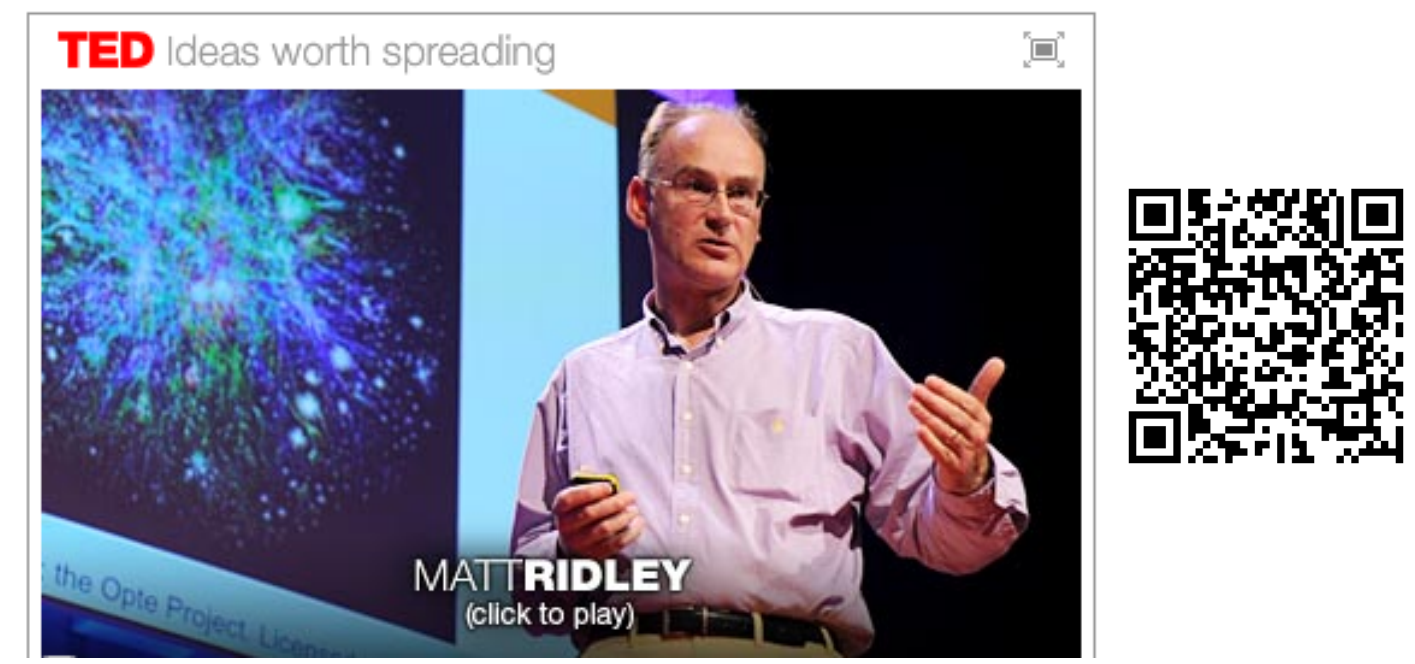

Figura 1.3 - TED Talk When ideas have sex, por Matt Ridley, disponível em: <http://www.ted.com/talks/lang/pt-br/matt_ridley_when_ideas_have_sex.html> ou pelo QRcode ao lado da imagem. Acesso em: 10.ago.2011.

No ambiente hiperconectado atual, onde virtualmente qualquer pessoa consegue conversar com qualquer outra pessoa, em qualquer tempo e em qualquer lugar do planeta, a velocidade de inovação é assustadora, e provavelmente por isso, temos percebido uma aceleração sufocante em praticamente qualquer área do conhecimento.

O processo de hiperconexão não acontece apenas com as pessoas, mas também com os sistemas e, virtualmente, com qualquer coisa. O surgimento e popularização de sensores (RFID, por exemplo) e dispositivos conectados (celulares, TV, câmeras, etc.) à internet têm causado mudanças significativas na internet e na web, conduzindo-nos para um cenário semântico que já se delineia hoje.

Do início da internet comercial, em meados dos anos 1990, aos dias de hoje, passamos da web estática para a web dinâmica. Da web read-only para a web read-write. Da web one-way para a web two-ways. Da web de páginas para a web como plataforma. Da web de reação para a web de participação ${ }^{4}$. Da web discurso para a web conversação ${ }^{5}$. E

\footnotetext{
${ }^{4}$ As tecnologias no início da web não permitiam a publicação de conteúdos de forma simples, de modo que apenas profissionais técnicos conseguiam colocar informações online (programando sistemas e páginas). Dessa forma, a grande maioria das pessoas apenas "navegava” nos conteúdos, lendo a web (ready-only), ou seja, em mão-única, da web para elas. A partir da disseminação da banda larga, as tecnologias passaram a possibilitar a participação de qualquer pessoa nos processos de publicação online e, assim, os sistemas que permitem as publicações e armazenam os dados online fazem com que a web se torne uma plataforma de participação - em que o usuário lê e escreve e não mais apenas lê páginas. A web torna-se um processo de duas mãos.
} 
estamos caminhando para a web da interação: a web semântica, a internet das coisas ${ }^{6}$.

Nesse caminho fluido de transformação da web e das pessoas, alavancado pelas tecnologias digitais, a O’Reilly Media classificou essas mudanças em três ondas, conhecidas como Web 1.0, Web 2.0 e Web 3.0. Apesar de esses termos sugerirem novas versões para Web, eles não se referem a qualquer atualização das especificações técnicas da web - que seriam centenas; mostram apenas uma divisão didática das fases da web que apresentam as mudanças acumulativas no modo com que os desenvolvedores de software e os usuários utilizam a Web. Assim, apesar de terem ocorrido inúmeras mudanças tecnológicas na web, os termos web 1.0, 2.0 e 3.0 estão mais relacionados às mudanças no comportamento dos usuários web do que às tecnologias que proporcionaram essas mudanças.

A Web 1.0 é a web estática, em que as pessoas apenas navegam e consomem informações. A Web 2.0 é a web da participação, em que as pessoas usam a web como plataforma para todo tipo de interação: blogs, vídeos, fotos, redes sociais. A Web 2.0 é o que chamamos de computação na nuvem - os aplicativos (como GMail, redes sociais, etc.) ficam na internet (nuvem de computadores) e são acessados por meio de computadores com conexão online. Hoje, a predominância de informações na web é de documentos. Em breve, com os sensores do tipo RFID e a mobile tags (como os QRcodes, por exemplo), qualquer coisa poderá fazer parte da internet, não apenas documentos. Assim, pessoas, animais, objetos, lugares ou 'absolutamente qualquer coisa' poderá ser parte da web. Chamamos isso de internet das coisas e é para onde caminhamos. No entanto, o volume e os diferentes tipos de informações e coisas que estão sendo acrescentados à web diariamente aumentam sua complexidade consideravelmente. Nesse cenário emergente, para se conseguir atuar na web e encontrar o que é relevante a cada instante precisaremos de um novo paradigma de busca e organização da informação, e esse novo paradigma é a web 3.0, ou a web semântica.

Na web semântica, além da informação em si, o contexto e as ligações referentes a essa

${ }^{5}$ No primeiro momento, em que só era possível 'ler’ a web, tínhamos uma situação análoga a um discurso apenas um polo emissor. A partir do momento em que se pode também 'escrever' na web, o discurso dá lugar à conversação.

6 Para mais informações sobre a web semântica e internet das coisas, ver <http://en.wikipedia.org/wiki/Semantic_Web> e <http://en.wikipedia.org/wiki/Internet_of_Things>. 
informação permitirão encontrar um significado que auxilie o uso da web. A Figura 1.4 dá acesso, via QRcode, a um breve vídeo produzido pela TV1 com explicações sobre a web semântica.

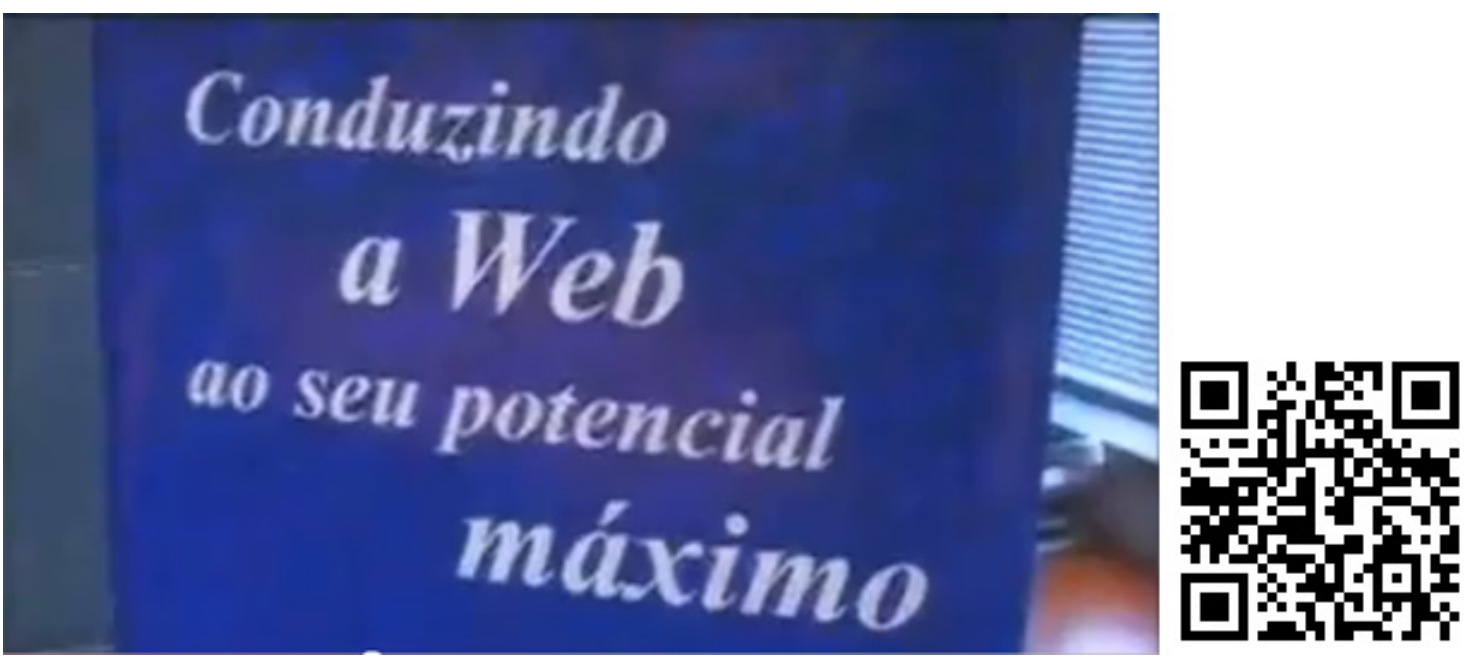

Figura 1.4 - Imagem e Qrcode para acesso ao vídeo da TV1 sobre web semântica Fonte: <http://www.youtube.com/watch?v=i4GG4etWjR8>.

Outra consequência da popularização do acesso à internet promovida pela banda larga, que possibilitou a plataforma da Web 2.0 com aplicações online participativas, foi a viabilização das redes sociais online e de sua adoção ao redor do planeta, já que se tornou comum as pessoas 'serem' online, ou seja, estarem o tempo todo simultaneamente online e offline, permitindo, assim, a sua formação (das redes).

A crescente penetração das redes sociais online no Brasil e no mundo, associada à sua forma de interação nãohierárquica e ao colapso do tempo e espaço, tem impactado o comportamento humano. O modo como nos relacionamos uns com os outros, com instituições e a tecnologia tem mudado sensivelmente e impactado praticamente todos os aspectos de nossas vidas. Dos primórdios das redes sociais online até os dias de hoje, temos presenciado transformações e números impressionantes.

O vídeo Social Media Revolution 2011 traz dados sobre o cenário das Mídias Sociais no mundo. Os dados foram coletados por Erik Qualmann em 2009, no seu livro Socialnomics, e depois atualizados ano a ano. O link para assistir ao vídeo está disponível na Figura 1.5 . 


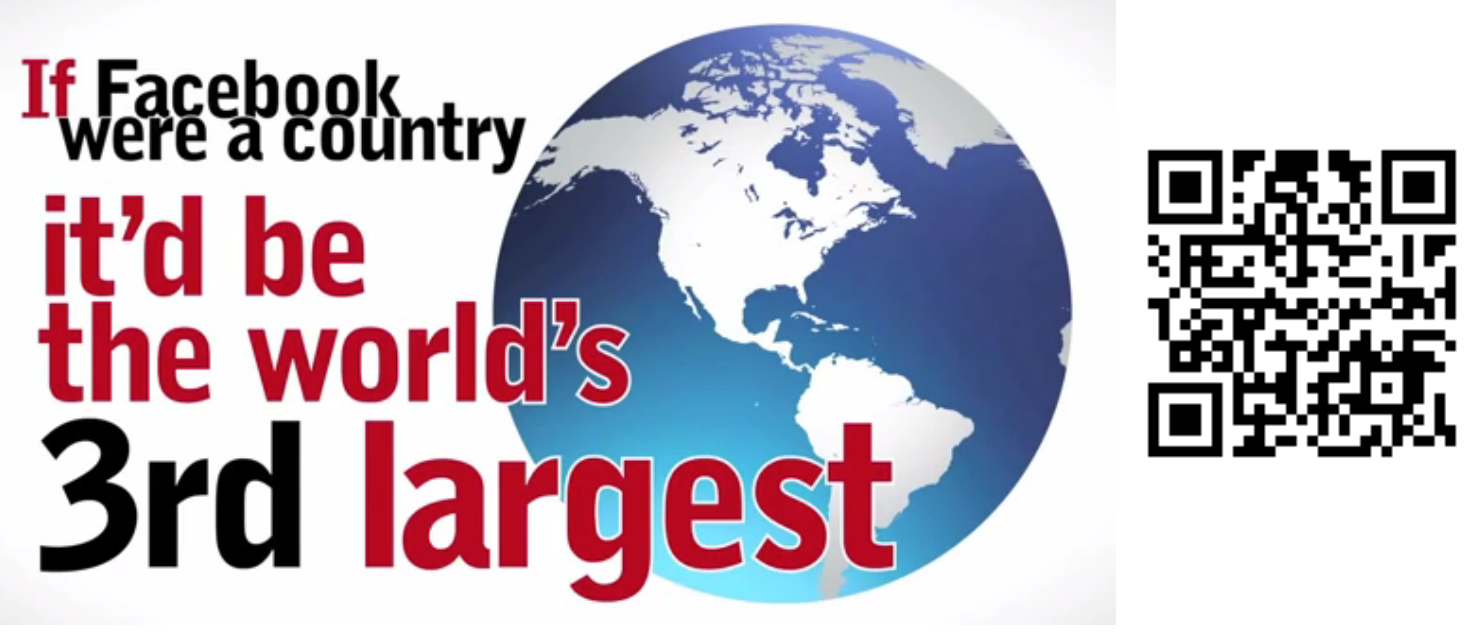

Figura 1.5 - Social Media Revolution 2011 - vídeo que pode ser acessado pelo QRcode ao lado da figura ou pelo link da fonte <http://youtu.be/GHRa-hbYk64>.

Outro vídeo que mostra as transformações que as redes sociais têm produzido é o documentário US Now <http://dotsub.com/view/34591ca8-0ef5-48fb-82e6-163a9f21298d>, que conta histórias de redes online que estão desafiando a noção de hierarquia existente, como: a) 0 Ebbsfleet United <http://www.ebbsfleetunited.co.uk/>, um clube de futebol gerido por seus fãs via internet; b) O Zopa <http://uk.zopa.com/>, um banco no qual todos os membros são gerentes e ajudam em financiamentos e empréstimos com pequenas contribuições; c) 0 Couch Surfing <http://www.couchsurfing.com/>, uma vasta rede online cujos membros compartilham suas casas com desconhecidos. Esses exemplos mostram o deslocamento do poder de gestão e econômico, que antes era mais hierárquico e centralizado e passa a distribuir-se entre as pessoas, tornando-se mais social.

A adoção dessas redes nas culturas ao redor do planeta tem sido tão grande que, hoje, as mídias sociais (conteúdos gerados nas redes sociais) são uma das formas mais importantes de mídia. Isso tem provocado mudanças profundas no comportamento e no relacionamento humano. 
Um fenômeno também associado à hiperconexão são as microtendências. Hoje, a adesão crescente das pessoas aos ambientes digitais e a facilidade de gerar e propagar conteúdos nesses ambientes fazem com que esses conteúdos sejam disseminados muito rapidamente, como se fossem vírus, ocasionando, eventualmente micro-tendências que podem modificar o cenário social. 0 impacto socioeconômico das microtendências é analisado no livro The Tipping Point (GLADWELL, 2002) ou, em português, O Ponto da Virada. Conceitos relacionados com a viralização e disseminação de tendências são discutidos ao longo do livro, com exemplos e análises.

Quanto mais conectado estiver o mundo, mais importantes se tornam as teorias que abordam a complexidade crescente decorrente dessa conexão global many-to-many, que se comporta muito mais pela lógica probabilística (que tão bem se aplica às mídias sociais) do que pela lógica determinista, mais característica das mídias de massa. Portanto, apesar de não serem o foco do presente trabalho, o estudo da teoria do caos e a compreensão de processos como viralização, comportamento de bandos, teoria da emergência, entre outros, passam a ser assuntos bastante valorizados para entender o novo cenário social de negócios que se apresenta e atuar nele.

\section{I.2. Parametrização da mídia: Explosão do Conteúdo, Big-Data e a Busca}

Web 2.0 é o termo cunhado por Tim O’Reilly em 2005 para definir a web como plataforma participativa de serviços, por meio da qual não apenas se consomem conteúdos, mas principalmente se colocam conteúdos. Blogs, sites de publicação de vídeo (como o Youtube), redes sociais (como Orkut, MySpace, Facebook etc.) são exemplos de ferramentas participativas da plataforma da Web 2.0, que é viabilizada pela conexão de banda larga à internet - sem isso, não seria possível participação.

Pela facilidade de criar, publicar e compartilhar conteúdos na Web 2.0, teoricamente qualquer pessoa pode exercer simultaneamente o papel de produtor, editor e disseminador de informações em grande escala. Ao mesmo tempo em que isso é bom, pois traz liberdade, também dá origem à multiplicação de conteúdos em velocidade vertiginosa. Soma-se a isso o fato de que normalmente não existe controle sobre a qualidade dessa enorme quantidade de conteúdo publicado. 
Essa explosão de conteúdo originado de diversas fontes em alta velocidade não consegue ser eficientemente manipulada e analisada com as tecnologias e práticas usadas para lidar com bancos de dados tradicionais. Em tecnologia da informação, as tecnologias que gerenciam e analisam informações em variedade, volume e velocidade enormes são chamadas de big-data ${ }^{7}$. A alta velocidade de streaming de informações faz com que não se tenha tempo suficiente para analisar os dados, pois eles continuam sendo gerados constantemente. Fontes de informações de big data são os mercados financeiros, sensores, torres de celulares, câmeras de tráfego e vigilância, a web, mídias sociais (posts, likes, follows, etc.), transações de e-commerce, entre outros (BRUST, 2012).

Isso traz duas consequências ao ambiente informacional: a) a parametrização da informação, que permite analisar qualquer tipo de informação digital em tempo real, inclusive dados não estruturados (como posts no Facebook, tweets, etc.) e comportamentos associados a contextos (semântica $\left.{ }^{8}\right)$; b) necessidade de mediação tecnológica para filtrar e obter valor da gigantesca massa de dados contínua.

No primeiro caso, a parametrização da informação permite que se cruzem dados de forma complexa e sofisticada, sem precedentes na história da humanidade. Um exemplo de uso do big data é o projeto Global Pulse das Nações Unidas, que vai usar um programa que decifra a linguagem humana na análise de mensagens de textos e posts em redes sociais para prever o aumento do desemprego, o esfriamento econômico e epidemias. Outro exemplo desse uso foi no terremoto do Haiti, quando pesquisadores americanos perceberam antes de todo mundo a diáspora de Porto Príncipe por meio dos dados de geolocalização de 2 milhões de chips de celulares, facilitando a atuação da ajuda humanitária (O GLOBO, 2012-1). Em ambos os casos, o uso de big data ofereceu antecipação e soluções a problemas sociais e humanitários, que não eram possíveis anteriormente.

A outra consequência da explosão de conteúdos é a necessidade de mediação

\footnotetext{
${ }^{7}$ Mais informações sobre big data podem ser encontradas em <http://en.wikipedia.org/wiki/Big_data>.

${ }^{8}$ Outro atributo do big data, em razão da proliferação de informações e da capacidade de cruzá-las, é a dificuldade de apagar dados, o que torna a privacidade uma preocupação comum (MARK2.0, 2012). A questão da privacidade é discutida mais à frente nesse texto.
} 
tecnológica para filtrar e validar os conteúdos, o que cria um ambiente fértil para os processos de busca.

Em função disso, estamos cada vez mais experimentando a Era da Busca, em que os mecanismos de busca (como o Google e Yahoo! na web; buscas em sistemas de localização GPS; buscas em redes sociais; buscas por lugares e pessoas no Second Life $<w w w . s e c o n d l i f e . c o m>$, por exemplo) são diária e frequentemente usados ao redor do mundo por pessoas, para encontrarem o que procuram nos infindáveis nós e rotas informativas.

A participação da busca em nossas vidas diárias tem se tornado tão forte que a palavra "google", nome do mais importante site de busca atualmente, tornou-se oficialmente um verbo da língua inglesa em 2006, no Merriam-Webster's Collegiate Dictionary:

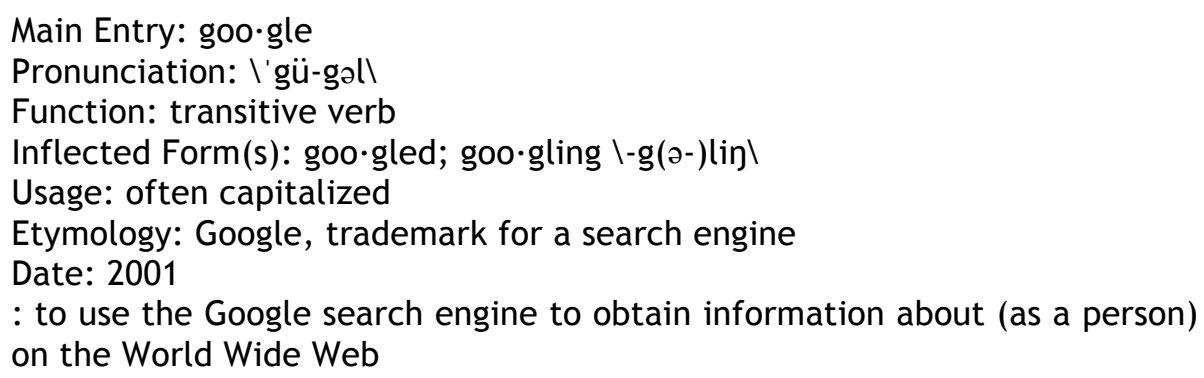

O uso do Google também tem povoado nosso imaginário e o cinema. Inúmeros filmes se apropriam do uso do Google em cenas com situações em que é necessário encontrar respostas certeiras. 0 filme $O$ Grande Dave (Meet Dave ${ }^{9}$ ) expressa a influência que o Google exerce hoje em nossa sociedade: no filme, os seres extraterrestres usam o Google para aprender tudo sobre os seres humanos e o planeta Terra, o que sugere que se pode conseguir qualquer informação confiável sobre nosso mundo e a resposta para qualquer questão simplesmente usando-se o Google. Outro exemplo é o filme Os Seis Signos da Luz (The Seeker: The Dark is Rising ${ }^{10}$ ), no qual o protagonista busca no Google informações relevantes sobre a disputa entre as trevas e a luz que dá desenvolvimento ao filme. Até o presente momento, a presença do Google nos enredos dos filmes

\footnotetext{
${ }^{9}$ Twentieth Century-Fox, 2008.

10 Twentieth Century Fox Film Corporation, 2007.
} 
normalmente ocorre como caminho para se obter resposta confiável e verdadeira para qualquer necessidade.

0 trabalho de arte Digital Oracles ${ }^{11}$ (GABRIEL, 2006) discute a importância da busca na vida das pessoas e o seu poder e influência no nosso cotidiano. A busca digital permeia cada vez mais a nossa existência, tornando-se uma das principais tendências para que consigamos operar no ambiente hiperinformacional que se desenvolve.

\section{I.3. Proliferação de Tecnologias e Plataformas}

Além da hiperconexão e explosão do conteúdo, outro fenômeno marcante que temos testemunhado na última década é a proliferação de tecnologias e plataformas tecnológicas de comunicação e informação. Hoje, além das plataformas tradicionais, como TV, rádio, mídia impressa em geral, contamos com um elenco digital cada vez mais extenso de tecnologias e plataformas, como o mobile, a busca, as redes sociais, as pessoas.

No escopo desse trabalho propomos uma sutil diferenciação conceitual entre tecnologias e plataformas. No sentido mais amplo, tecnologia refere-se à criação, uso e conhecimento de ferramentas.

Ampliando esta discussão, Pierre Lévy chega a definir o termo "tecnologias intelectuais", aquelas que desenvolveriam "raciocínios abstratos utilizando recursos cognitivos exteriores ao sistema nervoso" (Lévy, 1993:152). Desta forma, escritas simbólicas, o uso de diagramas, processos mentais controlados e automatizados, cáculos produzidos através do uso de papel e lápis, etc, seriam tratados por Lévy como tecnologias intelectuais, e sem elas não seríamos capazes de processos complexos de dedução e indução formais, pois estes não seriam recursos cognitivos espontâneos.

Apesar de uma coleção de tecnologias também poder ser definida como tecnologia (por exemplo, tecnologia espacial, ou tecnologia da agrícola), acreditamos que chamar de

11 Digital Oracles é um trabalho de arte online que pode ser acessado em <http://www.digitaloracles.com.br>. Participou de exposições no Brasil no exterior, como no FILE 2007 e ELO Electronic Literature Organization Conference, Portland, WA, USA, em 2008. 
'plataformas' a um conjunto de tecnologias, distintas ou similares, que trabalham juntas para uma finalidade maior, seja mais adequado. Plataformas, assim, referem-se aqui a estruturas tecnológicas com finalidades específicas associadas a uma atividade particular. Seguindo-se esse raciocínio, a linguagem, a escrita e a fala, por exemplo, são consideradas tecnologias que podem ser também usadas como plataforma de comunicação, arte, marketing, etc.

Dessa forma, a mobilidade seria uma plataforma que engloba diversas tecnologias distintas, como a web, telefonia celular, sensores, tags, RFID, GPS, computadores, tecnologias wireless, dentre várias outras, com a finalidade de conexão remota. A plataforma da busca utiliza diversas tecnologias (mobile, GPS, web, etc.) com a finalidade predominante de buscar. As plataformas de redes sociais são mais um exemplo do uso de diversas tecnologias distintas cuja finalidade é conectar pessoas em redes sociais. As plataformas alavancam atividades específicas mais amplas do que as tecnologias isoladas que as formam. O Facebook, o Twitter, o Fousquare e vários outros sistemas são tecnologias de redes sociais, cada uma com características específicas e que juntas, formam uma plataforma de redes sociais.

Como as atividades se sobrepõem - por exemplo, podemos querer fazer buscas enquanto estamos em trânsito, móveis -, as plataformas também podem se sobrepor (plataforma de busca mobile). Dessa forma, as plataformas de mídias sociais podem eventualmente se sobrepor a plataformas móveis, como as plataformas de busca podem se sobrepor às plataformas de redes sociais e assim por diante. As plataformas tecnológicas usam tecnologias comuns que permitem a sua sobreposição e alavancam as possibilidades.

Dessa forma, relacionamos a seguir as plataformas/tecnologias digitais que se popularizaram na última década:

- Páginas digitais (site, mini-site, hot-site, portal, blog, perfil, etc.)

- E-mail

- Realidades Mistas (realidade aumentada, virtualidade aumentada)

- Realidade Virtual

- Tecnologias Mobile 
- Plataformas digitais de Redes Sociais

- Plataformas digitais de busca

- Games \& Entretenimento digitais

- Tecnologias inteligentes de voz

- Vídeo digital / TV digital / Vídeo imersivo

A Tabela 1.1 apresenta essa relação de tecnologias e plataformas.

Tabela 1.1 - Lista de tecnologias e plataformas digitais ${ }^{12}$

\section{Páginas Digitais}

- site, mini-site, hot-site, portal, blog, perfil, etc.)

\section{E-mail}

\section{Realidade Virtual}

\section{Realidades Mistas}

- realidade aumentada

- virtualidade aumentada

Mobile

- RFID, mobile tag (QRcodes, Datamatrix, etc.), SMS/MMS, bluetooth, aplicativos, mobile TV, etc.

\section{Plataformas digitais de Redes Sociais}

- Facebook, Twitter, Linkedln, SlideShare, Youtube, Orkut, etc.

Plataformas digitais de Busca

- Google, Yahoo, Bing, Wolfram|Alpha, etc.

Games \& Entretenimento digitais

Tecnologias inteligentes de voz

Vídeo digital / TV digital / Vídeo imersivo

12 Essa tabela lista as principais tecnologias e plataformas digitais; no entanto, todas essas plataformas podem se misturar de diversas formas. Por exemplo, no caso do mobile, ele pode incluir a busca ou acesso à redes sociais, ou páginas, ou games. Além disso, um mobile também pode ser câmera, instrumento de leitura de mobile tags, vídeo digital ou TV. No caso do e-mail, outro exemplo, ocorre a mesma coisa - o e-mail é uma estética de comunicação específica com características particulares. Ele pode estar presente dentro do Facebook ou isolado em um aplicativo especialista de e-mail. Quando listamos o Facebook em redes sociais, estamos nos referindo ao Social Graph do Facebook como rede social, que pode se utilizar do e-mail também para comunicação entre nós. 
As plataformas/tecnologias apresentadas na Tabela 1.1. representam inúmeras possibilidades adicionais de conexão e interação, que ainda podem ser combinadas para exploração de novos processos criativos, experiências, conexões. No entanto, essas são apenas algumas categorias de tecnologias que evoluem constantemente. Quando adentramos no cenário digital, a quantidade de tecnologias que surgem em intervalos cada vez menores é impressionante. Além disso, cada tecnologia encontra-se em um estado de maturidade diferente em relação à sua adoção pela sociedade.

Muitas tecnologias, quando introduzidas no mercado, são recebidas com excesso de euforia, como panaceias, viram moda, e, depois de algum tempo, o entusiasmo passa e se percebe que elas não são solução para tudo, o que causa decepção. No entanto, depois do período de decepção, cada tecnologia acaba alcançando seu real papel no espectro tecnológico - sem ser solução pra tudo, mas tendo sua finalidade específica e, nesse momento de maturidade, alcança sua real importância no cenário social. Esse processo foi analisado pela Gartner Inc. em 1995 e batizado de Hype-Cycle ${ }^{13}$, que é uma representação gráfica da maturidade, adoção e aplicação social de tecnologias específicas.

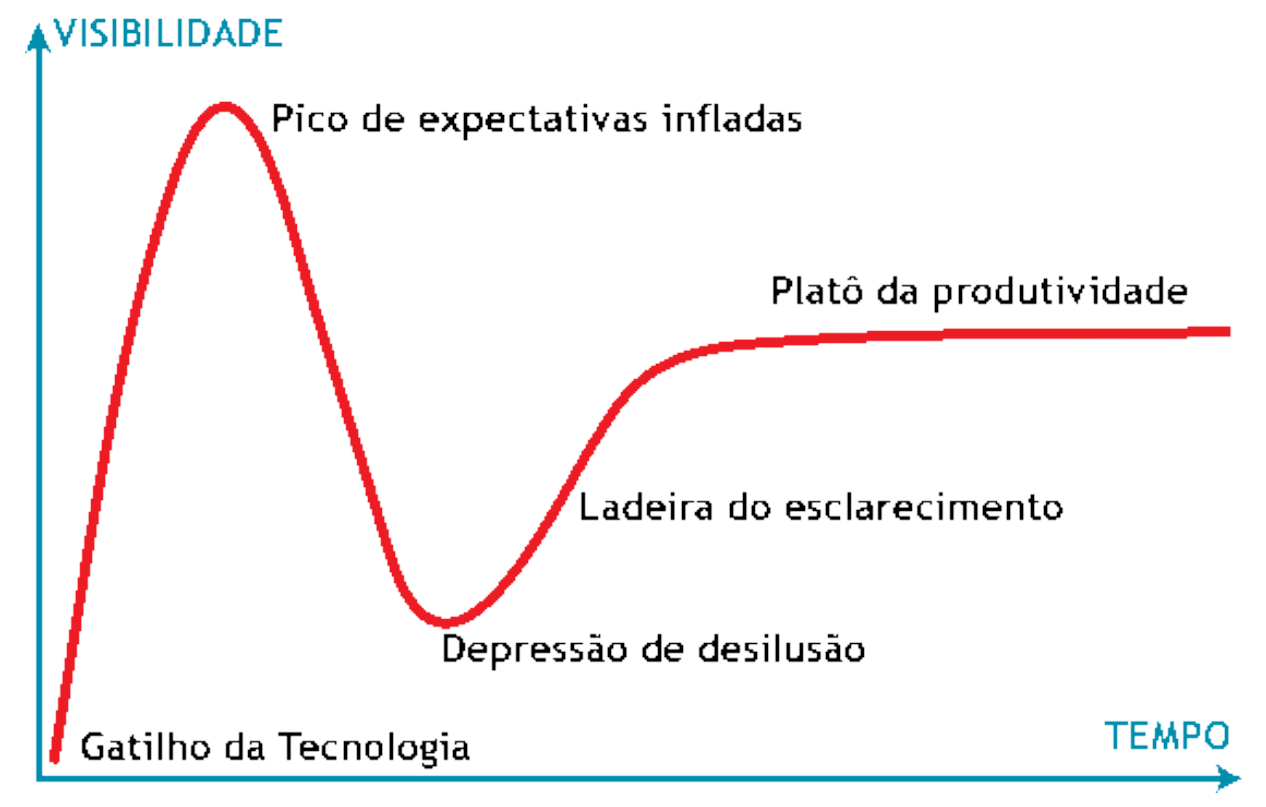

Figura 1.6 - Imagem do Hype-cycle de Gartner, criada por Jeremy Kemp. Fonte: <http://en.wikipedia.org/wiki/File:Gartner_Hype_Cycle.svg〉), traduzida por Martha Gabriel.

13 Mais informações sobre o Hype-cycle de Gartner podem ser obtidas em <http://en.wikipedia.org/wiki/Hype_cycle>. 
As cinco fases de um hype-cycle de Gartner (Fig. 1.6) são descritas a seguir:

- "Gatilho da Tecnologia" - Nesta primeira fase, algum fator se torna o gatilho da tecnologia, gerando interesse significativo pelo mercado e pela mídia. Esse gatilho pode ser o lançamento de um produto ou evento.

- "Pico das Expectativas Infladas" - Nesta segunda fase, o frenesi da publicidade normalmente gera um entusiasmo exagerado e expectativas irreais em relação à tecnologia. Devem existir algumas aplicações para a tecnologia, mas normalmente existem mais falhas.

- "Depressão de Desilusão" - As tecnologias entram nesse estado porque falham em atender às expectativas e rapidamente saem de moda. Consequentemente, a imprensa normalmente abandona $o$ assunto $e$ a tecnologia.

- "Ladeira do Esclarecimento" - Apesar de a imprensa ter parado de cobrir a tecnologia, alguns negócios continuam a usá-la e experimentá-la para compreender seus benefícios e aplicações práticas.

- "Platô de Produtividade" - O platô de produtividade é alcançado por uma tecnologia conforme seus benefícios se tornam amplamente demonstrados e aceitos. A tecnologia se torna gradativamente estável e evolui na segunda ou terceira geração. A altura final do platô varia, dependendo da aplicabilidade da tecnologia: se é amplamente aplicável ou beneficia apenas um nicho de mercado.

O hype-cycle de uma determinada tecnologia ajuda a avaliar em que estágio ela se encontra após sua introdução e quando atingirá o platô de produtividade. Exemplos recentes de tecnologias que estão em estágios diferentes do ciclo:

- Instant Messengers (ICQ, MSN, etc.) - Já alcançaram o platô de produtividade. Depois do seu lançamento, os instant messengers foram adotados de forma maciça como solução de comunicação. Depois de um tempo, percebeu-se que não eram ideais quando se necessitava de assincronicidade ou rastreamento de 
assuntos. Atualmente são amplamente usados para comunicação síncrona que se beneficie do formato instantâneo e curto.

- Second Life - 0 mundo virtual Second Life foi febre em 2007, quando atingiu o topo do ciclo (também chamado de hype). Na sequência, em 2008 e 2009, quando o marketing percebeu que o Second Life não podia ser explorado da mesma forma que um website, ele entrou na depressão da desilusão. Apesar disso, várias áreas se beneficiam dos mundos virtuais, como educação e recrutamento, e continuaram a usar o Second Life, que está subindo a ladeira do esclarecimento para, provavelmente, ocupar em breve o platô da produtividade.

- Realidade Aumentada - Apesar de as tecnologias de realidade aumentada existirem há algumas décadas, elas estão vivendo o período de hype (pico de expectativas) agora. 0 gatilho para disparar a entrada da realidade aumentada no mercado foram os lançamentos de dispositivos econômicos e amplamente adotados, como as webcams e os smartphones, que possibilitam o uso de realidade aumentada de maneira simples. Nesse estágio, em razão do encantamento tecnológico, proliferam aplicações que usam essa tecnologia, mas muitas delas são apenas pirotecnias tecnológicas.

A proliferação de tecnologias e plataformas digitais, somadas às plataformas e tecnologias tradicionais, oferece um cenário fértil para as mais diversificadas ações em virtualmente qualquer área do conhecimento - da medicina à arte. A possibilidade de mensuração que o ambiente digital propicia também é uma vantagem enorme em relação aos ambientes materiais, tangíveis, pois o digital permite sincronicidade (behavioral analysis). No entanto, para utilizar uma tecnologia com maestria, é necessário primeiro conhecê-la. E é aí que reside um dos maiores problemas do cenário digital: a velocidade de mudança, que muitas vezes não nos dá tempo de conhecer todas as opções e particularidades de tecnologias que se tornam disponíveis. 


\section{I.4. Era do Controle Distribuído}

A proliferação de plataformas e tecnologias digitais associadas à hiperconexão nos permite aumentar sensivelmente duas de nossas habilidades sociais: 1) a mensuração, que permite o aumento e, ao mesmo tempo, a dispersão do controle; 2) a expressão individual, que favorece o espetáculo.

Uma das principais transformações devidas à introdução das tecnologias digitais está relacionada à facilidade de mensuração que o ambiente digital proporciona. Enquanto nas mídias tradicionais analógicas (rádio, TV, revistas, jornais, etc.) são necessários processos externos a elas (como pesquisa de mercado, códigos promocionais, etc.), para rastrear acessos, resultados e comportamentos do usuário, nas mídias digitais esse rastreamento é nativo.

Quanto melhor se conhecem os gostos e comportamentos das pessoas, maior a probabilidade de saber o que elas querem (e o que não querem), e isso pode ser usado tanto para satisfazê-las quanto para manipulá-las. O ser humano sempre deixou rastros de gostos e comportamentos. No entanto, antes da popularização dos ambientes digitais, a mensuração desses rastros era muito mais difícil.

O ambiente digital é o paraíso para a proliferação de dados das pessoas, causando uma verdadeira avalanche de informações pessoais que os indivíduos fornecem em suas atividades diárias - surfar a internet, usar cartão de crédito, etc. Cada clique na web, cada telefonema, cada compra com cartões de crédito fornecem dados pessoais que engrossam o dossiê digital de cada indivíduo. O livro Numerati (BAKER, 2008) apresenta exemplos de como a análise dos rastros dos dados das pessoas permite conhecer seus hábitos e preferências - os fragmentos das informações pessoais são analisados para transformar e personalizar as experiências diárias dessas pessoas. Esse tipo de rastreamento, no entanto, tem causado preocupação também.

Um serviço criado pelo The Wall Street Journal, o What They Know <http://blogs.wsj.com/wtk/>, analisa o quanto expomos nossas informações nos sites que visitamos. Eles declaram na sua página de entrada que: 
O marketing está espionando os usuários na Internet - observando e gravando os cliques das pessoas e construindo e vendendo dossiês completos de suas atividades e interesses. A série What They Know documenta os novos usos de ponta dessa tecnologia de rastreamento na internet. O The Wall Street Journal analisou os arquivos de rastreamento instalado nos computadores das pessoas pelos 50 websites mais populares dos Estados Unidos, mais o WSJ.com (website do jornal). 0 jornal também criou um 'índice de exposição' (que determina o grau em que cada um desses websites expõe os visitantes ao monitoramento) estudando as tecnologias de rastreamento que eles instalam e as políticas de privacidade que guia o seu uso.

O site do What They Know apresenta um sistema interativo de navegação e visualização dos índices de exposição muito bem elaborado, que demonstra o poder da mensuração digital.

No entanto, a proliferação de informações pessoais no ambiente digital é tão grande, que nem é necessário um grande esforço para reunir muitos dados de uma determinada pessoa. O serviço gratuito online SPOKEO <http://www.spokeo.com/e-mail>, por exemplo, possui uma funcionalidade que permite criar um dossiê sobre as pessoas por meio do seu endereço de e-mail. Além da versão gratuita do serviço, que oferece muitas informações sobre a pessoa, existe também uma versão paga, que fornece um relatório completo sobre pessoas, por uma assinatura anual de US\$ 2,95 mensais. Ageolocalura 1.7 mostra a página de entrada do serviço gratuito e o QRcode na imagem dá acesso ao site mobile.

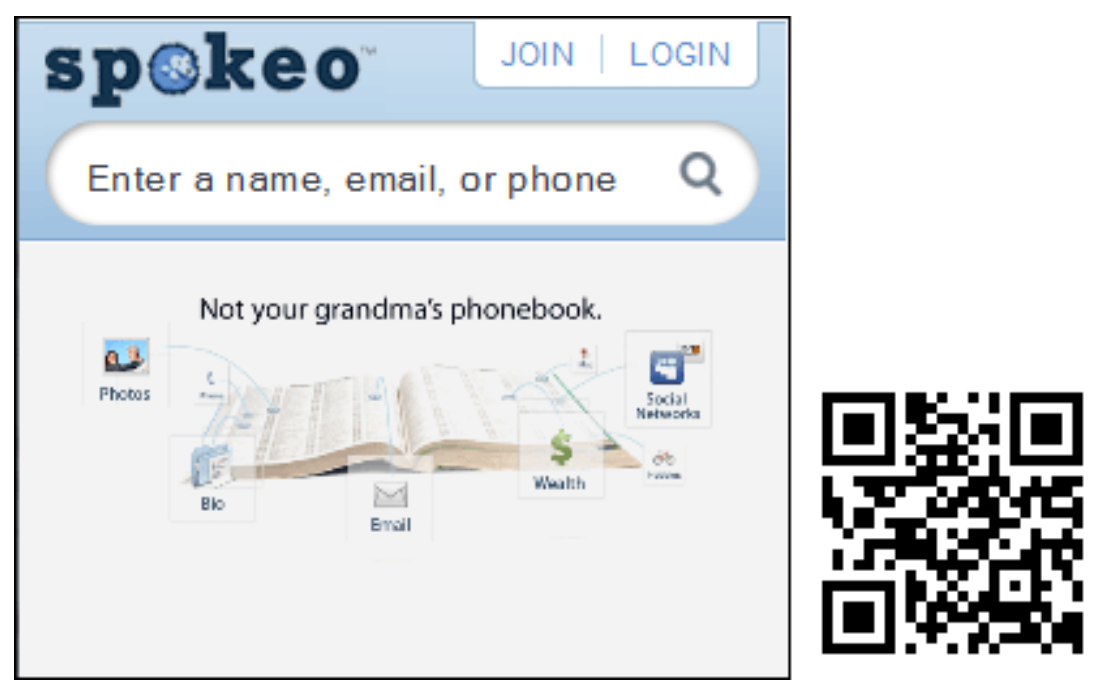

Figura 1.7 - Imagem da página de acesso ao serviço SPOKEO no celular, que pode ser acessado via QRcode ao lado da imagem. Fonte: <http://www.spokeo.com/m/>. 
Outro serviço que permite buscar informações sobre pessoas por meio de seus nomes ou e-mails é o buscador Pipl (http://pipl.com/). Uma vez digitado o nome ou e-mail de uma dada pessoa, o buscador reúne imagens, perfis sociais, informações de negócios e vários outros tipos de informações sobre ela.

Tendo em mente a facilidade com que os dados pessoais se disseminam no ambiente digital, as possibilidades de uso desses dados são inúmeras (desde práticas artísticas até processos de manipulação pessoal).

A obtenção e análise de dados sobre os indivíduos permitem conhecer comportamentos, preferências, aversões e inúmeros outros aspectos de suas personalidades, o que, como mencionado anteriormente, oferece poder tanto para auxiliá-los como para manipulálos. Isso não é novidade e tem sido usado estrategicamente desde a Antiguidade. Uma frase atribuída a Napoleão Bonaparte, general francês do século XIX, expressa a essência desse poder: "Duas alavancas movem o homem: interesse e medo."

Conhecer os interesses e medos das pessoas permite saber os fatores que as motivam a agir e possibilita: a) influenciar essas pessoas - tanto para o bem como para o mal (manipulando-as); e b) prever ou analisar comportamentos.

Se na época de Napoleão era muito mais difícil conseguir dados sobre as pessoas e conhecer seus interesses e medos, hoje, alavancadas pelo ambiente digital, as próprias pessoas fornecem suas informações pessoais de inúmeras maneiras, tanto conscientemente (como quando compartilham seus dados, fotos, preferências, aversões, localização, etc. voluntariamente nas redes sociais digitais) quanto de forma inconsciente (como quando fazem compras com cartão de crédito, navegam, buscam e clicam em links na web).

Essas ações de obtenção e análise de dados dos indivíduos para alcançar determinados objetivos por meio deles é chamada, de uma maneira mais ampla, de Engenharia Social. Existem diversas definições de Engenharia Social ${ }^{14}$, incluindo desde a mais ampla, como

\footnotetext{
${ }^{14}$ Ver definições de Engenharia Social em: <http://searchsecurity.techtarget.com/sDefinition/0, sid14_gci531120,00.html> e também na Wikipedia em: <http://en.wikipedia.org/wiki/Social_engineering_\%28political_science\%29>e <http://en.wikipedia.org/wiki/Social_engineering_\%28security\%29>.
} 
disciplina pertencente às ciências políticas, até uma mais restrita, associada à tecnologia e à segurança da informação.

No entanto, a intenção da Engenharia Social pode ser benéfica ou manipulativa. Como exemplo do primeiro caso, podemos citar os casos relatados no livro Freakonomics (LEVITT, 2005), que por meio da análise de dados e interesses de pessoas consegue desvendar fraudes e resultados que contrariam o senso comum.

Como exemplo de uso da engenharia social de forma manipulativa (ou negativa para os indivíduos envolvidos no processo), podemos citar a ação de hackers e crackers, que, para conseguir invadir sistemas, usam dados pessoais de indivíduos a fim de manipulá-los para que colaborem. Na maioria das vezes, o termo engenharia social é usado de forma pejorativa justamente por isso. Um caso muito famoso que ilustra o uso de engenharia social de forma manipulativa é o do hacker Kevin Mitnick, que foi preso em 1995 pelo FBI, solto em 2000, e hoje é um consultor de segurança da informação. A história da prisão do hacker é relatada no livro Takedown ${ }^{15}$ (e no filme homônimo). É interessante perceber a habilidade de Mitnick em obter a colaboração das pessoas, manipulando-as, por meio da engenharia social. Por exemplo, para conseguir as plantas que precisava de um edifício, Mitnick se informa detalhadamente sobre a pessoa que as tem. Quando ele solicita as plantas, a pessoa responde que não as pode dar sem autorização do chefe. Como Mitnik sabe quem é o chefe e também o quanto essa pessoa precisa do emprego, ele cita o nome do chefe, dizendo que está solicitando por ele, e diz que se não receber as plantas, a pessoa responsável será demitida. A pessoa acaba dando as plantas a ele. Um dos ditados mais conhecidos da área de segurança da informação é: “Uma corrente sempre arrebenta onde está o seu elo mais fraco. O elo mais fraco da segurança da informação é o ser humano".

Com o intuito de alertar as pessoas sobre os riscos de compartilhar na internet informações de localização geográfica em serviços de redes sociais como Foursquare e Twitter, Barry Borsboom, Boy van Amstel e Frank Groeneveld criaram no início de 2010 um site chamado Please Rob Me <www.pleaserobme.com> (ver Figura 1.8), que, em português, significa “Por favor me roube”. O site listava todas as casas que estavam vazias em cada momento e poderiam ser assaltadas. O site, hoje, não está mais

15 Informações detalhadas sobre o caso Kevin Mitnick estão no site Takedown em <http://www.takedown.com/>. 
operacional, pois seus criadores acreditam que já conseguiram o que queriam: alertar as pessoas sobre o assunto. Atualmente, o site apresenta links para várias matérias e artigos sobre os riscos do compartilhamento excessivo de informações sobre localização.

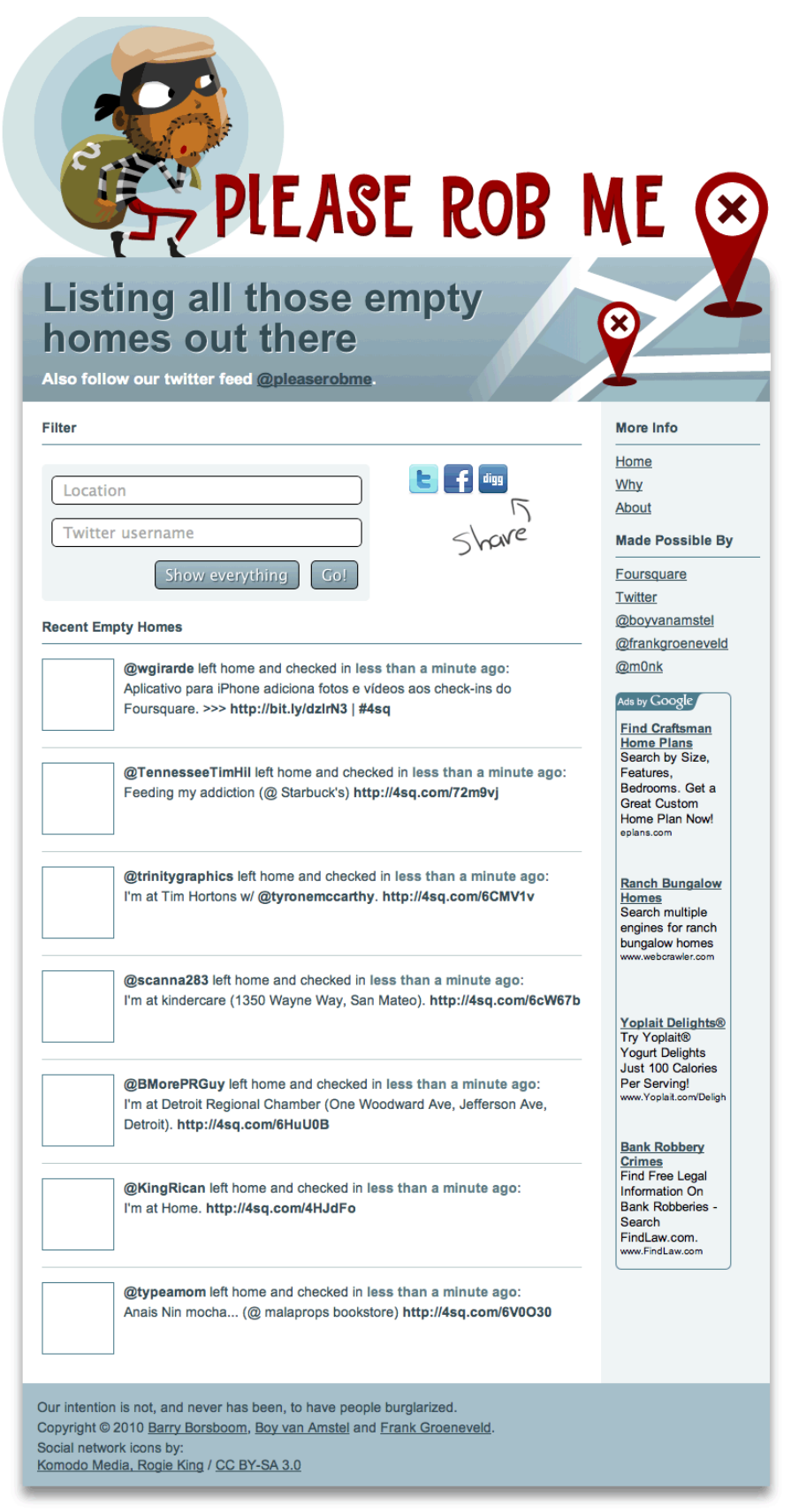

Figura 1.8 - Imagem da página de entrada do site Please Rob Me <http://pleaserobme.com> no início de 2010 mostrando uma relação de casas vazias que poderiam ser assaltadas. Fonte: <http://mashable.com/2010/02/17/pleaserobme/>. 
Enquanto no início de 2010 o site Please Rob Me alertava as pessoas sobre os riscos de compartilharem suas localizações nas redes sociais, em agosto, o Facebook - maior rede social mundial atualmente com quase 1 milhão de usuários - criou o Facebook Places <http://www.facebook.com/places/> para permitir que seus usuários compartilhem suas informações de geolocalização na rede social. Em 10/set/2010, menos de um mês após o lançamento do Facebook Places, o blog de tecnologia TechCrunch (SCHONFELD, 2010) noticiou a informação sobre uma rede de assaltantes nos Estados Unidos (em Nashua, New Hampshire) que assaltou 50 casas e roubou o equivalente a US\$ 100 mil em bens, mirando nas pessoas que faziam check-in em lugares via Facebook, alertando para o fato de que não estavam em casa.

Assim, o uso da engenharia social pode ser focado tanto para o bem como para o mal. A coleta e análise de dados é feita da mesma forma nos dois casos, mas é a intenção por trás de seu uso que determinará se ela será benéfica ou manipulativa. Por isso, a engenharia social é um assunto bastante polêmico nas diversas áreas do relacionamento humano em que pode ser aplicada.

\section{I.5. Mobilidade e Ubiquidade}

O sonho de estar 'sempre online, sempre conectado (à internet)' está se tornando real conforme se espalham as conexões de banda larga, tanto para computadores - devido a tecnologias como o ADSL, ISDN, entre outras, quanto para aparelhos móveis - devido a tecnologias como o 3G. Apesar de a banda larga não ser ainda uma realidade em todo lugar no mundo, as melhorias recentes na tecnologia e nas redes tendem a tornar essa realidade ubíqua em um futuro próximo.

A web é a primeira peça de uma rede maior que tem se tornado possível graças às conexões de banda larga, GPS (Global Positioning System) e tags de RFID (Radio Frequency Identification Tag). Essas tecnologias juntas têm permitido que a computação ubíqua se torne uma realidade rapidamente. Podemos conhecer muitos exemplos de computação ubíqua em Greenfield (2006), como prédios inteligentes, mobiliário inteligente, roupas inteligentes, objetos inteligentes, sinais de trânsito em rede, latas de refrigerante autodescritivas, interfaces gestuais e tags RFID embutidas em qualquer coisa, desde cartões de crédito até animais de estimação. 
A computação ubíqua é quase imperceptível, mas está em tudo ao nosso redor e afeta cada vez mais nosso cotidiano conforme é disseminada. A sedução de estar sempre conectado - a web, e-mails, redes sociais, mapas, etc. -, sem abandonar a mobilidade, é responsável pelo grande crescimento de popularidade dos aparelhos smartphones. Já em 2002, Fogg (2002) observava, no livro Persuasive Technology, que "as pessoas não adotam aparelhos móveis, elas se casam com eles".

O estudo Internet Trends (STANLEY, 2010) prevê que em 2014 o acesso à internet móvel ultrapassará o acesso via desktop; em 2020 a internet móvel será muitas vezes maior que a internet desktop.

A mobilidade é a grande tendência atual que tende a alavancar diversas outras tendências importantes. O maior problema para que as tecnologias móveis decolassem era o barateamento e penetração da banda larga móvel, que passou a acontecer no Brasil desde o final de 2010 com planos de operadoras oferecendo conexão ilimitada à internet por $\mathrm{R} \$ \mathbf{0 , 5 0}$ por dia. Isso tende a popularizar a mobilidade rapidamente e a transformar completamente o cenário tecnosocial, alavancando diversas outras tendências, como relacionado a seguir:

a) Tempo real - Conforme o ser humano se aparelha de dispositivos móveis, ele vai se tornando um sensor e um receptor do mundo. Hoje existem aproximadamente 6 bilhões de celulares, que representam 6 bilhões potenciais de captação e transmissão de dados em tempo real. A mobilidade colocou o planeta potencialmente conectado em tempo real.

b) Geolocalização - Os dispositivos móveis transformam as pessoas em verdadeiros GPS e sensores de localização das coisas ao redor. Os smartphones vêm automaticamente com GPS, transformando a relação do humano com o mundo ao redor. No mundo físico, todas as atividades do ser humano estão associadas ao local onde ele está. Com a geolocalização em tempo-real, isso passará a acontecer também no mundo digital. Além disso, a geolocalização permite que a pessoas interajam entre si baseadas em sua proximidade ou posição geográfica e que façam anotações e reviews em locais. A geolocalização, portanto, gera uma nova camada digital de dados sociais que permite enriquecer nossas experiências e interações com locais e pessoas relacionadas a eles. 
c) Internet das Coisas - A mobilidade tende a impulsionar a internet das coisas pois permite que todo tipo de coisa - pessoas, objetos, lugares, etc. - possa interagir com a internet.

d) Realidade Aumentada - Apesar do conceito e tecnologias de realidade aumentada não serem novos, um dos habitats mais naturais desse tipo de tecnologia são os dispositivos móveis, que permitem que o conceito de “ampliação da realidade” possa ser aplicado em praticamente qualquer lugar. Dessa forma, a evolução da realidade aumentada está intimamente associada à evolução da mobilidade.

e) Busca - A mobilidade torna possível nosso acesso à informação em praticamente qualquer lugar e em qualquer instante, potencializando a conveniência da busca (possibilitando que possamos buscar qualquer coisa, em qualquer lugar e em qualquer momento).

f) Vídeo - Conforme a pesquisa “Internet Trends” (STANLEY, 2010), em 2014, vídeo será o conteúdo mobile mais consumido: 69\% do conteúdo mobile será vídeo. Conforme as tecnologias de banda larga móvel melhoram, elas passam a permitir que vídeos sejam acessados de qualquer lugar, em qualquer tempo.

g) Social Everything - Os dispositivos móveis permitem que as pessoas comentem, apliquem tags, “curtam”, critiquem, deem dicas sobre qualquer coisa - pessoas, lugares, objetos, animais. Nesse sentido, a mobilidade está transformando todas as coisas em sociais.

h) Transmídia - Apesar de processos transmidiáticos já existirem desde antes da era digital, os dispositivos móveis catalisam a ligação entre as diversas mídias, analógicas ou digitais. QRcodes conectam a mídia impressa com a web via dispositivos móveis, por exemplo.

Dentre as tendências alavancadas pela mobilidade, talvez o tempo-real seja a que mais afete a cognição humana. Conforme as tecnologias interativas de informação e comunicação foram evoluindo ao longo da história, mais rapidamente as informações sobre um fato ocorrido em um lugar passaram a alcançar outros lugares ao redor do planeta.

Até a invenção dos telégrafos por Samuel Morse em 1835, o único modo de propagar 
informação era transportando fisicamente o seu mensageiro ${ }^{16}$. Durante a Revolução Francesa, em 1789, por exemplo, a notícia sobre a tomada da Bastilha demorou até um mês para chegar a algumas vilas distantes aproximadamente $100 \mathrm{Km}$ de Paris (HOBSBAWM, 1994). Desde então, os tempos de transmissão foram diminuindo cada vez mais, alcançando na televisão ao vivo o modelo mais próximo de tempo real que se havia experimentado até recentemente.

A mobilidade em banda larga associada às redes sociais presenciais, como o Twitter, tem modificado sensivelmente a velocidade com que a informação é transmitida, causando colapso total entre tempo e espaço.

No modelo do jornal impresso, as notícias do dia anterior são consideradas informações satisfatoriamente 'frescas'. No caso da televisão e do rádio, algumas horas separam o fato da notícia. Mesmo na televisão ao vivo, é necessário algum tempo para chegar fisicamente ao local do fato, instalar o set de transmissão e começar a operar. No modelo digital, no entanto, a duração de tempo entre algo acontecer no mundo e isso ser noticiado e propagado está hoje na casa de 2 minutos. Isso mesmo, 2 minutos. 0 terremoto que aconteceu em São Francisco, nos USA, em janeiro/2010, demorou apenas 2 minutos para ser noticiado no Twitter (MARKETING VOX, 2010). Além disso, no modelo digital, diferentemente da televisão, a transmissão é feita de muitos para muitos e não a partir de uma única fonte.

O fenômeno do colapso do tempo e do espaço na propagação da informação propiciado pelas tecnologias digitais móveis está transformando o mundo em um mundo em tempo real. Por outro lado, o fato de que virtualmente cada pessoa na face da Terra passa a ser um polo de transmissão de notícias via redes sociais presenciais mobile está causando outro fenômeno importantíssimo - o aumento da densidade de informação no tempo presente. Enquanto no passado as possibilidades de obter informação estavam limitadas a um número determinado de fontes e origens, hoje, em cada dado instante, o volume de informações geradas em tempo real por um número incontável de fontes e origens inunda o presente. Esse fenômeno é discutido pelo sociólogo Zygmunt Bauman em seu livro Modenidade Líquida (BAUMAN, 2001) e é também chamado por muitos de ‘Nowism' (RITZER, 2011). ${ }^{16}$ Com exceção de algumas técnicas de propagação de mensagens por pequenas distâncias com alcance
visual ou sonoro, como faziam determinadas tribos com sinais de fumaça ou assobios. 
O termo modernidade líquida para o mundo atual é usado em contraste a modernidade sólida, que o precedeu. De acordo com Bauman, a passagem da modernidade de sólida para líquida criou uma nova fixação sem precedentes dos indivíduos pelas atividades da vida, confrontando-os com uma série de desafios nunca antes experimentados. As formas sociais e as instituições não têm mais tempo suficiente para solidificar e não conseguem mais servir como modelos de referência para as ações humanas e planos de longo prazo; assim, as pessoas precisam encontrar outras maneiras de organizar suas vidas. Os indivíduos precisam juntar uma série interminável de projetos de curto prazo e episódios que não somam para um tipo de sequência, que os conceitos como 'carreira' e 'progresso' podem ser aplicados. Esse tipo de vida fragmentada requer que os indivíduos sejam flexíveis e adaptáveis para estarem sempre prontos para mudar de tática a curto prazo, para abandonar compromissos e lealdades sem remorsos e para buscar oportunidades conforme a disponibilidade presente. Na modernidade líquida, o indivíduo precisa agir, planejar ações e calcular os ganhos e perdas prováveis de seus atos (ou da omissão de agir) sob condições incertas.

Nesse sentido, na modernidade líquida, vivemos a filosofia do 'agora', segundo a qual o espaço de tempo de experiência chamado 'agora' é fundamental e nele a vida acontece. No Nowism, o passado e o futuro perdem importância e o 'agora', o presente, torna-se denso e é o que importa.

Em razão da propagação do Nowism, alavancada principalmente pela popularização do Twitter e demais redes presenciais, temos testemunhado a partir 2009 uma revolução nos sistemas de busca, uma guerra onde todos os buscadores passaram a otimizar seus sistemas para garimpar informações relevantes em tempo-real. O Google tem refinado constantemente seu algoritmo de busca para incluir o tempo-real e tem trabalhado em um protocolo para busca em real-time.

Além da corrida técnica para acompanhar o fluxo do tempo-real, temos presenciado também alguns impactos importantes desse fenômeno na sociedade. Podemos mencionar alguns exemplos que evidenciam que a informação em tempo real pôde contribuir para a solução de problemas sociais são: 
- Em 10/novembro/2009, um apagão de energia elétrica afetou 18 Estados no Brasil $^{17}$. Sem acesso a aparelhos de TV e rádios elétricos, as pessoas passavam e obtinham informações em tempo real sobre o apagão usando o Twitter. Esse processo ajudou as pessoas no Brasil todo que estavam no escuro.

- Nos terremotos do Haiti" (jan.2010) e do Chile ${ }^{19}$ (fev.2010) no início de 2010, além do envio de informações em tempo-real via Twitter, também foram organizadas ações em tempo-real para auxílio às vítimas.

- A erupção do vulcão Eyjafjallajökull, na Islândia, em 15/abril/2010 ${ }^{20}$ causou o fechamento de diversos aeroportos na Europa por dias, deixando pessoas ilhadas. As pessoas começaram a se mobilizar em tempo-real via redes sociais e Twitter (criando perfis e hashtags como \#ashtag, @getmehome, \#roadsharing e \#stranded) para conseguir obter informações atualizadas e encontrar outro modo de voltar para casa.

\section{I.6. Cibridismo}

Apesar de o digital abranger cada vez mais aspectos da vida humana, ainda existimos também fora do digital, no ambiente tradicional material, composto por átomos. Nicholas Negroponte, em seu livro A Vida Digital (NEGROPONTE, 1995), diz que temos dois tipos de ambiente - o formado de bits e bytes (ambientes digitais) e o formado de átomos (ambientes materiais). Tendo naturezas completamente diferentes e com características específicas, ambos coexistem na vida humana.

\footnotetext{
${ }^{17}$ Mais informações sobre o apagão de 10/Nov/2009 em: <http://g1.globo.com/Noticias/Brasil/0, ,MUL1374252$5598,00 . \mathrm{html}>$.

${ }^{18}$ Para saber mais sobre a ajuda humanitária no Haiti via Twitter, acesse o artigo <http://www1.folha.uol.com.br/folha/informatica/ult124u678620.shtml>e <http://ego.globo.com/Gente/Noticias/0, MUL1445910-9798,00KATY+PERRY+PEDE+AJUDA+AS+VITIMAS+DO+TERREMOTO+NO+HAITI.html>.

19 Notícia sobre o uso do Twitter para ajuda durante o terremoto do Chile: <http://www.netjoven.pe/noticias/36660/Terremoto-Chile-Twitter-es-fuente-de-informacion-minuto-aminuto.html> e <http://oglobo.globo.com/mundo/mat/2010/02/27/twitter-ajuda-atualizar-informacoes-sobreterremoto-no-chile-915953485.asp>.

${ }^{20}$ Mais informações sobre a erupção do vulcão na Islândia em abril/2010 em <http://gigaom.com/2010/04/17/volcano-stranded-travellers-turn-to-social-media/>. Fotos em: <http://www.boston.com/bigpicture/2010/04/icelands_disruptive_volcano.html>.
} 
No entanto, a hiperconexão e a proliferação de plataformas digitais passa a permitir ao ser humano transferir parte de si para o mundo digital possibilitando um estado de viver constantemente em trânsito entre as redes 'on' e 'off' line. O estado de 'ser' conectado está reconfigurando o ser humano em um “cíbrido", que é definido, por Peter Anders, como:

\begin{abstract}
Cíbridos - híbridos de material e ciberespaço - são entidades que não poderiam existir sem reconciliar a nova classe de símbolos com a materialidade que eles carregam. [...] Cíbridos são mais que simplesmente uma separação completa (entre material e simbólico). Entre esses dois podemos ter componentes compartilhados. (ANDERS, 2001).
\end{abstract}

Há dez anos éramos predominantemente offline. Nos últimos anos, começamos a nos tornar gradativamente mais online, simultaneamente ao nosso estado offline. Até recentemente existia uma separação física necessária entre ON e OFF line, pois, para transitarmos entre o online e o offline, precisávamos usar um equipamento fixo que nos levava a esse estado. Essa barreira entre ON e OFF line foi se dissolvendo aos poucos conforme a hiperconexão, a proliferação de plataformas e as tecnologias móveis se popularizavam no cenário social, e, aos poucos, o cibridismo se tornou realidade.

Portanto, não somos mais ON ou OFF line - somos ON e OFF ao mesmo tempo, simbioticamente, formando um ser maior que o nosso corpo/cérebro biológico, nos expandindo para todo tipo de dispositivo e abrangendo outras mentes e corpos.

Somos cíbridos, e vai se tornar cada vez mais difícil sermos apenas ON ou apenas OFF line - nossa essência quer circular livremente, sem rótulos ou limitações físicas, para obter uma experiência melhor, uma vida melhor, seja ela ON ou OFF line. Não precisamos mais sair de onde estamos para acessar uma máquina que nos leve para o online. Hoje, e cada vez mais, o online está com as pessoas onde quer que estejam e, em breve, estará conectado direto ao cérebro humano.

Assim, todas as áreas do conhecimento tendem a ser cada vez mais contaminadas pela integração entre ON e OFF line, e isso amplia as possibilidades de interação, geração de fluxos de informação de novas maneiras e experimentações estéticas.

O vídeo A Arte do Cibridismo apresenta uma entrevista com a pesquisadora Giselle Beiguelman trazendo reflexões adicionais sobre o assunto e pode ser acessado pelo QRcode da Figura 1.9. 


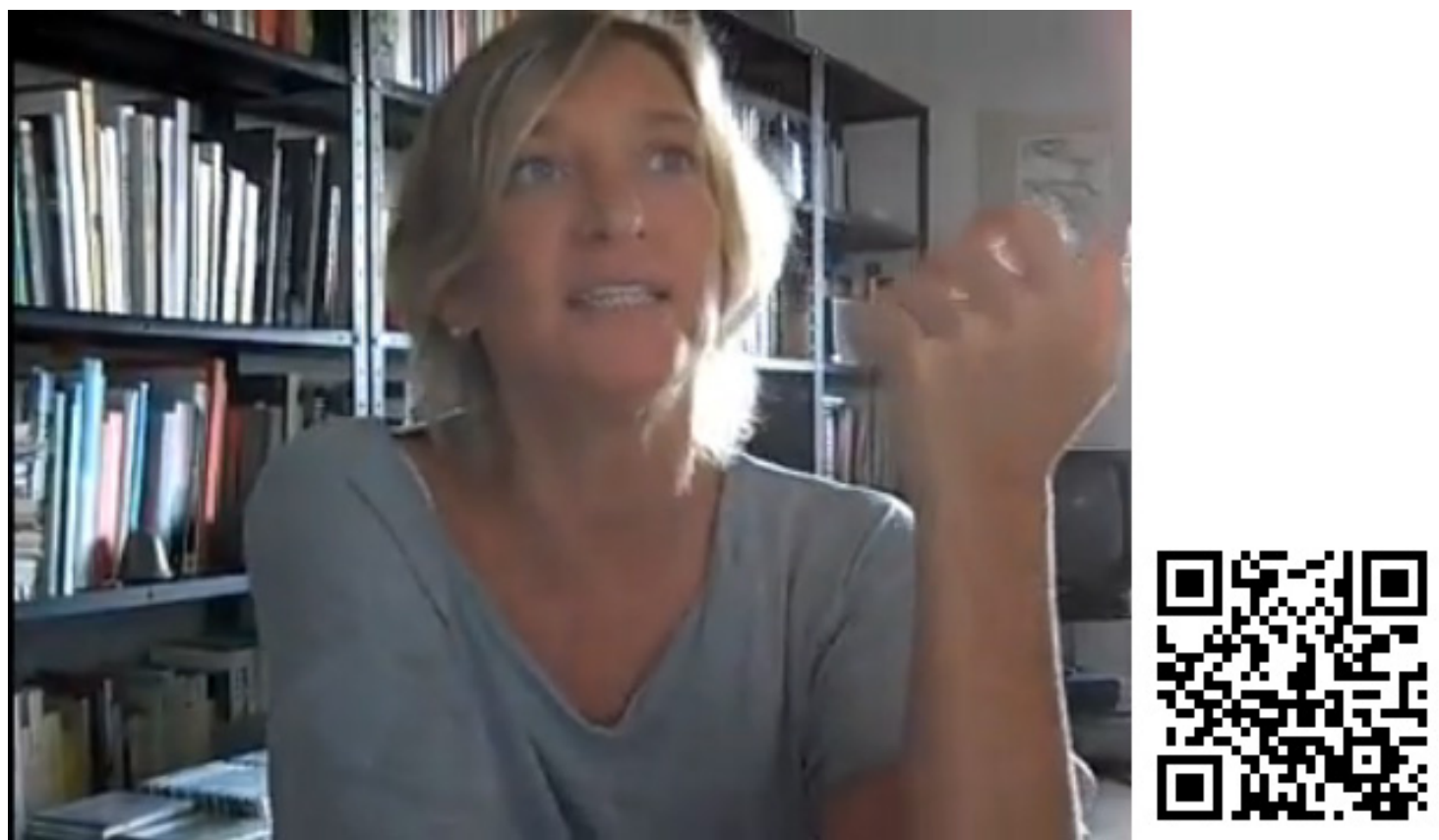

Figura 1-9 - Imagem do vídeo A Arte do Cibridismo, com Giselle Beiguelman, e QRcode de acesso ao vídeo em <http://www.youtube.com/watch?v=pwej1qB8ulg>.

\section{I.7. Impactos Sociais}

Enquanto até meados do século XX o ciclo de vida das tecnologias era maior que o ciclo de vida humano (as pessoas nasciam e morriam e as mesmas tecnologias estavam lá carro, avião, telefone, rádio, etc.), hoje o ciclo de vida das tecnologias é muito menor do que o ciclo de vida humano. Dessa forma, em poucos anos vimos ocorrer mudanças profundas na sociedade decorrentes das mudanças tecnológicas. Some-se a isso o fato de que as plataformas digitais fomentam uma explosão de conteúdos e soluções instantâneas, em tempo real. As pessoas têm cada vez mais contas digitais - vários endereços de e-mail, perfis em várias redes sociais, login em múltiplos aplicativos na nuvem, acessando tudo isso via diversos aparelhos distintos. Alguns referenciam esse fenômeno como "obesidade digital”. Em razão desse processo acelerado de mudança e inundação de soluções, muitas vezes não se tem tempo suficiente para refletir e analisar o que usar ou não. John Naisbitt chama esse paradoxo de High Tech, High Touch (NAISBITT, 2001): quanto mais tecnologia temos em nossas vidas, mais intoxicados e vazios de sentido nos tornamos, e mais precisamos do toque humano. Talvez a explosão das redes sociais digitais seja um dos indícios dessa necessidade do "high touch". 


\section{De espectadores a multitele-interativos}

0 vídeo The 4th Screen (ver Figura 1.10), elaborado em 2008 pela Nokia, mostra o impacto do surgimento das quatro telas que mudaram a vida humana nos últimos 100 anos - o cinema, a televisão, o computador e o celular (dispositivos móveis). Enquanto na primeira tela, o cinema, compartilhamos a experiência pública de espectadores, na televisão passamos a desfrutar dessa experiência de forma privada e a iniciar processos de interação por meio dela. A terceira tela, o computador, possibilita realmente interagir com o mundo e não mais apenas assisti-lo. E essa interação torna-se ainda mais privada. A quarta tela, dos dispositivos móveis, nos liberta dos cabos e fios para interagirmos a partir de qualquer lugar, em qualquer tempo, com mobilidade.
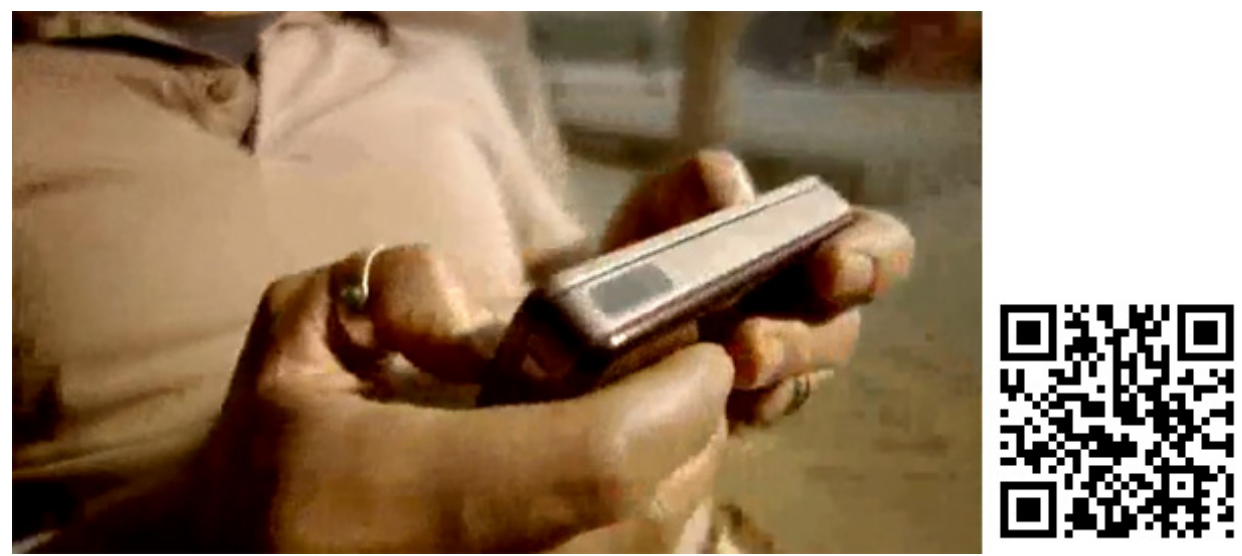

Figura 1.10 - Imagem e QRcode de acesso ao vídeo The Forth Screen (Fonte: <http://www.youtube.com/watch?v=XpeNk3E36YU>).

É interessante observar que essas quatro telas coexistem nas vidas das pessoas e que, no decorrer de cem anos apenas, as pessoas passaram de simples espectadores a multiteleinterativos. Quanto tempo as pessoas dedicam a cada uma dessas telas? A distribuição de tempo entre elas tem mudado ao longo dos anos, e a tela dos dispositivos móveis tem ganhado cada vez mais a preferência dos usuários.

O acesso à informação hoje começa na palma da mão das pessoas. Além de as quatro telas coexistirem em nossas vidas, em algumas situações elas coexistem simultaneamente. Uma das principais tendências atuais é as pessoas assistirem à televisão enquanto navegam na internet ou interagem com um dispositivo móvel (tablet ou smartphone). Esse comportamento modifica o fluxo de informações, tornando-o ainda mais dinâmico e complexo, de forma que uma mídia se alimenta da outra. 


\section{Agentes \& controle}

EPIC 2014 é um filme criado em 2004 por dois jornalistas, Robin Sloan e Matt Thompson, cujo tem é uma especulação sobre o futuro da mídia. Começando a narrativa em 1989, com a invenção da Web, e avançando até 2004, o vídeo evolui a partir daí de forma ficcional até 2014, quando o Google dominaria completamente a mídia, entregando apenas informações 'moldadas' a cada indivíduo. O filme causou bastante discussão e reflexão, pois enfatiza as questões da privacidade e dos direitos autorais decorrentes desse cenário. Na sequência, foi criado o EPIC 2015, que acrescenta ao final algo que 'burlaria' o domínio da mídia, algo muito parecido com o que é o Twitter hoje. 0 interessante é ressaltar que o Twitter só foi criado em 2006. Para assistir EPIC 2015, acesse o link na Figura 1.11.

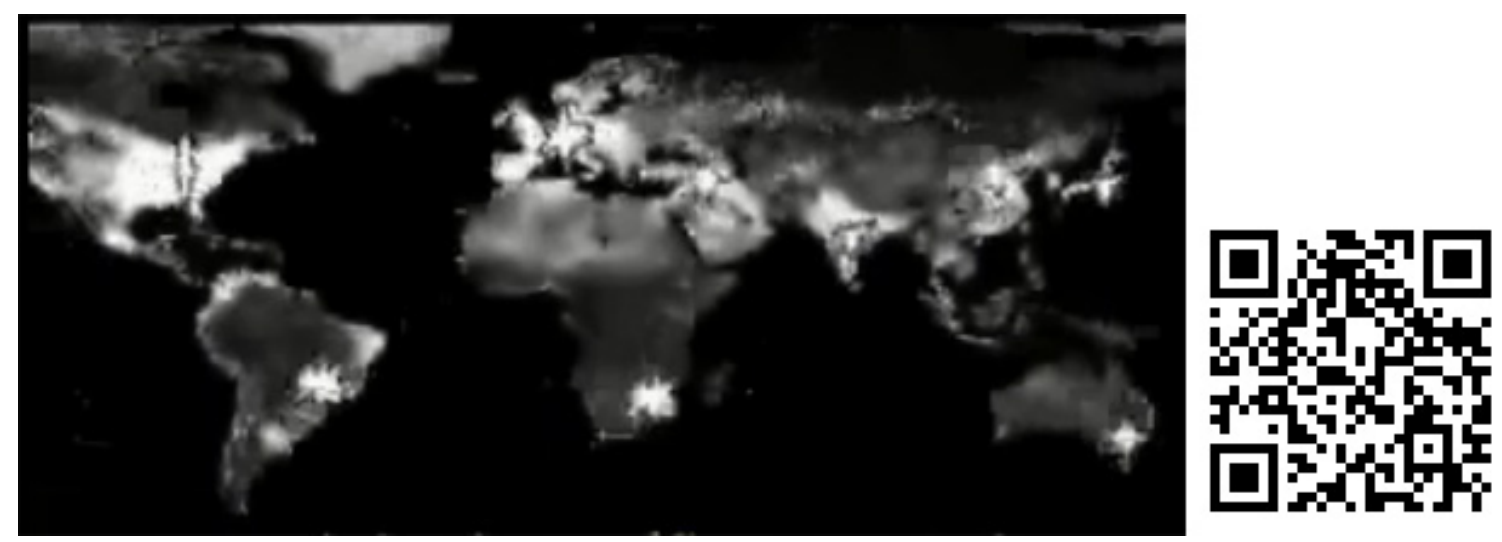

Figura 1.11 - Imagem do vídeo e QRcode de acesso ao filme EPIC 2015 no Youtube, legendado em português. Fonte: <http://www.youtube.com/watch?v=40Z-ANCEchM>. 


\section{Impacto do digital no comportamento humano}

Entre os diversos artigos e estudos que são publicados diariamente sobre os impactos do digital $^{21}$ no ser humano, 0 documentário Digital Nation ${ }^{22}$ <http://video.pbs.org/video/1402987791>, produzido em pela Frontline, mostra as transformações que o digital tem causado em diversos aspectos da vida humana - desde o multitasking (primeira parte do documentário) até a educação.

\section{A Noosfera \& as mentes conectadas}

As seções anteriores deste capítulo mostram as transformações tecnosociais nas últimas décadas, culminando no nosso contexto digital hiperconectado atual. No entanto, não é apenas o cenário social que está em transformação, mas também a humanidade e o planeta como um todo.

Alguns pesquisadores, cientistas e filósofos do Século XX previram de forma espetacular

${ }^{21}$ Outras referências interessantes sobre o impacto do digital na sociedade são:

- $\quad$ Artigo Internet vai deixar usuário mais inteligente, dizem especialistas <http://www1.folha.uol.com.br/folha/informatica/ult124u697332.shtml>.

- $\quad$ Artigo A revolução digital modifica a cultura? <http://www.mmonline.com.br/portal/noticia/A_revolucao_digital_modifica_a_cultura>.

- Artigo Agora vc é single! Levar 1 fora digital é 1 fenômeno em crescimento <http://www.bluebus.com.br/show/1/94994/agora_vc_e_single_levar_1_fora_digital_e_1_fenomeno_em_cres cimento>.

- $\quad$ Artigo Consumo de mídia digital se equipara à mídia tradicional nos Jogos de Inverno <http://tecnologia.uol.com.br/ultimas-noticias/reuters/2010/02/24/consumo-de-midia-digital-se-equipara-amidia-tradicional-nos-jogos-de-inverno.jhtm>.

- $\quad$ Artigo Twitter Helps Police Find Missing Man <http://www.kptv.com/news/23505393/detail.html>.

- $\quad$ Artigo $A$ internet pode contribuir para uma epidemia futura de senilidade (GALILEU, 2010) <http://bit.ly/cucNQu>

22 O documentário foi produzido em nove capítulos de 10 minutos: 1) Distracted by Everything; 2) What's It Doing To Their Brains?; 3) South Korea's Gaming Craze; 4) Teaching With Technology; 5) The Dumbest Generation?; 6) Relationships; 7) Virtual Worlds; 8) Virtual Experiences Changes Us?; 9) Where Are We Headed? 
o que estava por vir. Arthur Clarke, em 1964, previa, no programa de televisão $B B C$ Horizon, vários aspectos do nosso mundo atual conectado e o impacto disso na sociedade (Figura 1.12). Isaac Asimov, em 1988, descreve o futuro da educação, prevendo o impacto que a internet tem hoje nesse campo (Figura 1.13). Os vídeos com Arthur Clarke e Isaac Asimov explicando suas teorias estão disponíveis nos links e QRcodes das Figuras 1.12 e 1.13 , respectivamente.
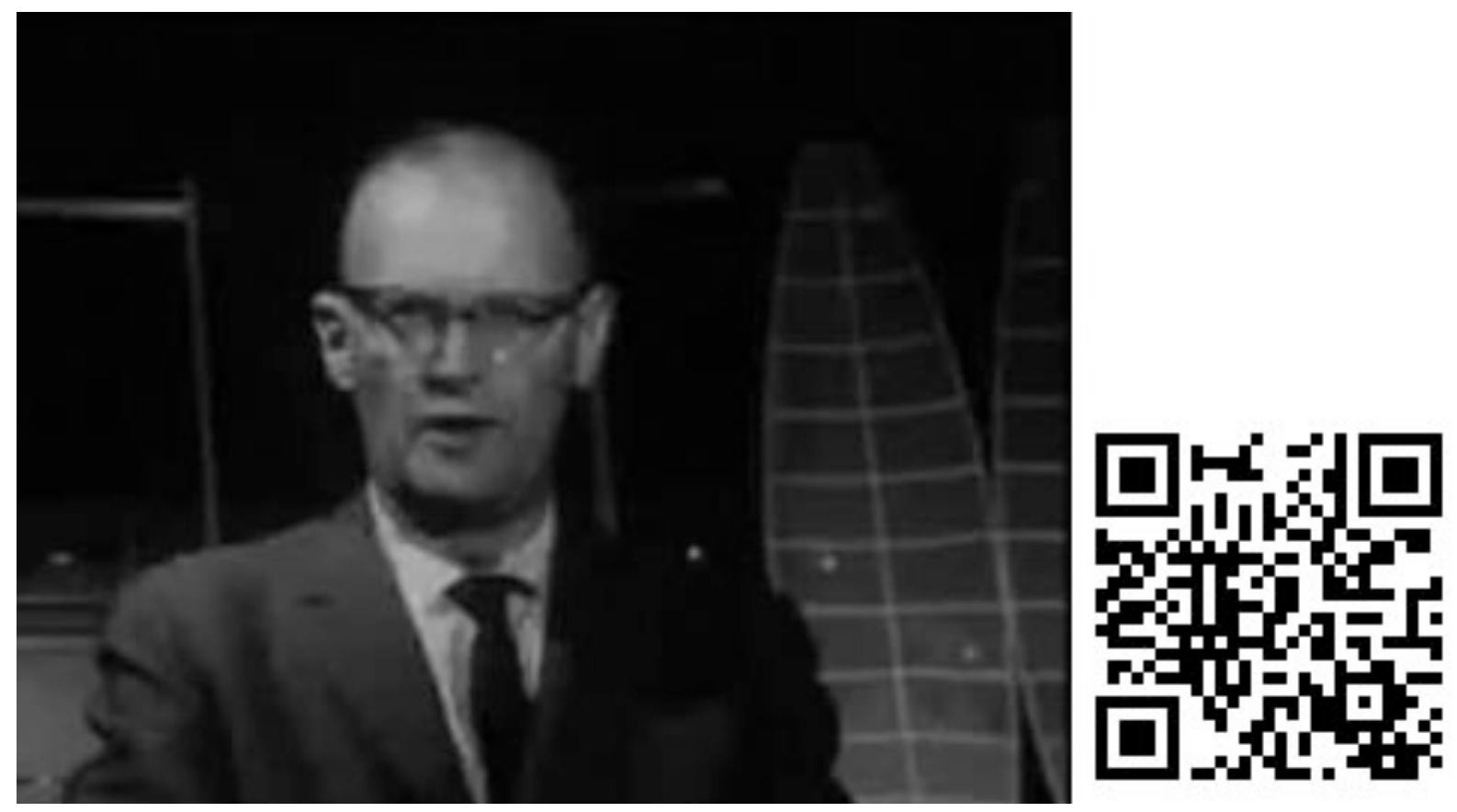

Figura 1.12 - Imagem do vídeo em que o inventor e escritor britânico Arthur Clarke, autor de “2001 - Uma Odisséia no Espaço", prevê os dias atuais. O QRcode da figura dá acesso ao vídeo, em inglês. Fonte: <http://www.youtube.com/watch?v=AOaZspeSBZU>. 

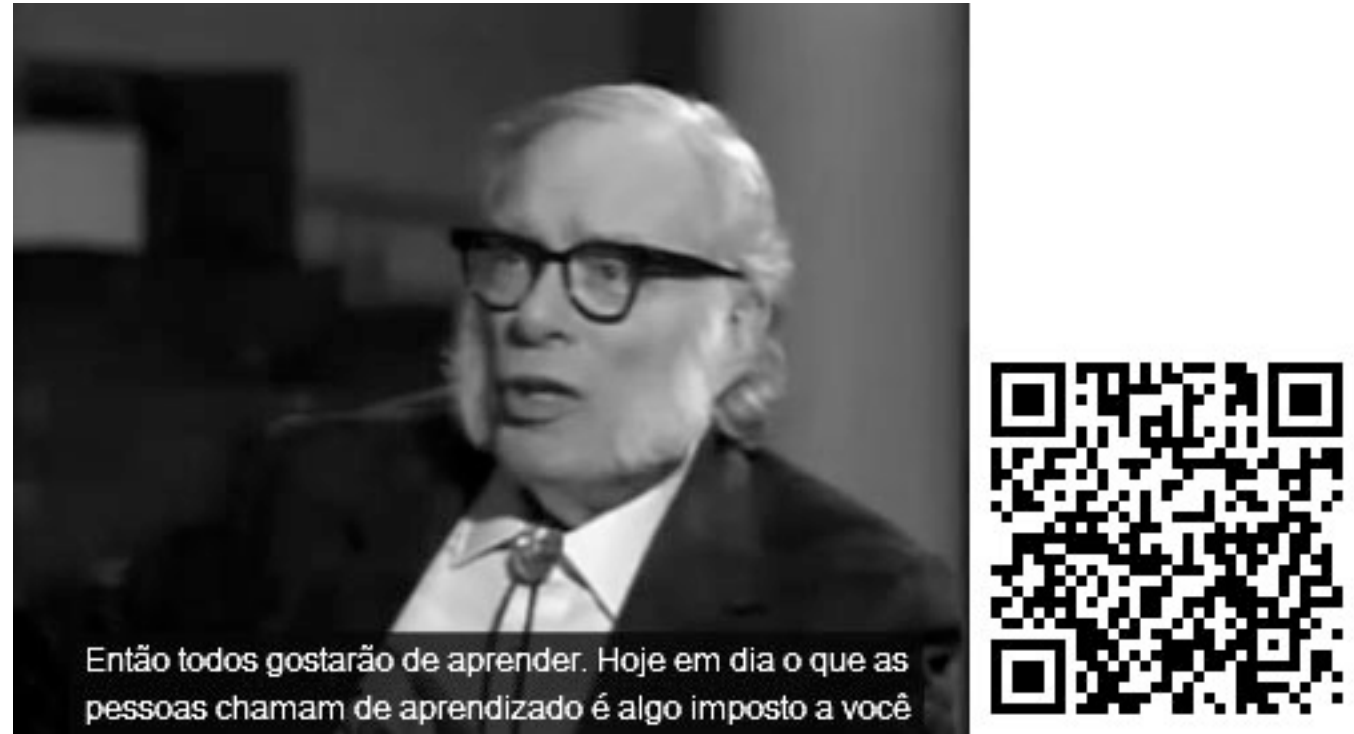

Figura 1.13 - Imagem do vídeo gravado em 1988 por Bill Moyers no programa de TV World of Ideas, em que o genial escritor Isaac Asimov, autor de "Eu Robô", prevê, entre outras coisas, as redes sociais digitais e aplicações como a Wikipedia, Yahoo Answers, etc. O QRcode da figura dá acesso ao vídeo, legendado em português. Fonte:

$<h t t p: / / w w w . y o u t u b e . c o m /$ watch? $v=C 15 N K P 1 y 6 \mathrm{Ng}$ \&fmt=18>.

Contudo, uma das previsões do passado mais impressionantes sobre os dias atuais é a teoria da "Noosfera"23, desenvolvida no início do século XX por Vladimir Vernadsky e Pierre Teilhard de Chardin. Segundo a teoria, além das camadas da atmosfera e da biosfera, a Terra evoluiria para mais uma camada: a noosfera, ou a camada do pensamento humano ("noos" vem do grego "nous" que significa mente). No pensamento original, para Vernadsky, a Noosfera é a terceira fase de desenvolvimento da Terra, depois da geosfera (matéria inanimada) e da biosfera (vida biológica). Assim como a emergência da vida transformou fundamentalmente a geosfera, a emergência da cognição humana (noosfera) transforma a biosfera. Para Teilhard, a noosfera emerge e é constituída pela interação das mentes humanas. Conforme a humanidade se organiza em redes sociais mais complexas, mais a noosfera cresce em consciência ${ }^{24}$.

Desse modo, a noosfera é formada pela integração de todo o pensamento humano em

\footnotetext{
${ }^{23}$ Mais informações sobre a Noosfera podem ser encontradas em: <http://en.wikipedia.org/wiki/Noosphere>.

24 Pierre Lévy discute a consciência coletiva no seu livro Inteligência Coletiva, de 1997. O livro Macrowikinomics, de Don Tapscott, também discute a emergência da consciência coletiva devido às tecnologias digitais mas com uma abordagem mais voltada a negócios.
} 
uma única rede inteligente, na qual o conhecimento é produzido e compartilhado por todos, como previsto por Isaac Asimov transformando sensivelmente a biosfera, como teorizado por Vernadsky e impactando profundamente a sociedade, como imaginado por Arthur Clarke. A internet e as tecnologias digitais de informação e comunicação são a infraestrutura que torna noosfera possível, cibridizando e interconectando nosso pensamento.

$* * *$

Este primeiro capítulo apresentou as transformações sociais e tecnológicas que modificam a relação das pessoas com o mundo, mediadas cada vez mais por tecnologias digitais. A proliferação tecnológica e de conteúdos, a disseminação da conexão e mobilidade, alavancando o cibridismo, o tempo-real, o nowism, o big data e a internet das coisas, desenvolvem um ambiente cada vez mais propício para processos transmídia, que para acontecerem precisam de mídias, conteúdos e conexões.

A cultura das telas interativas e da participação que se forma em função da evolução tecnológica também contribui para a propagação da transmídia, na arte ou em qualquer outra área do conhecimento. 


\section{CAPÍTULO II - PLATAFORMAS E TECNOLOGIAS DIGITAIS ATUAIS E EMERGENTES}

Como discutido no capítulo anterior, temos experimentado uma explosão tecnológica nas últimas décadas, especialmente na $1^{\text {a }}$ década do Século XXI. 0 intuito do presente capítulo é apresentar as principais tecnologias e plataformas digitais atuais e emergentes que transformam esse cenário, e que podem ser usadas e combinadas para alavancar possibilidades artísticas transmídia, como veremos mais à frente neste estudo.

Dentre as principais plataformas e tecnologias digitais, podemos citar:

- Páginas digitais

- Email

- Realidade Virtual

- Realidades Mistas

- Tecnologias Mobile

- Redes Sociais

- Plataformas de Busca

- Displays Digitais

- Games e Conteúdos de Entretenimento Digital

Podemos considerar que páginas digitais e e-mail são tecnologias já bastante conhecidas e estabilizadas na sociedade. Portanto, focaremos aqui as tecnologias e plataformas digitais emergentes: Realidades Mistas, Tecnologias Mobile, Redes Sociais, Plataformas de Busca e Outras Plataformas Digitais: Displays, Games e Entretenimento.

\section{II.1 - Realidade Virtual}

Cavernas digitais (ver Figura 2.1) são ambientes típicos de realidade virtual digital, mas ainda existem barreiras tecnológicas e econômicas que impedem seu uso comercial em larga escala pelo público. 


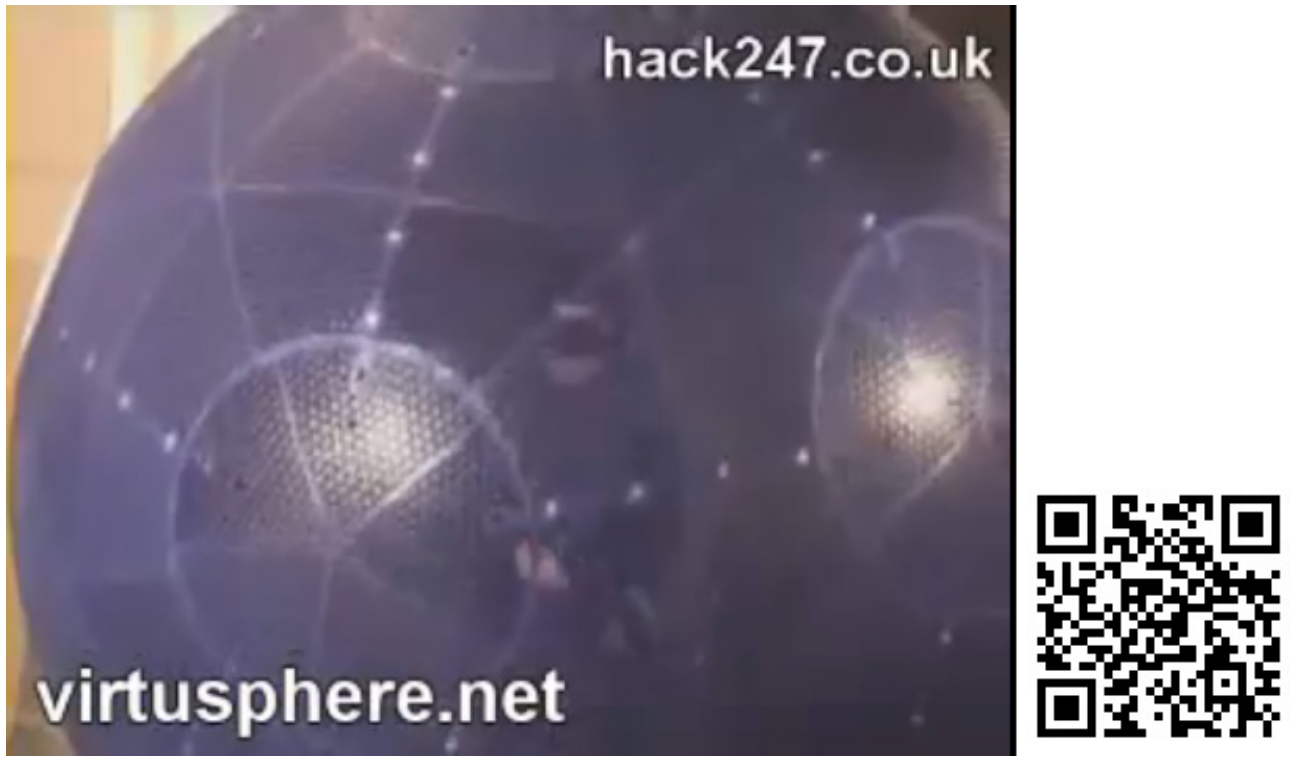

Figura 2.1 - Imagem do vídeo explicativo da VirtuSphere, exemplo de caverna de Realidade Virtual, que pode ser acessado pelo QRcode ao lado da imagem. Fonte: <http://www.youtube.com/watch?v=qTnnJR-hS7k>.

Por outro lado, games imersivos e os mundos virtuais, como o Second Life, inauguram um novo tipo de plataforma para realidade virtual, que já está disponível online e tem potencial para ações transmídia.

A popularidade do Second Life aconteceu principalmente em 2007, e por causa de várias ações equivocadas de marketing nessa plataforma, desde 2008 têm-se a impressão de que ela desapareceu e não tem utilidade. Conforme mencionado anteriormente sobre o Hype Cycle de Gartner, o Second Life foi hype, e depois de cair para a depressão da decepção, continuou crescendo a ladeira do esclarecimento para várias áreas e segmentos nos quais ele tem utilidade e aplicações diferenciais. O artigo Second Life Economy At Record High (RWW, 2010-1) mostra que o Second Life vem batendo recordes de movimentação financeira ano a ano desde 2008. Dessa forma, achamos adequado também apresentar brevemente os mundos virtuais online e seu funcionamento, mais especificamente o Second Life, para que, a partir de suas características, possam ser eventualmente usados em ações transmídia.

\section{Mundos Virtuais}

Apesar de sua aparência moderna, na realidade, os mundos virtuais online existem há décadas. Inspirados pelo jogo de tabuleiro Dungeons and Dragons (da década de 70), eles 
começaram simples, com os participantes teclando características e ações para seus personagens. Desde então, melhorias constantes na computação gráfica, somadas à cada vez mais penetrante conexão de banda larga à internet, têm impregnado esses mundos com um realismo surpreendente e intensa atividade de representação (role-playing) social. Mundos virtuais como o There, ActiveWorlds e Second Life tentam ir além do roleplaying ${ }^{25}$ para dar aos participantes mais poder de criar suas próprias experiências (BUSINESS WEEK, 2006-1).

O Second Life é, portanto, apenas um dos muitos mundos virtuais que foram inspirados pelo movimento de literatura cyberpunk, e particularmente pela novela Snow Crash, de Neal Stephenson. O Linden Lab, criador do Second Life, declarou que sua meta era criar um mundo como o Metaverso descrito por Stephenson - ambientes 3D totalmente imersivos, onde os humanos interagem (como avatares) uns com os outros (social e economicamente) e com agentes de software no ciberespaço -, que usa a metáfora do mundo físico, mas sem as limitações físicas (MANEY, 2007).

\section{O Second Life}

Tecnicamente, o Second Life é um Multi-User Virtual Environment (MUVE) em 3D na Web, onde as pessoas interagem por meio de seus avatares. O Second Life é inteiramente construído e de propriedade de seus residentes.

O Second Life (ver Figura 2.2) estourou na mídia no final de 2006 nos Estados Unidos e, no início de 2007, no Brasil. No entanto, em razão da crise global de 2008, depois de passar o hype, o Second Life sentiu o forte declínio na quantidade de dinheiro circulante inworld e uma sensível diminuição da quantidade de pessoas que o frequentam. No entanto, apesar disso, áreas como educação e recursos humanos continuam utilizando o Second Life como plataforma constante de interação.

${ }^{25}$ Role-playing game, também conhecido como RPG, é um tipo de jogo em que os jogadores assumem os papéis de personagens e criam narrativas colaborativamente. Mais informações em: < http://pt.wikipedia.org/wiki/Role-playing_game>. 


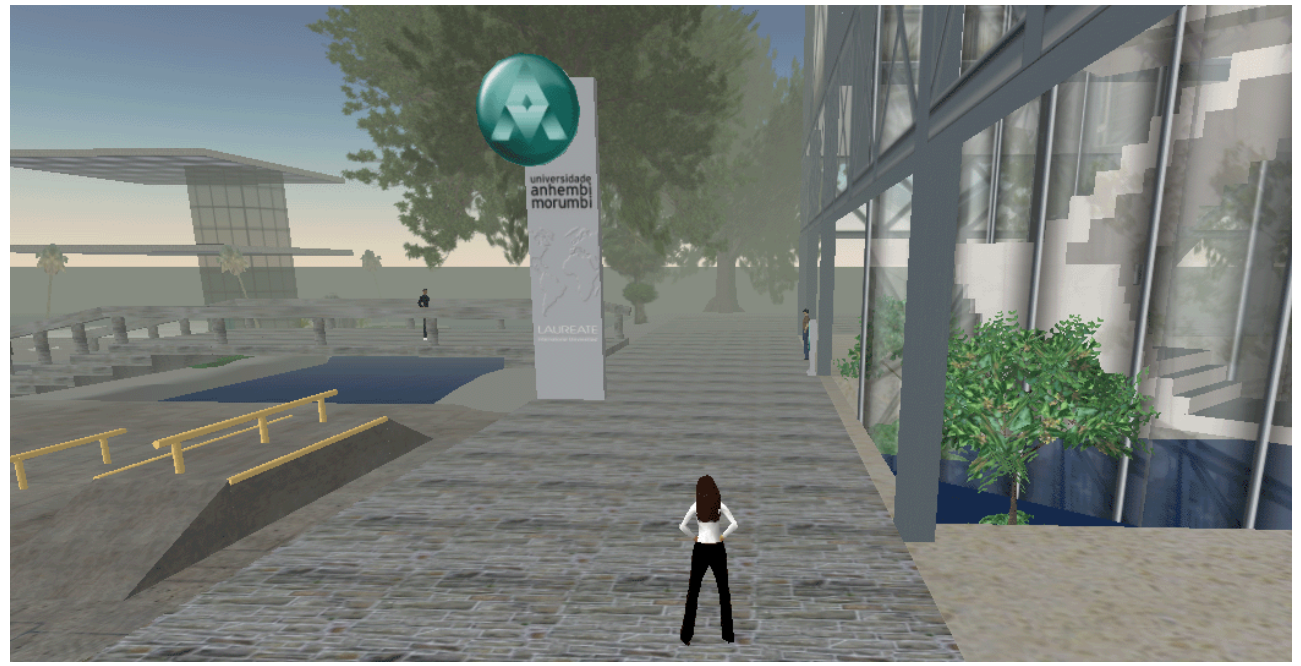

Figura 2.2 - Screenshot da entrada do campus da Universidade Anhembi Morumbi no Second Life. Foto: Martha Gabriel.

Todas as interações no Second Life são feitas por meio dos avatares. Avatares são as representações gráficas dos usuários em um ambiente virtual. 0 termo avatar vem da mitologia Hindu, onde se refere a um deus descendente que se incorpora em um ser humano e o controla. Nos mundos virtuais, os deuses são as pessoas por detrás dos avatares.

A interação dos avatares no Second Life é feita de diversas maneiras, como por exemplo, por meio de: a) conversações em modo texto em chats e Instant Messenger ou por meio de voz; b) gestos (que incluem uma infinidade de expressões que vão desde simples acenos até complexos passos de dança e flip backs); c) movimentos - andar, correr, voar, etc.; d) construção de todo tipo de conteúdo do mundo virtual; e) interação com scripts (de objetos) e outros avatares; f) transações monetárias; g) teleport - é possível, como no filme Star Trek, teleportar-ser instantaneamente para outro local no mundo, não importando onde se esteja; h) fotografar ou filmar (machinimas) qualquer coisa a qualquer instante sem necessitar de aparelhos/devices especiais; i) modificação de sua aparência (avatar); j) alteração de várias configurações do mundo (como o céu, que pode, por exemplo, permanecer sempre, dia ou noite, conforme se queira); k) modificação das vistas e visualizações, como, por exemplo, de primeira pessoa (que é a vista default do Second Life) para terceira pessoa (e se ver de frente), dentre outras formas de interação. 
A unidade básica da geografia no Second Life é a ilha. O mundo é formado por ilhas e águas, resultando em um mundo retangular plano. As ilhas podem ser compradas (atualmente, uma ilha comercial custa U\$ 2,500.00, e mais U\$ 300.00 mensais). Terras, que são frações de uma ilha, também podem ser compradas ou alugadas. As ilhas e terras podem ser compradas diretamente do Linden Lab ou por meio de leilões no próprio mundo virtual. 0 dono de uma ilha tem poderes maiores do que um rei, pois, além de poder definir que tipo de interações e regras se aplicam à sua ilha (o que os outros avatares podem fazer quando estão na ilha, como voar, criação de objetos, etc.), ele também pode escolher sua geografia e clima.

A economia no Second Life é baseada no Linden Dólar. Um Dólar Americano (US\$) vale hoje, aproximadamente, duzentos e setenta Linden Dólares (US\$ $1=\mathrm{L} \$ 270$ ). E para que serve o dinheiro no Second Life? Para as mesmas coisas em que é usado na First Life você faz suas roupas ou precisa comprá-las; você constrói sua casa ou contrata alguém para fazê-lo, e assim por diante. Para viver no SL não é realmente necessário possuir terras, propriedades ou dinheiro, e a criação do avatar para participar do mundo também é gratuita. No entanto, nessa situação, você fica limitado no que pode fazer, sujeito às regras do "dono da terra” em que você está a cada momento. Em razão da inexistência de taxas, impostos ou controle monetário no SL, os avatares podem transferir livremente dinheiro uns para os outros, sem a possibilidade de fiscalização dos países da FL.

Por enfatizar a criatividade e a comunicação, o SL é diferente dos outros mundos sintéticos online. Philip Rosedale, fundador do Linden Lab, diz que sua intenção era criar uma 'realidade estendida' no SL a partir da construção de uma versão virtual dela. Ao contrário dos outros mundos virtuais, que permitem que os participantes combinem os artefatos neles encontrados, o SL fornece aos seus residentes algo equivalente a átomos - pequenos elementos de matéria virtual chamados de 'primitivas' -, de modo que eles podem construir coisas a partir do zero. Como tudo no SL tem a intenção de torná-lo uma máquina de criatividade, o Linden Lab decidiu desde o início que os residentes deveriam ter a propriedade intelectual de suas criações. Assim, o criador determina se o objeto que ele concebeu pode ser copiado, modificado ou transferido. Graças a esses direitos de propriedade, os residentes negociam suas criações (ECONOMIST, 2006).

O Linden Lab não vende propaganda no SL, ao contrário, é uma empresa de propriedade 
virtual. Ela ganha dinheiro quando os residentes alugam propriedades - uma ilha, por exemplo - cobrando em média U\$ 20,00 mensais por acre virtual (ECONOMIST, 2006). Já os donos das ilhas e das terras podem comercializar todo tipo de espaço para promoção. Tudo no Second Life pode ser plataforma de comunicação e promoção, inclusive os corpos dos avatares.

\section{Novas Possibilidades}

O que o SL traz, afinal, de tão diferente e atrativo para as pessoas? Plataformas 3D e avatares são usados já há mais de uma década em games, e há muitos anos na web. Mesmo a possibilidade de ganhar (ou perder) dinheiro negociando com moeda própria do mundo virtual também já existia antes, como, por exemplo, no MMOG (Massive Multiplayer Online Game) Raganarok, que está online na Web desde 2005 e tem uma grande quantidade de usuários fanáticos. Redes sociais, como o Firefly (1996), por exemplo, também já existem há mais de uma década.

O Second Life, na realidade, é uma mistura, a coexistência, de tudo isso que já existia games, economia, redes sociais, etc. - exatamente como ocorre na First Life. E mais, a vida no Second Life não apenas toca a vida da First Life, como também a influencia e é por ela influenciado (como, por exemplo, no caso dos processos de transferência de dinheiro mencionada anteriormente). 


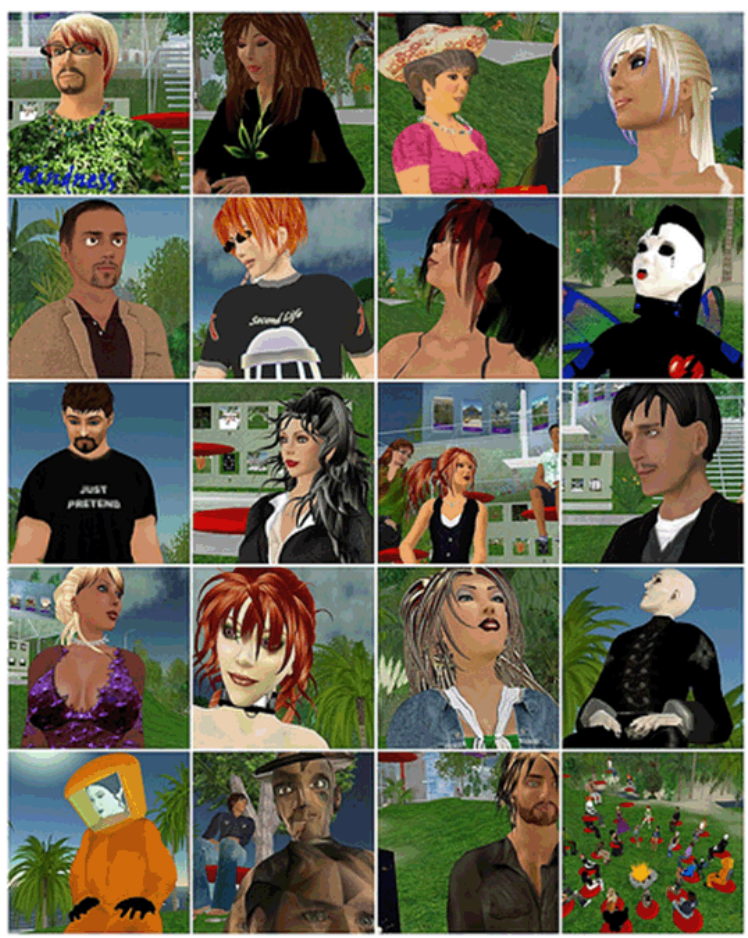

Figura 2.3 - Imagem que mostra na metade esquerda uma foto da pessoa e na metade direita a imagem de seu avatar no SL. Fonte: ISKOLD, 2007.

Assim, apesar do SL não ser uma novidade completa, ele inaugura uma rede social na web em 3D que liberta definitivamente seus usuários de sua aparência e comportamento na First life: no SL, um indivíduo pode ter a aparência e forma que quiser (inclusive parecida com ele próprio na FL, como em exemplos de avatares na Figura 2.3), com as funcionalidades que desejar. E não se trata apenas de ter uma foto diferente sua no ambiente (o pode ser feito em qualquer rede social online). No SL, você 'é' o seu avatar e você se comporta e se expressa totalmente por meio do seu avatar. A identificação com o avatar chega a ser tão grande no SL em alguns casos, que algumas pessoas passam o reveillon, namoram, casam e vivem quase que todas as horas acordadas do seu dia no SL. Processos parecidos costumam acontecer em games - existem casos reportados pela imprensa de pessoas que morreram de tanto jogar ou em decorrência de efeitos relacionados à sua participação em jogos online. No entanto, o SL não é um game você não está perseguindo nada e nem nada está perseguindo você. Não existem regras e objetivos prédeterminados como em um jogo, no entanto, existem tantos objetivos individuais quanto existem residentes (avatares) no mundo, o que torna o ambiente muito mais complexo e atrativo. 
A essência do SL é o social, e hoje ele possibilita a melhor vida digital que se pode ter. Os eventos que mais fazem sucesso no SL são os que envolvem o social - encontros, shows, festas, cursos, etc. Podemos comparar o ambiente do SL a um ambiente de playground - o playground permite a interação com outras pessoas, a escolha do brinquedo e tipo de participação (vários tipos de brinquedos - vários tipos de participação que atendem vários tipos de perfis). Quanto mais tipos de brinquedos, mais atrativo o playground se torna para vários públicos.

As características de participação do SL estão totalmente em sintonia com as tendências da Web 2.0 - na mesma linha do YouTube, Flickr, etc., o SL permite que o usuário (residente) crie todo o conteúdo existente no mundo e participe de diversas maneiras para interagir com os conteúdos que cria e com os conteúdos criados por outros, como buscas, marcadores de preferidos, etc. Isso provavelmente contribui para a atração que ele exerce no público de web.

Se considerarmos ainda as demais redes sociais existentes na web, como o Facebook, por exemplo, o SL acrescenta vários níveis extras de interação que o torna mais atrativo para alguns públicos de redes sociais, tais como a possibilidade de interagir em temporeal com gestures, possuir bens de qualquer natureza e ter seu próprio lugar espacialmente completo (e não apenas uma página de informação, como é o caso dos sites de redes sociais online como o Facebook, por exemplo), movimento e deslocamento real no ambiente para encontrar pessoas conhecidas e desconhecidas, experimentar sensações não possíveis na First Life (como voar ou modificar completamente sua aparência a qualquer instante), entre outros.

Levando-se em conta o pensamento de Naisbitt (1999) sobre a tecnologia e a busca humana de significado, talvez se possa dizer que o SL, apesar de totalmente baseado em tecnologia, paradoxalmente represente uma humanização dos mundos virtuais por meio de redes sociais e possibilidades de autoexpressão, aumentando assim o potencial de high touch.

Outro fator a destacar no SL é que o balanço entre quebrar e seguir as leis físicas torna o ambiente muito mais rico do que se apenas possível quebrar apenas as leis da física OU segui-las. Isso é interessante porque causa o efeito surpresa - nunca se sabe o que pode acontecer, se algo vai seguir ou burlar as leis da física, o que torna a ação de interação mais experimental do que na FL. 
Além de trazermos a simulação e o digital para nossas vidas cotidianas (digital life), por meio dos mundos virtuais como o SL, estamos também levando a vida cotidiana para o digital e a simulação (life digital).

Ainda, as funcionalidades de simulação no SL dão uma nova dimensão à linguagem (incluem-se nas simulações as facilidades de voar, teleportar e diversos tipos e pontos de vista dos avatares). Sugerimos que essas novas funcionalidades no SL que influenciam e afetam a linguagem dentro do mundo virtual tendem a afetar também a linguagem na web e a linguagem cotidiana na FL. No entanto, o processo ainda é muito recente, e avaliar em que grau e em que tempo isso acontecerá depende de pesquisas e estudos específicos sobre o assunto.

Mesmo não sendo exatamente uma novidade, acreditamos que o Second Life inaugura uma nova linguagem que tende a ficar e a influenciar as demais linguagens existentes, mesmo que esse mundo virtual específico do SL venha a ser superado ou substituído por outros mundos virtuais melhores no futuro. Do mesmo modo que o ICQ foi o precursor dos Instant Messengers e depois foi superado por outros sistemas de instant messengers melhores, foi ele, o ICQ, que inaugurou a nova linguagem usada por todos os seus sucessores e que influenciou e ainda influencia as demais linguagens. Assim, mesmo que o SL venha a ser substituído no futuro, sua linguagem provavelmente veio para ficar e para modificar o modo como 'criamos' o mundo.

Para acessar o Second Life, criar o seu avatar e começar a interagir no mundo virtual, os passos são os seguintes:

1. Acessar <www.secondlife.com> e criar uma conta;

2. Baixar o software de acesso ao Second Life e instalá-lo;

3. Iniciar o software de acesso ao Second Life, digitar login e senha da conta, e acessar o mundo virtual.

4. Depois disso, na primeira vez que for feito o acesso ao Second Life, o avatar entrará no mundo virtual surgindo automaticamente na ilha de orientação, local onde são fornecidas instruções sobre personalização do avatar, movimentação no mundo, etc.

A partir do primeiro acesso, toda vez que se acessar o Second Life, o avatar aparecerá no mundo exatamente na mesma posição que estava quando foi feito o último logout. 
0 trabalho de arte Skindoscope SL (GABRIEL, 2007) é um exemplo de obra transmídia no Second Life, pois as interações com o público acontecem em um fluxo entre o mundo virtual e o mundo físico. O trabalho consiste em uma árvore (ver Figura 2.4) em que cada folha é criada por um interator distinto, de forma que este escolhe a cor da folha em função da cor de sua pele (ele pode escolher a cor da sua pele humana natural ou a cor da pele do seu avatar, e aqui já acontece uma narrativa transmídia). A cada 10 interações, ou seja, a cada 10 folhas que nascem na árvore, ela 'produz' uma moeda de 1 Linden Dolar, que pode ser resgatada por qualquer avatar que nela toque. Essa transferência de dinheiro acontece realmente, e o dinheiro obtido no mundo virtual do Second Life poder ser transformado em dinheiro corrente no mundo físico, de forma que o dono do avatar pode utilizá-lo. Assim, existe um fluxo de mensagem entre os mundos virtual e físico, que faz com que a obra aconteça distribuída em mais de uma mídia e que cada qual contribua com suas potencialidades.

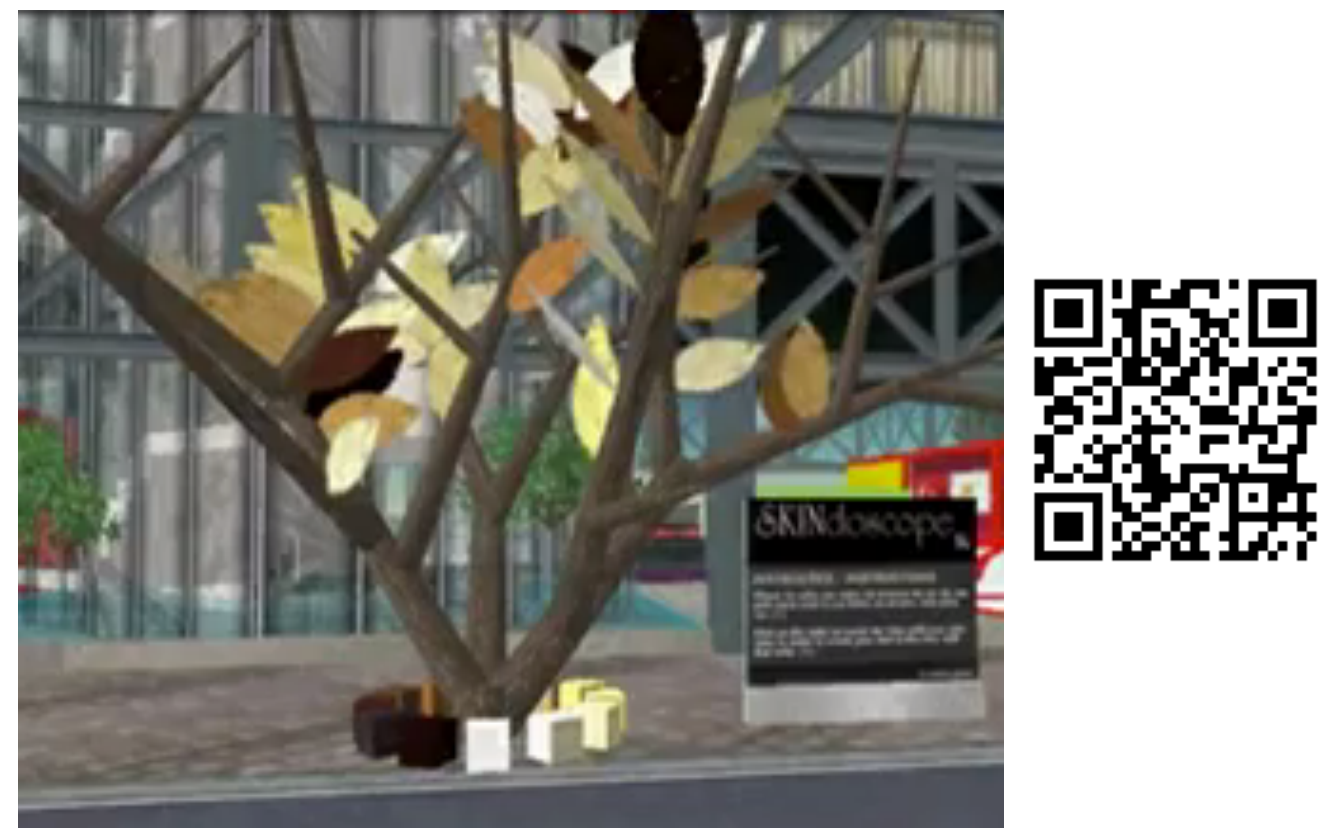

Figura 2.4 - Screenshot do vídeo explicativo do trabalho de arte Skindoscope SL, que pode ser acessado pelo QRcode ao lado da imagem. Fonte: <http://youtu.be/hF9vDsNsCWM>.

A realidade virtual apresenta um potencial muito grande para criarmos, simularmos e experimentarmos realidades que eventualmente não estão ao nosso alcance. Isso é particularmente interessante na simulação e experimentação de: 
- Realidades passadas que já não mais existem, como cidades medievais, por exemplo;

- Realidades que não conseguimos experimentar, em razão de limitações humanas, tecnológicas ou comerciais, como, por exemplo, navegar dentro de um vulcão, passear na superfície de Marte, viajar na órbita de um átomo, voar sem equipamentos, etc.

- Realidades que não podemos experimentar por limitações pessoais, como, por exemplo, lutar caratê aos 60 anos de idade quando nunca se praticou esse esporte, ou dançar tango, hip-hop, samba, ou qualquer outro tipo de dança, sem as termos aprendido antes ou sem termos adquirido a habilidade física para tal;

- Realidades inexistentes até o momento, como ambientes com qualquer valor de gravidade - maior ou menor que a da Terra -, teleportar-se, ter pele cor-derosa ou azul, ter 3 metros de altura, etc.

No entanto, diferentemente da realidade aumentada - cujas barreiras tecnológicas e comerciais estão se diluindo e popularizando-a -, a realidade virtual ainda sofre com algumas limitações tanto tecnológicas como comerciais. As caves de realidade virtual, por exemplo, ainda são ambientes tecnológicos caros e pouco portáteis e que, portanto, existem apenas em universidades e empresas de desenvolvimento de tecnologia. Ambientes virtuais como o Second Life, por exemplo, ainda precisam de computadores mais poderosos e conexões de banda larga altamente eficientes para que a experiência se torne interessante. Além disso, para serem acessados, esses mundos virtuais requerem programas específicos de acesso e separados dos browsers usuais de navegação na internet. Some-se ainda a isso a precariedade das tecnologias de áudio existentes nesses ambientes. Ainda assim, a história nos mostra que barreiras tecnológicas tendem a ser superadas e que, mesmo com essas limitações ainda, a realidade virtual, especialmente os mundos virtuais online, se bem utilizada, apresenta já hoje inúmeras oportunidades para várias áreas, inclusive para experimentações artísticas.

\section{2 - Realidades Mistas}

Realidade Mista (ou Mixed Reality) é definida como a fusão dos mundos físico e virtual para produzir novos ambientes e visualizações onde objetos físicos e digitais coexistem e 
interagem em tempo real.

Em 1994, Paul Milgram e Fumio Kishino conceituaram a 'Virtualidade Contínua' (Virtuality Continuum) (MILGRAM, 1994), conforme mostrado na Figura 2.5, como as condições possíveis de virtualidades que se estendem desde a realidade física até a realidade totalmente virtual. Entre esses extremos ocorrem vários níveis de realidade que misturam tanto elementos virtuais como físicos, consistindo de virtualidades misturadas, portanto, realidades mistas. Quando, em uma situação de realidade mista, prevalece a virtualidade sobre a realidade física, de forma que a realidade física esteja 'ampliando' as informações virtuais, temos estados de virtualidade aumentada. Diferentemente, em situações de realidades mistas em que o que prevalece é a realidade física sobre a virtualidade, e em que esta última amplia a realidade física, temos situações de realidade aumentada.

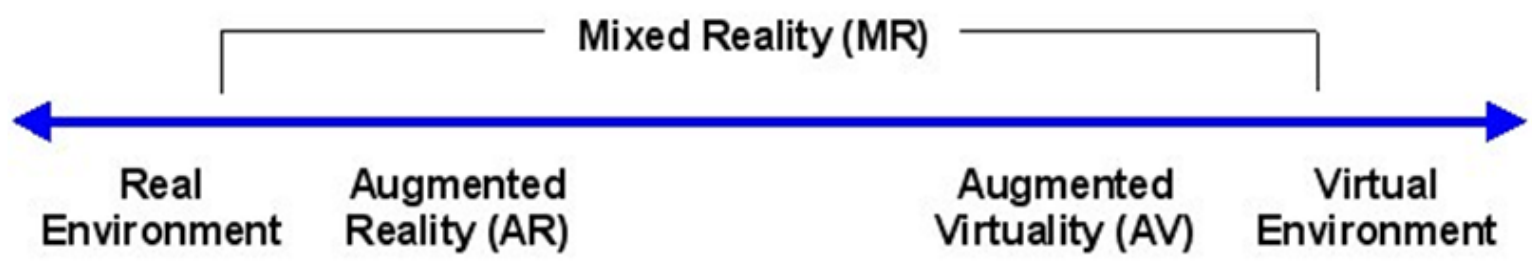

Figura 2.5 - Diagrama da Sequência de Virtualidade (Virtuality Continuum) que compõe as Realidades Mistas, criado por Paul Milgram e Fumio Kishino. Fonte: <http://en.wikipedia.org/wiki/File:Virtuality_Continuum_2.jpg>.

Deste modo, temos dois tipos de realidades mistas: a Realidade Aumentada (Augmented Reality) e a Virtualidade Aumentada (Augmented Virtuality), conforme misturam-se a realidade física e a virtualidade em diferentes graus. Quando os dados virtuais 'ampliam' a experiência na realidade física, temos a realidade aumentada. Quando os dados da realidade física 'ampliam' a experiência no ambiente virtual, temos a virtualidade aumentada.

No que se refere à aplicabilidade das realidades mistas, as possibilidades são ilimitadas. Teoricamente, qualquer área do conhecimento pode se beneficiar do uso de realidades mistas, desde a engenharia, medicina e educação até artes, entretenimento, comunicação, literatura, publicidade, marketing, etc. 
Para ilustrar os conceitos, apresentamos alguns exemplos de Virtualidade Aumentada e de Realidade Aumentada.

- Virtualidade Aumentada: um exemplo de virtualidade aumentada é a instalação de vídeo-arte DE PROXÉMICA. O que importa aqui é o que acontece na instalação virtual, nos personagens dentro do virtual, e quando pessoas no ambiente físico se aproximam, afetam a experiência dos personagens virtuais. Para assistir ao vídeo, acesse o QRcode da Figura 2.6.
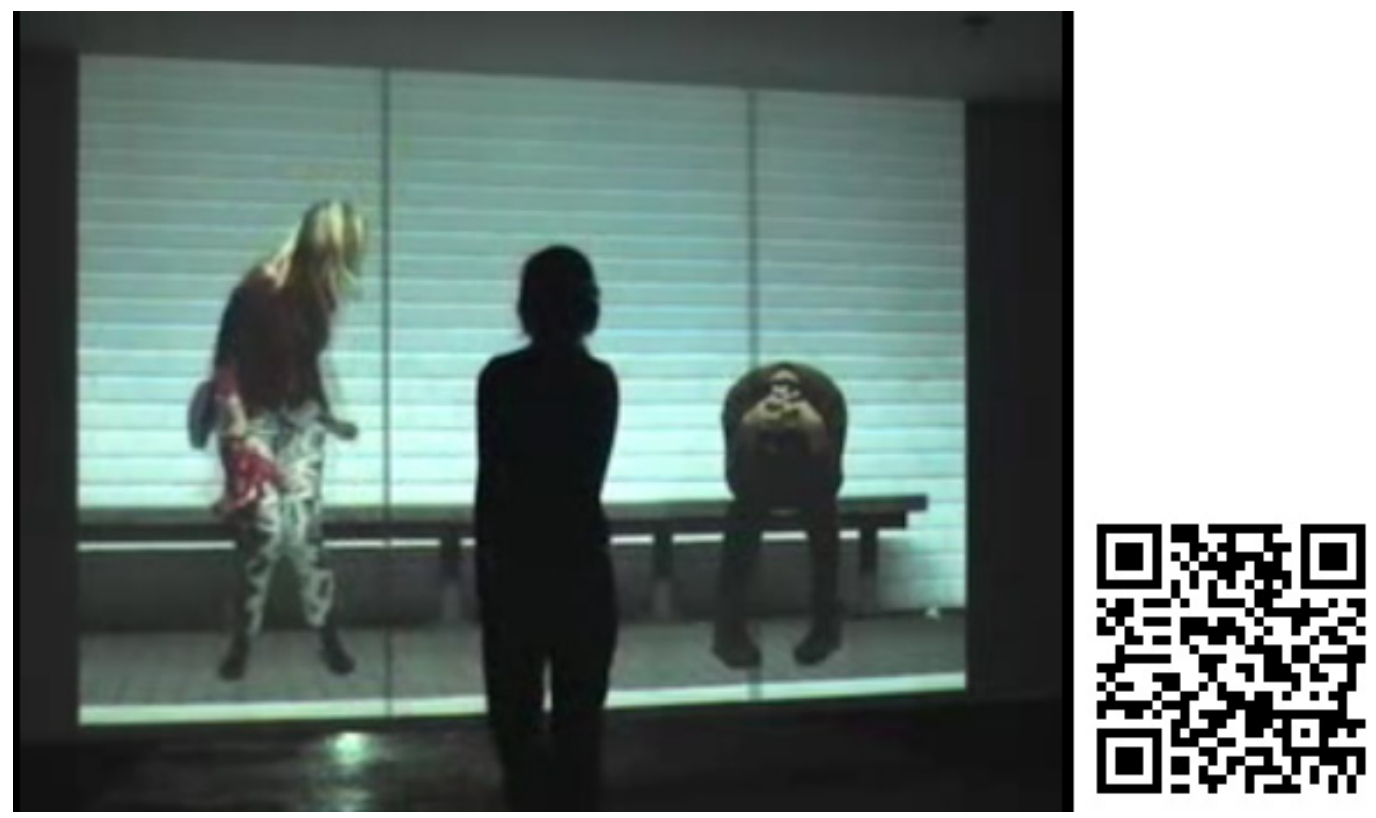

Figura 2.6 - Imagem da instalação de arte DE PROXÉMICA, exemplo de Virtualidade Aumentada, com o QRcode que linka para o seu vídeo de demonstração. Fonte: <http://www.youtube.com/watch?v=qTnnJR-hS7k>.

- $\quad$ Realidade Aumentada - Um exemplo de realidade aumentada foi a exposição We $A R$ in MoMA em 2010, no MoMA Museum em Nova York. A exposição, não convidada pelo MoMA, foi uma invasão virtual organizada pelos artistas Sander Veenhof e Mark Skwarek, que apresentou trabalhos em realidade aumentada ${ }^{26}$ de artistas do mundo todo, dentre os quais o brasileiro Álvaro Barata. Por meio de smartphones, apontando para locais específicos, os visitantes do museu conseguem ver as obras 
em realidade aumentada posicionadas em diversos lugares do MoMA. O vídeo explicativo da ação pode ser acessado pelo QRcode da Figura 2.7.
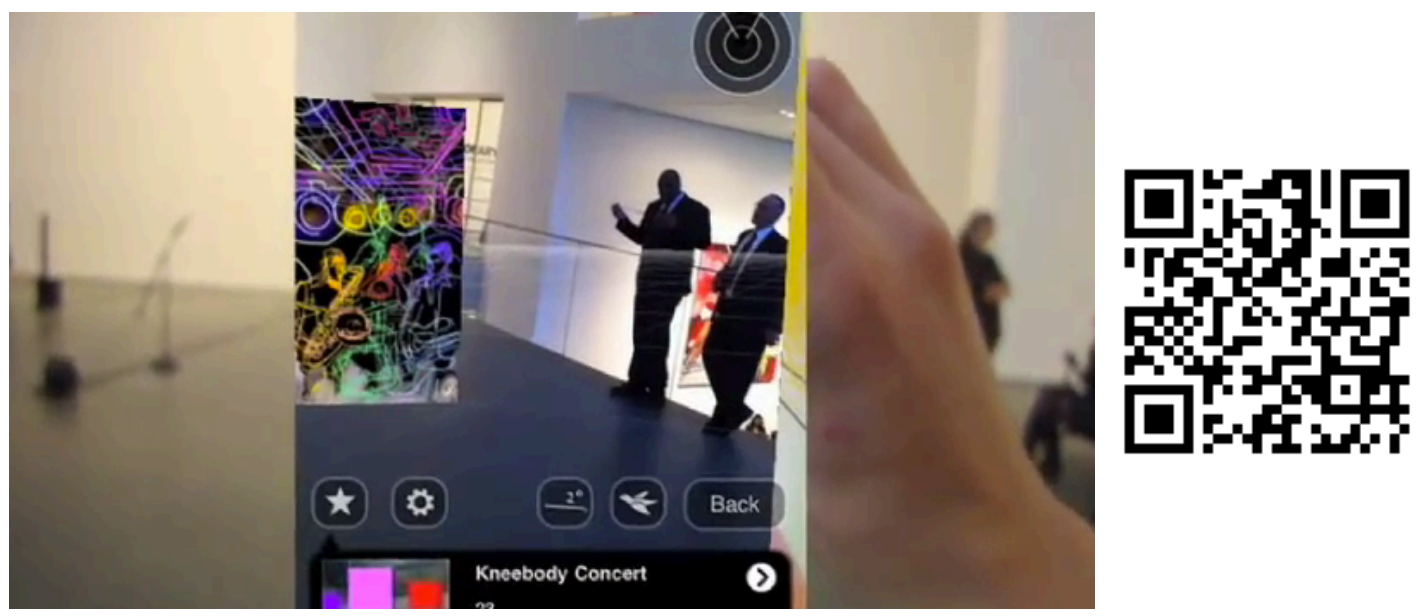

Figura 2.7 - Imagem do vídeo da We AR in MoMA, que pode ser acessado por meio do link do QRcode. Fonte: <http://youtu.be/b9T2LVM7ynM>.

Apesar de os conceitos e tecnologias referentes à realidade aumentada existirem há décadas, apenas recentemente essas tecnologias alcançaram o uso comercial e têm se popularizado, em razão de alguns fatores importantes: a) melhoria nas tecnologias de processamento de dados e imagem em computadores pessoais; b) barateamento e disseminação da banda larga de conexão à internet (tanto para desktop quanto para mobile); c) avanços nas tecnologias mobile, que permitem maior capacidade de processamento, visualização e conexão de dados nos smartphones e celulares; d) barateamento progressivo do hardware em geral: computadores, webcams, celulares, smartphones, etc.

Conforme esses fatores se tornam mais relevantes no cenário tecnosocial, mais eles tendem a alavancar o uso da realidade aumentada. Especialmente a mobilidade é um fator altamente catalisador de realidades aumentadas, pois ela permite trazer a qualquer ambiente de realidade física as camadas digitais virtuais que a ampliam. As tecnologias de geolocalização, como o GPS, por exemplo, potencializam sensivelmente a integração entre o mundo virtual e o ambiente físico da realidade, combinando-os ponto a ponto. Um exemplo disso são as novas funcionalidades de realidade aumentada que estão sendo introduzidas no Bing Maps, associando informações coletadas em tempo real por indivíduos nos locais (fotos, vídeos, etc.) e as informações digitais mapeadas 
online. A mesma lógica está sendo implementada para a visualização das constelações presentes no céu para cada local em dado momento. O acúmulo de informações na plataforma ao longo do tempo permitirá simular visualmente as modificações ocorridas, ao longo dos anos, tanto na Terra como no céu. Para ver o funcionamento dessa plataforma em desenvolvimento no Bing, assista ao vídeo apresentado por Blaise Aguera Y Arcas no TED 2010, disponível por meio do QRcode da Figura 2.8.
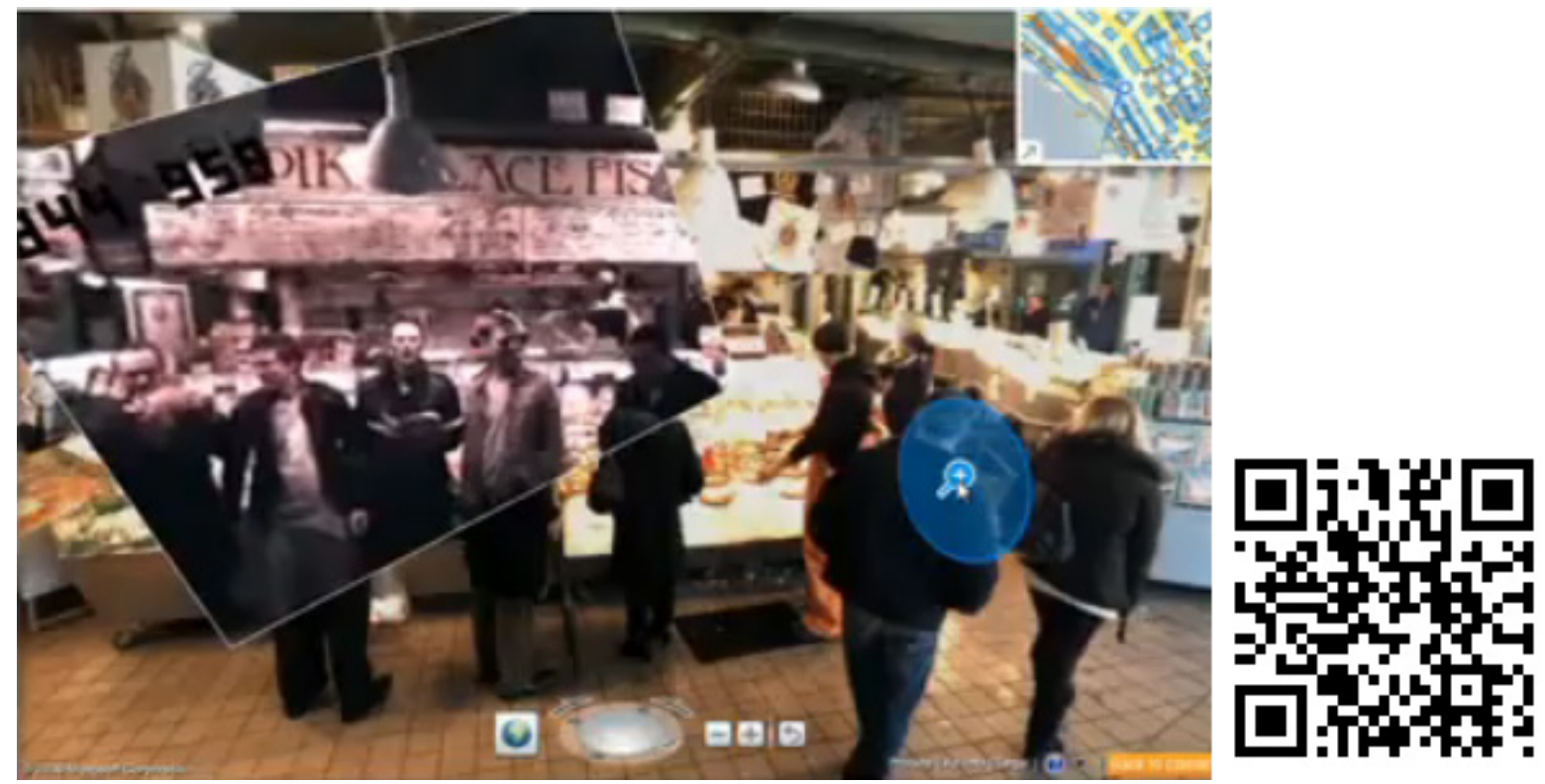

Figura 2.8 - Imagem do vídeo da apresentação de Blaise Aguera y Arcas no TED 2010 demonstrando mapas com realidade aumentada no Bing. O QRcode dá link para o vídeo. Fonte: <http://www.youtube.com/watch?v=9zD4v6iJV_o>.

$\mathrm{Na}$ sequência, trataremos com mais detalhes a realidade aumentada, trazendo mais exemplos de aplicação atuais.

\section{Realidade Aumentada}

Apesar de a história da realidade aumentada existir há décadas (ver figura 2.9), somente recentemente tornou-se possível a criação de aplicativos de realidade aumentada em equipamentos como celulares e webcams, interfaces de baixo custo e amplamente disseminadas no mercado, que impulsionou sua adoção e disseminação nas mais diversas áreas. 


\section{Augmented-Reality-History}

\section{February 18, 1962 First Simulator}

March 05, 1966 First Head Mounted Display

March 05, 1968 First Augmented Reality System

March 05, 1975 Artificial Reality Lab established

March 05, 1989 Virtual Reality invented

March 05, 1992 Augmented Reality Name March 05, 1993 First Outdoor Navigatio March 05, 1994 AR Defined

March 05, 1997 Marker system

March 05, 1997 AR Refined

March 05, 1999 ARToolkit । March 05, 2000 First AR March 05, 2003 In

Figura 2.9 - Imagem da timeline da história da realidade aumentada - timeline completa disponível em <http://www.xtimeline.com/timeline/Augmented-Reality-History>.

No Apêndice A, apresentamos diversos exemplos atuais de uso de realidade aumentada, com os QRcodes de acesso aos vídeos de demonstração.

De acordo com Gary Hayes (HAYES, 2009), existem 16 modelos de negócio para a Realidade Aumentada que apresentamos a seguir, comentando e exemplificando com base nos casos do Apêndice A:

1. In Sity - Auxílio para vendas por meio de visualização de projetos e produtos colocados no ambiente antes de realizados. Esse é o caso dos exemplos anteriores da Rossi, da USPS, Ikea, Zugara, Cisco, etc.

2. Utilidade - Uso da Realidade Aumentada para auxiliar o usuário, como sinalização, localização, etc. Os exemplos do Layar, Wikitude, USPS e outros apresentados estão nessa categoria.

3. Treinamento - Quando a Realidade Aumentada oferece treinamento para que as pessoas se tornem proficientes em alguma área ou consigam realizar uma tarefa 
específica. O exemplo da BMW (conceito) apresentado anteriormente mostra isso.

4. Social Gaming - Uso de jogos de RA em ambientes de redes sociais, o que potencializou sua propagação. O game Cannon Ballz apresentado na tabela é um exemplo típico.

5. Layers de Localização - Aplicativos de RA que apresentam informações sobre os locais, como localização de parques, restaurantes, reviews, etc. Os aplicativos de RA do Yelp!, LooKATOR ou TwittARound, por exemplo, incluem-se nesses casos.

6. Virtual Demo - Uso de RA para demonstrar produtos. O caso da Lego, com RA nas caixas dos brinquedos para mostrar como o produto seria depois de montado, é um desses casos.

7. Educação Experimental - Esse é o caso em que os aplicativos de RA auxiliam em processos educacionais, como apresentado da Arcane Technologies, em que se pode visualizar o cérebro por dentro.

8. Classificados - Diretórios em RA para localizar produtos e serviços locais de forma que as pessoas sejam guiadas para os produtos e serviços que procuram (via RA).

9. Virais em 3D - Aplicativos de RA criados para viralizar em 3D, como, por exemplo, o caso da Doritos (apresentado na tabela de exemplos de RA).

10. Compra Personalizada - A meta ideal desse tipo de aplicativo é o que acontece no filme Minority Report, quando as pessoas olham para um outdoor e a mensagem exibida é personalizada exclusivamente para essa pessoa, em função das suas características pessoais. Hoje, aplicativos como o e-commerce da Zugara são exemplos dessa categoria de modelo de negócios com RA.

11. Cooperação - Aplicativos de RA que permitem que as pessoas interajam, cooperando em ações específicas, como a vídeoconferência, por exemplo, mostrado no caso do aplicativo ZugStar. Hologramas de pessoas remotas apresentados para interagir com pessoas e objetos físicos seriam exemplos desse tipo de modelo de negócio. Na Figura 2.10 pode ser acessado o vídeo que mostra 
o CEO da Telstra apresentando uma palestra em uma conferência por meio de um holograma em real time.

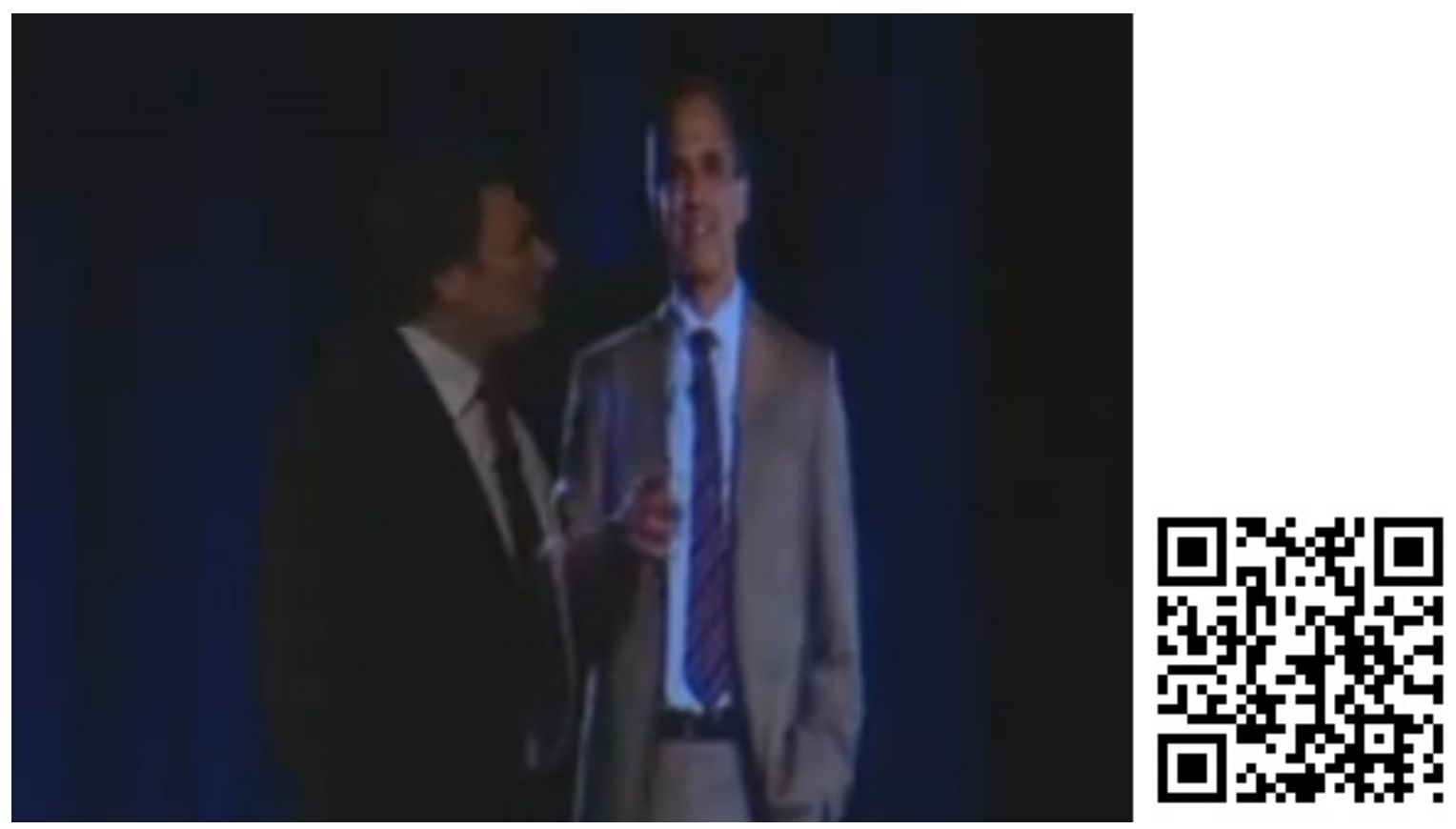

Figura 2.10 - Imagem do vídeo mostrando a interação do holograma do CEO da Telstra em uma conferência. O QRcode dá acesso ao vídeo. Fonte: <http://www.youtube.com/watch?v=IFMxUqxOaBs>.

12. Branding - Aplicativos de RA para promover a marca/empresa, como são os casos do Burger King e do Mini Cabrio apresentado na tabela de exemplos de RA.

13. Eventos Aumentados - Aplicativos de RA que permitem visualizar informações adicionais sobre eventos, como jogos e shows, quando as câmeras dos dispositivos móveis onde esses aplicativos estão instalados são apontadas para determinadas cenas, jogadores, artistas, etc., em tempo real.

14. Intertainment - Nova forma de TV e filmes experimentais em que as pessoas vivem a experiência do filme por meio de RA. Aplicações desse tipo devem começar a surgir como experiência de forma que as pessoas possam participar de cenas de filmes e shows por meio de RA e tecnologia de vídeo em 3D.

15. Compreensão de Sistemas Complexos - Aplicativos de RA que permitem interagir com partes de sistemas complexos que não podem ser divididos ou separados, 
como uma explosão, por exemplo. Esse tipo de aplicativo pode ter funcionalidade educacional ou de treinamento.

16. Reconhecimento \& Direcionamento - Aplicativos de RA com reconhecimento facial são cada vez mais comuns. Esses aplicativos permitem que saibamos com quem estamos interagindo e obtenhamos informações para ampliar a experiência com cada pessoa. Esse é o exemplo do aplicativo TAT Augmented ID, por meio do qual se reconhece a pessoa para a qual a câmera aponta, e as informações sobre ela são apresentadas de forma a auxiliar o direcionamento das ações.

Uma tendência no uso de hologramas como realidade aumentada são os hologramas tangíveis, que podem ser tocados e estão em desenvolvimento no Japão. Isso é especialmente importante em ambientes suscetíveis a alto grau de contaminação por toque, como hospitais, onde as pessoas propagam as doenças pelos toques nos botões de controles dos equipamentos hospitalares. 0 uso de hologramas como botões de controle evitaria a contaminação. 0 vídeo que pode ser acessado pela Figura 2.11 apresenta o desenvolvimento da holografia tangível.

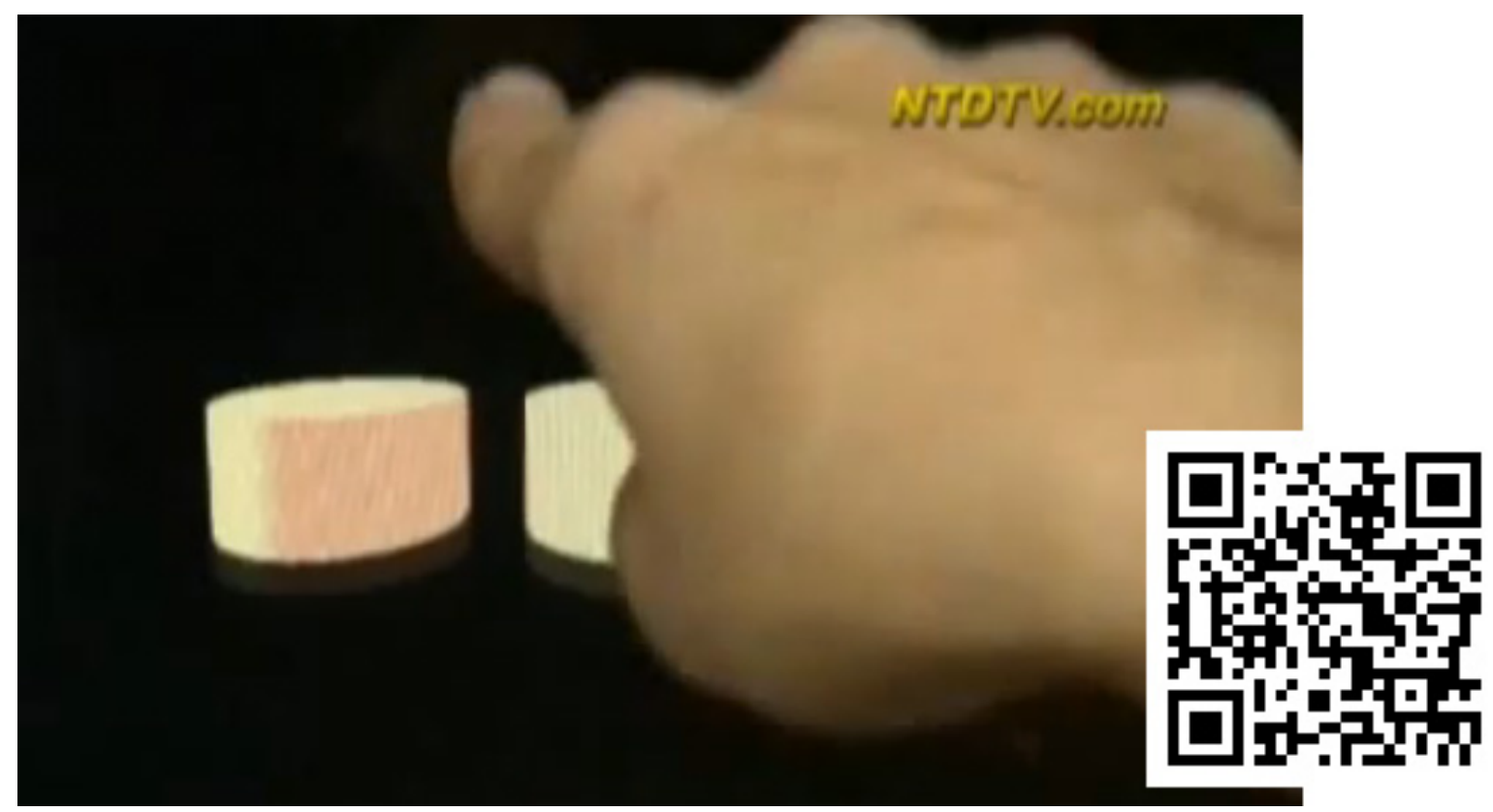

Figura 2.11 - Holografia Tangível: vídeo de demonstração do desenvolvimento, acessível via QRcode. Fonte: <http://www.youtube.com/watch?v=3seTlvQtlgc>.

Segundo um relatório da Juniper Research (IDGNow!, 2010), o mercado de realidade aumentada (RA) mobile vai alcançar US\$ 732 milhões em 2014, alimentado por 
downloads de aplicações pagas, publicidade e serviços de assinatura. Dessa forma, estamos apenas vislumbrando a ponta do iceberg dessa tecnologia, que deve transformar o modo como vemos e interagimos com o mundo.

\section{Produção de Realidade Aumentada}

Existem diversas formas de criar aplicativos de Realidade Aumentada, com e sem o uso de marcadores (markless), combinando diversas tecnologias, como visto nos exemplos apresentados anteriormente - tecnologias mobile, geolocalização, holografia, reconhecimento facial, reconhecimento de objetos, reconhecimento de formas e edifícios, etc. Virtualmente, qualquer linguagem de programação pode ser usada para criar realidades aumentadas. Para quem é programador, as possibilidades são inúmeras, pois qualquer coisa pode ser programada como marcador, ou trigger, de realidade aumentada - objetos, desenhos, cores, etc.

Um exemplo de realidade aumentada com marcador é a capa do livro Marketing na Era Digital, mostrada na Figura 2.12. Quando a capa é apontada para a web cam no endereço <www.martha.com.br/livros/marketing-era-digital/ra>, aparece na tela do computador um vídeo com a autora apresentando o livro.
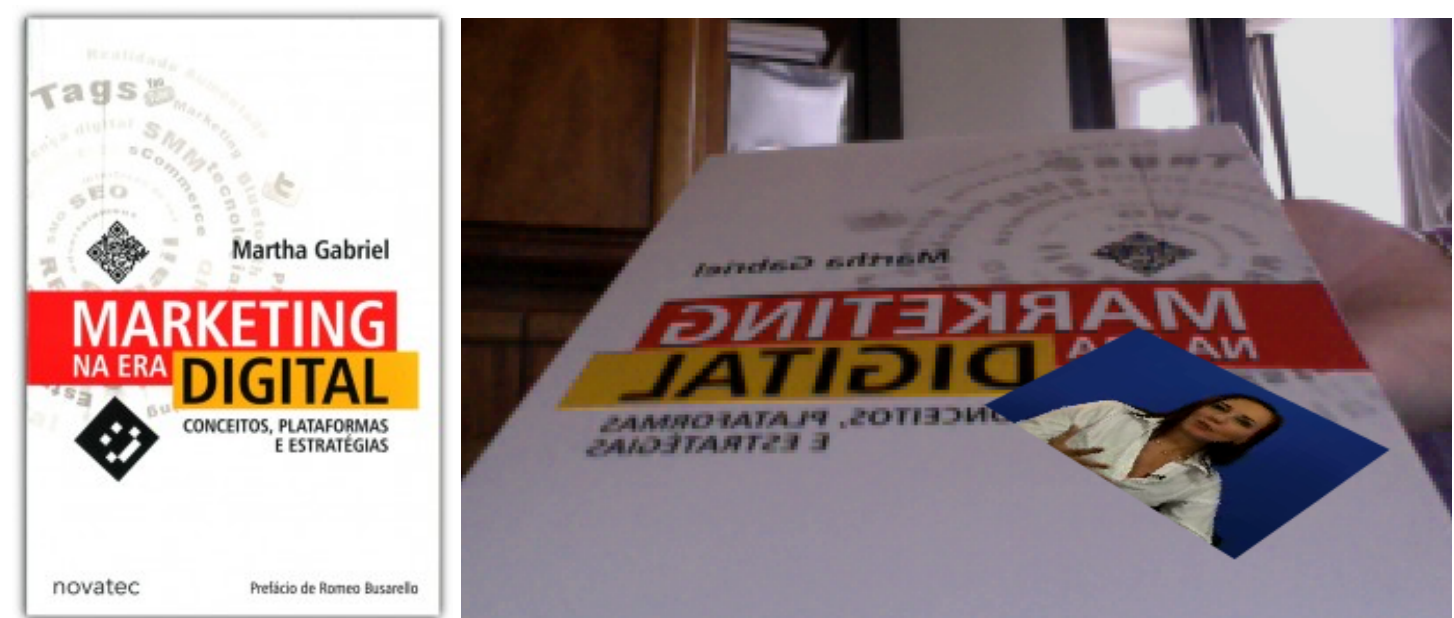

Figura 2.12 - À esquerda, foto mostrando a capa do livro Marketing na Era Digital com o marcador de realidade aumentada (logo abaixo da faixa vermelha), e à direita, uma foto da tela do computador mostrando o vídeo que aparece quando o marcador é apontado para a webcam, no endereço <www.martha.com.br/livros/marketing-era-digital/ra>. 
A Figura 2.13 apresenta um exemplo de realidade aumentada baseada em geolocalização. 0 aplicativo Monocle combina a visualização da câmera do celular com as tags de informações com nomes, distância e reviews de bares e restaurantes ao redor.

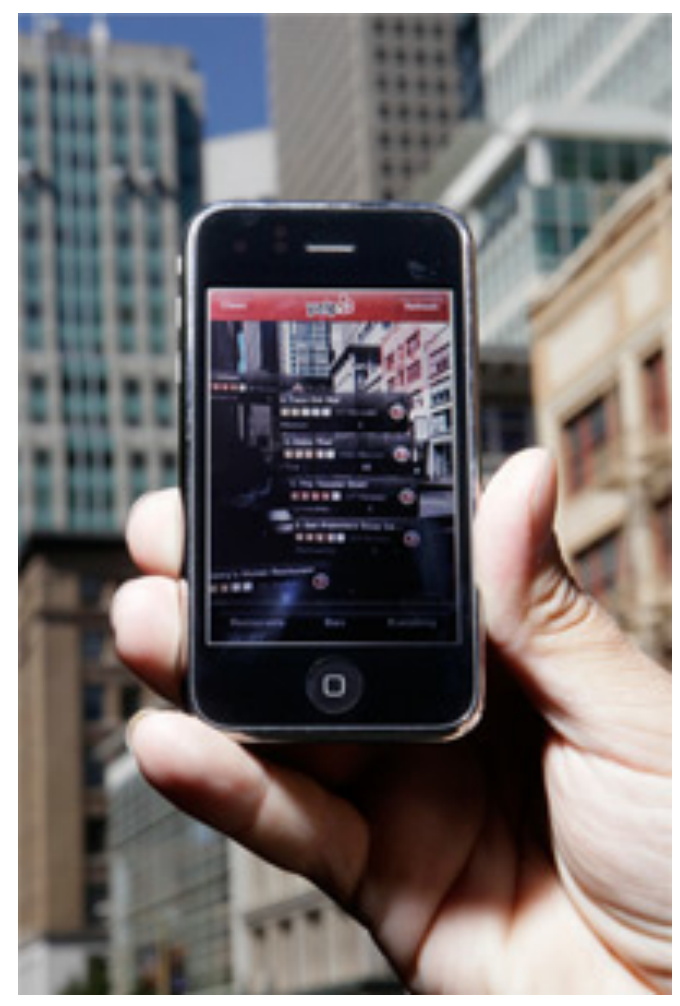

Figura 2.13 - Foto mostrando o aplicativo de realidade aumentada Monocle, no iPhone, que combina a visualização da câmera com tags indicando nomes, distâncias e reviews dos bares e restaurantes ao redor. (Foto: Marcio Jose Sanchez). Fonte: <http://computer.howstuffworks.com/augmented-reality2.htm>.

Um exemplo de realidade aumentada baseada em holografia é mostrado na Figura 2.14, no aeroporto inglês de Luton, em que um holograma dá informações aos passageiros. 


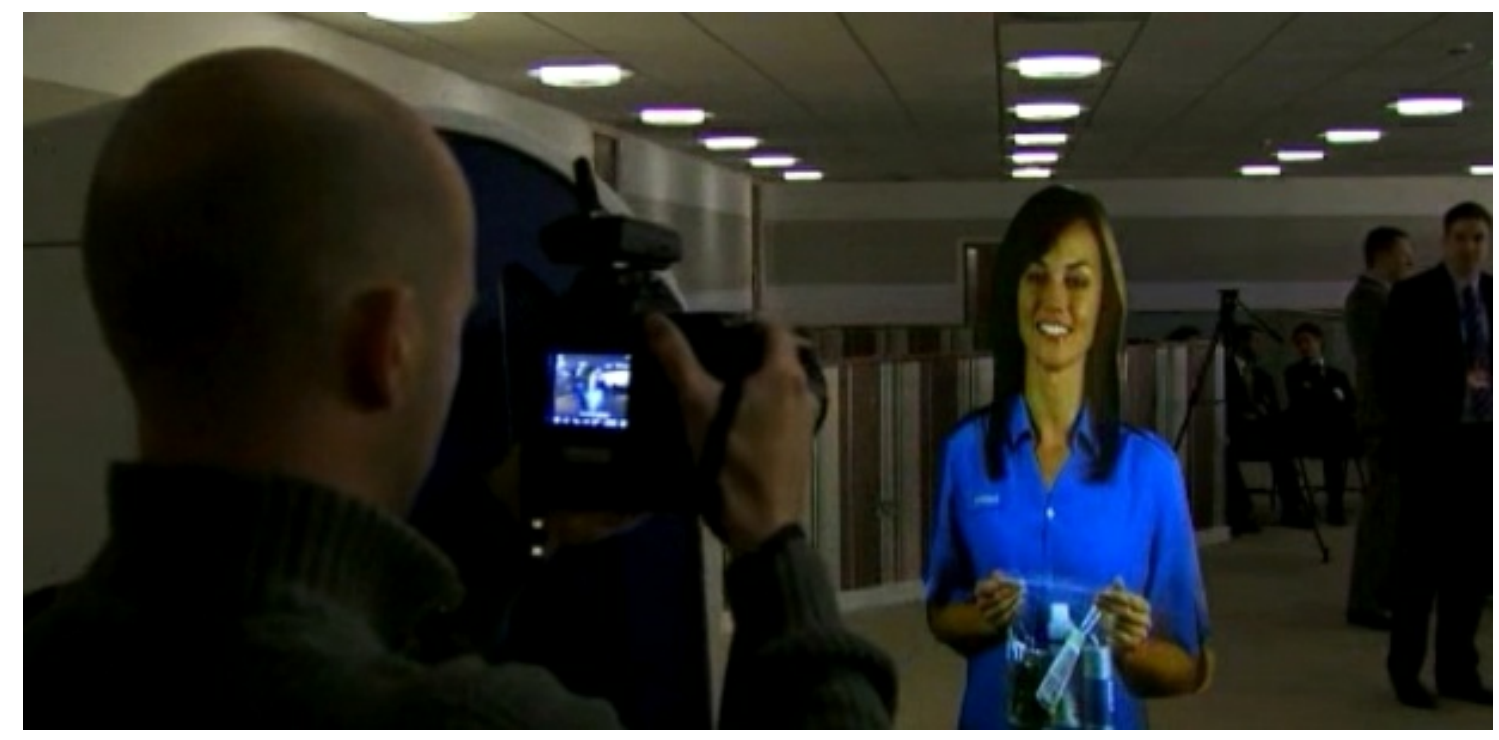

Figura 2.14 - Foto mostrando o holograma que dá informações a passageiros no aeroporto inglês de Luton. Fonte: <http://viagem.uol.com.br/ultnot/2012/05/22/hologramas-darao-informacoesa-passageiros-dos-aeroportos-de-nova-york.jhtm>.

0 rastreamento facial via webcam tem se tornado cada vez mais comum e também é usado como trigger $^{27}$ de realidade aumentada. A Figura 2.15 mostra um aplicativo de rastreamento facial e um uso dessa tecnologia com realidade aumentada.
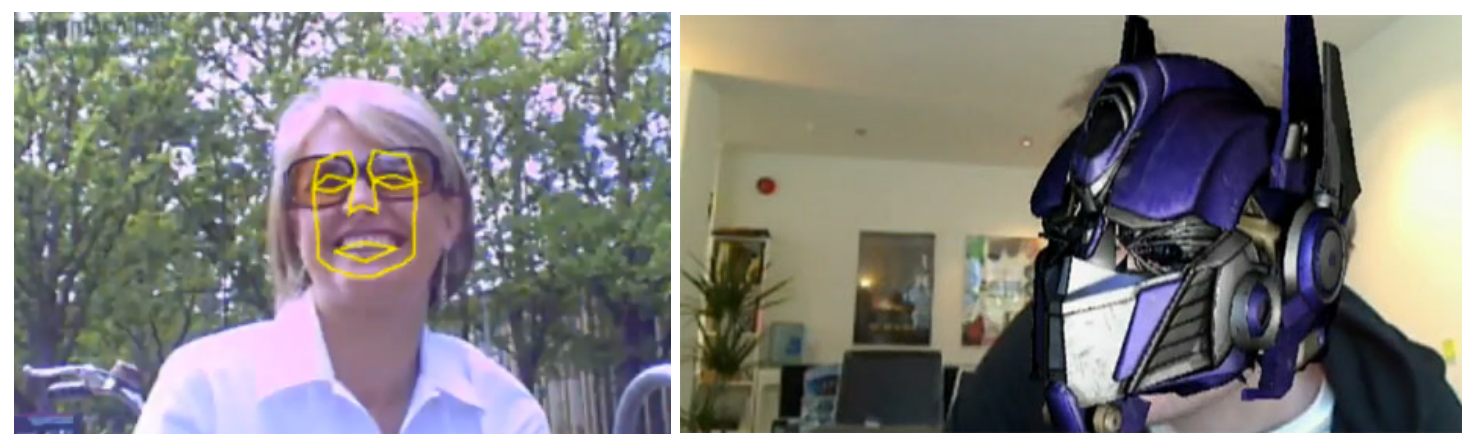

Figura 2.15 - À esquerda, uma imagem de demonstração de aplicativo de rastreamento facial via webcam (Fonte: http://wn.com/faceAPI_3D_headtracking_requires_only_a_webcam) e à direita, exemplo de aplicação em realidade aumentada em uma ação do Burger King em 2009 que

'colocava' no rosto dos interatores máscaras digitais do filme Transformers. Fonte:

<http: //comunicadores.info/2009/06/18/transformers-revenge-of-the-fallen-augmented-reality>.

27 Trigger é o gatilho no mundo físico que aciona a realidade aumentada. Quando o sistema encontra o gatilho, ele apresenta os objetos digitais para interagirem com os físicos. Um trigger pode ser teoricamente qualquer coisa: uma imagem, um objeto, uma cor, etc. Nos sistemas mais simples de realidade aumentada, o trigger normalmente é uma imagem, um marcador visual. 
Para quem não é programador, mas gostaria de criar sua própria realidade aumentada, existe a opção de usar a ferramenta de RA online no site EZFLAR <www.ezflar.com>. Nesse website, você pode selecionar facilmente qualquer arquivo no seu computador (áudio, vídeo, imagens, animações, etc.) ou textos para serem usados como RA. 0 aplicativo do EZFLAR já tem cinco tipos de marcadores predefinidos que podem ser usados para apresentar até cinco realidades aumentadas simultâneas. É bastante simples de usar.

\section{Desafios da Realidade Aumentada}

Apesar de a realidade aumentada estar se disseminando no mercado, ainda existem alguns desafios que precisam ser vencidos para essa tecnologia alcançar a maturidade, conforme listados por RWW (2010):

- Segurança e Spam - As aplicações de realidade aumentada podem, teoricamente, apresentar qualquer tipo de conteúdo digital interagindo com o ambiente em que estamos. Conteúdos digitais maliciosos e inapropriados podem ser disparados e apresentados via realidade aumentada, assim como mensagens indesejáveis e maliciosas que entopem nossa caixa de e-mail diariamente. Portanto, cuidados com segurança e políticas antispam devem fazer parte do processo de evolução dos aplicativos de realidade aumentada.

- (Social \& Real-time) versus (Solitário \& Previamente armazenado) - À medida que o uso de realidade aumentada se dissemine, cada vez mais as pessoas poderão tocar nas realidades aumentadas umas das outras. Além disso, a experiência de apontar os dispositivos para objetos será tão rica quanto as informações em tempo real que possam ser apresentadas sobre esses objetos. Para que tanto a realidade aumentada social como a obtenção de informações sobre o ambiente em real time aconteçam de forma natural, várias barreiras tecnológicas ainda precisam ser vencidas.

- Experiência do Usuário - Os desafios da realidade aumentada referentes à experiência do usuário são enormes. Imagine pessoas apontando dispositivos umas para as outras para obterem informações pessoais - isso pode não ser uma boa experiência de uso em alguns contextos. Segundo Joe Lamantia (2009), existem duas questões principais relativas à experiência do usuário em realidade aumentada: 1) que informações revelaremos do nosso contexto privado para serem apresentadas na 
camada de interface a outras pessoas?; e 2) é possível encontrarmos interfaces melhores para visualizar esse tipo de informação do que os modelos existentes até o momento?

- Interoperabilidade - Padrões para crescer são necessários em telefonia, estradas e tecnologias de redes, tanto quanto em qualquer setor tecnológico. Atualmente, os aplicativos de RA não 'conversam' uns com os outros.

- Abertura - Para que a realidade aumentada, no sentido amplo, se torne uma experiência rica em vários setores do conhecimento, é necessário encorajar a produção de aplicativos e conteúdos criados e integrados de forma aberta. Sem padrões abertos para a integração de aplicativos e conteúdos de todas as naturezas, cada sistema de RA fica limitado a si mesmo. Portanto, além de serem essenciais para a interoperabilidade, os padrões abertos são importantíssimos para o florescimento de um ambiente digital que enriqueça as camadas de realidade aumentada, globalmente.

\section{Referências adicionais}

Para reforçar e aprofundar o conhecimento sobre o assunto de realidades mistas, sugerimos as referências que seguem.

- Website Realidade Aumentada - o website <http://www.realidadeaumentada.net/> apresenta informações e cases sobre realidade aumentada.

- How Virtual Reality Works - matéria em inglês, bastante completa, no portal How Stuff Works - <http://electronics.howstuffworks.com/gadgets/other-gadgets/virtualreality.htm>.

\section{3 Tecnologias Mobile}

O objetivo desta seção é apresentar as tecnologias mobile disponíveis para uso em ações estratégicas de marketing. A penetração mobile em todas as populações no mundo transforma os dispositivos móveis em uma das plataformas mais dominantes e promissoras. 
O ser humano é mobile por natureza. Somos nômades em nossa origem, e muitas técnicas e tecnologias desenvolvidas ao longo da história da humanidade tiveram por objetivo ampliar e facilitar nossa mobilidade - domesticação dos mais diversos animais (de cavalo a elefantes) para nos transportar, bigas, carroças, bicicletas, carros, barcos, aviões, trens, naves espaciais, etc. Continuamos em busca de soluções que nos levem além, mais adiante, para descobrir novas fronteiras e de forma cada vez mais rápida. Quem sabe um dia consigamos realizar o sonho do teletransporte? Outra essência da natureza humana é a comunicação. O homem é um ser social e a comunicação é base da socialização. Testemunhamos também, ao longo da história, a evolução das técnicas e tecnologias de comunicação impulsionando a socialização - dos sinais de fumaça ao telefone celular VolP. Uma terceira característica do ser humano é a necessidade de obter informações constantemente para poder sobreviver e viver melhor no ambiente em que se encontra. O desenvolvimento de técnicas e tecnologias de informação também se esparrama pelos tempos, trazendo-nos ao cenário hiperconectado em que vivemos. Somos hoje nômades digitais, possibilitados e impulsionados por milhares de anos de desenvolvimento de tecnologias de mobilidade, comunicação e informação. 0 futuro é mobile porque a natureza humana é mobile, e as tecnologias digitais não apenas estão eliminando todas as restrições que nos impedem de exercitar nossa mobilidade instintiva, como também as estão alavancando.

É importante ressaltar que a plataforma mobile não se restringe apenas a aparelhos celulares, Smartphones e PDAs. Cada vez mais outros dispositivos integram as plataformas mobile, como PSPs, carros, aparelhos GPS, e-book readers, etc.

Abordaremos aqui desde as tecnologias mobile mais antigas que continuam sendo instrumentos importantes para exploração, como o Bluetooth e o SMS, até as mais recentes, que oferecem soluções bastante inovadoras. Discutiremos, então, as tecnologias móveis, como segue:

- RFID

- Bluetooth

- SMS / MMS

- GPS

- Mobile Tagging

Arte Transmídia na Era Digital 


\section{- Aplicativos Móveis}

- Mobile TV

Além das tecnologias apresentadas, a realidade aumentada, discutida anteriormente, também é uma tecnologia importante no cenário mobile. Vários dos exemplos apresentados na tabela de casos de realidade aumentada são exemplos de realidade aumentada móvel. Como as realidades mistas, incluindo a realidade aumentada, podem ser usadas não apenas nas plataformas mobile, decidimos abordá-las em uma seção a parte. No entanto, o habitat mais promissor para a realidade aumentada é o da mobilidade.

Cada tecnologia móvel aqui apresentada requer um tipo específico de hardware, não estando, portanto, necessariamente disponível em todos os tipos de dispositivos móveis. Desse modo, a utilização de cada tecnologia está condicionada à sua disponibilidade nos diversos dispositivos e hardwares presentes no mercado.

\section{RFID - Radio Frequency IDentification}

RFID (radio frequency identification) são sensores (também chamados de tags) aplicados ou incorporados a um objeto ou ser (produtos, coisas, lugares, pessoas, animais, etc.) com a finalidade de identificar ou rastrear esse objeto por meio de ondas de rádio. As tags RFID podem ser lidas de vários metros de distância e não precisam de contato visual com o leitor. Normalmente, os leitores são equipamentos dedicados a isso. Exemplos de aplicações comuns que já usam RFID no nosso dia a dia são: a) smart cards em crachás, que quando passados próximos aos leitores de catracas são lidos para dar acesso de entrada; b) serviço Sem Parar, que usa tags RFID fixadas nos parabrisas dos carros, que são detectadas pelos sensores dos pedágios e estacionamentos para fazer a cobrança automática.

No artigo 100 Uses of RFID <http://www.readwriteweb.com/archives/100_uses_of_rfid.php>, algumas das utilizações importantes citadas são: a) cronometrar corridas; b) controle de inventário de hospitais; c) melhoria da experiência de pacientes em hospitais; d) não necessidade de baterias no RFID como fator crucial em algumas aplicações; e) possibilitar a próxima revolução na mobilidade e wireless, por meio de identificação automática, coleta de dados e sistema de locatividade. 
A tecnologia de RFID é uma das principais alavancas para a Web 3.0 e a Internet das Coisas. O problema da utilização das tags de RFID em todos os objetos é seu custo, que gira em torno de 50 centavos de dólar, o que ainda é alto para alguns tipos de produtos. Com o barateamento das tags RFID, ou com o desenvolvimento de tecnologias similares mais acessíveis financeiramente, o taggeamento das coisas tende a ser ubíquo - tudo será taggeado e participará da rede. Nesse cenário, as geladeiras poderão reconhecer todos os produtos dentro dela, saber o que está dentro do prazo de validade ou não para alertar o usuário, conhecer as preferências de compra do usuário e enviar ordens de compra automaticamente quando os produtos acabarem. Nessas circunstâncias, as pessoas provavelmente receberão gratuitamente essas geladeiras inteligentes oferecidas por redes de supermercados, desde que o abastecimento de produtos seja feito automaticamente por essas mesmas redes. Esse modelo de negócios é bem parecido com o que acontece hoje com o mercado de telefonia celular - clientes de planos pós-pagos, que consomem automaticamente os créditos da operadora, recebem celulares de última geração gratuitamente ou quase de graça.

Uma das grandes vantagens das tags de RFID é que o leitor da tag não precisa ter contato visual com ela. Isso permite que ela seja 'sentida' automaticamente pelo leitor. Outra vantagem é o fato de essas tags terem a capacidade de oferecer muitas informações sobre os objetos em que estão fixadas, além de descrever situações de estado, como temperatura, alertando, por exemplo, quando um pacote de leite não se torna mais adequado ao consumo por mudanças na sua temperatura.

Um exemplo de uso do RFID é a ação The Real Life Like da Coca-Cola em Israel. A ação aconteceu em um acampamento de verão que reuniu milhares de adolescentes por três dias, o Coca-Cola Village, onde os participantes usavam pulseiras com RFID que permitiam que eles dessem 'likes' para as atividades e coisas do acampamento. Cada pulseira de RFID tinha as informações de login da conta da pessoa no Facebook e, assim, os 'likes' eram automaticamente atualizados em seus perfis e no perfil do Coca-Cola Village. Dessa forma, a ação permitiu a integração automática das coisas do mundo físico com a maior rede social online, o Facebook, com interações em tempo real. Para assistir ao vídeo do case com informações detalhadas da ação, use o QRcode ou URL fornecidos na Figura 2.16. 


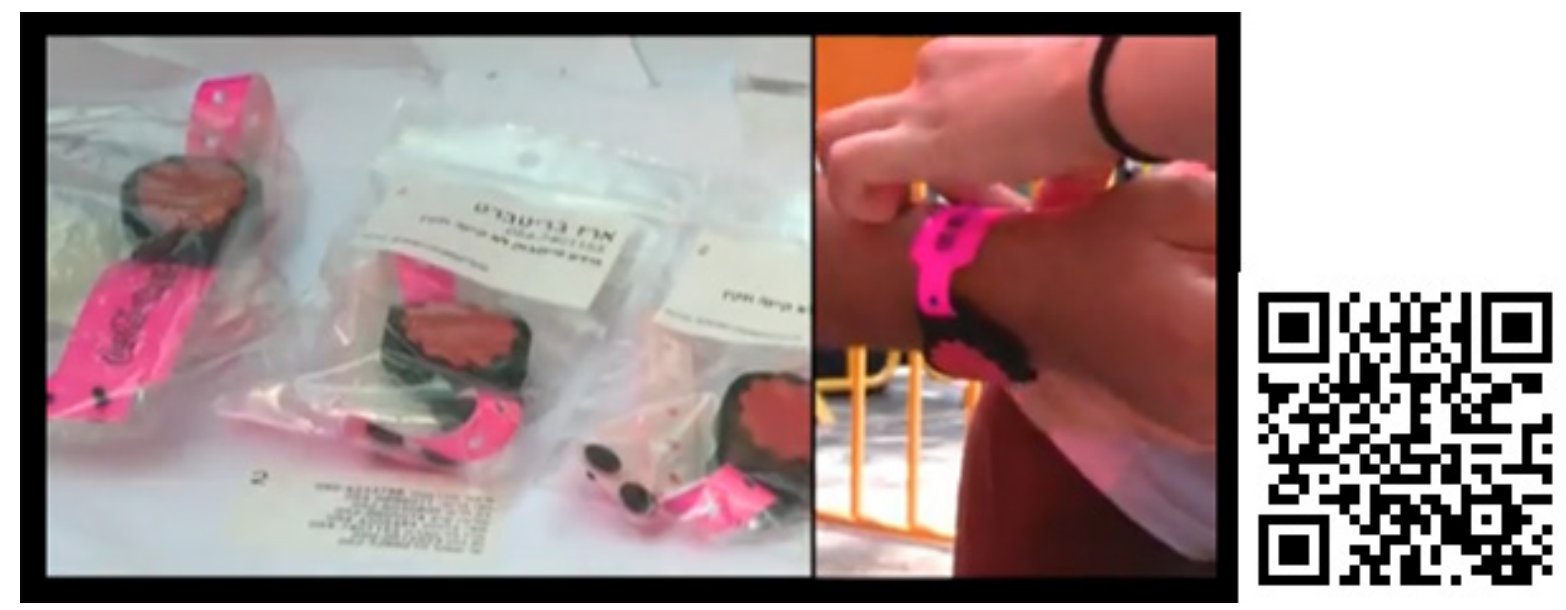

Figura 2.16 - Imagem do vídeo que apresenta o case The Real Life Like no Coca-Cola Village em Israel. $O$ vídeo pode ser acessado pelo link do QRcode. Fonte: <http://www.youtube.com/watch?v=xUv0GU5rfHg>.

Tim O’Reilly menciona no vídeo acessível pela Figura 2.17, que "O RFID são coisas usando tags e a Web 2.0 está aprendendo a reconhecer coisas. Estamos chegando a um tipo de realidade aumentada na qual nossos computadores terão sentidos que são tão bons quanto os nossos ou melhores, eles reconhecerão faces, objetos e terão lembranças."
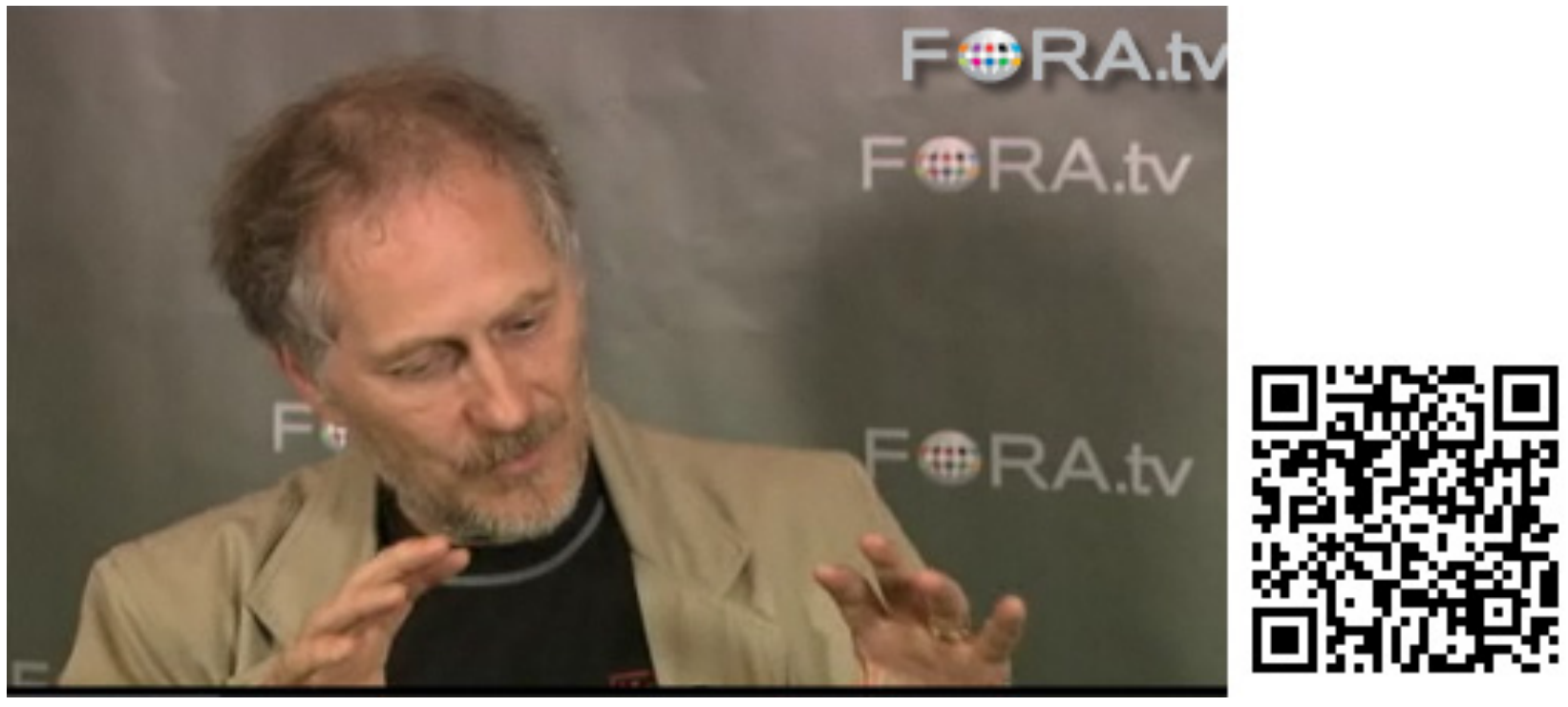

Figura 2.17 - Imagem do vídeo de entrevista de Tim 0'Reilly sobre Web 2.0, Web 3.0, Internet das Coisas, etc., que pode ser acessado pelo link do QRcode. Fonte: <http://fora.tv/2009/04/02/Tim_OReilly_Talks_Web_20\#fullprogram>. 
Tim O’Reilly declara ainda nesse vídeo (Fig. 2.17) que a interface do futuro será um par de óculos, que nos permitirá olhar para as coisas e estas serão reconhecidas para obtermos informações.

Segundo previsões da Juniper Research (MARKETING VOX, 2010-1), as vendas associadas à realidade aumentada móvel alcançarão 732 milhões de dólares até 2014. Em seu relatório Mobile Augmented Reality: Forecasts, Applications \& Opportunity Appraisal 2009-2014, a Juniper define “aplicações de realidade aumentada móvel” como dispositivos que usam câmeras, localizadores GPS, conexões de banda-larga, sensores de movimento e bússulas digitais para fornecer camadas de metadados sobre os arredores dos usuários.

\section{Bluetooth}

Bluetooth é uma tecnologia wireless que usando banda estreita (pequeno volume de dados) permite a troca de dados (por meio de ondas de rádio de curta frequência) entre dispositivos móveis,. A utilização de Bluetooth permite a criação de redes pessoais (PANs - Personal Area Networks), possibilitando com alto grau de segurança a conexão de diversos dispositivos. A grande vantagem do uso dessa tecnologia para conectar redes é seu baixo custo e também o baixo consumo de energia. 0 alcance das conexões é de aproximadamente 100 metros, o que é bastante razoável para seu objetivo principal, que é a eliminação de cabos para permitir a conexão wireless entre equipamentos móveis dentro de uma determinada área. O foco do Bluetooth não é conectar equipamentos com redes remotas, caso das WLAN, cuja conexão wireless é feita via tecnologias como o Wi-Fi em banda larga.

O uso mais popular do Bluetooth hoje é a conexão entre telefones celulares e headsets sem fio, que permitem que o usuário possa receber ligações com as mãos livres. Outro uso bastante comum do Bluetooth é a transferência de arquivos entre aparelhos celulares próximos. Mais utilizações incluem, entre outras:

- Comunicação sem fio de dispositivos de entrada e saída com o computador, como teclados e mouses;

- Substituição da tecnologia infravermelho em controles remotos; 
- Envio de anúncios e arquivos promocionais (como ringtones, por exemplo) a partir de um quiosque Bluetooth para aparelhos celulares próximos;

- Sistemas RTLS (real time location systems), que são usados para rastrear e identificar a localização de objetos em tempo real;

- Videogames como Wii, PlayStation 3, PSP Go e outros, para permitir conexões entre o console e os controles;

- Descoberta de equipamentos e configuração entre eles dentro de uma determinada área;

Apesar de ser uma das tecnologias mobile mais antigas, o Bluetooth é extremamente eficiente e pode ser a plataforma ideal para algumas experimentações, como a ação mobile Quick is Deadly da Nike para o tênis Zoom na China. A ação consistia de um outdoor eletrônico que enviava, via Bluetooth, uma mensagem para o celular das pessoas que passavam em frente dele. A mensagem disparava um cronômetro digital que passava a contar o tempo no instante em que a mensagem era recebida no celular da pessoa, e instruía essa pessoa a correr para a loja da Nike. 0 outdoor eletrônico foi colocado a um quarteirão de distância da loja da Nike e, quando a pessoa com a mensagem chegasse à loja, o cronômetro marcava o tempo final da corrida. Quem fizesse o menor tempo em cada dia ganhava um tênis Nike Zoom. A ação foi um sucesso - pessoas iam para o outdoor vestidas de trajes de corrida para conseguirem fazer o percurso mais rapidamente. Outra pessoas ficavam vendo o movimento na largada, no outdoor, ou na chegada, na entrada da loja da Nike. A ação é mostrada no vídeo que pode ser acessado pela Figura 2.18. 


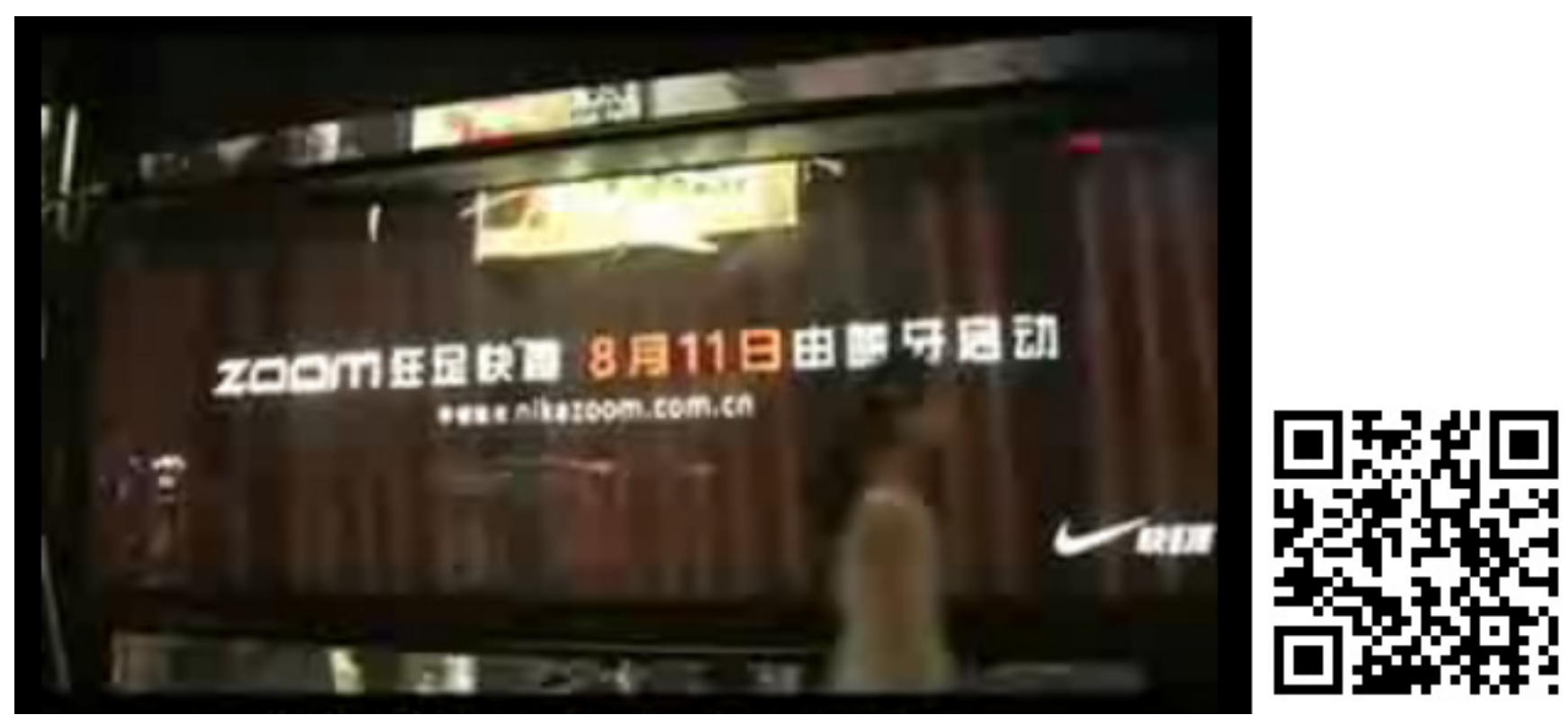

Figura 2.18 - Imagem do vídeo explicativo da ação Quick is Deadly da Nike para o tênis Zoom na China. $O$ vídeo pode ser acessado pelo QRcode da imagem.Fonte: <http://www.youtube.com/watch?v=v8D3bePGcwo>.

Outro exemplo criativo de uso do Bluetooth foi a campanha da C\&A na sua loja do Shopping Morumbi, em São Paulo, em agosto de 2009. As pessoas recebiam cupons de desconto de $10 \%$ por meio de seus celulares quando ativavam o Bluetooth. Na loja foram colocados cartazes como mostrado na Figura 2.19, e os cupons recebidos no celular via Bluetooth são mostrados na Figura 2.20. 


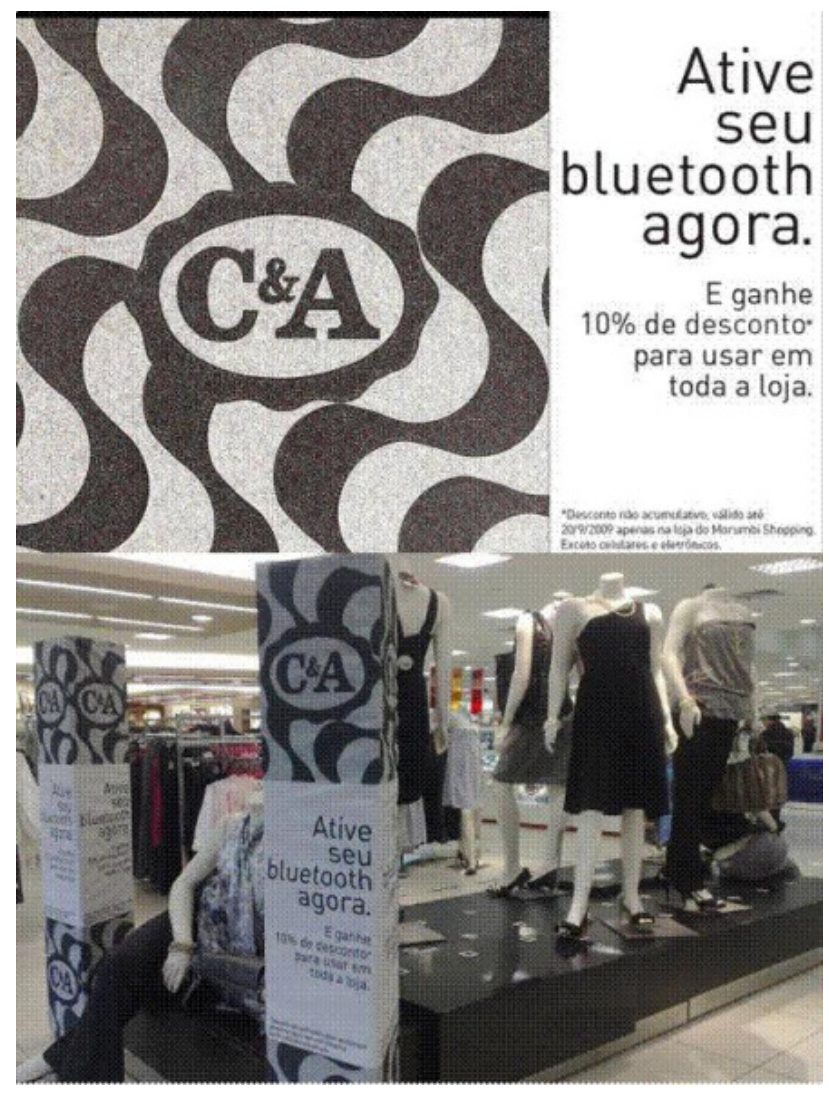

Figura 2.19 - Imagem da loja da C\&A em campanha de 2009. Fonte: <http://www.mobilepedia.com.br/cases/mobile-coupons-via-bluetooth-na-ca-mobile-marketing>.

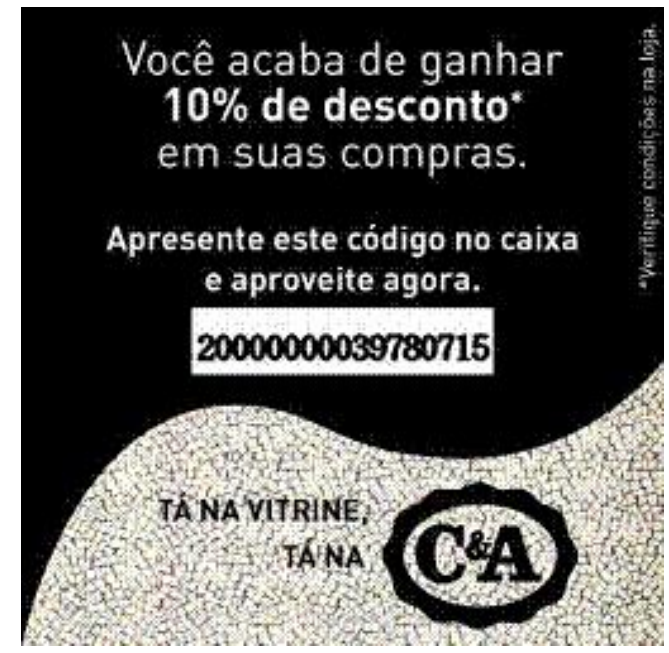

Figura 2.20 - Imagem do cupom de desconto recebido no celular via Bluetooth na campanha da C\&A em 2009. Fonte: <http://www.mobilepedia.com.br/cases/mobile-coupons-via-bluetooth-na-ca-mobilemarketing>. 
Uma das principais desvantagens do uso do Bluetooth é que alguns dispositivos, como o iPhone, não funcionam bem com essa tecnologia. Outro problema pode ser a falta de conhecimento de alguns tipos de público sobre o uso de conexões Bluetooth.

\section{SMS e MMS}

O SMS (Short Message Service), que completou 25 anos em agosto de 2010, é uma tecnologia que permite o envio de mensagens de texto pelo celular. No Brasil, a prática se popularizou apenas nos últimos anos, com o barateamento das taxas de envio, e hoje é a prática mais comum para envio de mensagens de texto pelo celular (DE LUCA, 2010).

Um exemplo de uso de SMS é o caso da vending machine interativa criada para a promoção do absorvente higiênico feminino Carefree. Em razão da natureza íntima da utilização do produto, a distribuição de amostras de Carefree em bares, baladas e restaurantes foi feita por meio de uma vending machine colocada nos banheiros femininos dos estabelecimentos, que era ativada pelo envio de um SMS e então liberava uma amostra do produto. A ação, que integra mundo físico e digital, pode ser vista no vídeo cujo acesso é possível pelo QRcode da Figura 2.21.
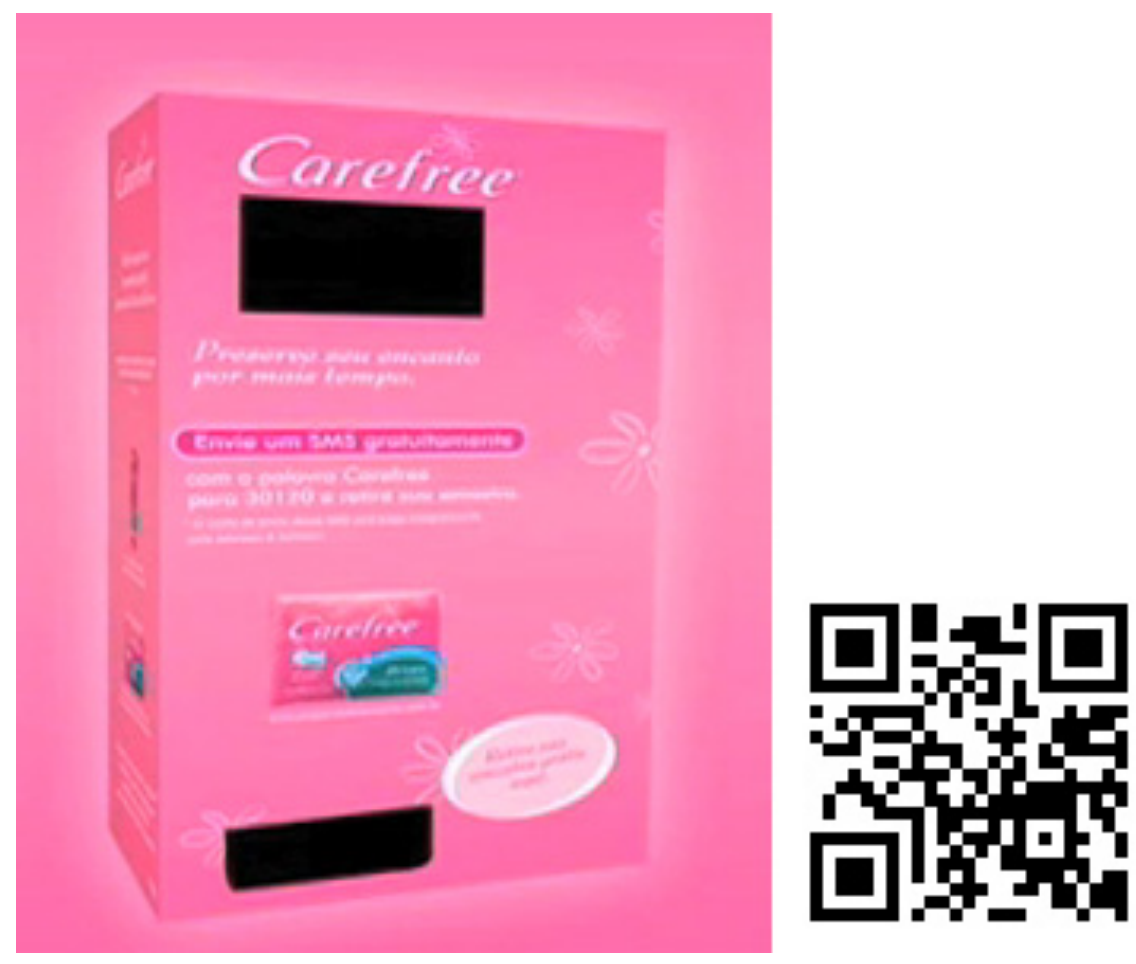

Figura 2.21 - Imagem do vídeo explicativo da ação Carefree - Interactive Vending Machine, da Unilever, desenvolvida pela PontoMobi. O vídeo pode ser acessado pelo QRcode da imagem.

Fonte: <http://vimeo.com/9680162>. 
Outra ação bastante criativa com o uso de SMS foi a campanha Qual a Maior Torcida do Rio Grande do Sul, que a operadora de telefonia móvel Claro promoveu nesse Estado. Os torcedores dos dois times de futebol mais populares do Rio Grande do Sul, deveriam enviar uma mensagem SMS com o texto "GREMISTAS" ou "COLORADOS" para responder à pergunta. 0 resultado era mostrado em um outdoor eletrônico colocado na cidade de Porto Alegre, RS (ver Fig 2.22).

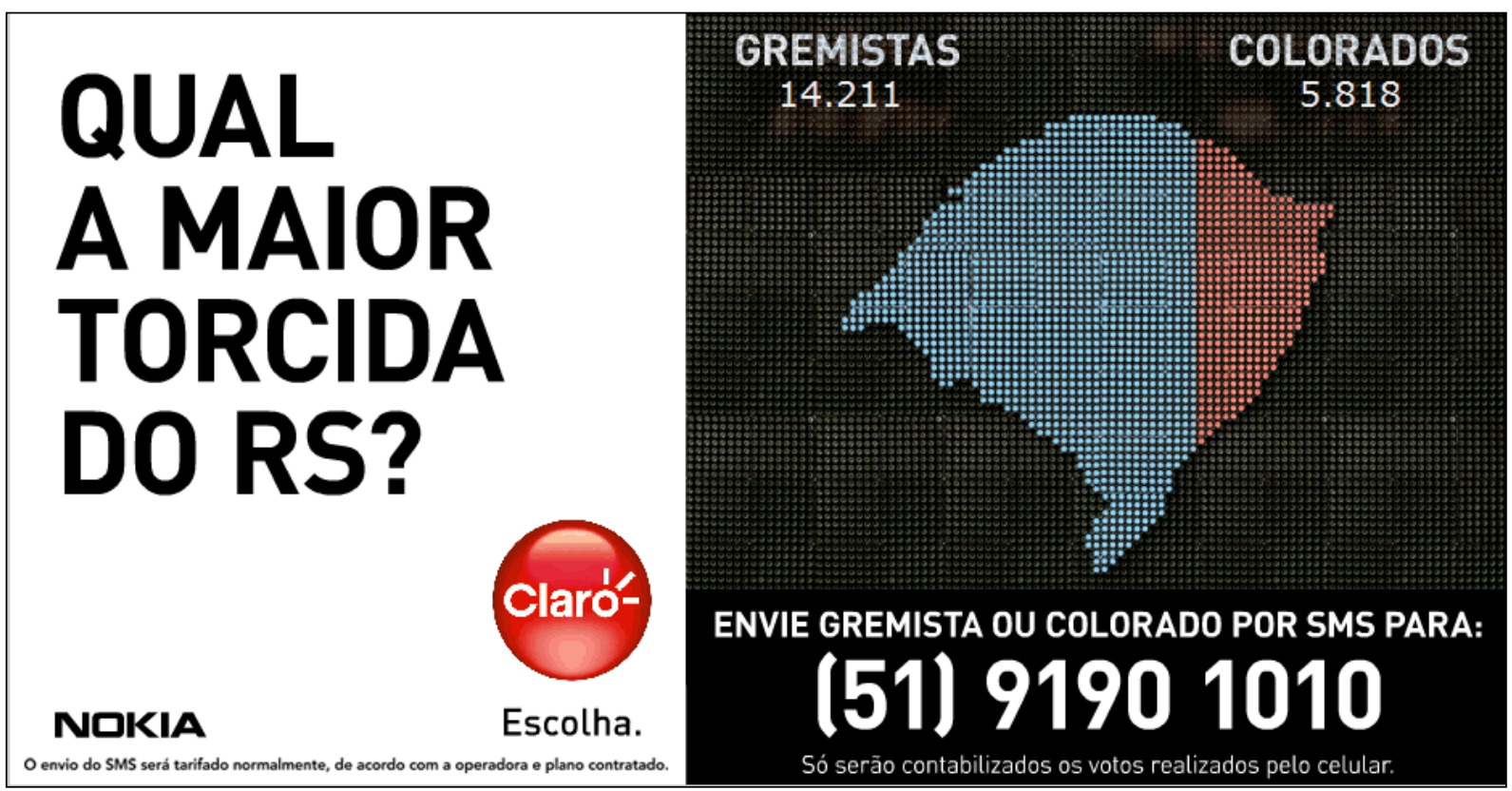

Figura 2.22 - Imagem do outdoor eletrônico que mostrava o resultado em tempo real das participações dos torcedores na campanha Qual a Maior Torcida do RS?. Fonte: <http://www.pontomobi.com.br/projetos/clarotelaointerativo/web.html>.

Além das ações promocionais, outro tipo de utilização para o SMS é o Mobile Commerce. Vending Machines e programas de TV que vendem produtos são exemplos de casos em que o SMS pode ser usado para fazer compras. Na Inglaterra, programas de TV que vendem por SMS já existem há vários anos - as pessoas enviam o SMS de compra conforme instruções dadas durante a programação e recebem os produtos pelo correio. Assim, existem inúmeras possibilidades de uso do SMS como sistema para micropagamentos via mobile commerce. 
As ações que usam SMS normalmente envolvem uma empresa de integração mobile para que todos os participantes possam enviar as mensagens para o mesmo número, independentemente da operadora de celular de cada um.

Outra tecnologia, similar ao SMS, mas que possui capacidades multimídia, não se limitando ao envio de mensagens apenas de texto, é o MMS (Multimedia Messaging Service). Esse tipo de tecnologia permite incluir conteúdos multimídia nas mensagens que são enviadas. 0 uso mais comum do MMS é o envio de mensagens com fotografias, vídeos e ringtones. No entanto, como o custo de envio de MMS é bem maior que o de SMS, seu uso é bem menos popular. Com relação a ações, o maior problema no uso do MMS, além da baixa penetração de uso, é a interoperabilidade entre as operadoras de telefonia celular, que dificulta ações mais amplas.

Um ótimo exemplo de uso do MMS é o do lançamento do filme The Bourne Ultimatum, em 2007. Para receber wallpapers, screensavers e trailers do filme, as pessoas fotografavam o anúncio do filme, veiculado em diversos canais de mídia impressa, e enviavam a foto via MMS. A imagem era analisada por uma algorítmo que verificava se ela era a correta (usando tecnologia de reconhecimento de imagens) e qual o tipo de celular de quem enviou o MMS, e ele fornecia o conteúdo já otimizado para aquele modelo de aparelho (PICTUREPHONING, 2007).

\section{GPS - Global Positioning System}

GPS (Global Positioning System) é um sistema via satélite que fornece a localização confiável de dispositivos receptores do sistema. Um sistema GPS é composto de três partes: a espacial, a de controle e a do usuário. As partes espaciais e de controle são operadas por satélites, e a parte do usuário é o dispositivo receptor, que calcula sua localização tridimensional (latitude, longitude e altitude) associada ao tempo por meio dos sinais que recebe dos satélites.

Até recentemente, receptores de sistemas GPS eram dispositivos caros, acessíveis apenas a governos (normalmente para uso militar) e grandes empresas. 0 barateamento desses dispositivos receptores alavancou o uso comercial do GPS, que hoje se estende do rastreamento de transporte de cargas à navegação por dispositivos celulares. Algumas aplicações com uso do GPS: 
- Vigilância - permite saber a localização precisa do equipamento de vigilância para determinar e mapear locais;

- Mapeamento - criação de mapas por meio de informações precisas de localização obtidas por dispositivos GPS;

- Navegação - dispositivos GPS medem digitalmente a velocidade e direção do movimento e auxiliam na navegação (tanto alertando sobre os limites de velocidade estipulados quanto instruindo sobre o caminho percorrido ou ainda, orientando sobre qual caminho seguir para alcançar determinado destino);

- Geo-tagging - aplicação de coordenadas de localização a objetos digitais, como fotografias e outros documentos, com o objetivo de mapeá-los;

- Telefonia Celular - a utilização de dispositivos GPS nos aparelhos celulares permite sua localização exata, o que possibilita diversas aplicações de LBS (Location Based Services) via celular, como: geo-tagging em mensagens, fotos ou documentos; chamadas de emergência (911, nos Estados Unidos, por exemplo, que fornece a localização exata de quem liga);

- Rastreamento de objetos - veículos, pessoas, animais ou qualquer objeto podem ser rastreados com precisão quando equipados com um receptor GPS;

- Recreação e Arte - o GPS possibilita diversos tipos de atividades recreativas, como "pega-pega" digital (geocaching ${ }^{28}$ ), gincanas territoriais (geodashing), geodrawing ${ }^{29}$ (uso de rastros gravados por GPS para a criação de desenhos e esculturas - os rastros podem ser gravados em 2D, em rotas na superfície, ou em 3D, durante voos) e waymarking ${ }^{30}$ (mapeamento da localização de tipos de dados específicos de interesse, como restaurantes, museus, etc., usando GPS, com intenção de usos diversos). 0 site gpsgames.org oferece vários jogos baseados em sistemas GPS.

Atualmente, dispositivos GPS para navegação em veículos estão se tornando bastante populares, e uma grande parte dos aparelhos celulares já vem com receptores GPS. Isso

\footnotetext{
${ }^{28}$ Um exemplo de geocaching é o trabalho de arte Can You See Me Now do grupo inglês Blast Theory. Mais informações podem ser obtidas em <http://www.canyouseemenow.co.uk/>.

${ }^{29}$ Exemplo de geodrawing - Yellow Arrow <http://yellowarrow.net/v3/>.

${ }^{30}$ Exemplo de waymarking - Murmur <http://murmurtoronto.ca/about.php $>$.
} 
cria uma infraestrutura extremamente interessante para todo tipo de ação de geolocalização.

Algumas ações de geolocalização interessantes estão associadas às tecnologias de realidade aumentada. Aplicativos para encontrar a agência bancária ou a estação de metrô mais próximas se baseiam nos dispositivos GPS dos aparelhos celulares para saber onde o usuário está e, assim, orientá-lo na navegação. Serviços como Foursquare, Gowalla e Google Latitude usam o GPS no celular dos usuários para mapear as localizações das suas interações.

Um exemplo de ação usando o GPS é a campanha de fidelização que a Spoleto, rede de culinária italiana, fez utilizando o Foursquare (ver Fig. 2.23). Nessa ação, os clientes que frequentam os restaurantes registram suas visitas por meio do Foursquare, e os que adquirem status de majors de cada filial do restaurante recebem brindes, como pratos gratuitos.

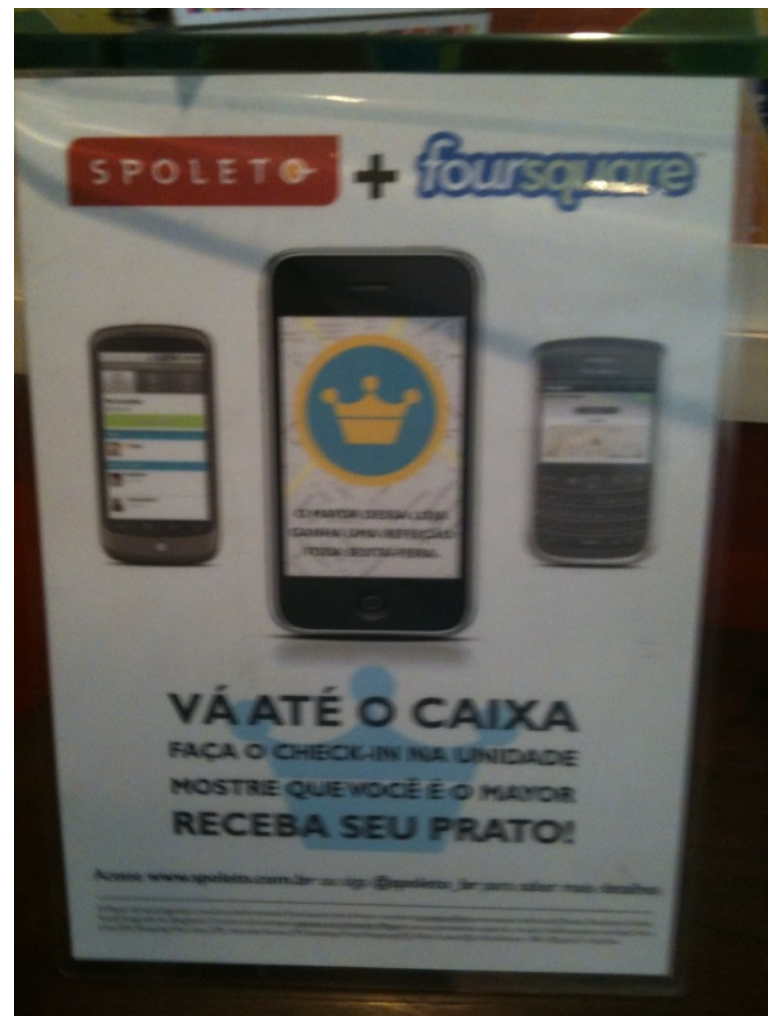

Figura 2.23 - Fotografia do cartaz da promoção SPOLETO + FOURSQUARE, tirada em $1^{\circ}$ de agosto de 2010 na loja do SPOLETO da Al. Santos, em São Paulo. Fonte: Martha Gabriel. 
Considerando-se que tudo o que fazemos depende do local onde estamos, a geolocalização proporcionada pelos dispositivos GPS tem um grande potencial para ações que entreguem valor relacionado não apenas ao local onde as pessoas estão em um dado momento, mas também aos lugares por onde passaram. As rotas dizem muito sobre o comportamento e necessidades das pessoas. Isso é um alavancador para a segmentação geográfica e o desenvolvimento de serviços específicos. Aplicativos como Where do you go <http://www. wheredoyougo.net> criam mapas de calor usando as localizações de um usuário no Foursquare, ou seja, criam um mapa visual que mostra os locais que aquela pessoa mais frequenta.

\section{Mobile Tagging}

Mobile tags são códigos de barras bidimensionais (2D-barcodes) que permitem encriptar URLs, entre outros tipos de dados. A grande vantagem desse tipo de código de barra é que eles podem ser escaneados e decodificados por um dispositivo móvel (aparelho celular, smartphone ou PDA's) com câmera. Dessa forma, as mobile tags podem funcionar como botões digitais de links para a web, que podem ser aplicados em praticamente qualquer coisa física. Essa é uma das grandes vantagens que as mobile tags trazem ao mundo - possibilitam a criação de gateways físicos para o mundo online, via dispositivos móveis.

Chamamos de Mobile Tagging o processo de ler e decodificar uma mobile tag, conforme mostrado na Figura 2.24.

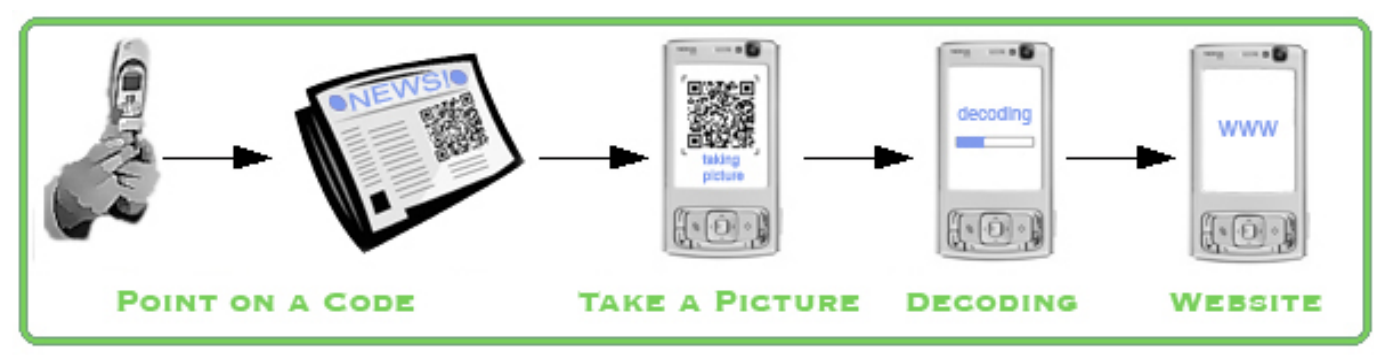

Figura 2.24 - Processo de Mobile Tagging. Fonte: <http://en.wikipedia.org/wiki/Mobile_tagging>.

Existem dezenas de padrões de códigos de barra 2D, mas nem todos funcionam como mobile tags, ou seja, nem todos podem ser acessados via dispositivos móveis. Alguns 
padrões de códigos 2D que podem ser usados como mobile tags são mostrados na Figura 2.25. Os dois padrões de mobile tags mais usados atualmente são o QR Code (Quick Response Code) e o DataMatrix, dos quais o QR Code é o mais popular, tanto que virou sinônimo de mobile tag (muitas pessoas não conhecem o termo mobile tag e usam inadequadamente o termo QR code para representar qualquer tipo de mobile tag).

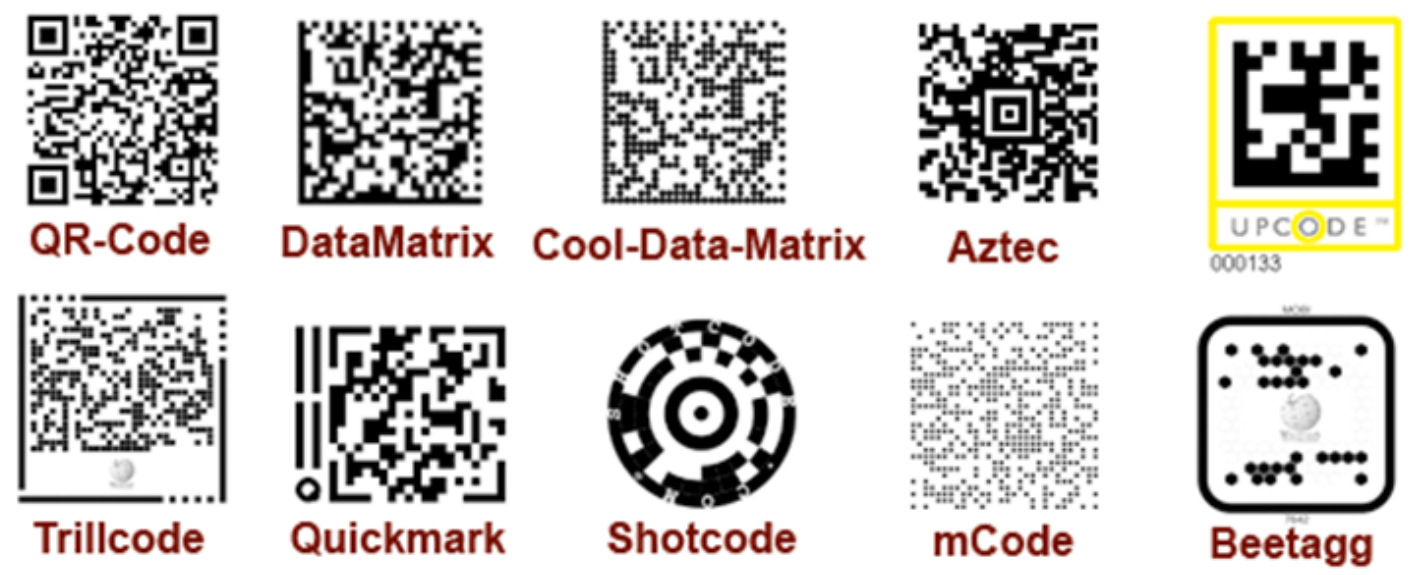

Figura 2.25 - Tipos de mobile tags. Fonte: <http://mobile-tagging.blogspot.com/2007/09/what-ismobile-tagging.html>.

Um padrão interessante entre as mobile tags, mesmo não sendo tão popular quanto o QR code, é a Beetagg, pois nesse tipo de código 2D é possível incluir uma imagem visual, colorida, junto com o código na tag. Isso é muito útil para a inserção de logos nos códigos, personalizando-os. A Figura 2.26 mostra uma Beetagg com link para o perfil @marthagabriel no Twitter <http://twitter.com/marthagabriel> e que, desta forma, está personalizada com o logo do Twitter, indicando ao que está relacionada.

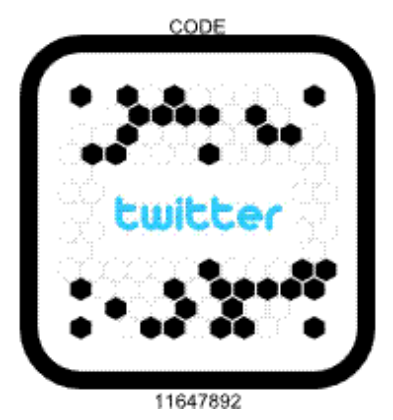

Figura 2.26 - Imagem de uma Beetagg linkando para o perfil de Martha Gabriel no Twitter $<$ www.twitter.com/marthagabriel>. 
A Microsoft também criou seu padrão de código de barras 2D, a Microsoft Tag (Figura 2.27), que é colorida e apresenta algumas particularidades, como a possibilidade de sempre rastrear o escaneamento da tag.

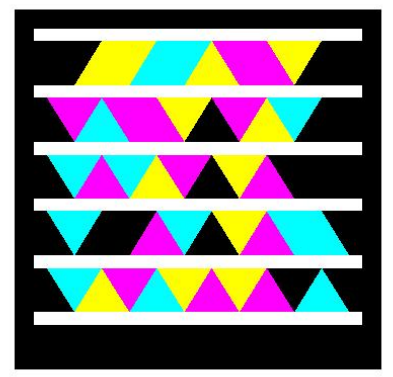

Figura 2.27 - Imagem de uma Microsoft Tag linkando para <www.martha.com.br>.

Os padrões tradicionais de mobile tags são baseados em alto contraste de elementos na imagem. Novas tecnologias de mobile tags têm sido desenvolvidas, como é o caso do Bokode, um padrão ótico de mobile tag baseado na luz e que tem características promissoras como capacidade de armazenamento maior de informações e possibilidade de ser escaneado de longa distância. O Bokode foi lançado pelo MIT no SIGGRAPH 2009, e o vídeo acessível pelo QRcode da Figura 2.28 mostra seu funcionamento. 

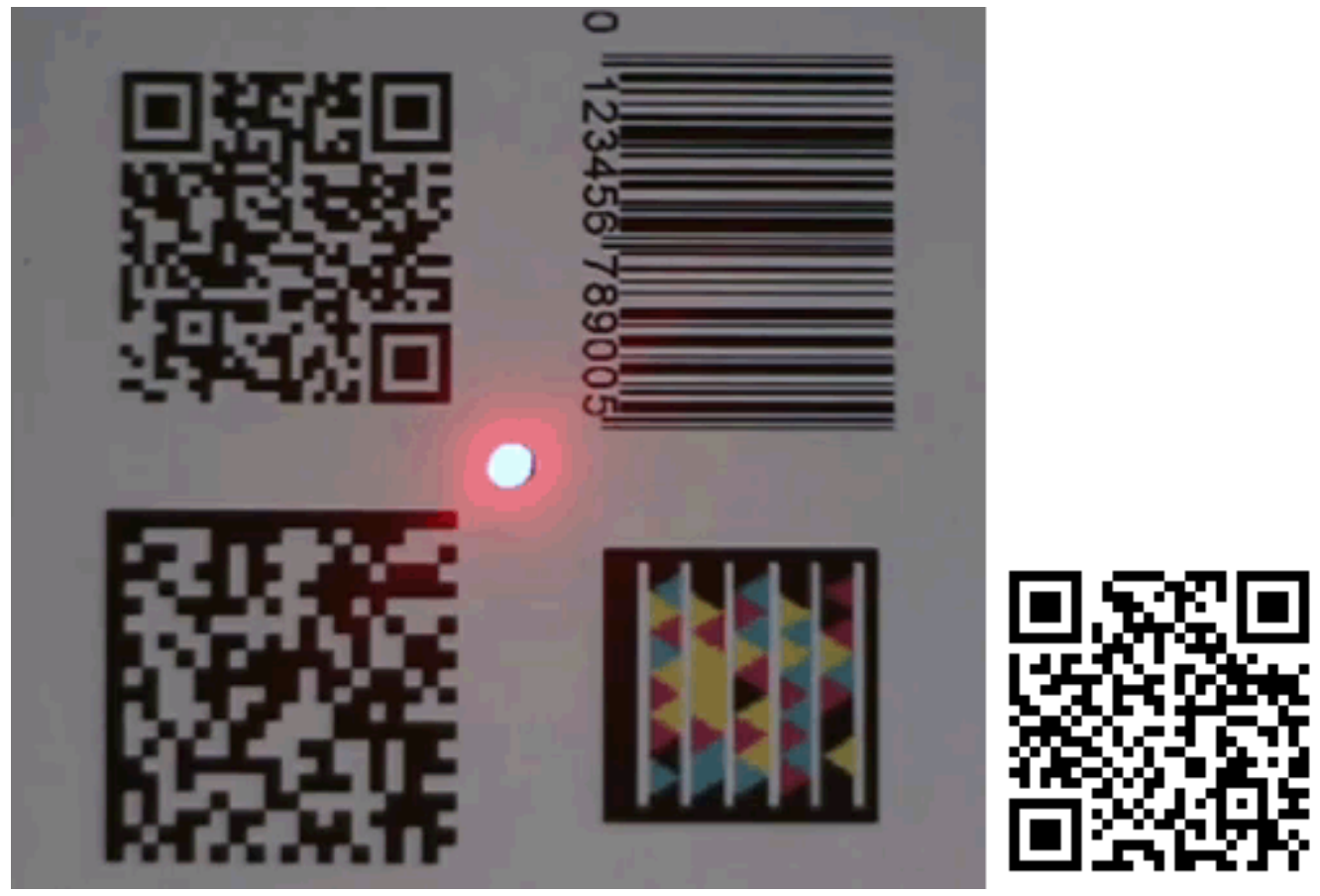

Figura 2.28 - Imagem do vídeo LabCast do MIT, demonstrando as características e funcionalidade do Bokode. O Vídeo pode ser acessado pelo QRcode da direita na imagem. Fonte: <http://www.youtube.com/watch?v=wG7vXI1/1wg>.

É possível encriptar diversos tipos de informações em um código de barras 2D, tais como textos, contatos (nome, e-mail, etc.) ou URLs (endereços na internet). No entanto, o tipo de informação encriptada mais poderosa são realmente as URLs, ou seja, links para acesso à internet.

Enquanto um código de barras linear tradicional, como o mostrado na Figura 2.29, consegue encriptar apenas dados numéricos e é capaz de armazenar somente até 20 dígitos, um código de barras 2D permite encriptar dados não apenas numéricos, como também alfanuméricos e em diversos alfabetos diferentes, além de ter uma capacidade de armazenamento de informações muito maior.

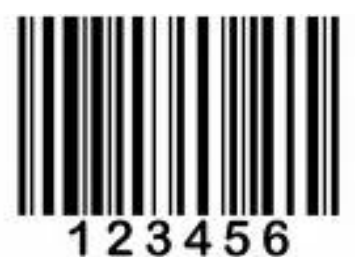

Figura 2.29 - Imagem de um código de barras linear que armazena o número "123456". 
Um QR Code (Figura 2.30), por exemplo, é capaz de lidar com milhares de caracteres de todos os tipos de dados, tais como numéricos e caracteres alfanuméricos, Kanji, Kana, Hiragana, símbolos, binários e códigos de controle (DENSO-WAVE, 2009).

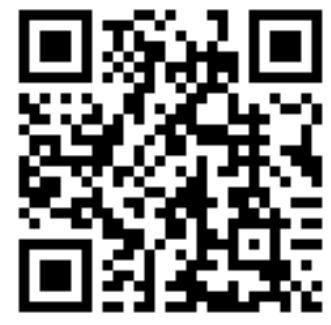

Figura 2.30 - Imagem de um QR Code armazenando e linkando para a URL <http://www.martha.com.br/>.

A capacidade de armazenamento de um QR code, para os diversos tipos de dados, é apresentada na Tabela 2.1.

Tabela 2.1 - Tabela mostrando a capacidade máxima de um QR code para armazenamento de dados. Fonte: DENSO-WAVE, 2009.

\begin{tabular}{|l|l|}
\hline \multicolumn{2}{|c|}{$\begin{array}{r}\text { QR Codes - Capacidade Máxima de } \\
\text { Armazenamento por Tipo de Dados }\end{array}$} \\
\hline Apenas Numérico & 7.089 caracteres \\
\hline Alfanumérico & 4.296 caracteres \\
\hline Binário (8 bits) & 2.953 bytes \\
\hline Kanji, full-width Kana & 1.817 caracteres \\
\hline
\end{tabular}

Outra vantagem das mobile tags sobre os códigos de barra lineares é o modo de se ler e decodificar a informação. Enquanto as mobile tags podem ser decodificadas por virtualmente qualquer aparelho celular com câmera (bastando a instalação de software 
de leitura apropriado), os códigos de barra lineares exigem scanners, hardwares específicos para tal. Essa característica - a de poder se apropriar de uma plataforma de hardware (aparelhos celulares) já disponível, com penetração global e uma das mais populares em todas as classes sociais - torna o uso de mobile tags extremamente simples e com potencial de impactar praticamente qualquer pessoa no planeta.

Resumindo alguns dos principais benefícios das mobile tags, podemos citar:

- Capacidade de armazenamento alta;

- Encripta vários tipos de informações (URLs, textos, contatos, SMS) e dados (numéricos, alfanuméricos de diversos alfabetos);

- Rastreamento da mídia offline (impressa e eletrônica);

- Não requer hardware específico para leitura ou criação dos códigos - usa plataforma já existente de computadores (para criar os códigos) e dispositivos móveis (para leitura);

- Gratuito: tanto a criação como a leitura das mobile tags - existe uma variedade grande de sistemas gratuitos online para criar mobile tags e também de leitores;

- Usabilidade - não necessita digitação nos dispositivos móveis, usando apenas escaneamento de imagens;

- Inclusão digital - tecnologia acessível de baixo custo, com grande potencial de inclusão digital conforme os custos de banda larga móvel também vão se tornando mais acessíveis;

- Sustentabilidade - a possibilidade de usar os códigos no ambiente digital libera vários produtos da necessidade de impressão (como tickets aéreos, por exemplo), colaborando com o meio ambiente;

- Realidade aumentada - acrescenta layers digitais às coisas e a lugares físicos;

- Flexibilidade - o usuário tem o poder de escolher o nível de detalhamento que deseja no acesso online.

A seguir, discutiremos o cenário atual e os tipos de aplicações existentes e potenciais para as mobile tags. 


\section{Cenário e aplicações}

Atualmente, como mencionado antes, o padrão de mobile tag mais popular do mundo é o QR code, que já é comum e um sucesso no Japão. Na Inglaterra, o padrão mais usado, mas ainda de forma mais modesta, é o Datamatrix. A disseminação das mobile tags está fortemente associada à popularização da banda larga mobile. Conforme aumenta a penetração global da banda larga mobile, tende a aumentar também a adoção de mobile tags ao redor do mundo.

Por detrás do mobile tagging está tanto a ideia de uma convergência absoluta de mídias (pois as tags podem 'conter' quaisquer tipos de mídias - vídeo, textos, páginas, músicas, aplicativos, etc. - quanto a ideia de uma plataforma perfeita para processos transmidiáticos - que veremos mais à frente nesse texto, uma vez que as tags podem ser usadas para conduzir as mensagens e estórias de uma mídia para outra.

Justamente por atuarem como um link físico para o mundo online digital, as mobile tag funcionam também como instrumentos de ampliação da realidade, acrescentando um layer de informações digitais às coisas físicas (pessoas, objetos, lugares, etc.) na realidade. Desse modo, o mobile tagging é atualmente um dos processos mais simples e econômicos de criar realidade aumentada.

O uso de móbiles tags pode beneficiar virtualmente todas as áreas do conhecimento. Alguns exemplos de uso de mobile tags nas mais diversas áreas são apresentados a seguir.

\section{Entretenimento}

A área de entretenimento pode se beneficiar do uso de mobile tags tanto para comunicação, facilitar os processos de relacionamento com públicos específicos, criação de jogos e experiências.

O Clip musical Integral do conjunto Pet Shop Boys é um excelente exemplo de uso de QR codes integrados na linguagem do vídeo, pois as pessoas que queriam ler os $Q R$ codes precisavam acessar o vídeo no Youtube ou em alguma mídia onde pudessem parar nas imagens para poder scanear os códigos. Como o clip foi veiculado originariamente na TV e as pessoas precisavam acessar a internet para decifrar o código no clip usando o celular para aí acessar outro destino, essa ação é um excelente exemplo de transmídia, na qual a estória começa no clip da TV, continua no Youtube na Internet e depois no 
celular. Foi uma ação tão inovadora na época que ganhou Leão em Cannes em 2008. A Figura 2.31 apresenta o link para assistir ao vídeo no Youtube.

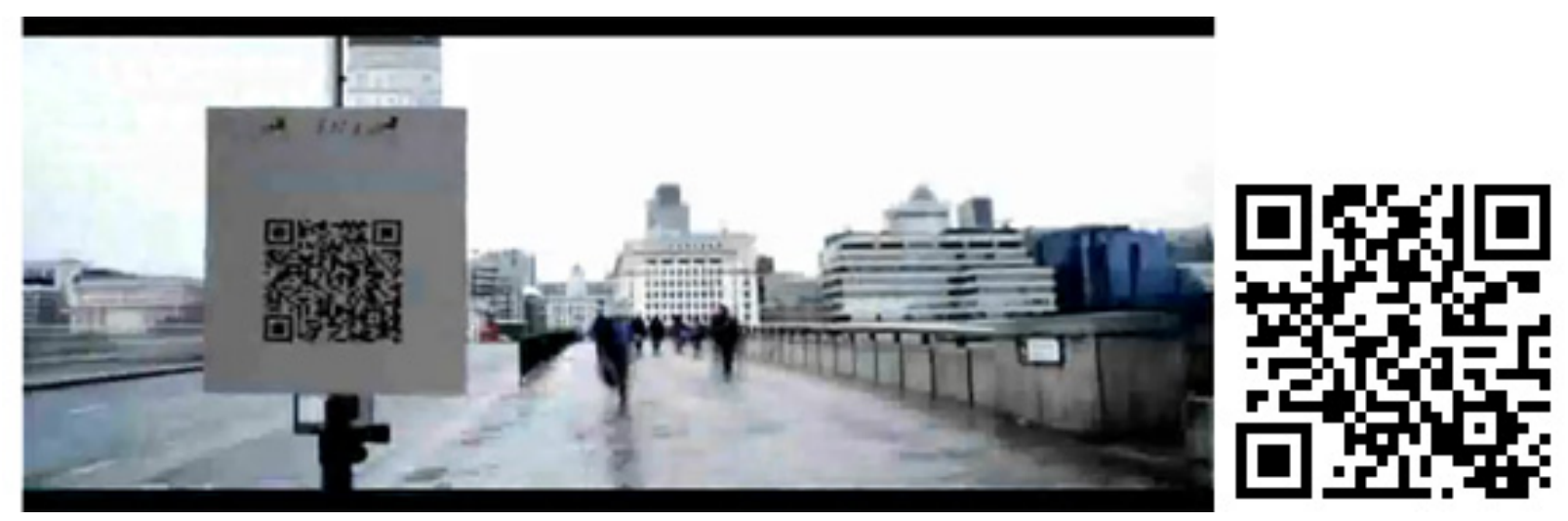

Figura 2.31 - Imagem capturada do clip Integral com o QR code para acessar o vídeo. Fonte: <http://www.youtube.com/watch?v=dotvLcWV3jw>.

\section{Área Pública, Artística e Cultural}

Nas áreas de arte e cultura, além do potencial estético e tecnológico dos diversos padrões de mobile tags para uso como fonte criativa, sua aplicação em catálogos e sinalizações culturais pode trazer benefícios enormes.

Em museus, por exemplo, poderiam ser usados QR codes ao lado de obras de arte para o acesso a informações online detalhadas sobre cada trabalho. Esse processo informativo por meio de mobile tags é muito mais interessante e econômico do que os tradicionais audioguias de museus e monumentos, que além de frequentemente funcionarem mal e muitas vezes obrigarem que as pessoas a enfrentar filas para pegá-los e devolvê-los, são engessados em seu uso. Com as mobile tags, além de cada visitante usar seu próprio aparelho celular para acessar as informações da obra/local, ele pode controlar o grau de profundidade que deseja em cada caso. As informações online podem conter, além de áudio, também vídeo e textos, com vários níveis de detalhamento. Assim, o processo tende a satisfazer de forma muito mais eficiente e prazerosa todos os tipos de públicos.

Do mesmo modo, o uso de mobile tags pode ser feito também em monumentos, locais públicos, transportes públicos, permitindo até mesmo que as pessoas anotem comentários e sugestões online junto às informações digitais associadas a cada local. 
Um projeto interessante que ilustrava as possibilidades que as mobile tags trazem à área pública, visando conectar lugares físicos com suas informações na Wikipedia <www.wikipedia.org>, é a Semapedia ${ }^{31}<w w w . s e m a p e d i a . o r g>$. 0 site incentivava as pessoas a colocarem tags da Semapedia em todos os lugares que constavam da Wikipedia, linkando as páginas com as informações relativas a eles. Dessa forma, cada local recebe uma nova camada de informação dinâmica proveniente do mundo digital online, acrescentando mais uma dimensão ao seu uso.

Na área pública, várias utilizações de mobile tag poderiam auxiliar a população, como a obtenção de informações online sobre transportes que passam em cada local. Se cada ponto de ônibus tivesse um QRcode que desse acesso a todas as informações dinâmicas sobre rotas que passam por aquele local e também informações sobre os próximos ônibus a passar e o tempo de espera, seria excelente. 0 interessante é que essas informações online muitas vezes já existem, faltando apenas ser integradas aos locais físicos por meio das mobile tags, ficando assim ao alcance da população de forma bastante simples e eficiente.

Além da facilidade de acesso, a possibilidade de permanência da informação online tem o potencial de, ao longo do tempo, permitir que todo o acervo artístico e cultural da humanidade esteja catalogado online e acessível a qualquer instante pela mobile tag correspondente a cada item/local. Imaginem podermos assistir a vídeos de autores de obras comentando seus próprios trabalhos, enquanto visitamos um museu (virtual ou não). Se isso existisse no passado, hoje poderíamos assistir Van Gogh, Renoir, Michelangelo, Leonardo Da Vinci e muitos outros apresentando suas ideias sobre cada obra que criaram.

\section{Área Empresarial Privada}

Na área privada, existem infindáveis aplicações possíveis que se beneficiam das mobile tags. Criam-se com elas links para o site da empresa. Essas tags podem ser usadas em cartões de visita, folhetos, catálogos, fachadas de prédios, móveis, etc.

Um exemplo desse uso por algumas companhias aéreas, como a Swiss Air (Figura 2.32) e

31 A Semapedia está descontinuada. É comum que projetos interessantes e inovadores não consigam sobreviver por falta de um modelo de negócios que os sustente. 
a Lufthansa, é a emissão de cartões de embarque mobile com as informações de checkin encriptadas em mobile tags que podem ser lidas diretamente da tela do celular na hora do embarque. A Swiss Air usa o padrão Aztec, enquanto a Lufthansa e outras usam QRcodes.

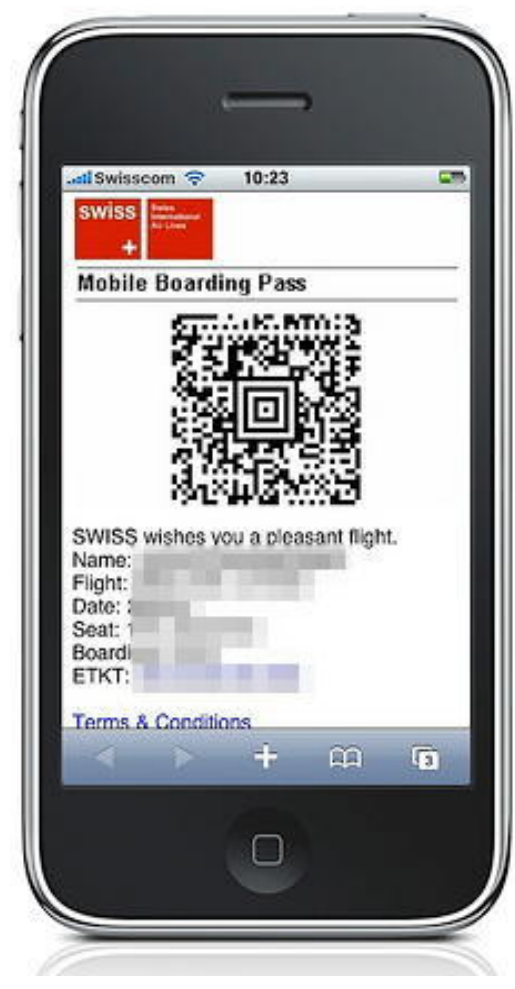

Figura 2.32 - Foto de um iPhone com um cartão de embarque mobile da Swiss air usando o padrão Aztec de mobile tag. Fonte: Fotografia de Simon Aughton published no Flickr in 2009 sob uma licença Creative Commons Licence (os dados pessoais foram desfocados na imagem), obtida em <http://www.explainthatstuff.com/how-data-matrix-codes-work.html>.

Tickets de shows também poderiam usar esse mesmo processo e serem lidos diretamente da tela do celular, sem a necessidade de imprimir e distribuir tickets físicos.

\section{Área Pessoal}

Mobile tags, especialmente QR codes, têm sido usados por pessoas em cintos, camisetas, tatuagens e cartões de visita. As tags fazem links para sites e informações pessoais ou encriptam informações de contato.

Um uso particular de mobile tags no Japão é sua aplicação em túmulos. Algumas famílias têm usado QR codes em lápides, que, quando acessados, linkam para vídeos e gravações 
de voz da pessoa falecida ${ }^{32}$. Pode ser um modo interessante de preservar a memória das pessoas. A imagem da Figura 2.33 mostra o uso de QRcode em lápides no Japão.

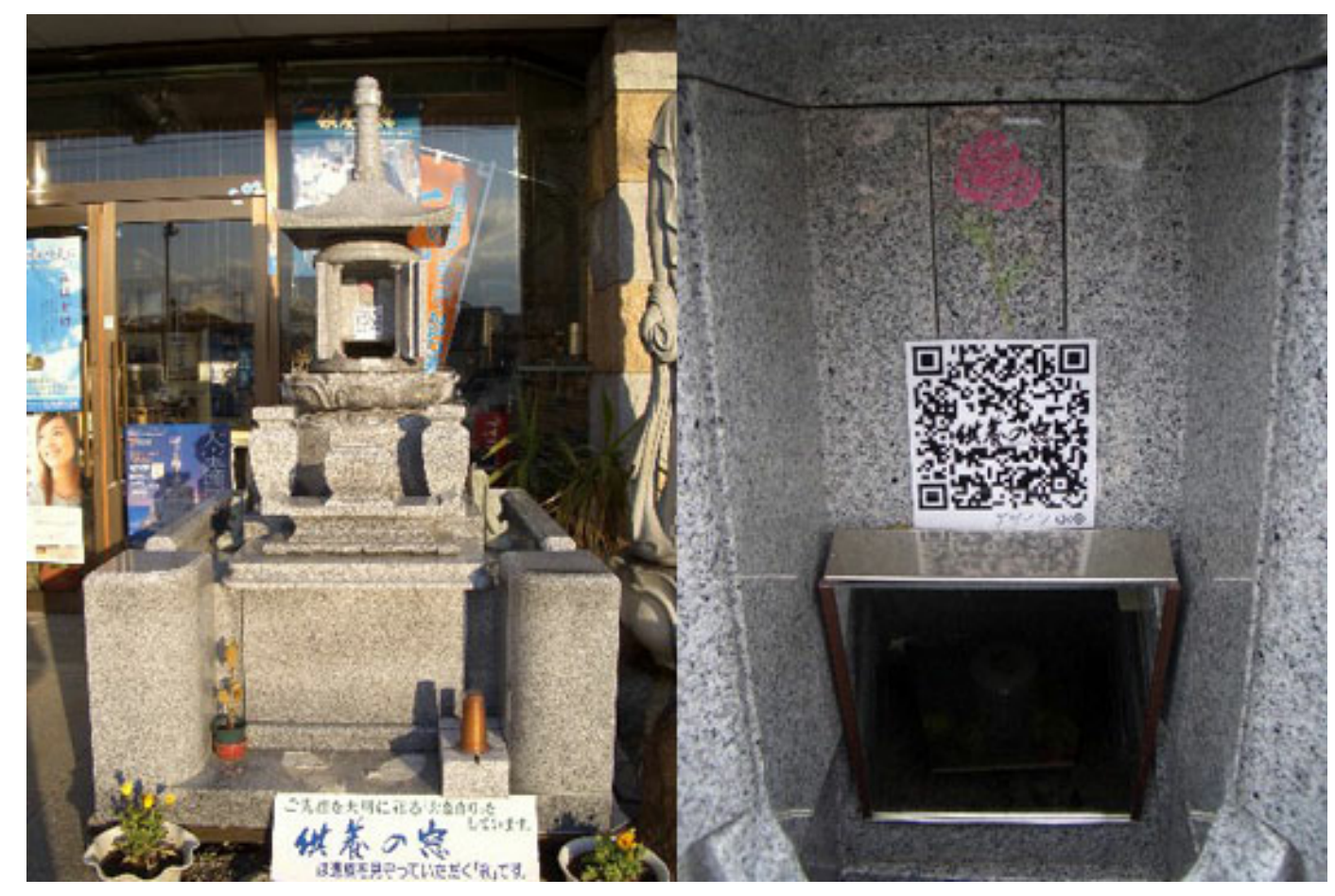

Figura 2.33 - Foto de um túmulo com QRcode no Japão obtida em <http://www.japantrends.com/qr-code-graves-give-a-memorial-window>.

\section{Educação}

A área de educação talvez seja uma das que mais se beneficiem das mobile tags. A possibilidade mais óbvia é usar $Q R$ codes em materiais impressos com links para conteúdos digitais, a fim de proporcionar uma experiência mais rica ao leitor, acrescentando-se as camadas digitais ao conteúdo impresso. Alguns exemplos criativos são apresentados a seguir:

- Tabela periódica dos elementos <http://viral-notebook.com/blog/2012/02/20/qr-coded-periodictable-of-elements-published-in-journal-of-chemical-education/> - um estudante italiano criou uma tabela periódica onde cada elemento é representado por um QRcode que dá

32 Ver vídeo da reportagem sobre o uso de QRcodes em tumbas em (SCHOFIELD, 2008). 
acesso às suas características. Uma ampliação dessa ideia poderia ser, ao invés de apenas dar acesso às informações básicas dos elementos, que mostrasse um vídeo sobre o elemento e suas características, ampliando a informação multimídia da tabela.

- Prática em laboratórios com QRcodes - para ensinar os alunos a usar os materiais de laboratório de forma adequada, o professor Dr. Jo Badge, da Leicester University, colocou um QRcode em cada instrumento do laboratório - o código dava acesso a um vídeo que explica como usar o equipamento.

- Jogos educativos - um professor de Física na Austrália usou QRcodes para criar um jogo educativo com o objetivo de ensinar sobre orientação/navegação. Os alunos deveriam seguir as instruções obtidas em cada QRcode e operar a bússola para encontrar a pista final ${ }^{33}$.

\section{Marketing}

As possibilidades de uso de mobile tags em marketing são infinitas. Um dos usos mais óbvios é colocar QRcodes em todo tipo de embalagem para dar link para informações online adicionais sobre os produtos, o que pode ser particularmente interessante em embalagens pequenas, que não têm espaço disponível para muita informação impressa.

Outro uso para as mobile tags no marketing é fornecer links para downloads diretos de brindes digitais, como rigtones, clips ou games mobile. Mais uma utilização possível para enriquecer a relação consumidor-produto é o uso de mobile tags em menus de restaurantes, nos quais o cliente pode ver o prato (vídeo, por exemplo) e obter informações detalhadas sobre valores nutricionais e calóricos.

As mobile tags podem beneficiar qualquer dimensão estratégica do marketing produto, preço, praça e promoção. Alguns exemplos ilustrativos são apresentados a seguir.

- NBuilding, Japão - O N Building é um centro comercial no Japão que apresenta suas promoções na fachada do edifício por meio de QRcodes dinâmicos. Para acessar o vídeo explicativo, use o QRcode da Figura 2.34.

\footnotetext{
${ }^{33}$ Mais informações sobre o QRcodeOrienteering Game em <http://mrrobbo.wordpress.com/2009/03/05/qr-codeorienteering/>.
} 


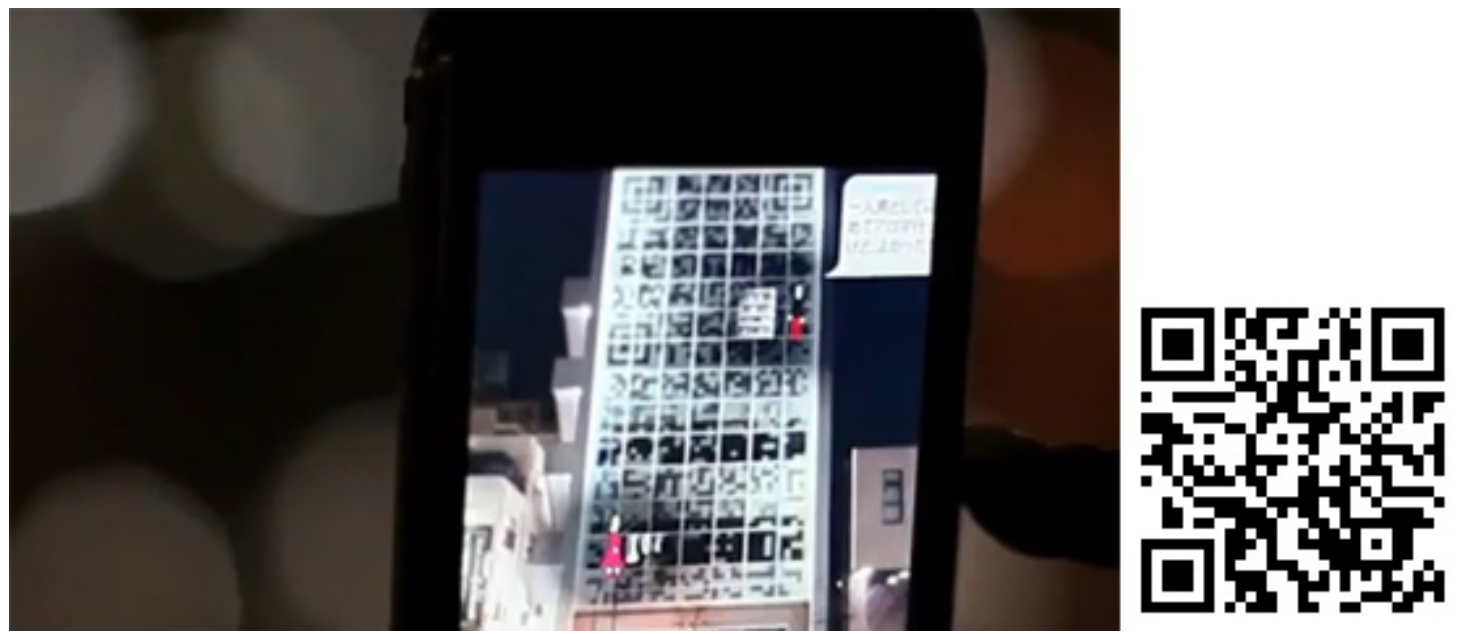

Figura 2.34 - Imagem do vídeo sobre o NBuilding no Japão, que pode ser acessado pelo QR code. Fonte: <http://www.youtube.com/watch?v=n1ANVCDHYA4>.

- Calvin Klein - A empresa usou um outdoor (Figura 2.35) que dava acesso a um conteúdo censurado, por meio de um QRcode gigante. Para assistir ao comercial censurado, pode-se escanear o QRcode do outdoor da Figura 2.35 ou ir diretamente ao endereço que ele acessa: <http://ckj.mobi/pr>.

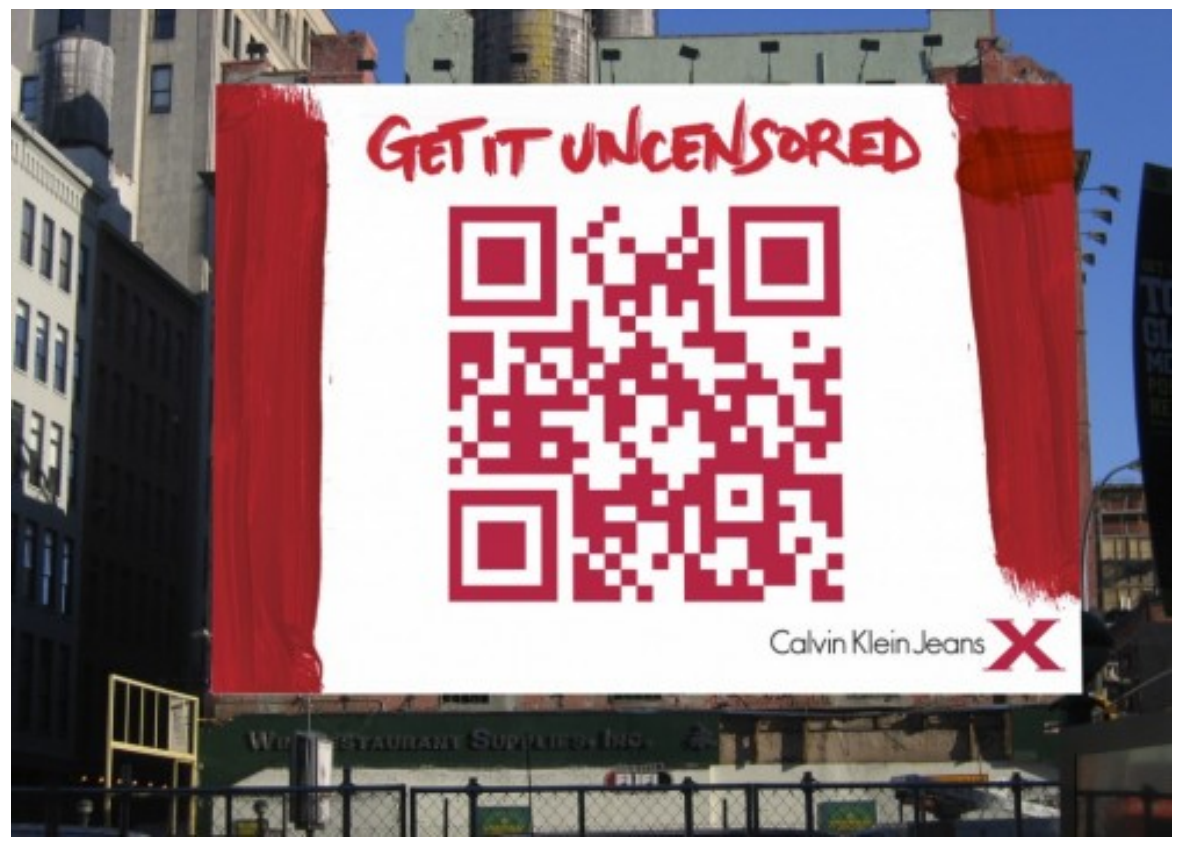

Figura 2.35 - Imagem outdoor da Calvin Klein dando acesso à propaganda censurada. Para ver o vídeo, escanear o QRcode do outdoor. Fonte: <http://declubz.com/blog/2010/07/17/qr-codeadvertising/>. 
- Google Reviews ${ }^{34}$ - sistema de reviews do Google, que usa QRcodes para as pessoas poderem acessar e fazer reviews sobre estabelecimentos comerciais, como restaurantes.

- Weather Channel - o canal de televisão americano apresenta na tela um QRcode que dá acesso ao download do aplicativo do canal para dispositivos móveis com sistema operacional Android. Um trecho do programa em que aparece o QRcode pode ser visto no vídeo, cujo acesso é feito pelo QRcode da Figura 2.36. Essa ação é particularmente interessante, pois alavanca a utilização transmídia dos conteúdos do canal.

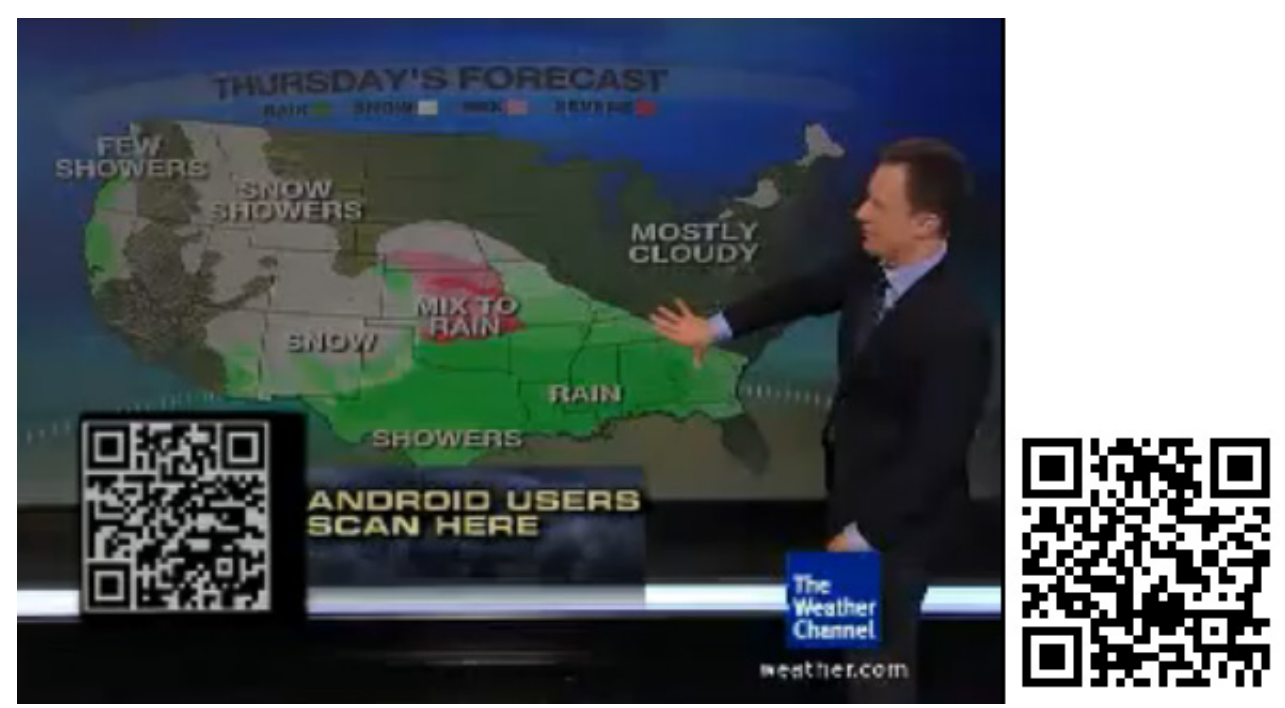

Figura 2.36 - Imagem do programa sobre o clima no Weather Channel, que apresenta um QRcode para download do aplicativo mobile do canal em aparelhos celulares Android. O vídeo sobre ser acessado pelo QRcode ao lado da imagem. Fonte: <http://www.youtube.com/watch?v=N3e3WwoW9LQ>.

Veremos, a seguir, como instalar leitores de mobile tags nos dispositivos móveis e, também como criar os vários padrões de mobile tags.

Instalação de leitores de mobile tags

Para usar as mobile tags, lendo-as por meio de um aparelho celular, é necessário: a) possuir um celular com câmera; b) instalar um leitor apropriado para a leitura dos

34 Para informações completas sobre o sistema de review de lugares no sistema Google, acessar <http://googleblog.blogspot.com/2009/12/explore-whole-new-way-to-window-shop.html>. 
códigos de barra 2D. A maioria dos celulares de nova geração já vem com câmera e software leitor de QRcode instalados. Nos aparelhos que não possuem ainda um software leitor de mobile tags instalado, ou nos aparelhos que têm software leitores apenas para QRcodes, é necessário instalar os leitores de mobile tags desejados.

Existem diversos tipos de leitores de mobile tags disponíveis para download na web. Apresentamos aqui algumas sugestões de leitores de mobile tags (são todos gratuitos). Para instalar o software, basta acessar a URL indicada para cada um deles usando o navegador do aparelho celular (ou via Apple Store, no caso do iPhone):

- $\quad$ i-nigma - <www.i-nigma.mobi (lê QR code e Datamatrix)

- Beetagg - <get.beetagg.com> (lê QR code, Datamatrix e Beetagg)

- Microsoft - <www.microsoft.com/tag> (lê Microsoft Tag)

Após instalar o software no celular, para ler uma mobile tag, é necessário abrir a câmera do aparelho (em alguns modelos, as câmeras abrem automaticamente quando o software de leitura é iniciado), iniciar o software leitor e apontar para a tag, escaneando-a (não há necessidade de fotografar a tag). Quando o reconhecimento ocorre, o software congela a imagem e a tag é decodificada. É um processo bastante simples e eficiente. Como cada leitor acessa tipos específicos de mobile tags, muitas vezes é necessário instalar mais de um software leitor no aparelho para poder ter acesso a vários tipos de mobile tags.

É possível também ler mobile tags nos computadores desktop por meio de webcams. Isso é particularmente útil quando se deseja acessar pelo computador, e não pelo celular, informações em mobile tags impressas. Um interessante software leitor de QRcodes via Webcam é o bcWebCam: ele é freeware e pode ser baixado em <http://www.bcwebcam.de/en/index.htm>.

Outra opção para a leitura de mobile tags são softwares que permitem decodificar diretamente a imagem digital do código, sem a necessidade de escaneá-la via webcam ou celular. Isso é particularmente interessante quando se está navegando no desktop e se deseja testar e acessar os códigos no próprio computador. O software bcTester (também freeware) é uma ótima opção para isso e pode ser baixado em <http://www.bctester.de/en/index.htm>. 
Além dos demais códigos 2D disponíveis ao longo deste texto, a Figura 2.37 pode também ser usada para testar a instalação do(s) software(s) leitores de mobile tags. Nesse caso, essa figura encripta informações de contato, diferentemente dos demais códigos que encriptam URLs. Observe-se também que é possível incluir legendas textuais nas mobile tags, com indicações sobre o código, como feito no caso dessa figura:

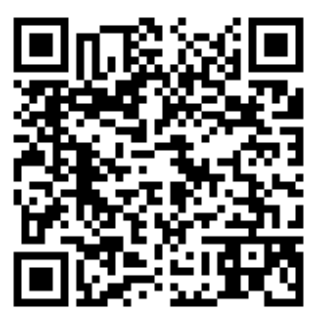

Contact

Figura 2.37 - Imagem de um QRcode com informações de contato.

\section{Criação de mobile tags}

A criação de mobile tags é extremamente simples, gratuita e pode ser feita por meio de ferramentas online. Existem muitos modos de criar os diversos padrões de mobile tags. Apresentamos aqui algumas sugestões. Para criar o tipo de mobile tag desejado, basta acessar a URL do sistema referente ao seu tipo, via navegador do computador, como segue:

- i-nigma - <www.i-nigma.com> (cria QRcode e Datamatrix)

- Beetagg - <generator.beetagg.com> (cria QRcode, Datamatrix e Beetagg)

- Microsoft - <www.microsoft.com/tag> (cria Microsoft Tag)

As tags podem também ser criadas dinamicamente, em função de necessidades específicas. Um exemplo disso é o trabalho de arte SENSITIVE ROSE, apresentado anteriormente nesta seção. Nesse trabalho, após cada interação, o sistema cria dinamicamente o QRcode a ser apresentado em função da participação da pessoa.

\section{Aplicativos Móveis}

Aplicativos móveis são programas computacionais específicos instalados nos dispositivos móveis, como celulares, PDAs, etc. 
Apesar de existirem há anos, os aplicativos móveis foram alavancados apenas depois do surgimento do iPhone. A facilidade de compra e instalação de aplicativos nessa plataforma ajudou a disseminar a cultura de utilização de aplicativos mobile. Além disso, o modelo de negócios da Apple Store incentiva, e muito, os desenvolvedores de aplicativos. Enquanto nas plataformas anteriores e de outros fabricantes de dispositivos móveis os desenvolvedores ficavam com uma porcentagem mínima da venda de seus aplicativos, na Apple Store ocorre justamente o oposto - a maior parte da receita vai para o criador do aplicativo.

Outro acontecimento importante que tende a impulsionar ainda mais a plataforma de aplicativos móveis foi o lançamento do iPad e tablets subsequentes. 0 potencial dessa plataforma, tanto para livros e notícias como para aplicativos de todos os tipos, é imenso.

Dessa forma, o aumento da oferta de opções de hardware mobile e da quantidade de aplicativos disponíveis, aliado à crescente disseminação da cultura de seu uso ${ }^{35}$, torna os aplicativos móveis uma plataforma interessante para experimentações artísticas.

\section{Aplicativos Online e Offline}

Os aplicativos móveis podem funcionar sem conexão com a internet ou podem usar conexões online. Exemplos de aplicativos que não usam conexões online são diversos jogos, utilitários e simuladores, que não necessitam de informações fora do aparelho. Já os aplicativos que usam conexões online são aqueles que utilizam informações e dados da internet ou fornecem dados para plataformas na internet, como é o caso de aplicativos móveis de pagamento de contas ou de acesso às condições meteorológicas e qualquer outro tipo de dado online.

Um vídeo interessante que mostra os dois tipos de aplicativos no iPhone pode ser acessado pelo QRcode da Figura 2.38. O vídeo apresenta a Mobile Phone Orchestra da Universidade de Stanford. A orquestra é composta de músicos que tocam aplicativos de iPhones simulando instrumentos e sintetizando sons. Esses aplicativos funcionam dentro do aparelho, sem necessidade de qualquer conexão externa. No mesmo vídeo também

\footnotetext{
${ }^{35}$ O mercado de aplicativos para smarphones movimentou 2,2 bilhões de dólares já em 2010, e a previsão é que movimente 15 bilhões até 2013, segundo uma pesquisa da Research2guidance. Fonte: <http://www.mobilepedia.com.br/noticias/mercado-de-aplicativos-movimenta-22-bilhoes-de-dolares>.
} 
pode ser vista uma aplicação de ocarina, instrumento musical de sopro. O uso da ocarina também não requer conexão alguma com a internet. No entanto, na parte final do vídeo é mostrada uma funcionalidade do aplicativo de ocarina que só é possível com conexão online - ver o mapeamento dos lugares do mundo em que alguém está tocando aquele aplicativo de ocarina naquele momento e ouvir a pessoa tocar. Para isso, o aplicativo precisa estar conectado à internet.
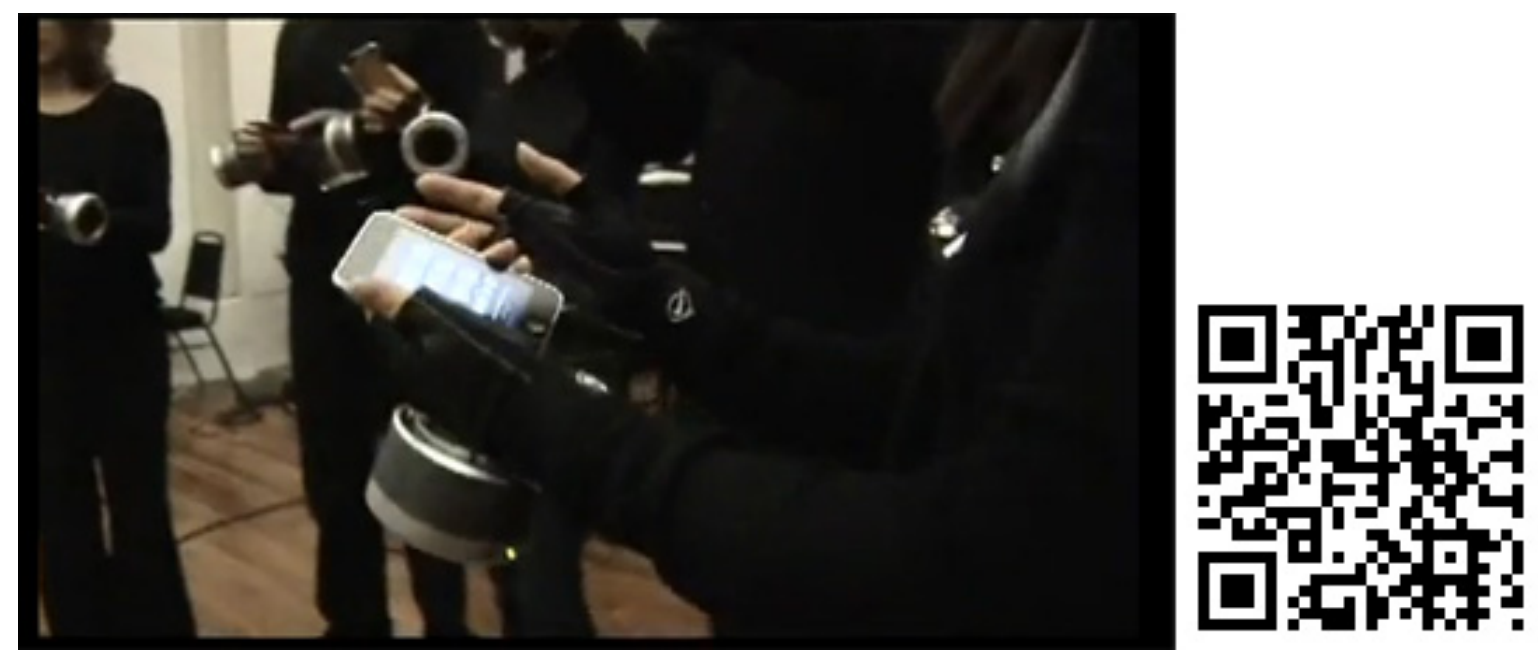

Figura 2.38 - Imagem do vídeo de demonstração da Stanford University Mobile Phone Orchestra. $\mathrm{O}$ QRcode dá acesso ao vídeo. Fonte: <http://www.youtube.com/watch?v=ADEHmkL3HBg>.

Um aplicativo interessante, que transforma posts de blogs em podcasts, é o BlogRadio <http://www.youtube.com/watch?v=DPvSsnekZOk>. Para que o aplicativo funcione, é necessário conectá-lo com os blogs online. Vários outros aplicativos necessitam de conexão, como o Shazam e o SoundHound (que 'ouvem' uma música e a identificam) e o aplicativo de realidade aumentada para identificação pessoal, o TAT ID <http://www. youtube.com/watch?v=tb0pMeg1UN0>.

No caso do iPad, um aplicativo que se apropria de forma muito adequada das capacidades e características do dispositivo de consumir informação é o Flipboard $<$ www.flipboard.com/> - ele transforma perfis no Twitter e no Facebook em revistas digitais navegáveis, expandindo os conteúdos. O vídeo acessível pela Figura 2.39 traz Jonatas Abbott apresentando de forma bastante didática as funcionalidades do Flipboard para o iPad. 


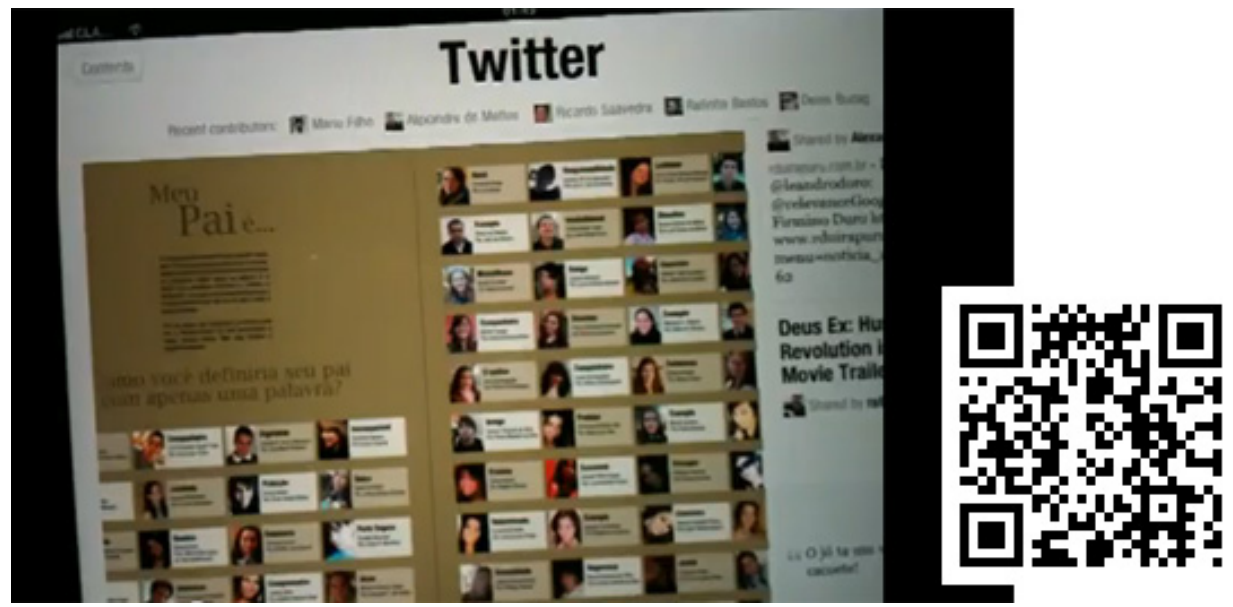

Figura 2.39 - Imagem do vídeo de demonstração do Flipboard para iPad, apresentado por Jonatas Abbott. O QRcode dá acesso ao vídeo. Fonte: <http://www.youtube.com/watch?v=8_QcQtP26Uo>.

\section{Desenvolvimento de aplicativos}

O desenvolvimento de aplicativos requer contratação de empresas ou de programadores especializados. Assim como para desenvolver um software para os sistemas operacionais Mac, Windows ou Linux é necessário contratar programadores especializados, também para o desenvolvimento de aplicativos para os sistemas operacionais mobile.

Os principais sistemas operacionais móveis são o Symbian (Nokia), o RIM (Blackberry), o iOS (Apple), o Android (Google), o Windows's Mobile (Microsoft). Segundo a Gatner Inc. ${ }^{36}$, o sistema operacional Symbiam detém a maior fatia do market share, com $43 \%$ do mercado, seguido pela RIM (18\%), Android (17\%), i’OS (14\%) e Windows Mobile (5\%).

A escolha do tipo de aplicativo a desenvolver e para quais plataformas depende de diversos fatores, como o objetivo de negócios e de marketing, o público-alvo, a penetração dos sistemas operacionais nos mercados-alvo, etc.

\section{Mobile TV}

De forma ampla, Mobile TV (ou Televisão Móvel) é qualquer tecnologia que permita assistir televisão em dispositivos móveis. A primeira televisão de bolso foi vendida publicamente em 1977 por Clive Sinclair e era chamada de Microvision ${ }^{37}$.

\footnotetext{
${ }^{36}$ Artigo sobre o mercado mobile em agosto/2010: <http://www.gartner.com/it/page.jsp?id=1421013>.

${ }^{37}$ Informações detalhadas por ser obtidas na Wikipedia em <http://en. wikipedia.org/wiki/Mobile_television>.
} 
Enquanto até recentemente os dispositivos de TV móvel eram aparelhos dedicados a captar TV e rádio apenas, na última década os avanços tecnológicos nos dispositivos móveis em geral - como telefones celulares, PDAs, etc. - e sua popularização ao redor do planeta fizeram com que hoje a plataforma móvel tenha se tornado um dos formatos emergentes e promissores para a Mobile TV, ou Televisão Móvel.

Segundo Xavier (2010), especialista no mercado mobile no Brasil, existem três tipos de tecnologias, ou plataformas, para a Mobile TV:

1) TV Móvel Aberta - acesso aos conteúdos abertos e gratuitos da TV em padrão digital, por meio de aparelhos compatíveis com essa tecnologia. Vantagens: conteúdo gratuito e boa definição. Desvantagem: pouca penetração de aparelhos com essa tecnologia no mercado, falta ainda maior popularização.

2) TV Móvel Paga - acesso aos conteúdos disponíveis nos diversos canais tradicionais de televisão por assinatura, por meio de um aplicativo disponibilizado pelas operadoras de telefonia móvel. Vantagens: grande quantidade e variedade de canais disponíveis. Os preços de acesso estão cada vez mais acessíveis e o volume de assinantes vem crescendo de forma consistente. Desvantagem: o acesso é pago.

3) TV Móvel Web - acesso ao conteúdo de áreas de vídeos de sites móveis de grandes portais na Internet. Vantagens: abundância de conteúdo produzido originariamente para a web, bem editado, geralmente curto (até 3 minutos) e bem catalogado; excelente para o acesso em ambientes de rede Wi-Fi. Desvantagem: alto consumo de banda larga móvel, que, apesar de estar se tornando mais acessível e popular, ainda tem problemas de velocidade de acesso e falta de penetração na população em razão do custo.

Um exemplo de TV Móvel Web é a campanha Caminhar com Gigantes, de Johnnie Walker Black Label, que foi veiculada na TIM TV (ver Fig.2.40) e apresenta diversos filmes de aproximadamente 4 minutos com personalidades sendo entrevistados por Lorena Calábria. Dois vídeos da campanha - um com José Simão e outro com Amyr Klink podem ser vistos por meio dos links dos QRcodes na Figura 2.40. 

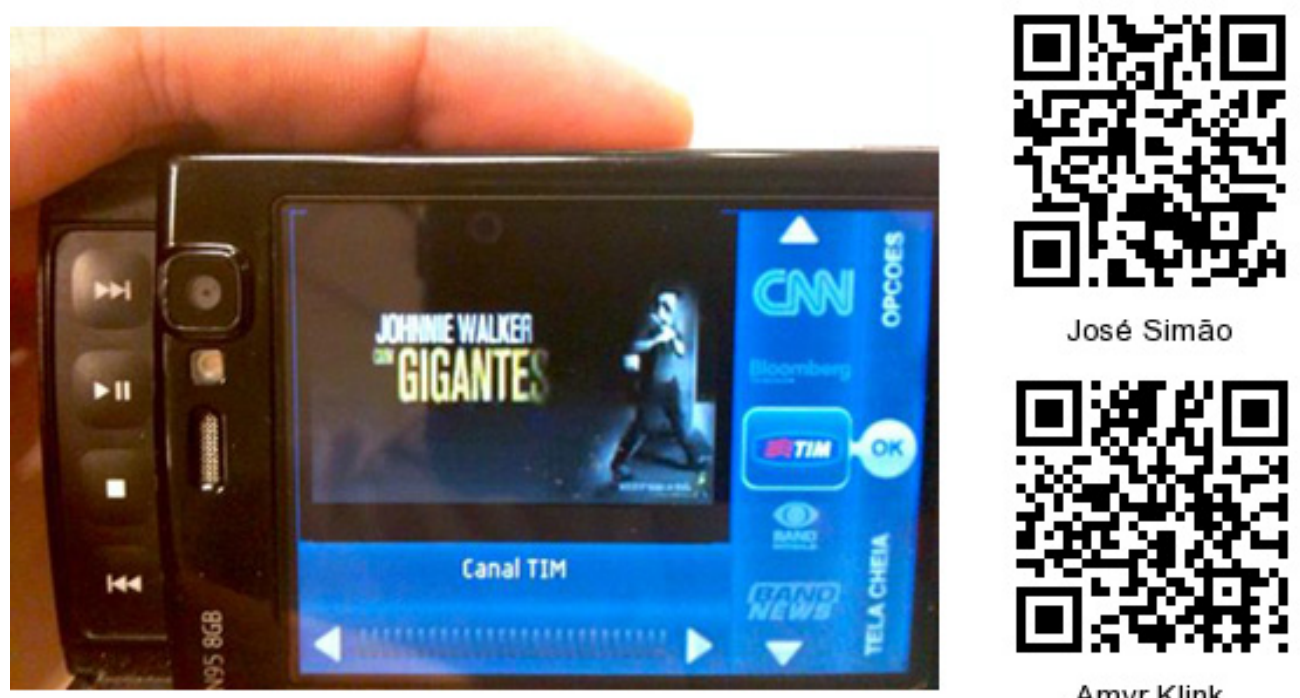

José Simão

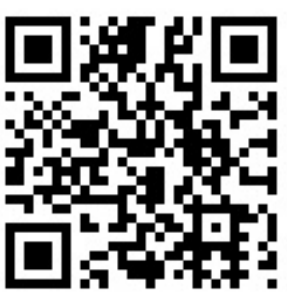

Amyr Klink

Figura 2.40 - Foto de celular mostrando a TV TIM veiculando campanha do Johnnie Walker Black Label. Os QRcodes dão acesso aos vídeos da campanha com as entrevistas de José Simão e Amyr Klink. Fontes: foto em (XAVIER, 2010), vídeo com Amyr Klink:

<http://www.youtube.com/watch?v=VamsfFbu8Uk>, vídeo com José Simão: <http://www.youtube.com/watch?v=7T8Du_60oNI>.

\section{Considerações sobre a mobilidade}

Conforme comentado anteriormente, a mobilidade é uma das principais tendências humanas, que vem sendo não apenas satisfeita pelas tecnologias emergentes, como também alavancada, impulsionada. No entanto, o grau de disseminação e popularização de cada tecnologia móvel é bastante distinto entre as culturas e locais diferentes. Exemplo disso é o contexto tecnológico do Japão, que tem uma penetração mobile e $3 G$ altíssima, em contraste com diversos países da África ou mesmo da Europa e locais no Brasil, que ainda estão galgando etapas para atingir uma situação mínima suficiente para a penetração mobile de várias das tecnologias aqui apresentadas. Ainda, algumas tecnologias que têm sido utilizadas em áreas restritas têm grande potencial de ampliação do campo de uso, como o RFID.

Dessa forma, a escolha das tecnologias e plataformas móveis a serem utilizadas requer uma análise e planejamento criterioso, que leve em consideração os objetivos do projeto e o contexto de penetração das tecnologias. 


\section{II.4 Redes Sociais Online}

As redes sociais digitais são uma das plataformas que mais crescem e penetram globalmente, modificando comportamentos e relacionamentos, e apresentando novas possibilidades. Assim, compreender sua dinâmica, os seus diversos tipos no ambiente online digital, e discutir suas características tornam-se essenciais para que possam ser usadas como plataformas de experimentação e uso nas diversas áreas do conhecimento.

\section{Da fogueira ao cérebro social}

Apesar de parecer um assunto novo, as redes sociais existem há pelo menos três mil anos, quando homens se sentavam ao redor de uma fogueira para conversar sobre assuntos de interesse comum. O que mudou ao longo da história foi a abrangência e penetração das redes sociais, conforme as tecnologias de comunicação interativas foram se desenvolvendo: escrita, correios, telégrafo, telefone, computador, telefone celular, etc.

$\mathrm{Na}$ era computacional, podemos destacar algumas tecnologias que, particularmente, pavimentaram o caminho para o cenário de redes sociais online que temos hoje: as BBS (Bulletin Board System) e as primeiras comunidades online, e-mail, chat, sistemas de instant messenges (ICQ sendo o pioneiro), a Web 2.0, sistemas de redes sociais online e, recentemente, os sistemas de redes sociais presenciais, como o Twitter. A plataforma participativa da Web 2.0, possibilitada pela penetração da banda larga em grande escala e pelo barateamento do hardware de acesso (computadores, notebooks, etc.), forneceu o ambiente propício para o florescimento das redes sociais online. Sem a possibilidade de estar conectado e interagir o tempo todo para poder compartilhar conteúdos de forma natural, os indivíduos não poderiam manter uma rede social online. Sistemas de redes sociais online já existiam antes da Web 2.0, como o Firefly, por exemplo, surgido em 1996. No entanto, esses sistemas não conseguiram massa crítica de público para prosperar. 0 primeiro site de redes sociais a se tornar realmente popular foi o Friendster, em 2003, que pode ser considerado um salto evolutivo nos sistemas de redes sociais, influenciando os que o seguiram. 0 artigo $A$ Decade of Social Media (FISHER, 2010) apresenta uma linha do tempo das redes sociais.

A introdução da mobilidade, especialmente por meio dos smartphones, que permitiu que as interações nas redes sociais sejam em tempo-real (real time), em qualquer lugar, tem 
incentivado também, sensivelmente, a participação nas redes sociais digitais online. Segundo pesquisas (TECHCRUNCH, 2010) da fabricante de navegadores Opera sobre o uso mobile de redes sociais, estamos presenciando uma explosão de acesso, principalmente no Facebook e no Twitter - o primeiro tornou-se a maior rede social mobile no mundo e o segundo é a que mais cresce. Outro estudo feito pela Forrester Research (TECHCRUNCH, 2010) revela que o acesso a redes sociais via dispositivos móveis como tendência crescente e que "Os telefones celulares se tornarão gradativamente a cola que gruda o gráfico social, oferecendo ferramentas criativas, imediatez, presença, localização e contexto quando interagindo com o mundo real (físico)".

Redes sociais, portanto, são estruturas sociais que existem desde a Antiguidade e que vêm se tornando mais abrangentes e complexas com a evolução das tecnologias de comunicação e informação. No entanto, é importante ressaltar que redes sociais têm a ver com pessoas, relacionamento entre pessoas, e não com tecnologias e computadores. Tem a ver com 'como usar as tecnologias' em benefício do relacionamento social. A essência das redes sociais é a comunicação, e as tecnologias são elementos catalisadores que facilitam as interações e o compartilhamento comunicacional.

Enquanto as redes sociais primitivas eram limitadas no tempo, pela linguagem oral, e no espaço, pela geografia, hoje, as redes sociais digitais online colapsaram as barreiras de tempo e espaço, podendo teoricamente abranger um número ilimitado de 'amigos' ou relacionamentos. Se por um lado os limites técnicos estão desaparecendo, por outro surgem os limites humanos de gestão do relacionamento. Um estudo de 1992 mostra que o cérebro humano é capaz de administrar, no máximo, 150 amigos. Esse limite ficou conhecido como Dunbar's Number em homenagem ao autor do estudo, Robert Dunbar (WIKIPEDIA, 2010). Existem correntes de pesquisadores que acreditam que a capacidade cognitiva do ser humano aumentou nas últimas décadas, e que a Geração $Y$ é capaz de administrar mais que 150 amigos nas redes online. Don Tapscott, em seu livro Grown Up Digital (TAPSCOTT, 2008), acredita que não apenas o Dunbar's number tenha sido derrubado, mas também a teoria dos Seis Graus de Separação (WIKIPEDIA, 2010). No entanto, Robert Dunbar declarou em uma entrevista ao Times Online, em 2010, que: “O interessante é que você pode ter 1500 amigos, mas quando você realmente observa o tráfego nos sites, você vê que as pessoas mantêm o mesmo círculo íntimo de 150 pessoas que nós observamos no mundo real" (GOURLAY, 2010). 
Outra questão interessante relacionada com o tamanho das redes sociais é a mudança no comportamento das pessoas que fazem parte dela conforme o número cresce. No artigo In Praise of Online Obscurity (THOMPSON, 2010), Clive Thompson discute o que acontece quando uma rede social passa de centenas para milhares de amigos. Enquanto em grupos pequenos existe realmente uma conversação que domina a relação e a mantém social, em grupos grandes o fator social normalmente se quebra em razão do aumento de escala, e, a partir de então, a característica dominante passa a ser o broadcast.

Isso sugere novamente, como no caso do Dunbar's number, que, hoje. o tamanho efetivo das redes sociais de um indivíduo torna-se limitado muito mais por fatores humanos do que por quaisquer outros, como os tecnológicos, a distância, a diferença de fusos horários, etc. Enquanto ao longo da história fatores como tempo, espaço e os meios de comunicação limitavam o tamanho das redes sociais humanas, atualmente essas barreiras foram amplamente diminuídas pelas tecnologias de comunicação e informação. As limitações mais determinantes agora são humanas.

O modo como o cérebro humano se modificará pelo uso das novas tecnologias de comunicação e informação é outra questão interessante. Termos como 'cérebro global', 'inteligência coletiva', 'cérebro social', tornam-se cada vez mais comuns. Uma especulação levantada por Nova Spivack (SPIVACK, 2010) é de que a web seria uma nova camada no cérebro humano - o metacortex - e que essa camada digital e social transcende o cérebro individual, funcionando como um cérebro global que conecta todos os nossos cérebros. Paul Buchheit (criador do Gmail e Friendfeed) chama isso de "o cérebro social”. Como o cérebro individual evoluirá em consequência do cérebro social e vice-versa é um assunto pesquisado por várias áreas do conhecimento e foge ao escopo do presente trabalho. No entanto, sabemos que as transformações que isso implica geram impactos no modo como as pessoas vivem e se relacionam, afetando de forma cada vez rápida e intensa o mercado. Isso significa que as regras do jogo estão mudando rapidamente e que é preciso agilidade para compreendê-las e utilizá-las apropriadamente para construir ações estratégicas bemsucedidas.

\section{Redes Sociais: Conceito e Tipos}

Podemos definir rede social como

uma estrutura social formada por indivíduos (ou empresas), chamados de nós, que são ligados (conectados) por um ou mais 
tipos específicos de interdependência, como amizade, parentesco, proximidade/afinidade, trocas financeiras, ódios/antipatias, relações sexuais, relacionamento de crenças, relacionamento de conhecimento, relacionamento de prestígio, etc. (WIKIPEDIA, 2010)

Dessa forma, tanto online quanto offline, existem diversos tipos de redes sociais, conforme o tipo de interdependência que elas desenvolvem.

Existem milhares de sites de redes sociais na internet, conectando pessoas e interesses dos mais diversos tipos. Alguns exemplos de sites de redes sociais online, de acordo com seu foco principal de inter-relacionamento ou com as características dos seus membros são:

- Amizade, informação, geral - Orkut <http://www.orkut.com>, Facebook <http://www.facebook.com>, Hi5 <http://hi5.com/>, Sonico <http://www.sonico.com/>, Badoo <http://badoo.com/>, Twitter <http://www.twitter.com/>

- Aprendizado de Idiomas - LiveMocha <http://www.livemocha.com/>

- Apresentações - $\quad$ SlideShare <http://www.slideshare.net>, Scribd <http://www.scribd.com/>

- Arte - DeviantArt - <http://www.deviantart.com/>

- Bares, bebidas, pubs, botecos - Drinkedln <http://www.drinkedin.net/>

- Bookmarks - Delicious <http://delicious.com/>

- Caronas - TipCar <http://www.tipcar.com.br>

- Cinema e filmes - MovieMobz <http://www.moviemobz.com/> e iCheckMovies <http://www.icheckmovies.com/>

- Crianças - ScuttlePad <http://www.scuttlepad.com/>

- Divórcio - Divorce360 <http://www.divorce360.com/>

- Doação de Sangue - Veia Social <http://www.veiasocial.com.br/>

- Exercício Físico - Rede Personal Trainer <http://www.redepersonaltrainer.com.br/> 
- Fumantes - Smoking Passions <http://www.smokingpassions.com/>

- Gastronomia - All Recipes <http://allrecipes.com.br/>

- Geeks, nerds - Intellect Connect <http://www.intellectconnect.com/>

- Imagens - Visualize Us <http://vi.sualize.us/>

- Leitura/Livros - Skoob <http://www.skoob.com.br/>

- Localização Geográfica - Loopt <http://www.loopt.com/>, FourSquare <http://foursquare.com/>

- Mães - CafeMon <http://www.cafemom.com/>, Black Moms Club <http://blackmomsclub.ning.com/>

- Marcas - Drimio <http://www.drimio.com/>

- Modelos - Model Xpress <http://www. modelxpress.com/>

- Música - Last.fm <http://www.last.fm/>, Blip.fm <http://blip.fm>

- Namoro - Match <http://www.match.com>. A Wikipedia mantém uma lista de redes sociais de namoro online em <http://en.wikipedia.org/wiki/List_of_online_dating_websites>

- Notícias - Digg <http://digg.com/>, Reddit <http://www.reddit.com/>

- Pessoas Bonitas - Beautiful People <http://beautifulpeople.com/>

- Pessoas com DST (doenças sexualmente transmissíveis) - Positive Singles <http://www.positivesingles.com/>

- Profissional (relações de trabalho e profissiões) - Linkedln <http: //www.linkedin.com>

- Plástica (cirurgias plásticas gratuitas) - MyFreelmplants <http://myfreeimplants.com/>

- Previsões - Zii Trend <http://www.ziitrend.com/>

- Sonhos - MatchADream <http://www.matchadream.com/>

- Vídeos - YouTube <http://www.youtube.com>, Vimeo <http://www.vimeo.com> 
Uma lista atualizada de sites ativos de redes sociais é compilada na Wikipedia em: <http://en.wikipedia.org/wiki/List_of_social_networking_websites>. Sites 'defuntos' de redes sociais, que foram populares no passado, mas não existem mais, também são listados na Wikipedia em <http://en.wikipedia.org/wiki/List_of_defunct_social_networking_websites>.

Além dos sites de redes sociais já existentes, é possível criar de forma muito simples e fácil um site de rede social específico, como para empresas, eventos, congressos ou qualquer outra necessidade particular. O Ning <http://www.ning.com> é uma plataforma online gratuita para criação de redes sociais. Ela oferece a maior parte das funcionalidades estruturais que um site de rede social precisa e permite a customização do ambiente. Muitas redes sociais são construídas com o Ning.

É interessante notar que, da mesma forma que as pessoas participam de vários grupos sociais offline, elas também tendem a participar de mais de um site de redes sociais online. Assim, é muito comum que uma pessoa que tenha perfil no Facebook também tenha conta no Twitter e no LinkedIn, por exemplo. Essa proliferação de perfis em redes sociais gera um problema de gestão das diversas contas online e, por isso, ferramentas como o Zooloo <http://www.zooloo.com/> centralizam o acesso e gestão de várias redes sociais no mesmo lugar. No caso do Zooloo, é possível centralizar as redes Facebook, Twitter, Linkedln e outras.

\section{Organização e estrutura das Redes Sociais}

Como mencionado anteriormente, redes sociais são um assunto antigo, inerente ao ser humano. Os primeiros estudos sobre o tema começam apenas no final do século XIX e evoluíram até a atual Teoria das Redes Sociais ${ }^{38}$.

Segundo a Teoria das Redes Sociais, uma rede social é composta de atores (nodes, ou nós) e laços (ties). Os nós são as pessoas ligadas pelos laços. 0 gráfico resultante dos laços entre as pessoas revela que estes normalmente são bastante complexos e envolvem muitos tipos de ligações entre elas. Teorias matemáticas antigas, como a Teoria dos Grafos $^{39}$, de 1736, por exemplo, são usadas para o estudo das redes sociais. A Teoria dos Grafos é um ramo da matemática que estuda as relações entre os objetos de um determinado conjunto, e pode ser aplicada às redes sociais como sendo um conjunto

\footnotetext{
${ }^{38}$ Ver detalhes sobre a Teoria das Redes Sociais em: <http://en.wikipedia.org/wiki/Social_network_theory>.

${ }^{39}$ Wikipedia - Teoria dos Grafos: <http://en.wikipedia.org/wiki/Graph_theory>.
} 
de pessoas, que são os objetos que delas participam. Muitos softwares de análise de redes sociais usam hoje a Teoria dos Grafos em seus algorítmos.

Um dos primeiros escritores a descrever a natureza dos laços entre pessoas foi o cientista e filósofo alemão Johann Wolfgang Von Goethe, em 1809, na sua clássica Elective Affinities ${ }^{40}$.

O estudo dos laços em redes sociais é bastante importante para a análise do capital social de cada nó (indivíduo) - o valor que cada indivíduo recebe da rede social. A qualidade dos laços interpessoais de um nó e as informações que esses laços circulam determinam o capital social desse nó.

Os laços interpessoais podem ser de três tipos: fortes (amigos, famílias, pessoas com quem matemos relações próximas), fracos (conhecidos, pessoas com quem mantemos relações mais superficiais) ou ausentes (pessoas que não conhecemos ou com quem não nos relacionamos). Em 1973, no artigo $A$ força dos laços fracos (GRANOVETTER, 1973), Mark Granovetter demonstra que, tanto em marketing quanto em política, os laços fracos permitem alcançar populações e audiências que não são acessíveis por meio dos laços fortes.

Os laços fracos são responsáveis pela maior parte da estrutura das redes sociais, ou seja, constituem a maior parte das ligações entre nós. Os laços fracos também são responsáveis pela maior parte da transmissão de informações entre as redes, ou seja, mais notícias e novidades fluem para os indivíduos por meio dos laços fracos do que pelos laços fortes. Isso provavelmente ocorre porque os amigos próximos (laços fortes) tendem a frequentar os mesmos círculos que nós, e as informações que eles recebem se sobrepõem consideravelmente às que também temos. Conhecidos (laços fracos), por sua vez, conhecem pessoas que não conhecemos e, portanto, recebem mais informações novas.

Esse fenômeno faz com que as maiores oportunidades e ameaças se concentrem nos laços fracos em uma rede social. Eles podem ampliar ou reduzir o capital social de um nó em função das informações que circulam. No ambiente digital, em razão da alta velocidade da circulação de informações, o papel dos laços fracos torna-se ainda mais

40 Mais informações sobre a história do estudo dos laços interpessoais em: <http://en.wikipedia.org/wiki/Interpersonal_ties>. 
crítico. Assim, a habilidade de mapear os laços fracos nas redes sociais é essencial para qualquer estratégia de atuação nas mesmas.

Um livro que analisa as influências das relações humanas e seu poder na configuração das redes sociais é Connected: The Surprising Power of Our Social Networks and How They Shape Our Lives (CHRISTAKIS, 2009). O livro trata das influências invisíveis que um nó exerce para além dos nós imediatamente conectados a ele, e de como a rede em si é afetada. Na Figura 2.41, o QRcode dá acesso a um vídeo de $18 \mathrm{~min}$ no qual um dos autores, Christakis, fala dessas influências sociais durante um TED Talks nos Estados Unidos.
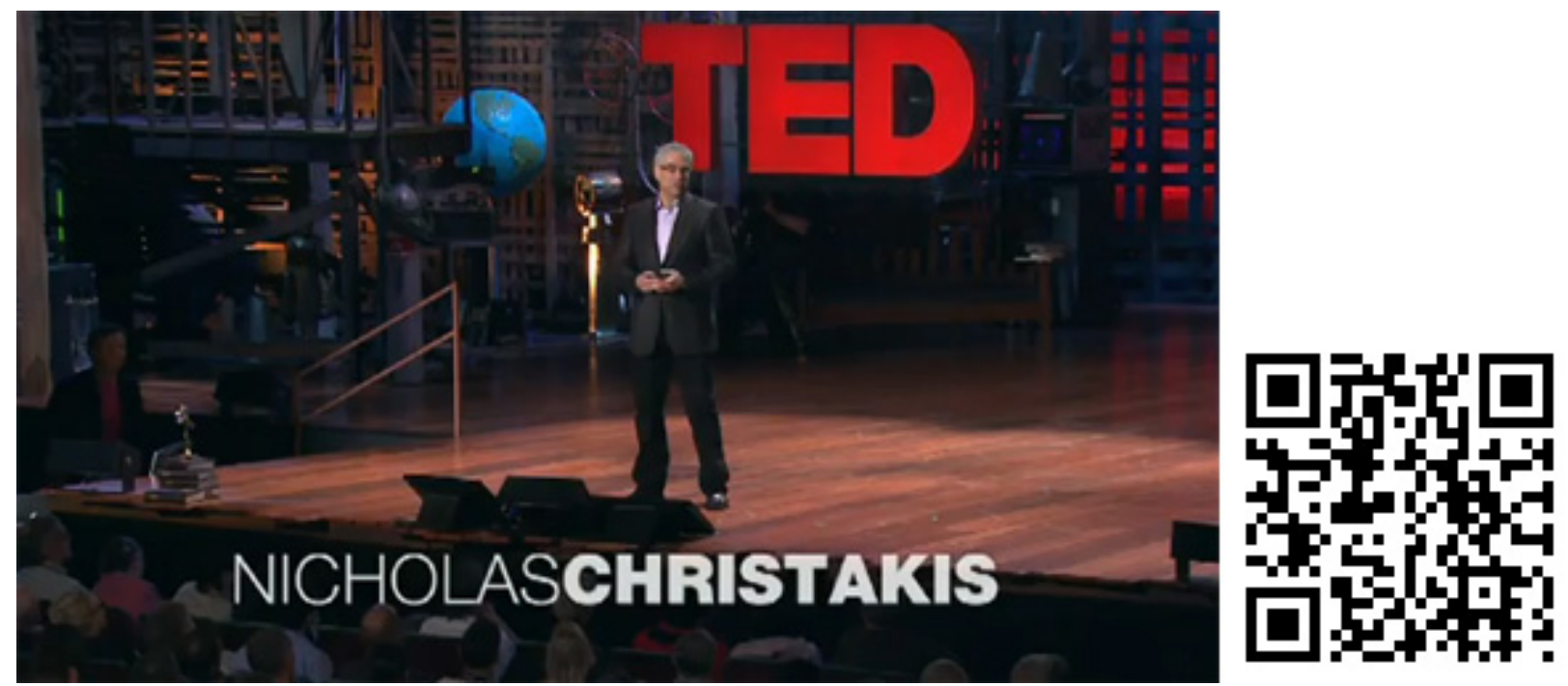

Figura 2.41 - Imagem do video do TED Talk com Nicholas Christakis: The hidden influence of social networks. O QRcode dá acesso ao vídeo.

Fonte: <http://www.youtube.com/watch?v=2U-tOghblfE>.

\section{Capital Social}

Capital social é o valor que cada nó, indivíduo, adquire, por meio das redes sociais a que pertence. O capital social é composto de vários valores decorrentes das relações entre nós (capital social relacional) e das percepções que os nós têm sobre os outros (capital social cognitivo).

Segundo Recuero (2009, p.107), alguns dos valores mais comumente relacionados aos sites de redes sociais e sua apropriação pelos nós (indivíduos), em termos de capital social, são a Visibilidade, a Reputação, a Popularidade e a Autoridade: 
- Visibilidade - Valor decorrente da presença do ator na rede social. Quanto mais laços um nó tem, maior sua visibilidade. Além de ser um valor em si só, a visibilidade é também matéria-prima para a criação de outros valores do capital social. A visibilidade é um capital social relacional.

- Reputação - Percepção construída de um nó pelos demais atores da rede, implicando três elementos: 'eu', o ‘outro' e a relação entre ambos. A reputação de um nó é consequência de todas as impressões dadas e emitidas sobre esse nó. Assim, a reputação pode ser influenciada pelas ações do indivíduo, mas não depende somente delas, mas também das construções dos outros sobre essas ações. A reputação não está associada à quantidade de conexões de um nó em uma rede social, mas às impressões que as conexões têm sobre esse nó. Por isso, a reputação é um capital social relacional cognitivo.

- Popularidade - Valor relacionado à audiência de um nó - medida quantitativa da localização de um nó na rede. Quanto mais conexões um nó tem, mais popular ele é, e mais centralizado na rede ele se torna. Nós populares tendem a ser mais influentes na rede. A popularidade é um valor mais relacionado com os laços fracos do que fortes, porque a percepção do valor da popularidade está associada à quantidade de conexões e não à qualidade desta. A popularidade é um capital social relacional.

- $\quad$ Autoridade - Poder de influência de um nó na rede, do qual depende sua reputação. A autoridade é decorrente não apenas do capital social relacional, mas também do capital social cognitivo.

É importante conhecer os diversos tipos de capitais sociais em uma rede, pois eles constituem elementos importantes para a definição de estratégias nessas redes.

Sistemas de monitoramento em redes sociais tentam mensurar da melhor forma possível as influências e os tipos de capitais sociais em uma rede para detectar possíveis oportunidades de experimentação e ação.

Nas redes sociais digitais, muitas vezes o termo Whuffie é utilizado como sinônimo de capital social. O termo é originário do livro de ficção científica de 2003 Down and Out in the Magic Kingdom, de Cory Doctorow, no qual Whuffie é a moeda de uma economia baseada em reputação. A conta de Whuffies de uma pessoa, nessa sociedade, é visível a qualquer um, pois todos possuem um implante cerebral que thes dá uma interface com a 
rede $^{41}$. A analogia entre os Whuffies e o capital social em redes sociais é tão adequada que, em 2009, durante a conferência TechCrunch50, foi lançado o The Whuffie Bank <http://thewhuffiebank.org/>, uma companhia sem fins lucrativos que mede o capital social de um perfil no Twitter ou no Facebook.

\section{Redes Socias \& Mídias Sociais}

É importante conceituar adequadamente as mídias sociais, pois é muito comum haver confusão entre os termos 'redes sociais' e 'mídias sociais'.

Se, por um lado, redes sociais têm a ver com pessoas conectadas em razão de um interesse comum, mídias sociais têm a ver com os conteúdos (texto, imagem, vídeo, etc.) gerados e compartilhados pelas pessoas nas redes sociais. Dessa forma, nem as redes sociais nem as mídias sociais, em sua essência, têm a ver com tecnologia, mas com pessoas e conexões humanas. A tecnologia apenas facilita e favorece a interação das pessoas e a criação e compartilhamento de conteúdos por elas. Assim, os sites de redes sociais como o Facebook, por exemplo, são plataformas que possibilitam, facilitam e potencializam: a) a conexão de pessoas com outras pessoas, ampliando o alcance das redes sociais pessoais; e 2) ferramentas de armazenamento e compartilhamento que alavancam o volume de mídias sociais criadas pelas pessoas. Assim, um site de redes sociais online é apenas uma plataforma tecnológica que favorece a atuação das pessoas para a interação e compartilhamento de conteúdos em suas redes sociais.

Desse modo, fica claro que Facebook, Twitter, Foursquare, etc. não são redes sociais e nem mídias sociais - eles são plataformas de redes sociais e mídias sociais. As pessoas que se utilizam das estruturas desses sites de redes sociais para compartilhar seus conteúdos é que são as redes sociais. Essas redes sociais transcendem os sites de redes sociais, pois um indivíduo de uma rede social específica (por exemplo, a sua família) pode ter perfis e se utilizar da plataforma de vários sites de redes sociais.

Eventualmente, esses sites são chamados de mídias sociais porque muitos dos conteúdos gerados por seus usuários ficam armazenados neles. Nesse contexto, e de uma forma mais ampla, faz sentido que sejam chamados de mídias sociais.

41 Para mais detalhes sobre Whuffies e outros sistemas similares de capital social ficcional, ver <http://en.wikipedia.org/wiki/Whuffie>. 
As mídias sociais têm se tornado tão relevantes na sociedade que já estão surgindo sites de redes sociais que pagam para os usuários fazerem parte delas. Um exemplo disso é a Klikot <http://klikot.com/>, que divide os lucros de publicidade com seus usuários, que são quem produzem os conteúdos em qualquer rede social. Quanto mais conteúdo produzir e mais visitas receber no Klikot, mais dinheiro o usuário acumula. Os pagamentos são feitos em contas do PayPal <www.paypal.com>.

\section{Redes Sociais no Brasil e no Mundo}

Os principais sites de redes sociais no mundo hoje são: Facebook, Twitter e Youtube. No entanto, o cenário de plataformas sociais está cada vez mais amplo, como mostra a Figura 2.42.

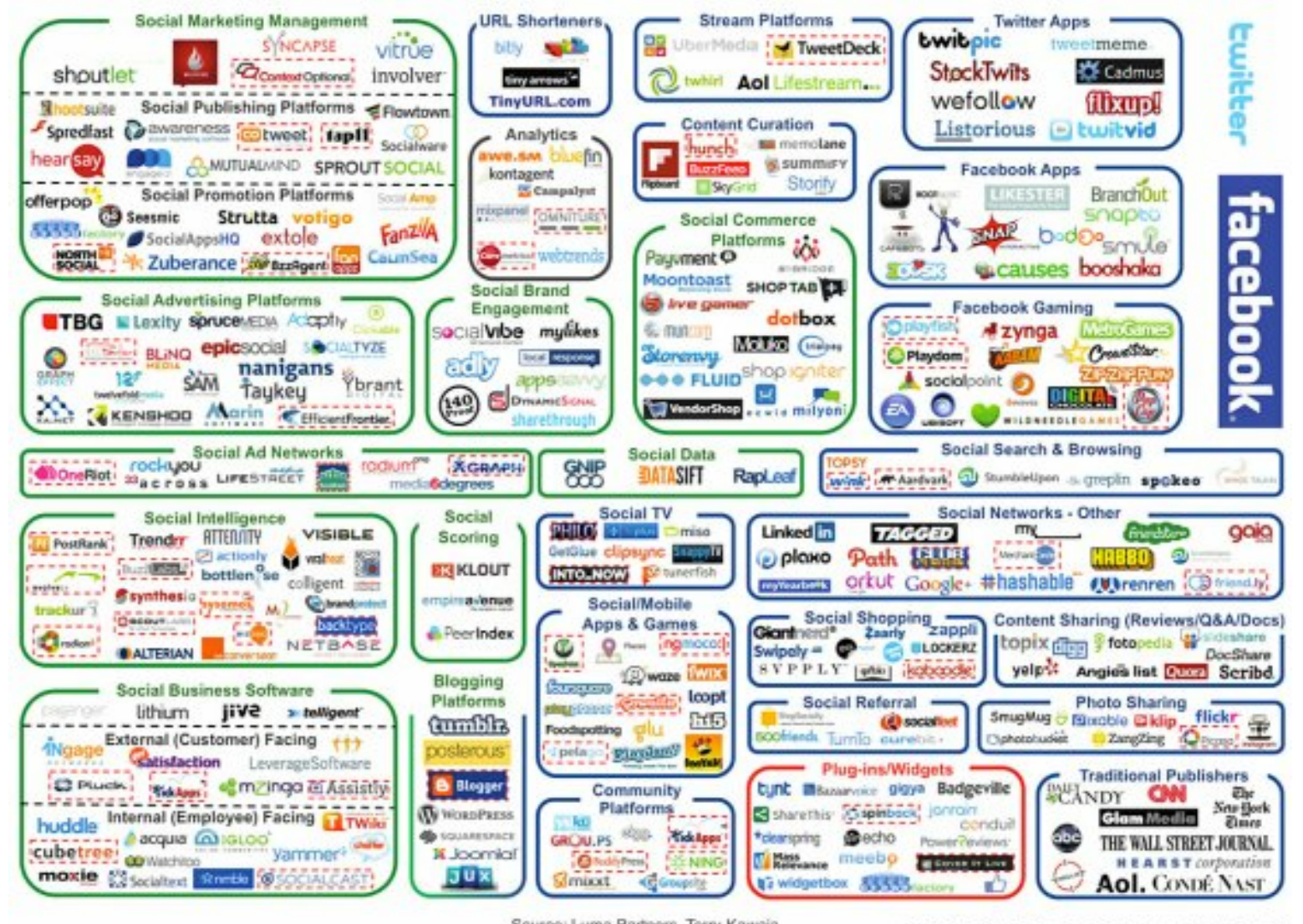

Figura 2.42 - Gráfico que apresenta a proliferação das plataformas de redes sociais online. Fonte: <http://www.businessinsider.com/social-media-marketing-landscape-complicated-2012-5>. 
Alguns links para pesquisas sobre o uso da Internet e em Redes Sociais no Brasil (as URLs podem ser acessadas pelo código encurtado, para facilitar a digitação):

- Comportamento Brasil Internet 2011, pela F/Radar - <http://goo.gl/YqmqT>

- Ibope 2011 - Dados sobre Internet e Mídias Sociais no Brasil <http://goo.gl/9DnPk>

- The State of Internet in Brazil - 2011, ComScore - <http://goo.gl/2zNIM>

\section{Cases}

Para ilustrar o impacto das redes sociais na cultura e na sociedade, no Brasil e no mundo, apresentamos a seguir alguns cases relacionados a isso:

- Artigo MIT: A social network that ballooned - uso das redes sociais por uma equipe do MIT em um desafio para se encontrar balões meteorológicos: <http://web.mit.edu/newsoffice/2009/red-balloon-challenge-1211.html>.

- Artigo Fugitivo confunde polícia pelo Facebook - Um britânico de 28 anos que escapou da prisão em setembro de 2009 usou o Facebook para dar informações desencontradas, enigmáticas, para confundir os investigadores <http://info.abril.com.br/noticias/internet/fugitivo-confunde-policia-por-facebook-271220093.shl>.

- Artigo California Earthquake Tests Real-Time Search Beliefs - pesquisa pelos tweets emitidos após o terremoto na Califórnia no início de 2010 mostra que o real-time no mundo tem uma demora de apenas 2 minutos, que foi o tempo que levou entre o início do terremoto e o primeiro tweet sobre ele: <http://www.marketingvox.com/california-earthquake-tests-real-time-search-beliefs$045939 />$.

- $\quad$ Artigo Twitter Helping Haiti Earthquake Victims - esse artigo mostra como as redes sociais ajudam na mobilização de auxílio humanitário, potencializando as doações e participação de pessoas do mundo todo: <http://www.webpronews.com/topnews/2010/01/14/twitter-helping-haiti-earthquakevictims>. 
- Twitter vira fonte de informações durante o apagão no Brasil em novembro/2009 <http://noticias.r7.com/tecnologia-e-ciencia/noticias/mesmo-sem-luz-twitter-vira-fonte-deinformacoes-em-tempo-real-20091110.html>.

- Artigo How social media is changing the way we travel - artigo que mostra como as mídias sociais estão mudando o modo como viajamos (planejamento, informando as pessoas, mantendo 0 entretenimento, etc.): <http://socialmediatoday.com/mattrhodes/162618/how-social-media-changing-way-wetravel>.

\section{Ferramentas}

Apresentamos a seguir algumas ferramentas para potencializar o uso de redes sociais:

- Construção de redes sociais customizadas: Ning <http://www.ning.com/> - ferramenta para construção de redes sociais.

- Visualização de dados de redes sociais (Digg, Facebook, Flickr, Google Maps, Last.fm, Reddit, Twitter, Youtube): várias ferramentas de visualização <http://pulse2.com/2010/02/03/31-interesting-social-media-data-visualization-tools/>.

- Pesquisa de disponibilidade de nickname em mais de 340 redes sociais: KnowEm <http://knowem.com/>.

\section{Considerações Adicionais}

Algumas referências adicionais para aprofundar no estudo de redes e mídias sociais estão relacionadas a seguir:

- Material acadêmico sobre Mídias Sociais <http://www.midiassociais.blog.br/links/material-academico-sobre-midias-sociais/ >.

- Livro Connected: The Surprising Power of Our Social Networks and How They Shape Our Lives - Nicholas A. Christakis \& James H. Fowler, 2009. 


\section{II.5 Busca online}

A busca não é uma coisa nova, o ser humano busca desde sempre. No entanto, a forma de buscar e a penetração da busca no cotidiano das pessoas mudaram muito. Se na préhistória o ser humano buscava a caça movido por instintos e usando ferramentas de pedra e metal, hoje buscamos praticamente qualquer coisa primeiramente no mundo digital, por meio de ferramentas online e em tempo real. 0 objetivo dessa seção é discutir a importância que a busca tem adquirido no cenário atual, o quanto ela influencia a sociedade e pode ser utilizada como plataforma tecnológica nas diversas áreas do conhecimento.

\section{A busca e o contexto atual}

Em 1965, o cofundador da Intel, Gordon E. Moore, preconizou o que ficou conhecido posteriormente como a famosa Lei de Moore, declarando que o número de transistores que poderiam ser colocados em um circuito integrado crescia exponencialmente, dobrando a cada dois anos. Desde então, por mais de cinquenta anos, essa tendência tem se provado verdadeira não apenas para os transistores, mas também para quase todas as mensurações de capacidade dos dispositivos eletrônicos digitais, até mesmo da quantidade de conteúdo produzido e armazenado no mundo.

A Lei de Moore descreve uma das forças impulsoras das mudanças tecnológicas e sociais do final do século $X X$ e início do século $X X I$, e, talvez tenha na web seu representante mais proeminente.

O crescimento contínuo da web e o consequente aumento de sua complexidade tornam o contexto atual extremamente propício a uma Era da Busca. Fatores como a plataforma colaborativa da Web 2.0 e a expansão da computação ubíqua (alavancada pelas plataformas móveis e sensores) colaboram para a explosão da quantidade de conteúdo online, resultando no fenômeno da Cauda Longa (Long Tail). No entanto, por outro lado, conforme a quantidade e a complexidade do conteúdo disponível aumentam, maior se torna a dificuldade do ser humano em encontrar o que precisa e sua angústia em razão disso, conforme discutido no livro O Paradoxo da Escolha. Dessa forma, a solução para conseguirmos lidar com o volume gigantesco de informação é a busca, que tem permeado cada vez mais todas as plataformas digitais, conduzindo-nos para uma Era da Busca. 


\section{Mecanismos de busca na web}

Em português, o termo search engine é traduzido como "mecanismo de busca" ou "buscador", e é usado para designar um sistema de recuperação de informações que tem a finalidade específica de auxiliar na busca de informações armazenadas em ambientes computacionais. Ou seja, buscadores são sistemas designados para buscar a informação desejada e, portanto, quanto mais relevante for o resultado apresentado pelo buscador e quanto mais rapidamente ele trouxer esse resultado, mais útil ele se torna.

A história dos buscadores computacionais se confunde com a história da própria internet e remonta à primeira metade do século XX, quando Vannevar Bush publicou o artigo As We May Think ${ }^{42}$ em 1945, no qual ele desenvolve os conceitos de hipertexto e extensão da memória e concebe o MEMEX ${ }^{43}$, uma máquina hipotética que armazenaria todos os livros, gravações, comunicações dos indivíduos, de forma a permitir consultas mecanizadas rápidas e flexíveis.

Nos anos 1960, Ted Nelson criou o projeto Xanadu ${ }^{44}$, cujo objetivo era criar uma rede computacional hipertextual com uma interface simples. Apesar de o projeto não ter decolado, seu trabalho serviu de inspiração para muito do que é a web hoje.

Também no início da década de 1960, o cientista Joseph Carl Robnett Licklider publicou um memorando com uma discussão sobre o conceito de uma 'rede computacional intergaláctica', na qual se encontram as primeiras ideias de uma rede computacional que permitisse uma comunicação geral entre computadores. Essas ideias continham quase tudo o que compõe a internet atual e foram a base para outros desenvolvimentos, culminando com o projeto e lançamento da rede ARPANET ${ }^{45}$ (Advanced Research Projects Agency Network) em 1968, que se tornou a origem da internet atual, o substrato para a busca computacional.

Entre os anos 1960 e 1990, as pesquisas e publicações de Gerard Salton alavancaram a busca computacional. Suas equipes nas universidades de Harvard e Cornell desenvolveram o sistema de recuperação de informação SMART. Salton publicou o livro $A$

\footnotetext{
42 Disponível online em: <http://www.theatlantic.com/magazine/archive/1945/07/as-we-may-think/3881/>.

${ }^{43} \mathrm{O}$ nome MEMEX tem origem na fusão dos termos MEMory índex (indexador de memória, em português).

${ }^{44}$ Além de criar o projeto XANADU, Ted Nelson foi também quem cunhou o termo ‘hipertexto' em 1963.

${ }^{45}$ Fonte: <http://en.wikipedia.org/wiki/Arpanet>.
} 
Theory of Indexing em 1975, e é considerado o 'pai' das tecnologias da busca moderna.

Na década de 1980, Tim Berners Lee desenvolveu um projeto baseado no conceito de hipertexto para facilitar o compartilhamento e atualização da informação entre pesquisadores. Em 1989, trabalhando no CERN, ele desenvolveu o protocolo HTTP, que funda a World Wide Web na internet. 0 primeiro website construído foi publicado online em 6 de agosto de 1991 e ficava em <http://info.cern.ch/>

O primeiro buscador web criado foi o Archie $^{46}$, em 1990, por Alan Emtage, um estudante da McGill University em Montreal. O programa copiava todas as listas de diretórios localizados em sites de FTP $^{47}$ público, criando uma base de dados de nomes de arquivos que podiam ser buscados. No entanto, o Archie não indexou os conteúdos desses sites porque o volume de dados era tão pequeno que podia ser buscado manualmente.

Desde então, conforme a web crescia e se tornava mais complexa, as tecnologias de busca evoluíam. Podemos ver na Tabela 2.2 a relação dos principais buscadores criados desde então ${ }^{48}$.

Tabela 2.2 - Linha cronológica dos buscadores web

\begin{tabular}{|l|l|l|}
\hline \multicolumn{3}{|c|}{ BUSCADORES - Linha do Tempo } \\
\hline \multirow{2}{*}{ ANO } & \multicolumn{1}{|c|}{ BUSCADOR } & \multicolumn{1}{c|}{ Situação Atual } \\
\hline \multirow{2}{*}{1993} & W3Catalog & Fechado \\
\cline { 2 - 4 } & Aliweb & Fechado \\
\cline { 2 - 4 } & JumpStation & Fechado \\
\hline \multirow{2}{*}{1994} & WebCrawler & Ativo, Agregador \\
\cline { 2 - 4 } & Go.com & Ativo, Yahoo Search \\
\cline { 2 - 4 } & Lycos & Ativo \\
\hline \multirow{2}{*}{1995} & AltaVista & Fechado (URL redirecionada para o Yahoo!) \\
\cline { 2 - 3 } & Daum & Ativo \\
\hline
\end{tabular}

\footnotetext{
${ }^{46} \mathrm{O}$ primeiro nome pretendido era "archives" (arquivos), mas foi encurtado para Archie.

${ }^{47}$ FTP (File Transfer Protocol) é um protocolo para trasnferência de arquivos.

${ }^{48}$ Fonte: Wikipedia <http://en.wikipedia.org/wiki/Web_search_engine\#cite_note-0>.
} 


\begin{tabular}{|c|c|c|}
\hline & Magellan & Fechado \\
\hline & Excite & Ativo \\
\hline & SAPO & Ativo \\
\hline & Yahoo! & Ativo, lançado como um diretório \\
\hline \multirow[t]{4}{*}{1996} & Dogpile & Ativo, Agregador \\
\hline & Inktomi & Adquirido pelo Yahoo! em 2002 \\
\hline & HotBot & Ativo (lycos.com) \\
\hline & Ask Jeeves & Ativo (ask.com, Jeeves foi retirado) \\
\hline \multirow[t]{2}{*}{1997} & Northern Light & Fechado \\
\hline & Yandex & Ativo \\
\hline \multirow[t]{2}{*}{1998} & Google & Ativo \\
\hline & MSN Search & Ativo como Bing \\
\hline \multirow[t]{5}{*}{1999} & AlltheWeb & Fechado (URL redirecionada para o Yahoo!) \\
\hline & GenieKnows & Ativo, renomeado Yellowee.com \\
\hline & Naver & Ativo \\
\hline & Teoma & Ativo \\
\hline & Vivisimo & Fechado \\
\hline \multirow[t]{2}{*}{2000} & Baidu & Ativo \\
\hline & Exalead & Adquirido pela Dassault Systèmes \\
\hline 2002 & Inktomi & Adquirido pelo Yahoo! \\
\hline 2003 & Info.com & Ativo \\
\hline \multirow[t]{3}{*}{2004} & Yahoo! Search & $\begin{array}{l}\text { Ativo, lançamento de seu próprio sistema de } \\
\text { busca (ver Yahoo! Directory em 1995) }\end{array}$ \\
\hline & A9.com & Fechado \\
\hline & Sogou & Ativo \\
\hline \multirow[t]{4}{*}{2005} & AOL Search & Ativo \\
\hline & Ask.com & Ativo \\
\hline & GoodSearch & Ativo \\
\hline & SearchMe & Fechado \\
\hline
\end{tabular}




\begin{tabular}{|c|c|c|}
\hline \multirow[t]{6}{*}{2006} & wikiseek & Fechado \\
\hline & Quaero & Ativo \\
\hline & Ask.com & Ativo \\
\hline & Live Search & $\begin{array}{l}\text { Ativo como Bing, lançado com outro nome } \\
\text { pela MSN Search }\end{array}$ \\
\hline & ChaCha & Ativo \\
\hline & Guruji.com & Ativo \\
\hline \multirow[t]{4}{*}{2007} & wikiseek & Fechado \\
\hline & Sproose & Fechado \\
\hline & Wikia Search & Fechado \\
\hline & Blackle.com & Ativo \\
\hline \multirow[t]{8}{*}{2008} & Powerset & Adquirido pela Microsoft \\
\hline & Picollator & Fechado \\
\hline & Viewzi & Fechado \\
\hline & Boogami & Ativo \\
\hline & LeapFish & Fechado \\
\hline & Forestle & Ativo \\
\hline & VADLO & Ativo \\
\hline & Duck Duck Go & Ativo, Agregador \\
\hline \multirow[t]{4}{*}{2009} & Bing & $\begin{array}{l}\text { Ativo, lançado como outra marca e substitui o } \\
\text { Live Search }\end{array}$ \\
\hline & Yebol & Ativo \\
\hline & Mugurdy & Fechado por falta de fundos \\
\hline & Goby & Ativo \\
\hline \multirow[t]{4}{*}{2010} & Yandex & Ativo,lançado para busca global (inglês) \\
\hline & Cuil & Fechado \\
\hline & Blekko & Ativo \\
\hline & Yummly & Ativo \\
\hline 2011 & Interred & Ativo \\
\hline
\end{tabular}


O primeiro mecanismo de busca a se tornar popular na web foi o Yahoo!, criado em 1994 e lançado em 1995. Muitos outros surgiram e desapareceram (como pode ser visto na Tabela 2.2), ressaltando o reinado atual do Google, que foi lançado em 1998 e é considerado hoje o maior, mais conhecido e mais usado mecanismo de busca disponível na web. No vídeo da Figura 2.43, o Google apresenta sua história e a evolução de seus processos de busca.

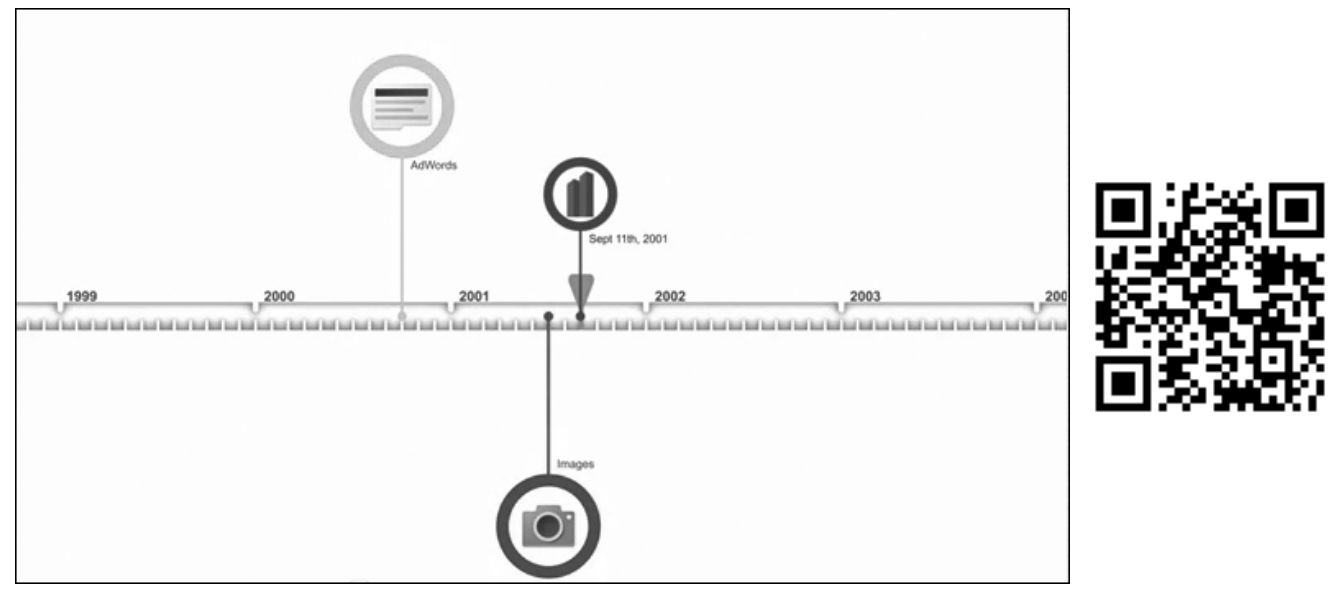

Figura 2.43 - Vídeo Evolution of Search <http://youtu.be/mTBShTwCnD4> (acesso disponível pelo QRcode ao lado da imagem).

Em 2009, a Microsoft lançou o Bing, que foi responsável por aquecer de forma saudável o mercado, impactando o Google, que introduziu, em razão disso, diversas melhorias em seu sistema e interface visual.

O Powerset, lançado em 2008 (adquirido pela Microsoft em 2009), é o primeiro buscador semântico lançado na web, seguido pelo Wolfram Alpha ${ }^{49}$, lançado em 2009. A busca semântica é o próximo passo na evolução da busca e da web. 0 vídeo da Figura 2.44 apresenta de forma sucinta a web semântica ${ }^{50}$.

${ }^{49}$ O Wolfram Alpha é mais que um buscador web, pois ele, na realidade, não apenas busca informações na web, como também analisa as questões para responder. Por exemplo, se se entrar com o termo "Martha Gabriel” no Google, ele retorna links na web, mas se se entrar o mesmo termo no Wolfram Alpha, ele reconhece que é um nome e retorna o significado do nome, estatísticas sobre a quantidade de pessoas que usam esse nome no mundo, etc.

50 O vídeo traz exemplos de como funciona a web semântica, como no caso de quando se faz a busca por um restaurante. No caso da Web 2.0 apenas, é preciso digitar o tipo de restaurante que se que e onde se 

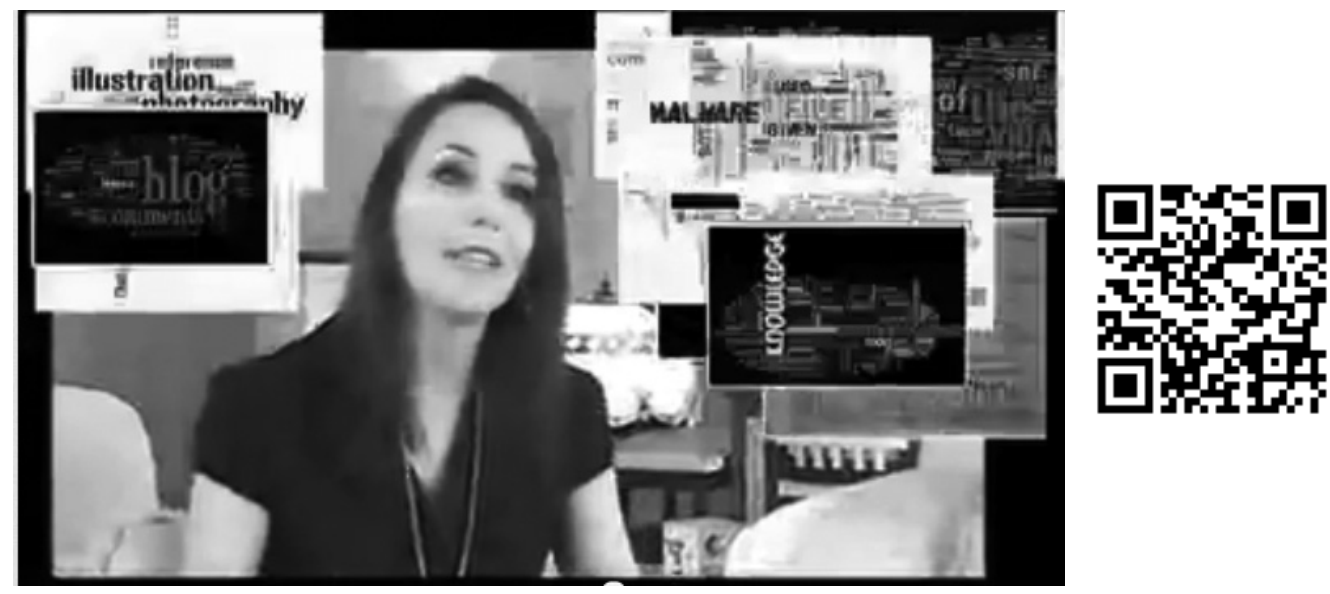

Figura 2.44 - Vídeo Web Semântica <http://youtu.be/i4GG4etWjR8> (acesso disponível pelo QRcode ao lado da imagem).

Em 2011 o Google lançou a sua rede social, o Google+, e está cada vez mais usando as informações sociais (principalmente proveniente do Google+) para calcular relevância e apresentar os resultados para as buscas. No início de 2012, o Google lança seu novo algoritmo de busca, o “Google plus your World”, em que passa a fornecer resultados baseado em relacionamentos, ao contrário do modelo anterior baseado em conteúdo. Dessa forma, as dimensões social e semântica são as próximas fronteiras da evolução da busca.

O sucesso dos mecanismos de busca é indiscutível. Uma pesquisa da Pew Internet (Pew Internet, 2011), mostra que 92\% das pessoas online usam busca. Em outro estudo (Fallows, 2004), 87\% das pessoas que usam buscadores declararam que encontraram a informação que precisavam na maioria dos casos. Em 2005, a busca tornou-se a segunda atividade mais popular da internet, perdendo apenas para o uso de e-mail, conforme pesquisa da Pew Internet e American Life Project. Hoje, as pesquisas mostram que a busca e e-mail são as duas atividades mais populares na internet, e os seus usos empatam, como mostrado na Figura 2.45.

está. No caso da busca semântica, o dispositivo já sabe quem é a pessoa que busca a informação, que tipo de comida gosta e onde está, ou seja, ele atribui significado à essa busca e traz um resultado mais adequado para quem busca, que é a resposta à pergunda de "onde comer". 


\section{Over time, search and email are most popular online activities}

$\%$ of internet users who do each activity

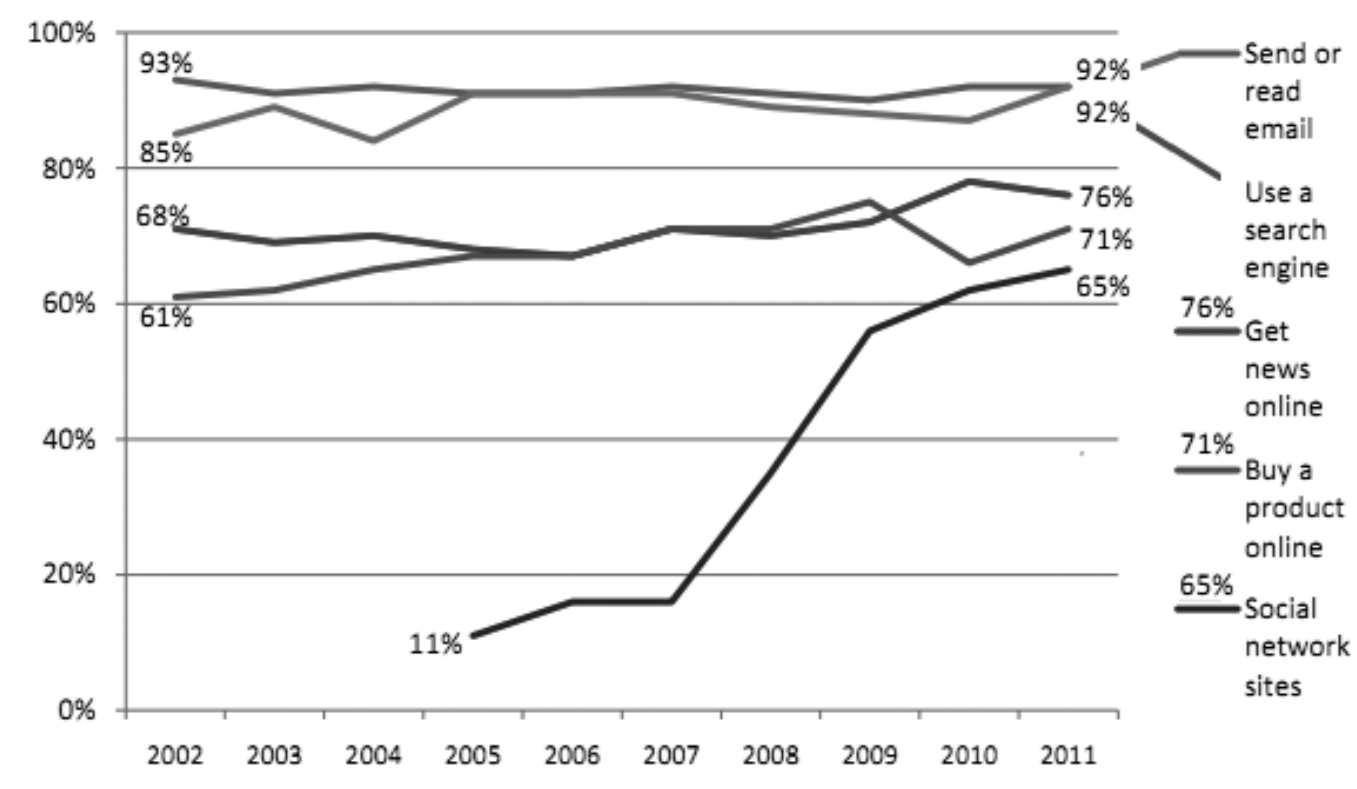

Source: The Pew Research Center's Internet \& American Life Project tracking surveys, 2002-2011. Social network site use not tracked prior to February, 2005. For more activity trends, go to pewinternet.org.

Figura 2.45 - Estatísticas de atividades online. Fonte (PEW, 2011).

O surgimento dos smartphones, que permitem um fácil acesso à web móvel, impactou ainda mais o uso dos buscadores. Segundo o Marketing Vox, o iPhone, quando surgiu, gerou 50 vezes mais consultas no Google do que qualquer outro dispositivo móvel. Isso sugere que quanto maior for a facilidade de uso e busca na web por meio dos dispositivos móveis, mais as pessoas devem buscar por meio deles, em qualquer lugar e a qualquer tempo.

A grande popularidade e o uso crescente dos mecanismos de busca talvez possam ser explicados pelo fato de que a humanidade marcha entusiasticamente em sua busca e sede por informação e conhecimento. Conforme o ditado popular, "conhecimento é poder", e, hoje, o conhecimento pode ser encontrado mais rapidamente que nunca por meio do uso da internet.

As opções de busca na web são inúmeras e irresistíveis. Existe sempre algo interessante a ser encontrado. Simples buscas de palavras isoladas, buscas de trechos completos de 
textos, buscas com refinamentos booleanos, definições idiomáticas, buscas de imagens, locais, sons, fuso horário, clima, notícias e pessoas são apenas alguns exemplos do que podemos obter por meio dos mecanismos de busca. A interface de busca do Google, por exemplo, tem uma variedade enorme de funções que são acionadas pela digitação de comandos e operadores especiais no próprio campo de busca. Uma lista dos principais comandos e operadores da interface do Google.com é apresentada na Figura 2.46. 


\section{Meteorologia}

3 Exemplo: Tempo Rio de Janeiro Pesquisar

\section{Calculadora}

Exemplo: $\quad\left(5^{*} 9\right)+3=$

Conversão de unidades

Exemplo: $10,5 \mathrm{~cm}$ em pol Pesquisar

Definiçôes de dicionário

Exemplo: Definir pescar Pesquisar

\section{Corretor ortográfico}<smiles>[C-]1C=CC=C1</smiles>

$$
\text { Exemplo: imobiriaria }
$$

\section{Pesquisar}

\section{Pesquisa local}

* Exemplo: pizzaria Rio de Janeiro Pesquisar

Horários de exibição de filmes

$$
88 \text { Exemplo: Filmes Rio de Janeiro Pesquisar }
$$

\section{Conversão de moeda}

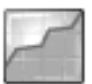

$$
\text { Exemplo: }
$$

250 libras em reais

Pesquisar

\section{Mapas}

$$
\text { Exemplo: mapa Rio de Janeiro Pesquisar }
$$

\section{Preencha a lacuna}

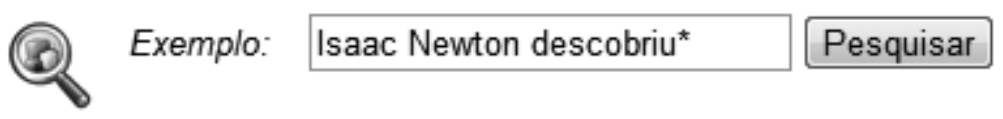

\section{Kastreamento de pacotes}

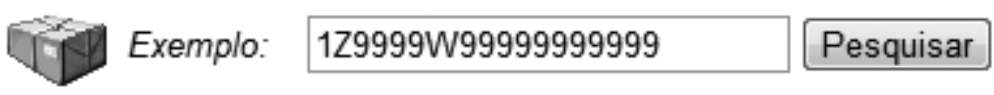

Figura 2.46 - Comandos e operadores do Google listados em <http://www.google.com.br/help/features.html> (acesso disponível pelo QRcode ao lado da imagem). 
Os refinamentos nas interfaces e nas funcionalidades de busca estão cada vez mais sedutores. O Google Instant, por exemplo, vai mostrando os resultados de busca no Google conforme a pessoa vai digitando. Esse recurso economiza para o usuário cerca de 2 a 5 segundos por busca (GOOGLE, 2011).

Focando no Google como um todo, e não apenas na interface de busca, vemos a extensa lista de serviços que ele oferece, como mostrado na Figura 2.47. Note-se a quantidade de serviços que são oferecidos em conjunto com o mecanismo de busca, tais como webmail (GMail), mapas (Google Earth, Google Maps), instant messengers (GTalk), comunidades de relacionamento (Orkut, além do Google+ que não está listado na tabela, mas é uma das principais plataformas hoje associadas ao buscador), editores de texto, planilhas e imagens (Google Docs, Picasa), tradutor (Google Translate), etc. 


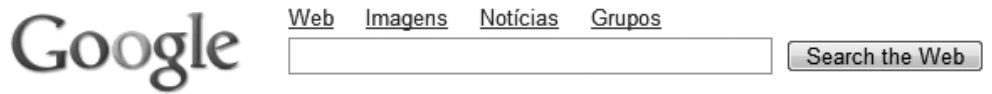

\section{Mais produtos Google}

\section{Pesquise}

\& Acadêmico

Pesquise trabalhos acadêmicos

Alertas do Google

Receba atualizações por e-mail sobre os assuntos que quiser

- Barra de ferramentas

Adicione uma caixa de pesquisa ao seu navegador

(C) Google Chrome

Um navegador criado para ser rápido, simples e seguro

( Earth

Explore o mundo do seu computador

iGoogle

Adicione notícias, jogos e muito mais à página inicial do Google

- Imagens

Pesquise imagens na web

Livros

Pesquise textos de livros na íntegra e descubra novos textos

- Maps

Consulte mapas e encontre a melhor rota

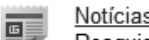

Pesquise milhares de notícias

1. Pesquisa de blogs

Encontre blogs sobre os assuntos que lhe interessam

Q Pesquisa na web

Pesquise bilhões de páginas

\section{Comunique, mostre e compartilhe}

31 Agenda

Organize o seu programa e compartilhe eventos com amigos

B Blogger

Expresse as suas idéias online

Google Docs

Crie e compartilhe projetos on-line. Acesse seus arquivos onde estiver.

M Gmail

Um serviço de e-mail rápido e pesquisável com menos spam

ㅇ. Grupos

Crie listas e grupos de discussão

$\therefore$ Latitude

Veja onde seus amigos estão nesse momento

Orkut

Conheça gente nova e mantenha contato com seus amigos

(-) Panoramio

Explore e compartilhe fotos do mundo

Picasa

Encontre, edite e compartilhe as suas fotos

SketchUp

Construa modelos $3 \mathrm{D}$ rápida e facilmente

9 Talk

Ligações e mensagens instantâneas via computador

文 Google Tradutor

Araduza instantaneamente textos, páginas da web e arquivos em mais de 50 idiomas.

YouTube

Assista, faça upload e compartilhe videos

\section{Use no celular}

Google Celular

Coloque os produtos Google no seu celular

[9. Google Maps para celular

Visualize mapas e a sua localização e obtenha informações de rota no seu celular

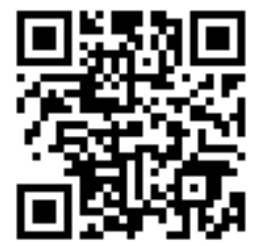

Figura 2.47 - Produtos e serviços do Google listados em <http://www.google.com.br/options/> (acesso disponível pelo QRcode abaixo da imagem). 
Os demais buscadores, como Yahoo e Bing, por exemplo, também estão associados a uma rede mais ampla de serviços, envolvendo comunidades, webmail, etc. Essa infinidade de produtos, serviços e funcionalidades associadas às plataformas de buscas tornam-nas ainda mais abrangentes, poderosas e cada vez mais presentes em nossos hábitos.

A busca tem se tornado tão importante no ambiente online que tem se confundido com os sites de redes sociais. 0 Youtube é hoje o $2^{\circ}$ maior buscador do mundo, perdendo em volumes de busca apenas para o Google. O Twitter é o buscador que cresce mais rapidamente no mundo (SOCIAL MEDIA TODAY, 2010).

\section{Oráculos digitais ${ }^{51}$}

Em razão da crescente importância e influência que os buscadores web têm adquirido no cotidiano das pessoas, fazemos aqui uma analogia entre eles e os oráculos antigos.

Segundo a Wikipedia, um oráculo é "uma pessoa ou ação considerada fonte de conselho sábio ou opinião profética; uma autoridade infalível, normalmente de natureza espiritual". Ainda, podemos definir um oráculo como:

Oráculo - Palavra de múltiplo sentido, indicando, fundamentalmente, a resposta da divindade a uma consulta formulada. Essa resposta era dada pela boca de um sacerdote, da pitonisa ou da sibila. Além disso, designava, também, os santuários a que acorriam os devotos para suas consultas. A busca do oráculo constituía uma prova de submissão do mortal aos desígnios divinos. Conhecendo a vontade dos deuses, o homem tomava suas decisões em função dela. [...] Constituíam-se de expressões vagas e indeterminadas, sujeitas a várias interpretações (ABRÃO, 2000, p. 222).

Desde a Antiguidade, como na Grécia e Roma antigas, os oráculos têm sido usados pelos homens para ajudar em suas escolhas, caminhos e decisões. Se observarmos atentamente, essa característica fundamental dos oráculos - de indicar o caminho a ser seguido - tem sido usada mais do que nunca na Era Digital em que vivemos, conduzindonos à Era da Busca. Mecanismos de busca (como Yahoo, Google etc.) são usados diária e frequentemente ao redor do mundo para auxiliar os humanos a encontrar caminhos e

51 Oráculos Digitais também é o nome dado a um trabalho de arte de 2006, que discute a influência dos buscadores no cotidiano das pessoas baseando-se nos questionamentos de privacidade, origem de dados, importância desses sistemas. O trabalho pode ser acessado em: <http://www.digitaloracles.com.br/>. 
informações na infinidade de pontos e rotas da teia computacional da web. Oferecendo respostas, informações e muitas vezes sugestões sobre o que buscamos, e nos ajudando a tomar decisões, os mecanismos de busca na web funcionam como verdadeiros 'oráculos digitais'.

Da inegável utilidade e importância desses oráculos digitais, sem os quais nossas capacidades de acesso e penetração na web seriam muito restritoa, provém também o grande poder que eles exercem sobre nós e a sociedade como um todo. A partir do momento em que usamos tais mecanismos e acreditamos no resultado recebido, ouvindo sua voz, damos a eles poder e credibilidade.

Da mesma forma que na Antiguidade as pessoas usavam os oráculos submetendo-se a seu poder, que determinava muitas vezes o destino de nações inteiras, observando-se aqui que os usuários dos buscadores - oráculos digitais atuais - também se submetem a eles. No entanto, enquanto na Antiguidade o poder divino ou místico dos oráculos era do conhecimento de seus usuários, no caso dos oráculos digitais as pessoas talvez pensem que estão no controle de suas buscas sem perceber o poder que os oráculos exercem. Apesar de os mecanismos de busca na web serem entidades digitais, e não espirituais ou divinas, talvez seus 'conselhos' sejam tão poderosos quanto ou até mais que os dos oráculos da Antiguidade.

\section{Importância e poder dos buscadores}

Conforme pesquisa da Pew Internet \& American Life Project (PEW, 2011), cada vez mais pessoas usam os mecanismos de busca online, e quanto mais experiente um usuário se torna na web, mais ele usa esses mecanismos. Portanto, podemos dizer que os buscadores tendem a exercer influência cada vez maior, já que cada vez mais pessoas se tornam usuárias da web, ficando mais experientes ao longo do tempo.

Assim, se as pessoas frequentemente utilizam em seu cotidiano os resultados obtidos nos buscadores, podemos supor que eles afetam não apenas o cotidiano individual dessas pessoas, mas também a sociedade onde estão inseridas, que consequentemente participa da web e da vida digital.

O poder dos buscadores em determinar nossos caminhos ou escolhas está intimamente ligado à confiança que atribuímos a eles. Na Antiguidade, o poder divino atribuído aos oráculos avalizava suas respostas. $\mathrm{Na}$ internet, a crença de que estamos obtendo 
respostas corretas para nossas buscas é o poder que avaliza os oráculos digitais (como vimos anteriormente, segundo pesquisa da iProspect (IPROSPECT, 2006), 86\% das pessoas que usam buscadores acreditam nos seus resultados). Poderíamos ainda acrescentar que o poder dos mecanismos de busca se amplifica em razão de dois fatores importantes que não estavam presentes nos oráculos antigos: disponibilidade e facilidade de uso. Ou seja, conveniência.

Ao contrário dos oráculos antigos, estamos frequentemente a apenas um clique de distância de qualquer oráculo digital, e sua resposta normalmente é instantânea e clara, não exigindo que decifremos "expressões vagas e indeterminadas, sujeitas a várias interpretações".

\section{Por trás dos buscadores}

Por meio de seus algoritmos, os mecanismos de busca determinam, dentro da base indexável, quem ou quais websites e documentos podem ou não ser adicionados a ela. Os critérios de filtragem visam garantir relevância máxima nos resultados que serão entregues a cada busca, ou seja, procuram evitar spam nas bases de dados e visam fornecer a melhor resposta para a busca do usuário. No entanto, ainda assim, quem determina o que deve ou não ser apresentado são os buscadores. E mais, eles possuem o poder de 'apagar' ou 'eliminar' e de 'controlar' ou 'filtrar' todos os resultados que consumimos.

Esses poderes podem determinar quem 'vive' ou 'morre' na vida digital, e isso certamente tende a ter consequências na sociedade offline conforme ela também se torne mais dependente e se alimente mais e mais das informações providas pelos mecanismos de buscas. As percepções e certezas das pessoas têm dependido cada vez mais das buscas online. 0 modo como as pessoas percebem e se relacionam com 0 mundo está mudando, tornando-se cada vez mais mediado pelo digital.

\section{Ditadura dos Top 10}

Um outro poder, e talvez o maior que os mecanismos de busca tenham, é determinado pelos hábitos de consulta de seus usuários: não ler muito além da primeira página de resultados fornecidos como resposta a uma busca. O relatório da iProspect (IPROSPECT, 2006) sobre a busca mostra que $90 \%$ dos usuários clicam na primeira página de resultados, 68\% abandonam a busca depois da primeira página e $90 \%$ não vão além da 
terceira página de resultados de busca. Esses hábitos dos usuários tornam a primeira página de resultados de busca extremamente importante, pois estar ou não entre os Top 10 resultados em uma busca pode determinar a sobrevivência e sucesso de um website ou seu desaparecimento e fracasso.

Não figurar entre os primeiros resultados listados em uma determinada busca pode significar 'não existir'. Podemos chamar esse fenômeno de 'a ditadura dos Top 10', em nome da qual cada vez mais pessoas e empresas se esforçam para encontrar técnicas de otimização de posicionamento nos mecanismos de busca para aplicar em seus websites, na tentativa de colocá-los e mantê-los no topo dos resultados de busca.

É interessante notar que mesmo uma pessoa que não seja usuária de mecanismos de busca na web pode ser afetada por eles em uma sociedade onde eles exerçam influência. Exemplo disso é quando não somos encontrados na web em razão da 'ditadura dos Top 10' ou por não termos sido ainda 'indexados' na base de dados dos mecanismos. Isso traz à tona uma importante questão existencial que interliga os mundos online e offline: "o que não é encontrado, não existe”. Assim, fica claro que a influência e o poder dos buscadores podem ir além do domínio dos usuários que os consultam, atingindo também a sociedade e elementos externos a ele.

\section{Domínio dos buscadores e questões relacionadas}

A preocupação com a dominância do Google entre os buscadores e sua rápida expansão e crescimento em poucos anos, abrangendo cada vez mais novos serviços e segmentos, inspiraram em 2004 o filme EPIC 2014, mencionado e discutido no capítulo 1, que sugere a extinção da mídia no futuro pelo Google. Além das especulações sobre tendências para o futuro, questionamentos atuais e legítimos sobre privacidade durante o uso dos mecanismos de busca têm palpitado na mídia. Um artigo da ZDNet.com, intitulado FAQ: When Google is not your friend (MCCULLAGH, 2006) (Dúvidas frequentes: Quando o Google não é seu amigo), apresenta um resumo das vulnerabilidades de privacidade durante processos de uso de mecanismos de busca, incluindo o Google, e aponta como as informações sobre os históricos de buscas são coletadas e podem até mesmo ser usadas contra os próprios usuários.

Informação é poder, realmente. No entanto, no momento em que usamos os buscadores para obtermos informações que nos trarão algum tipo de poder, também estamos 
fornecendo informações a eles em troca e, assim, dando poder a eles também. Para começar, informações como o endereço IP do usuário, data e horário da busca, o que está sendo procurado, etc. são informações prontamente disponíveis para os mecanismos de busca. Portanto, esse poder associado a informações vale para os dois lados. Muitas vezes, inadvertidamente, estamos fornecendo informações sobre nossos gostos, necessidades, preferências, interesses, tendências políticas, religiosas, sexuais, etc. Essas informações, isolada ou conjuntamente com a massa de informações fornecidas por todos os usuários dos mecanismos de busca, podem ser usadas para determinar tendências, mapear e filtrar informações e até policiar e restringir. Este é um grande poder, sem dúvida, independentemente de ser usado ou não.

\section{Busca vertical e buscadores além do Google}

No Brasil, o Google é o mecanismo de busca escolhido por mais de $90 \%$ dos usuários. Já no Japão, há uma distribuição de usuários mais uniforme entre os diversos mecanismos de busca ou o uso de buscadores personalizados, não havendo uma hegemonia tão grande por parte de um único buscador. Nos Estados Unidos, a participação do Bing/Yahoo vem crescendo bastante.

No site NetMarketShare, é possível acompanhar, por período e de forma contínua e atualizada, a evolução do market share dos diversos buscadores: <http://marketshare.hitslink.com/search-engine-market-share.aspx?qprid=4>.

Além dos buscadores horizontais, como Google, Bing, Yahoo, etc., que indexam de forma geral toda a web, existem vários mecanismos de busca vertical, que têm foco especializado e indexam informações referentes apenas a uma área específica, por exemplo, veterinária, odontológica, etc.

Fazendo-se uma comparação com os canais de televisão, os mecanismos de busca vertical seriam a TV a cabo, enquanto os buscadores amplos (Google, Yahoo, etc.) seriam a TV aberta. Alguns especialistas acreditam que os buscadores verticais impactarão os buscadores amplos da mesma forma que a TV a cabo impactou e tem impactado a TV aberta, roubando boa parte de sua audiência.

Alguns buscadores verticais, com focos específicos, são relacionados a seguir:

- ClipBlast <http://clipblast.com/>- Excelente buscador de vídeos na web. A vantagem do ClipBlast sobre o Youtube é que o Youtube só busca vídeos postados dentro dele e 
o ClipBlast busca vídeos em diversos sites de compartilhamento de vídeos, incluindo o Youtube.

- Cliqset <http://search.cliqset.com/> - Além de uma metarede social que permite compartilhar em seu ambiente, no Twitter, no Facebook e no Yahoo!, o Cliqset é também um ótimo buscador social que varre todas essas redes sociais e concentra os resultados em um único lugar.

- Codase <http://www.codase.com/> - Buscador especializado na busca de códigos fonte de programas (source code search engine).

- Flickr <http://www.flickr.com/> - Rede social e buscador baseado em imagens. 0 Flickr é o maior site de compartilhamento de fotos e imagens do mundo, e pertence ao Yahoo!.

- Hunch <http://www.hunch.com/> - Buscador de recomendações que ajuda os usuários a obter recomendações sobre quase tudo, incluindo livros, carros, software, roupas, etc. As recomendações são fornecidas mediante uma série de respostas que os usuários dão a perguntas relacionadas com o termo buscado.

- Pipl <http://pipl.com/> - Buscador vertical com foco em encontrar pessoas. Pipl reúne imagens, perfis sociais, informações de negócios, e-mail e vários outros tipos de informações sobre pessoas.

- Searchtastic <http://searchtastic.com/> - Excelente buscador para posts do Twitter. Não tem limitação de data (como ocorre nos buscadores internos do Twitter), permitindo a busca de posts de meses passados e também exportar os resultados de busca para o Excel para criar relatórios ou data mining.

- Simply Hired <http://www.simplyhired.com/> - Buscador de empregos que traz resultados obtidos de uma variedade de fontes diferentes na web.

- Yelp <http://www.yelp.com/> - Rede social que permite que os usuários façam reviews e busquem estabelecimentos comerciais, como restaurantes, hotéis, fornecedores de serviços. Os resultados de busca apresentam a distância geográfica entre o usuário e os itens relacionados.

Além de todas as opções de buscadores já existentes, qualquer empresa ou pessoa pode 
criar seu próprio buscador personalizado, conforme explicado a seguir, usando, por exemplo, o próprio Google, por meio das CSE (Custom Search Engines).

\section{Criação de Meta Search Engines customizadas (Google CSE)}

O Google Custom Search Engines (CSE) permite a criação de meta buscadores a partir do banco de dados do Google, mas focando sites específicos. Para tanto, é necessário possuir uma conta no Google (ou Gmail) e usar os recursos do Google Custom Search Engines (CSE).

Essa plataforma permite, entre outras coisas, criar um site de busca personalizado com o logo e o visual de uma empresa, para as buscas apenas no site da empresa, usando o mecanismo de busca do Google por trás.

Para criar uma CSE (Custom Search Engine, ou Search Engine personalizada, em português), deve-se acessar <http://www.google.com/coop/cse/> e seguir os seguintes passos:

- Clicar em "Create a Custom Search Engine”;

- Preencher os campos com as informações sobre a Search Engine a ser criada. Os campos mínimos necessários para a criação são Search Engine Name, Description, One or More Keywords e At Least one URL to be Searched;

- Ao preencher o formulário, pode-se escolher entre duas versões de CSE: a Standard Edition e a Business Edition. A primeira (Standard) é gratuita, mas apresenta anúncios do Google nas páginas de resultados. A versão Business é paga (inicia em US\$ 100/ano) e não apresenta os anúncios nas páginas de resultados;

- Depois de selecionar o campo de "I have read and agree to the Terms of Service", a CSE está criada.

Depois de criar a CSE, pode-se gerenciá-la acessando "manage your existing search engines" em <http://www.google.com/coop/cse/>. O painel de controle permite tanto a modificação dos dados de configuração inicial quanto a manutenção de refinamentos, Look and Feel, etc.

Uma vez criada uma CSE, ela se torna disponível por default na base de dados do Google Co-op e será encontrada pelas crawlers rapidamente. 


\section{Busca universal}

"Universal Search" ou busca universal é o sistema de busca que mistura listagem de notícias, vídeos, imagens, buscas locais e em livros, dentre os itens de resultados de busca das páginas web. O Google incorporou o sistema de busca universal em seu algoritmo em 2008, e isso afeta o resultado das buscas. Vídeos do YouTube, por exemplo, passaram a fazer parte dos resultados de busca.

Nesse contexto, as buscas verticais, ou específicas, que eram anteriormente ignoradas pela maior parte dos usuários de buscadores agora ganham importância. Serviços de buscas verticais do Google agora são apresentados na busca regular, em razão do sistema incorporado de busca universal. Exemplos desses serviços: Blog Search, Book Search, Catalogs, Code Search, Directory, Finance, Images, Local/Maps, News, Patent Search, Product Search, Scholar, Video e Web Search. Para conhecer as diversas áreas específicas de busca vertical que o Google considera, visitar a página <http://www.google.com/options/>, que traz uma lista imensa.

\section{Busca semântica e além do texto: o futuro da busca}

Além da busca textual, que envolve a busca por palavras-chave e a busca semântica, outros tipos de busca tendem a se popularizar: busca por imagens (visual), busca aural (voz e música) e busca social (busca dentro das redes sociais ou em sistemas que permitam a anotação de comentários dos usuários).

Cada vez mais os buscadores têm tentado incorporar a semântica em seus algoritmos. Busca semântica é um processo para melhorar as buscas online por meio de dados de redes semânticas que eliminam ambiguidades nos termos de busca e textos na web, visando gerar resultados mais relevantes.

Assim, em vez de usar algoritmos como o PageRank do Google para prever relevância, a busca semântica usa o significado dos termos na linguagem para produzir os resultados de busca relevantes. A meta é entregar a informação solicitada pelo usuário em vez de uma lista de resultados com palavras-chave soltas relacionadas.

A busca semântica tem mudado completamente o modo como os resultados de busca são produzidos, e apresentados. Hoje, o processo é baseado em palavras-chave e, no futuro, precisará basear-se em significados, na semântica. Normalmente, a busca semântica envolve o uso de algoritmos de inteligência artificial e, assim, torna-se bastante 
complexa. Por isso, ainda são poucos os sistemas de busca semântica, apesar de esta ser uma forte tendência. Podemos citar como exemplos de sistemas de busca semântica o PowerSet <www.powerset.com> e o Wolfram Alpha <www.wolframalfa.com>, que respondem às perguntas dos usuários em linguagem natural e sem se basearem em palavras-chave. O QRcode da Figura 2.48 dá acesso ao vídeo em que Stephen Wolfram, criador do Wolfram Alfa, explica a evolução do algoritmo que deu origem ao sistema semântico, que ele denomina de sistema de computação e não busca.

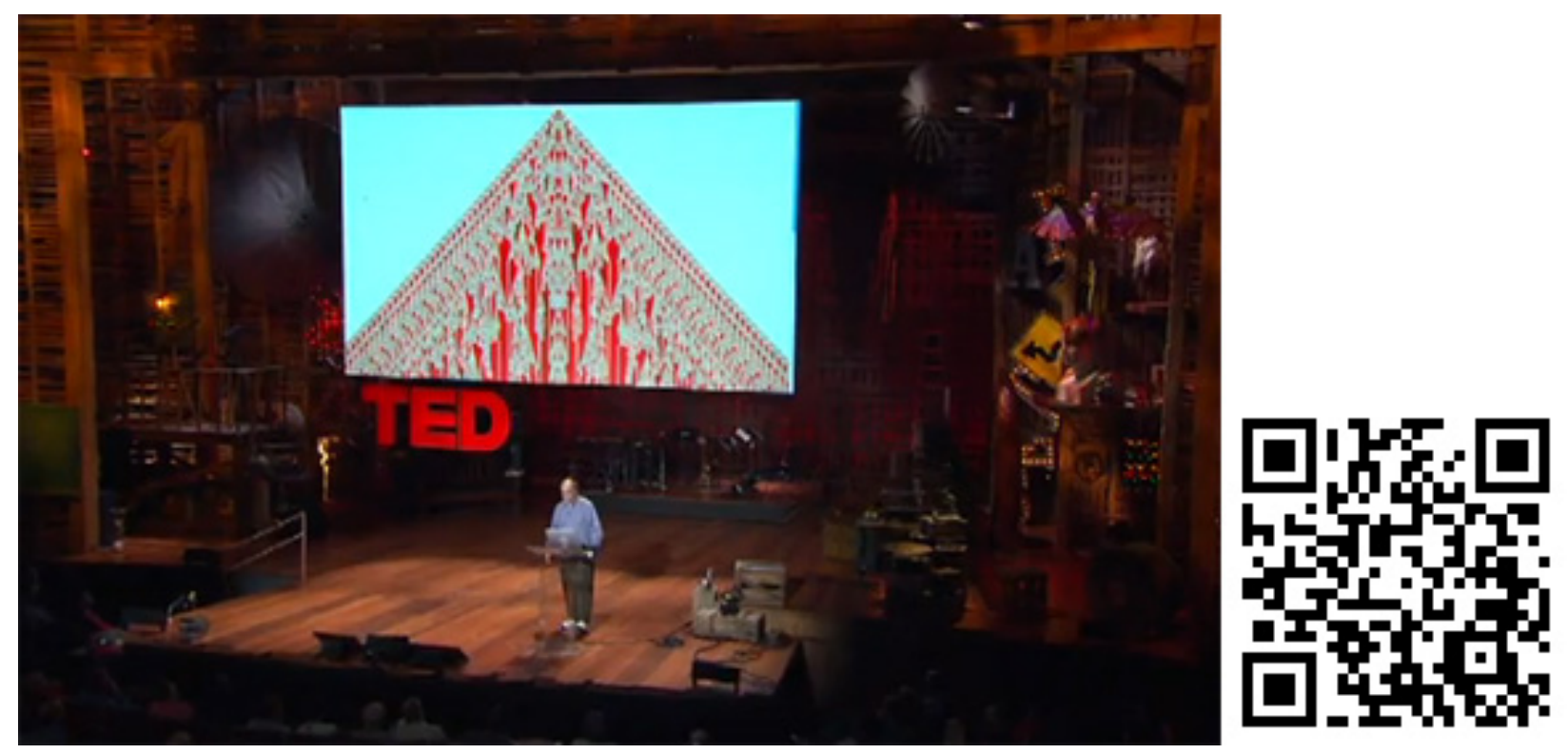

Figura 2.48 - Imagem do vídeo Computing a theory of everything, com Stephen Wolpram no TED Talk 2010. O vídeo pode ser acessado pelo QRcode. Fonte: <http://www.youtube.com/watch?v=60P7717-XOQ>.

Outra tendência promissora para a busca é o uso de anotações dos próprios usuários nos resultados de busca, uma mistura de busca com Wikipedia (crowd computing). Um exemplo desse tipo de buscador é o Mahalo.com <www.mahalo.com>, que além de permitir que as pessoas adicionem informações também funciona como uma meta-search engine, apresentando os resultados de busca em outros sistemas, como Google, Yahoo, Live Search, Wikipedia, YouTube, Flickr, etc. O Google também tem essa funcionalidade que permite que os usuários alterem a ordem de apresentação e comentem os resultados de busca: o Google SearchWiki. Para usar esse recurso é necessário que a pessoa tenha uma conta no Google (qualquer serviço do Google) e esteja logada no momento em que faz a busca. É importante ressaltar que as mudanças feitas na ordem dos resultados de busca aparecem apenas para essa pessoa e não afetam os resultados dos demais usuários 
do Google. No entanto, existe a possibilidade de que, no futuro, essas alterações dos usuários possam contribuir de alguma forma para o cálculo de posicionamento orgânico das buscas, apesar da polêmica em torno da possibilidade de manipulação. 0 vídeo Google SearchWiki <http://www.youtube.com/watch?v=t8Pl1HOdIXE>, postado no YouTube, traz um ótimo minitutorial de dois minutos sobre o assunto.

A busca além do texto também merece destaque como tendência cada vez mais forte. Conforme as tecnologias de reconhecimento de imagem e som se aperfeiçoam, soluções cada vez mais interessantes começam a surgir para a busca de imagens e músicas/sons/voz.

Um exemplo de busca por reconhecimento de imagens é o aplicativo SnapTell <http://www.snaptell.com/>, que, uma vez instalado em um dispositivo móvel, permite que uma imagem capturada pela câmera do aparelho seja enviada para reconhecimento e busca de informações sobre o que foi fotografado. O SnapTell tem sido usado em campanhas publicitárias envolvendo ações de engajamento do público por meio da captura e envio de imagens específicas para reconhecimento.

Quanto à busca por música, podemos citar os ótimos Shazam <http://www.shazam.com/music/web/home.html> e SoundHound (para iPhone), para plataformas mobile, e o Midomi <www.midomi.com> para plataformas desktop. Esses sistemas permitem buscar uma música (music recognition) que esteja tocando ou se um trecho dela for cantarolado, devolvendo informações como o nome da música, o artista, etc.

Busca por reconhecimento de voz também já é possível, e deve se tornar cada vez mais popular à medida que o desempenho do reconhecimento melhore. Podemos citar alguns exemplos de sistemas de busca por reconhecimento por voz: o serviço 102 da Telefônica em São Paulo, que foi lançado em 2004, para o qual você liga por telefone e conversa com a aplicação para encontrar o telefone de uma empresa ou pessoa que conste do diretório de assinantes da operadora; em 2007, o Google Labs lançou um serviço de busca local nos Estados Unidos (empresas locais) usando reconhecimento de voz, o experimento Google Voice Local Search, ou 1-800-G00G-411 <http://www.google.com/goog411/>; a plataforma de busca por voz (em serviços locais) da Microsoft é o Microsoft Live Search 411, baseado nas soluções tecnológicas da TellMe <http://www.tellme.com/>. 


\section{A busca e o real time}

Outra tendência bastante forte no cenário da busca é incorporar o real-time. Desde a popularização do Twitter em meados de 2009, as pessoas estão cada vez mais acostumadas a obter informações quase que em tempo real. Isso tem impactado sensivelmente os buscadores, pois resultados com notícias do dia anterior podem ser considerados não relevantes pelos usuários.

Em razão disso, as mudanças nos sistemas de busca têm sido frequentes. O Google lançou o algoritmo Caffeine, que, além de varrer mais rapidamente a web, almejando o tempo real, também visa incrementar a parte semântica das buscas.

\section{A busca e a web profunda (deep web)}

Conforme mencionado anteriormente, existe uma parte da web que não é indexada pelos buscadores tradicionais. Essa parte da web não visível pelos buscadores é conhecida como deep web ${ }^{52}$, deep net, invisible web ou, simplesmente, web profunda.

Normalmente, as áreas da web onde os robots dos buscadores não conseguem entrar para indexar são bancos de dados que precisam de senha para acesso, páginas que pertencem a redes privadas de organizações, páginas geradas dinamicamente em resposta a um comando.

No entanto, existem buscadores específicos para atuar na web profunda, como apresentado a seguir (BASU, 2010):

- Complete Planet <http://aip.completeplanet.com/> - Referindo-se a si mesmo como a “porta de entrada para a Deep Web”, o Complete Planet torna simples o acesso à massa de banco de dados dinâmicos que estão escondidos da busca tradicional. Os banco de dados indexados vão da agricultura ao tempo, passando por comidas, bebidas e assuntos militares.

- DeepPeep <http://www.deeppeep.org/> - O foco desta ferramenta são as informações obtidas por meio dos formulários que acessam os bancos de dados e serviços web. Os domínios acessados pelo DeepPeep são: automobilístico, aeronáutica, biologia, hotelaria, trabalho/empregos e locação.

\footnotetext{
${ }^{52}$ Para mais informações sobre a Deep Web, ver: <http://en.wikipedia.org/wiki/Deep_Web>.
} 
- DeepWebTech <http://www.deepwebtech.com/> - Fornece cinco buscadores e plug-ins de navegadores para tópicos específicos. Os buscadores cobrem as áreas de ciências, medicina e negócios na web profunda.

- IncyWincy <http://www.incywincy.com/> - Funciona como uma meta search engine para a web invisível. Faz buscas na web, em diretórios, em formulários e em imagens e fornece gratuitamente o serviço de busca com alerta.

- Infomine <http://infomine.ucr.edu/> - Ferramenta criada por uma associação de universidades americanas (como a University of California, a Wake Forest University, a California State University e a University of Detroit) para minerar (mine em inglês) informações de banco de dados, jornais eletrônicos, livros eletrônicos, mailing lists, catálogos de cartões de bibliotecas online, artigos, diretórios de pesquisa e muitos outros recursos.

- Infoplease <http://www.infoplease.com/> - Ferramenta de busca focada em enciclopédias, almanaques, atlas e biografias.

- Intute <http://www.intute.ac.uk/> - Ferramenta mais focada no Reino Unido, mas com recursos de estudo e pesquisa fornecidos por algumas das mais importantes universidades da região. Fornece acesso gratuito a mais de 60 tutoriais online para aprendizado na internet.

- Scirus <http://www.scirus.com/srsapp/> - Ferramenta com foco puramente científico que consegue navegar em jornais científicos, home pages de cientistas, cursos, patentes, intranets institucionais, etc.

- TechXtra <http://www.techxtra.ac.uk/> - Concentra-se em engenharia, matemática e computação. Fornece notícias da indústria, anúncio de empregos, relatórios técnicos, dados técnicos, recursos de ensino e aprendizagem, com artigos e informações relevantes de websites.

- The WWW Virtual Library <http://vlib.org/> - Considerado o mais antigo catálogo da web, foi iniciado por Tim Berners-Lee, o criador da web, e lista uma quantidade relevante de recursos em uma grande quantidade de assuntos. 


\section{Personalização de resultados de busca}

Mais uma tendência dominante na área de busca é a personalização dos resultados em função do comportamento do usuário (behavioral targeting). O Google já utiliza a personalização por comportamento para todos os usuários que estiverem logados em algum serviço do Google ou que estejam com os cookies ativados. A personalização dos resultados, portanto, acontece de duas formas:

- Signed-in personalization - personaliza os resultados de busca de quem está logado em qualquer serviço do Google, baseando-se na Web History do usuário;

- Signed-out customization - personaliza, usando um cookie, os resultados de busca para quem não está logado em nenhum serviço do Google, baseando-se na informação das buscas passadas no navegador do usuário.

Dessa forma, atualmente, quando dois usuários diferentes fazem a busca pela mesma palavra-chave no Google, eles podem receber resultados bastante diferentes. 0 objetivo da personalização dos resultados é aumentar a relevância dos links para os usuários da busca.

Em setembro de 2010, o Google lançou o Google Instant Streaming, que apresenta sugestões de busca em tempo real conforme o usuário vai digitando os termos de busca no campo. Antes de lançar o Google Instant, o Google sugeria, via Google Suggest, o que digitar na busca, baseado no volume de busca das palavras-chave. Ou seja, a sugestão apontava os termos mais populares de busca. Com a introdução do Google Instant, as sugestões em tempo real são de resultados de busca em tempo real, ou seja, a sugestão agora aponta os sites mais populares na busca já considerando a personalização para o usuário. Com isso, a busca, além de personalizada, ficou mais rápida e em tempo real, com sugestões do que buscar.

Apesar de o Google Instant não afetar os resultados das buscas em si (uma vez que sugere os resultados para a busca da mesma forma que antes, calculando relevância, e apresentando-os em função disso), ele pode afetar a intenção de busca, já que vai apresentando os resultados sugeridos em tempo real conforme a pessoa digita as palavras.

Na apresentação de lançamento do Google Instant Streaming, em 8/set/2010, Sergey Brin, um dos fundadores do Google, declarou que "We want to make google the third 
half of your brain" ("Nós queremos tornar o Google a terceira metade do seu cérebro"), e eles certamente estão dando mais um passo em direção a isso.

\section{Referências adicionais}

Outras fontes para conhecer a história da busca, não abordada neste estudo:

- Livro: Busca: Como o Google e Seus Competidores Reinventaram os Negócios (BATTELLE, 2005).

- Infográfico: Timeline da História da Busca - <http://ppcblog.com/search-history/>.

\section{II.6 - Games, Vídeos, Conteúdos Digitais e Display}

Apesar de já existirem há bastante tempo no mundo offline, algumas plataformas ganham impulso no ambiente digital online, tornando-se plataformas digitais populares para serem consideradas nas experimentações artísticas. Essas plataformas são: display, games e vídeos, como veremos a seguir.

\section{Displays Digitais Online}

A evolução nas tecnologias de hardware de display (sensores, câmeras, software de reconhecimento, realidade aumentada, etc.) e a infraestrutura de conexão com a internet oferecem soluções digitais online e interativas, além dos domínios dos banners dentro de sites. Além das possibilidades de display ampliarem em qualquer conteúdo digital visual, como jogos e aplicativos mobile, as tecnologias digitais de integração com o mundo físico (como a realidade aumentada) ampliam ainda mais o campo de aplicação dos banners digitais. Outdoors com sensores e câmeras podem interagir com as pessoas ao redor, e sua conexão com a internet permite ações integradas em tempo real.

Apresentaremos a seguir alguns cases que envolvem o uso de tecnologias emergentes em displays.

\section{Display com Realidade Aumentada}

A rede de fast food Burger King criou um banner publicitário utilizando a realidade aumentada para promover seus sanduíches que custavam 1 dólar nos Estados Unidos.

O banner era apresentado em diversos sites e ativava um sistema em Flash de realidade 
aumentada, de forma que, quando os usuários seguravam uma nota de um dólar na frente da webcam, os sanduiches de 1 dólar do Burguer King eram mostrados em cima da nota. Além disso, o sistema rastreava o rosto do usuário e colocava sobre ele uma máscara do rei, símbolo da empresa (King). O vídeo que mostra o funcionamento do banner pode ser visto por meio do QRcode da Figura 2.49.

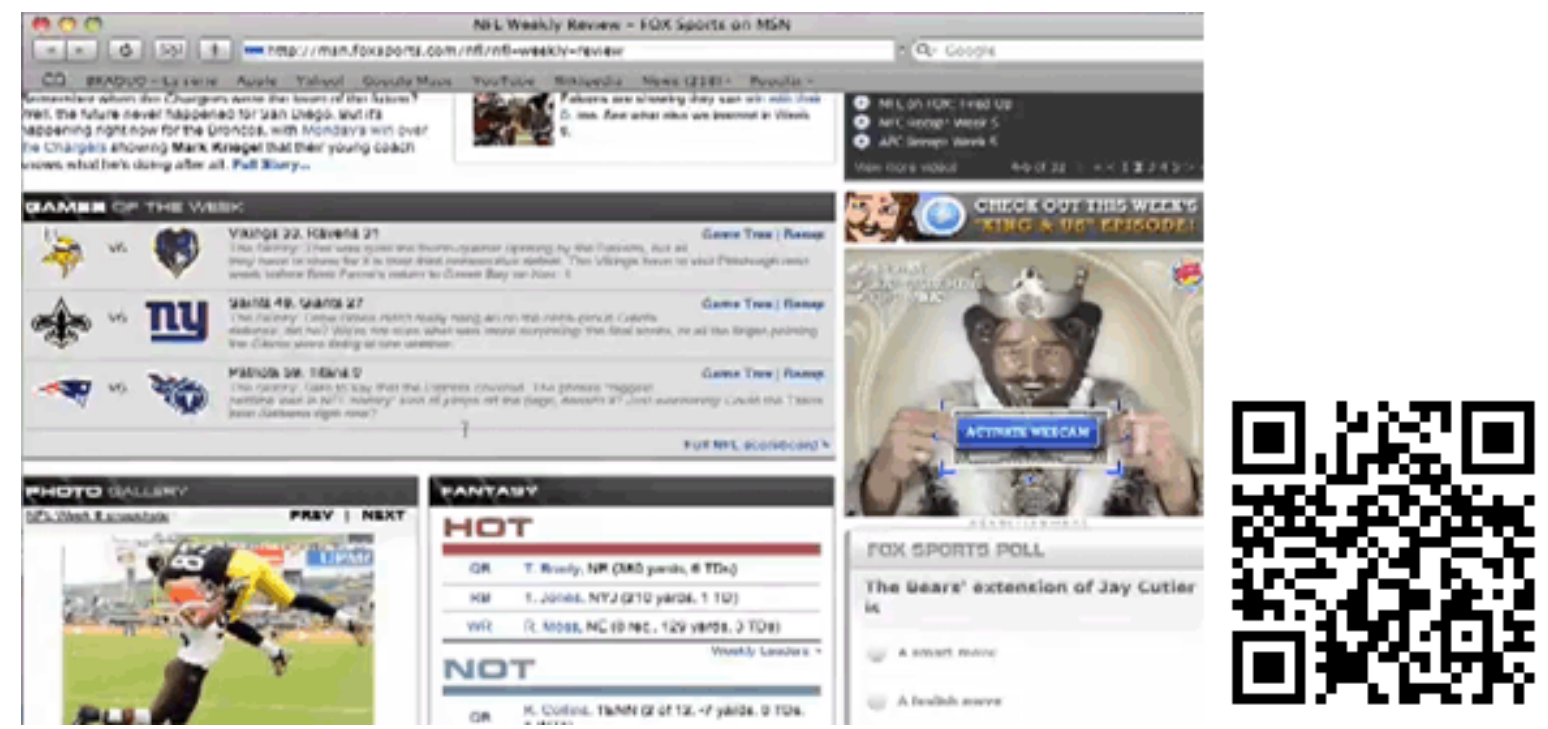

Figura 2.49 - Imagem e QRcode de acesso ao vídeo de demonstração do banner em realidade aumentada da promoção de 1 dólar do Burguer King. Fonte:

<http://www.youtube.com/watch?v=jDaniAhBLLQ>.

Outro exemplo foi o uso de um banner para promover o filme Arthur and the revenge of Maltazard, em 2009, na França. O banner era exibido dentro de um game de realidade aumentada em 3D, que era ativado por um marcador nas caixas de cereais Chocapic da Nestlé53. O QRcode da Figura 2.50 dá acesso ao vídeo de demonstração do jogo de realidade aumentada em 3D. 


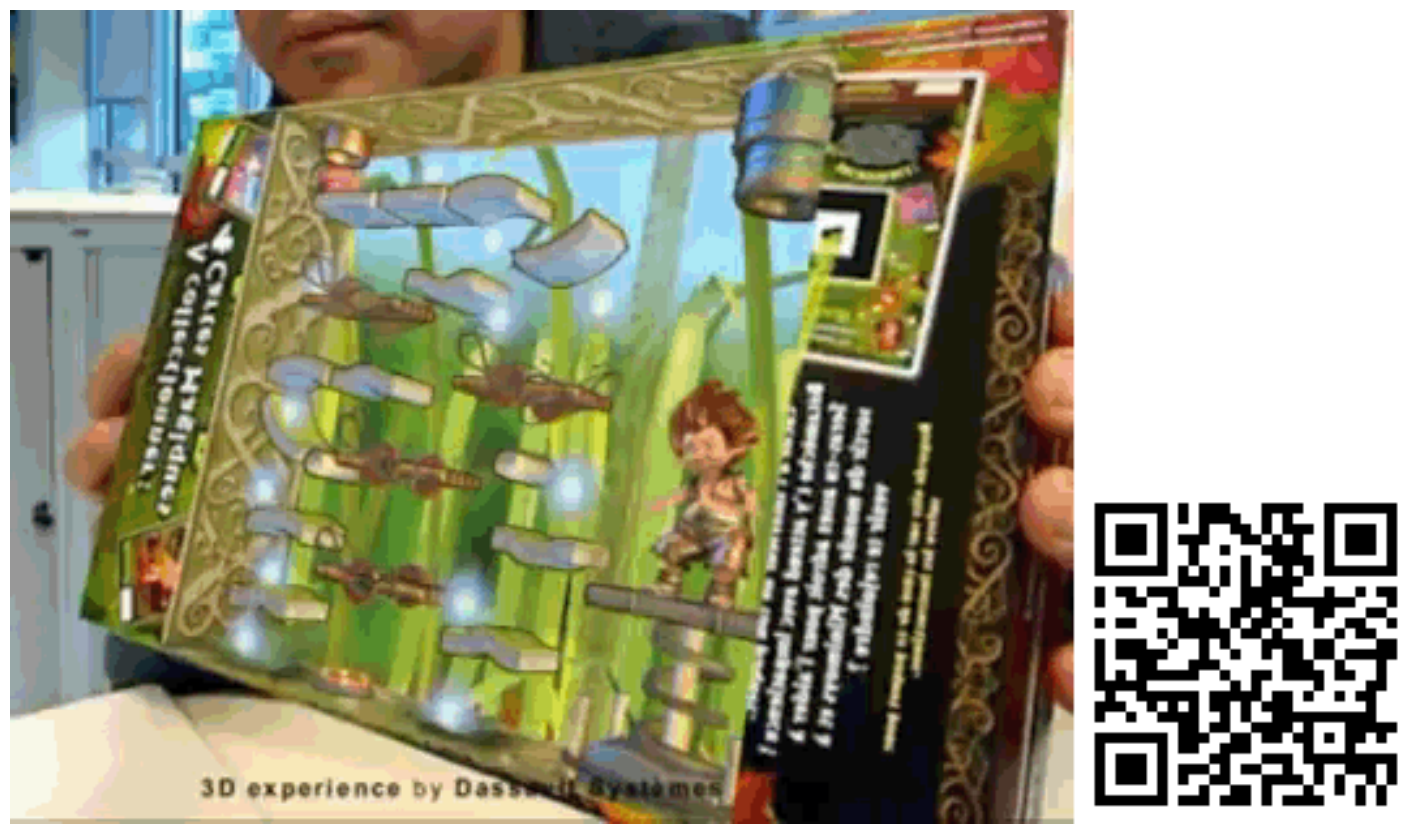

Figura 2.50 - Imagem e QRcode de acesso ao vídeo de demonstração do game de realidade aumentada em 3D nas caixas de cereal Chocapic. Fonte: <http://www.youtube.com/watch?v=TzCMAgVrPFc>.

\section{Displays digitais personalizados}

Outra tecnologia interessante para displays digitais foi utilizada em Tokio. Displays com câmera escaneavam as pessoas que passavam e mostravam os anúncios de acordo com a idade e o sexo delas. O QRcode da Figura 2.51 dá acesso à matéria (em inglês) com uma das imagens exibidas pelo display.

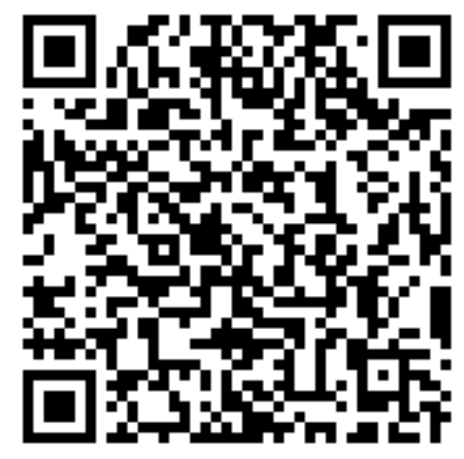

Figura 2.51 - QRcode de acesso à matéria Camera-equipped digital billboards scan humans in Tokyo, serve up tailored ads. Fonte: <http://www.engadget.com/2010/07/15/camera-equipped-digitalbillboards-scan-humans-in-tokyo-serve-u/>. 
Ainda estamos no início das experimentações e uso de tecnologias de reconhecimento de padrões humanos por grupos, e futuramente, de reconhecimento individual. No entanto, à medida que essas tecnologias forem evoluindo, elas possibilitarão diversos graus de personalização do conteúdo do display a ser apresentado. Isso representa um potencial de experimentação jamais possível antes.

\section{Displays Sociais}

Uma das principais tendências é a socialização de tudo. Ou seja, tudo que puder se tornar social, será. Os displays não são exceção.

Uma ação impactante que inclui a dimensão social nos displays é a campanha 15 Seconds of Fame $^{54}$ (15 segundos de fama) da agência RG/A para o lançamento da loja de roupas American Eagle Outfitters no Times Square, New York, em 2009. Pessoas que compravam produtos na loja eram convidadas a posar em um mini estúdio fotográfico e, momentos depois, a foto do consumidor era projetada no outdoor de telas LED de 1400 m2 (ocupando a altura de 25 lojas no prédio), visível a todo Times Square, um dos locais mais visitados do mundo. O outdoor construído de telas de LED mostrava conteúdo 18 horas por dia. A Figura 2.52 mostra o outdoor da campanha no Times Square, NY. 0 QRcode dá acesso ao vídeo de um consumidor que, enquanto filmava o outdoor, viu sua foto ser exibida.

\footnotetext{
54 Informações detalhadas sobre a campanha 15 Seconds of Fame estão disponíveis no site da RG/A, em: <http://www.rga.com/news/release/2009/american-eagle-flagship>.
} 


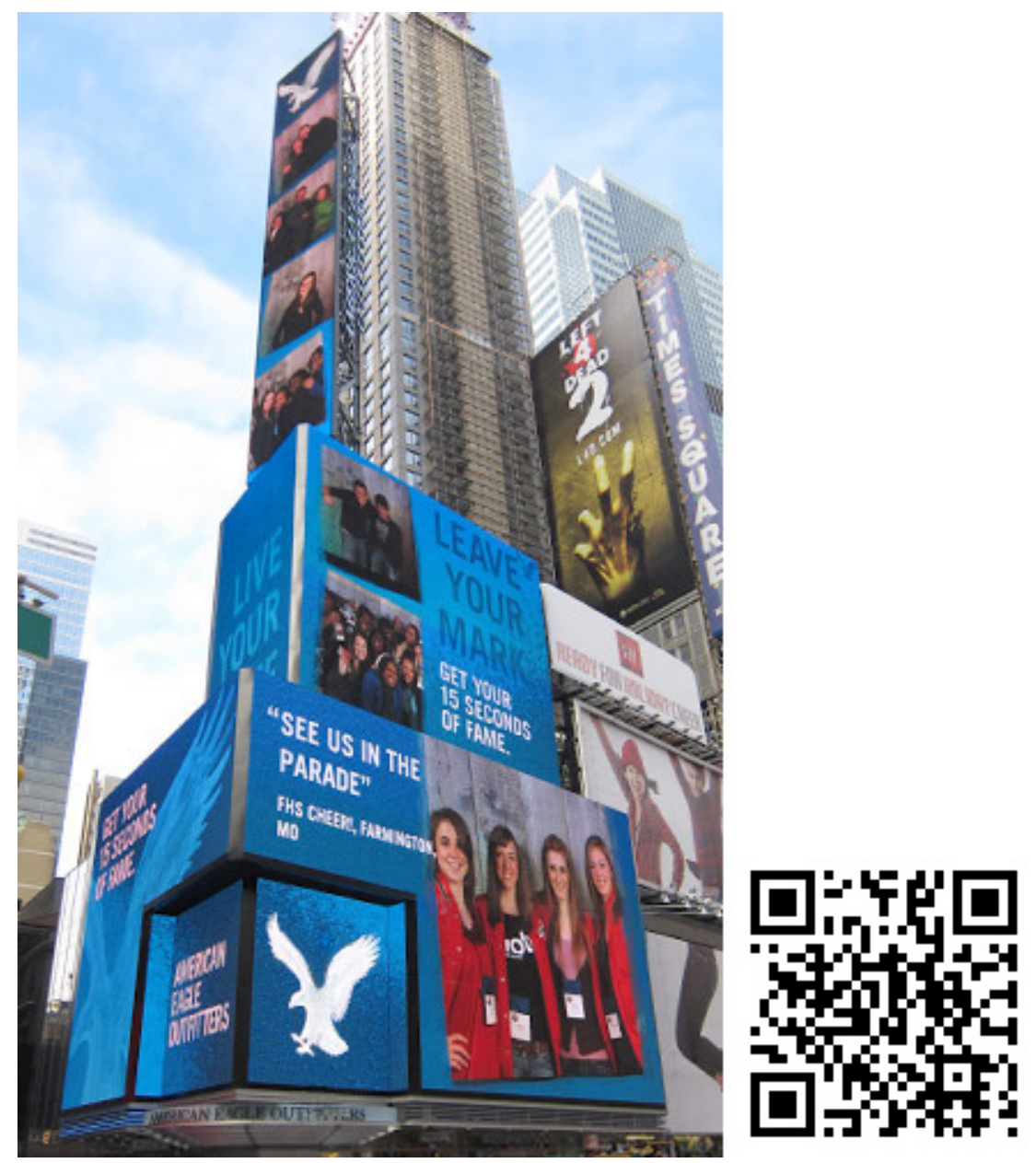

Figura 2.52 - Imagem do outdoor digital da campanha 15 Seconds of Fame no Times Square e QRcode de acesso a vídeo de um consumidor que gravou o outdoor funcionando. Fontes: foto <http://www.rga.com/news/release/2009/american-eagle-flagship> / vídeo <http://www.youtube.com/watch?v=PogpdJHpL4E>.

\section{Vídeo}

Uma das principais tendências é o vídeo. A evolução das tecnologias de vídeo na web, associada à disseminação de plataformas de publicação (como o Youtube) e consumo (como os celulares), tem alavancado a participação dos vídeos no ambiente digital. Algumas novas tecnologias trazem possibilidades inusitadas ao uso de vídeos, como: a) vídeo imersivo; b) game em vídeo; c) ad overlay e d) full screen. Veremos cada caso a seguir.

\section{Vídeo Imersivo}

A Figura 2.53 mostra um aplicativo de vídeo imersivo da Immersive Media 
$<$ www.immersivemedia.com> que permite passear por New York (como se fosse um vídeo game) usando controles de mouse e teclado. O QRcode dá acesso ao site do vídeo, que apresenta diversos outros exemplos de vídeos imersivos.
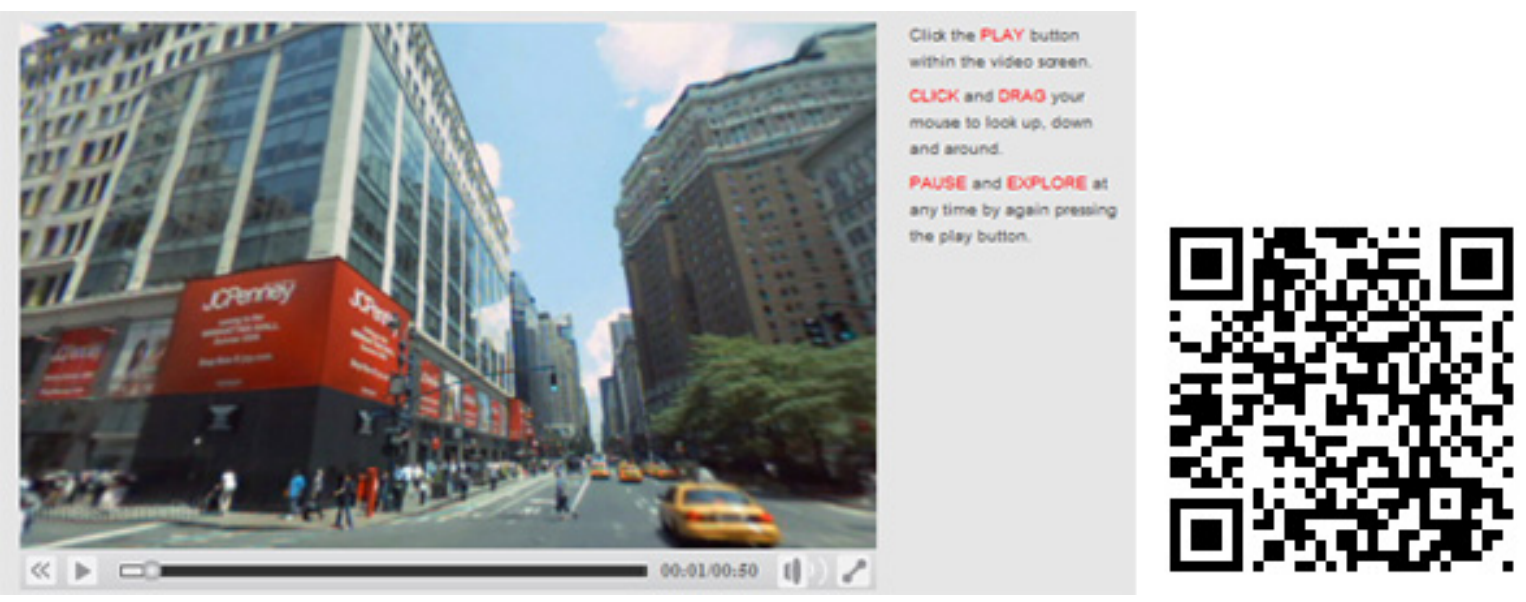

Figura 2.53 - Imagem de aplicativo vídeo imersivo que permite passear e explorar New York city. O QRcode dá acesso ao vídeo. Fonte: <www.immersivemedia.com/demos/index.php>.

\section{Vídeos interativos}

Novas possibilidades de interação com vídeo nas plataformas sociais do Youtube e do Vimeo surgem constantemente. Ações de vídeo que extrapolam o seu quadro de exibição e tomam a tela toda são chamados de Immersive Flash Video. Alguns exemplos são apresentados a seguir:

- Wario Land: Shake It!" <http://www.youtube.com/wariolandshakeit2008> - ação em vídeo no Youtube na qual o vídeo sacode e destrói a interface. Veja a Figura 2.54 com as imagens de início e final do vídeo. 

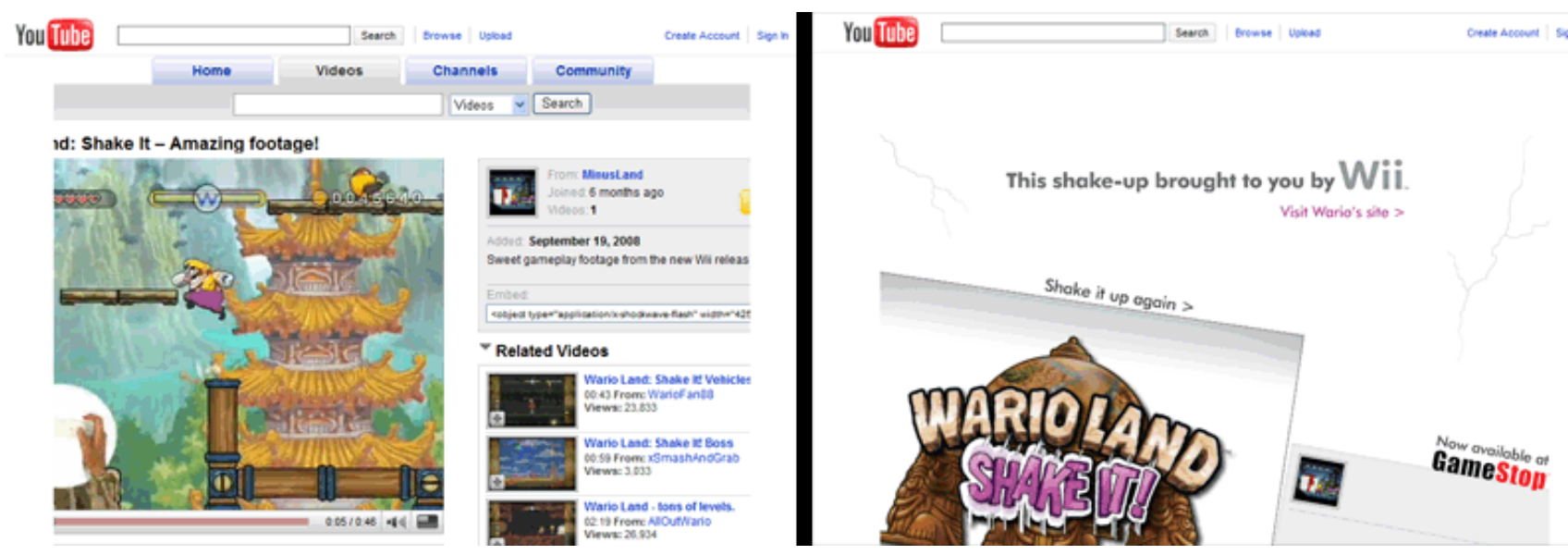

Figura 2.54 - Imagens do início e final do vídeo Wario Land: Shake It!, no Youtube. Fonte: <http://www.youtube.com/wariolandshakeit2008>.

- Let it Shine <http://vimeo.com/4281939> - ação em vídeo no Vimeo para a Honda, desenvolvida pela Wieden + Kennedy/Amsterdam, na qual o vídeo se expande e envolve a tela toda, interagindo com a interface.

- And Then There Was Salsa <http://vimeo.com/9194146> - ação no Vimeo, no início de 2010, que também toma conta da tela toda, com uma animação bastante rica e vívida de Goodby Silverstein, no ritmo de salsa.

Outra ação interessante de Immersive Flash Video, que vai além da interação entre o vídeo e a interface do Youtube ou do Vimeo, é o caso do vídeo interativo $A$ hunter shoots a bear (Fig. 2.55) da Tipp-Ex, no Youtube, lançado em agosto/2010. Nesse vídeo, além da interação entre o vídeo e a interface, ocorre também a interação com o usuário. A Tipp-Ex é uma marca de corretivos para texto, e, nessa ação, o caçador no vídeo, que inicialmente deveria atirar (shoot) em um urso, recusa-se a fazê-lo, usa o Tipp-Ex para apagar o termo "shoot" e pede para o interator digitar outra coisa pra ele fazer com o urso. Quando se digitam termos como "plays with", "loves", etc., outros vídeos dão sequência $a$ isso. 0 vídeo pode ser acessado em: <http://www.youtube.com/tippexperience>. 

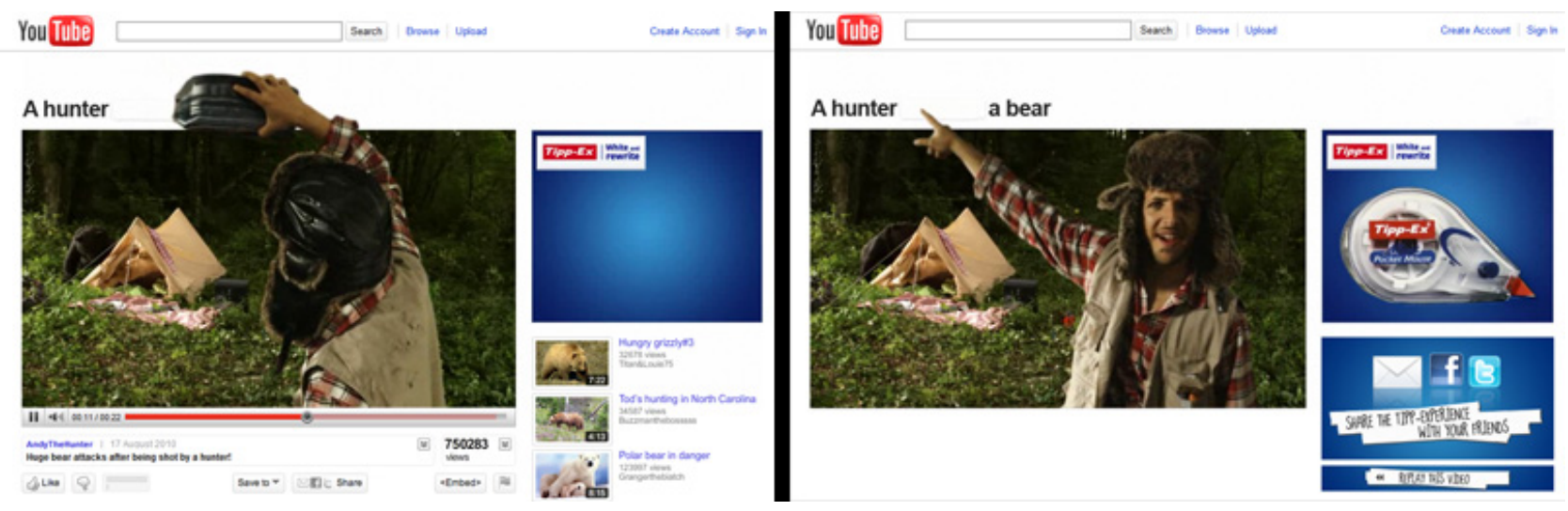

Figura 2.55 - Imagens do vídeo A hunter shoots a bear da Tipp-Ex no Youtube. Fonte: <http://www.youtube.com/tippexperience>.

\section{Youtube Games}

Além dos vídeos imersivos interativos e dos vídeos imersivos em Flash no Youtube e Vimeo, uma outra vertente interessante para ações com vídeos são os jogos em vídeo no Youtube.

Os jogos no Youtube são criados por meio das funções de anotações em vídeo ${ }^{55}$, que permitem criar tanto textos simples sobre o vídeo quanto links que apontem outros vídeos do Youtube. Dessa forma, usando-se a opção dos links, é possível desenvolver jogos com vídeos encadeados clicando-se esses links. Para assistir a um vídeo explicativo sobre as funcionalidades de anotação no Youtube, deve-se acessar o endereço <http://www.youtube.com/watch?v=UxnopxbOdic ou use o QRcode da Figura 2.56.

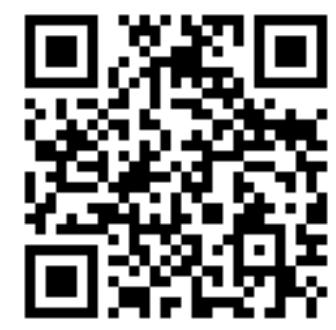

Figura 2.56 - QRcode de acesso ao vídeo How to use YouTube annotations. Fonte: <http://www.youtube.com/watch?v=UxnopxbOdic>.

\footnotetext{
${ }^{55}$ Para saber mais sobre anotações em vídeo, acessar: <http://www.youtube.com/t/annotations_about>.
} 
O primeiro Youtube game de que se tem notícia é o A Car's life, de 2008, que pode ser acessado em <http://www.youtube.com/watch?v=4ahyHfNqquQ>. Nesse jogo, o jogador precisa clicar nos links antes que o carro se destrua em cada fase. A cada clique, um novo vídeo é carregado, levando o jogador para a próxima etapa. A seguir, apresentamos alguns outros jogos que usam o mesmo tipo de técnica no Youtube:

- Bboy Joker <http://www.youtube.com/watch?v=GR3ywoc2Cp4> - jogo de desafio de breakdance entre os personagens Batman e Coringa.

- Can you beat the bell? <http://www.youtube.com/watch?v=lfDNoM2q9xc> - jogo de corrida entre dois personagens para ver quem consegue chegar sem atraso à escola (beat the bell).

- Desafio de Fotos do Oscar 2009 <http://www.youtube.com/watch?v=6Zj45rmDXWl> jogo das diferenças usando imagens de filmes que concorreram ao Oscar 2009.

- Shoot the Banker <http://www.youtube.com/watch?v=Jy3like8Y70> - jogo de atirar bolas em um banqueiro que fica provocando o interator.

- Super Mario Slots <http://www.youtube.com/watch?v=87vmdNm5eJE> - tradicional jogo de Super Mario.

- The Time Machine <http://www.youtube.com/watch?v=18rJ1WML60Y> - jogo de aventura com viagem no tempo.

- Youtube Street Fighter <http://www.youtube.com/watch?v=LPQ1XrllZmA> - tradicional jogo de street fight.

\section{Bens virtuais}

Bens virtuais existem já há bastante tempo em jogos e mundos virtuais, como o Second Life, esão responsáveis por boa parte do movimento da economia de alguns desses ambientes. No caso do Second Life, além da comercialização de ilhas no mundo virtual, carros e qualquer outro tipo de bem virtual que possa acrescentar valor à vida digital dos avatares são comercializados. A comercialização de corpos e acessórios para avatares, por exemplo, é bastante popular. Normalmente, bens virtuais são elementos digitais desejados pelos participantes de ambientes digitais e que precisam ser conquistados ou comprados. 
Uma nova vertente de entretenimento, os jogos sociais, como o FarmVille, por exemplo, associados à penetração mobile têm alavancado o interesse pelos bens virtuais. Enquanto o Second Life e os jogos tradicionais contam com públicos mais restritos, os jogos sociais ampliam enormemente a penetração dos jogos por meio das plataformas de redes sociais, e têm popularizado os bens virtuais. Assim, além do interesse econômico óbvio decorrente da comercialização dos bens virtuais nas redes sociais, a popularização dos jogos sociais também os torna plataformas interessantíssimas para experimentações.

\section{Games}

Os jogos são excelentes plataformas interativas que podem se beneficiar de quaisquer tecnologias digitais, como plataformas de redes sociais, realidade aumentada, mobilidade ou qualquer outra. O mercado de games movimenta 60 bilhões de dólares anuais (FOLHA, 2010), tem sido fortemente impactado pelas plataformas sociais e móveis e tem se beneficiado da realidade aumentada.

0 game em realidade aumentada 3D nas caixas do cereal Chocapic <http://www.youtube.com/watch?v=TzCMAgVrPFc> mostrado na Figura 2.49 é um excelente exemplo game que usa essa tecnologia.

No que se refere às plataformas sociais, elas têm impulsionado os jogos online, pois ampliam seu mercado para os usuários comuns das redes sociais. 0 mercado tradicional de jogos tem um público fiel, mas relativamente estagnado. Plataformas como o Facebook possibilitam que as pessoas utilizem suas redes sociais nesses sites para jogar, incentivando a prática. Jogos como Farmville, Mafia Wars, Pet Society e Restaurant City são sucessos no Facebook. O jogo Colheita Feliz, equivalente ao Farmville do Facebook, é sucesso no Orkut. Esses jogos em plataformas de redes sociais são os chamados social games ou jogos sociais. Segundo uma matéria no Estadão (ESTADÃO, 2010), 20\% dos americanos já jogaram algum jogo social; desses, 35\% são novos no meio e nunca haviam jogado um jogo virtual antes. Esse grupo é composto, na maioria, por mulheres e idosos, o que mostra a disseminação desse tipo de jogo por diversas segmentações demográficas. Segundo dados do IBOPE (IBOPE, 2010), no Brasil, dos 7,2 milhões de usuários que estiveram no Facebook em dezembro de 2009, 32\% participaram de algum jogo social.

O jogo social traz uma nova dimensão tanto às redes sociais quanto aos games - estamos 
vivenciando uma 'gameificação' das redes sociais e uma sociabilização dos games.

No que se refere aos jogos, uma das principais limitações dos games tradicionais de computador é que é necessária para se jogar de forma confortável com boa performance, uma máquina mais poderosa. Os games sociais, no entanto, funcionam em máquinas bem mais simples, possibilitando que virtualmente qualquer pessoa que tenha acesso às plataformas de redes sociais online também possam jogar um game social. Isso amplia, portanto, o público que pode jogar. Quanto às plataformas de redes sociais online, antes dos jogos sociais as pessoas tinham como atividade apenas as trocas de informações, e a competição ficava restrita somente à comparação da quantidade de amigos que as pessoas tinham em seus perfis. Com os jogos sociais, as pessoas competem e colaboram umas com as outras, em uma atividade contínua e viciante. Estudos mostram que muitos usuários desses jogos acordam de madrugada para manter as atividades no game. Dessa forma, os jogos sociais não apenas ampliam o público de games como também modificam a rotina dos usuários nas redes sociais, alavancando engajamento.

Podemos questionar se esse tipo de comportamento emergente decorrente dos jogos sociais é bom para a sociedade, mas não podemos negar que ele é altamente benéfico para o negócio de games.

A Figura 2.57 apresenta os 25 jogos sociais mais populares no Facebook, segundo a Inside Social Games ${ }^{56}$ em agosto de 2010.

${ }^{56}$ Fonte: <http://www.insidesocialgames.com/2010/08/02/top-25-facebook-games-for-august-2010/>. 


\begin{tabular}{|c|c|c|c|c|c|c|}
\hline Rank & & Game & Monthly Actives & Developer & MAU Change & (Last Month) \\
\hline 1 & 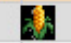 & FarmVille & $59,755,656$ & Zynga & $-3,757,866$ & $63,513,522$ \\
\hline 2 & 9 & Texas HoldEm Poker & $40,536,552$ & Zynga & $11,812,898$ & $28,723,654$ \\
\hline 3 & $\mathrm{~S}$ & Café World & $34,393,017$ & Zynga & $13,861,844$ & $20,531,173$ \\
\hline 4 & $\bar{M}$ & Mafia Wars & $31,167,271$ & Zynga & $12,779,846$ & $18,387,425$ \\
\hline 5 & 5 & FrontierVille & $24,235,212$ & Zynga & $10,516,150$ & $13,719,062$ \\
\hline 6 & a & PetVille & $18,095,681$ & Zynga & $3,144,383$ & $14,951,298$ \\
\hline 7 & M & Treasure Isle & $17,297,179$ & Zynga & $-3,904,367$ & $21,201,546$ \\
\hline 8 & 3 & MindJolt Games & $16,311,751$ & MindJolt & $-3,042,472$ & $19,354,223$ \\
\hline 9 & Bu & Pet Society & $13,857,212$ & Playfish & $-660,593$ & $14,517,805$ \\
\hline 10 & ) & Zoo World & $12,602,258$ & RockYou & $2,935,029$ & $9,667,229$ \\
\hline 11 & 跑 & Restaurant City & $12,392,422$ & Playfish & $1,424,371$ & $10,968,051$ \\
\hline 12 & $\nabla$ & Bejeweled Blitz & $12,240,072$ & PopCap Games & $2,008,075$ & $10,231,997$ \\
\hline 13 & 的 & Happy Aquarium & $12,090,318$ & CrowdStar & $-1,030,604$ & $13,120,922$ \\
\hline 14 & F & Birthday Cards & $11,142,168$ & RockYou & $-7,577,673$ & $18,719,841$ \\
\hline 15 & 9 & FishVille & $9,262,565$ & Zynga & $-3,710,756$ & $12,973,321$ \\
\hline 16 & 商 & Social City & $8,920,363$ & Playdom & $-1,017,171$ & $9,937,534$ \\
\hline 17 & $\overrightarrow{2}$ & Happy Island & $8,879,556$ & CrowdStar & $1,122,857$ & $7,756,699$ \\
\hline 18 & $\Rightarrow$ & YoVille & $8,802,174$ & Zynga & $-1,395,570$ & $10,197,744$ \\
\hline 19 & 8 & Happy Pets & $7,612,158$ & CrowdStar & $-52,840$ & $7,664,998$ \\
\hline 20 & 圈 & Hotel City & $7,611,692$ & Playfish & $-1,431,591$ & $9,043,283$ \\
\hline 21 & & Family Feud & $6,843,074$ & iWin \& Backstage & $-204,575$ & $7,047,649$ \\
\hline 22 & 急 & Country Life & $5,663,862$ & Country Life & $-1,109,698$ & $6,773,560$ \\
\hline 23 & $\vec{\alpha}$ & Ninja Saga & $5,345,599$ & Ninja Saga & $-294,402$ & $5,640,001$ \\
\hline 24 & $\sqrt{9}$ & Farm Town & $5,290,586$ & Slashkey & $-993,256$ & $6,283,842$ \\
\hline 25 & 兼 & Nightclub City & $5,257,658$ & Booyah & N/A & N/A \\
\hline
\end{tabular}

InsideSocialGames.com

Figura 2.57 - Tabela dos Top 25 social games no Facebook, segundo a Inside Social Games, em agosto/2010. Fonte: <InsideSocialGames.com>.

Os jogos sociais alavancam a economia de bens virtuais associados a eles. As pessoas conseguem bens virtuais para avançar nas etapas dos jogos usando dois tipos de moeda: a) mérito e habilidade do jogador, que geram dinheiro virtual para a compra de bens virtuais; b) cartão de crédito internacional, que permite a compra de bens virtuais gastando alguns dólares. O lucro anual dos jogos sociais em 2010 foi de US\$ 835 milhões, conforme previsões da InsideVirtualGoods, e esse valor pode ultrapassar os US\$ 2 bilhões, conforme a ThinkEquity (UOL JOGOS, 2010).

A evolução e penetração da tecnologia móvel também estão revolucionando o mercado de games, pois ampliam também a plataforma de utilização dos jogos. Enquanto os dispositivos móveis do passado apresentavam diversas restrições de hardware e era raro que se conectassem à internet, a disseminação atual dos smartphones, associada à penetração e melhorias na banda larga móvel, tem alavancado o uso de jogos nos 
celulares, via aplicativos que se conectam com a plataforma online, permitindo assim, também, a socialização desses jogos. De acordo com a empresa de pesquisa iSuppli (FOLHA, 2010), o volume de vendas de celulares que podem ser usados para jogos deve crescer em um terço, chegando a 1,53 bilhão de unidades em 2013.

Alguns artigos que trazem informações adicionais sobre a expansão do mercado de games, tanto nas plataformas sociais quanto mobile estão relacionados a seguir.

- Electronic Arts alerta para mudanças no universo de videogames <http://www1.folha.uol.com.br/tec/783659-electronic-arts-alerta-para-mudancas-nouniverso-de-videogames.shtml>.

- Com lucro de US\$ 835 milhões, jogos sociais ampliam mercado de games <http://jogos.uol.com.br/playstation2/ultnot/2010/06/24/ult530u7901.jhtm>.

- Jogos Sociais: Padrões de Interação e Consumo - apresentação de Thiago Falcão no Slideshare <http://www.slideshare.net/falc4o/jogos-sociais-padres-de-interao-e-consumo>.

Este capítulo teve como objetivo introduzir e apresentar as principais plataformas e tecnologias digitais, atuais e emergentes, mostrando a ampliação de opções midiáticas, de interação, de comunicação, de integração, etc.

O intuito aqui não é esgotar as possibilidades tecnológicas possíveis ou aprofundar no conhecimento específico de cada uma delas - o que seria impossível -, mas mostrar a diversidade e complexidade do cenário tecnológico que emerge e se dissemina na vida cotidiana das pessoas. Os processos transmidiáticos utilizam as plataformas e mídias disponíveis - digitais ou não - e, assim, a miríade de possibilidades tecnológicas que emerge e sua inerente complexidade oferecem novas formas de experimentação e desenvolvimento transmídia. 


\section{CAPÍTULO III - TRANSMÍDIA E CONVERGÊNCIA}

Com a proliferação e penetração das plataformas e mídias digitais no cotidiano das pessoas, misturando-se às plataformas e mídias tradicionais, dois fenômenos importantes passaram a acontecer intensamente: a transmídia e a convergência. Apesar de esses fenômenos não serem novidades, eles se tornam bastante relevantes no cenário atual permeado de tecnologias, encontrando, assim, o ambiente propício para a sua ampla disseminação e experimentação, permitindo a ampliação das possibilidades artísticas e potencializando e integrando pontos de interação.

No nosso contexto atual, provavelmente estejamos vivendo a maior revolução das comunicações da história, como argumenta Manovich (2001, p.19):

É provável que assim como a imprensa no século 14 e a fotografia no século 19 tiveram um impacto revolucionário no desenvolvimento da sociedade e cultura modernas, hoje estamos no meio de uma revolução de novas mídias - a mudança de toda a cultura para formas de produção, distribuição e comunicação, mediadas por computador. Esta revolução é discutivelmente mais profunda que as anteriores, e estamos apenas começando a registrar seus efeitos iniciais. Sem dúvida, a introdução da imprensa afetou apenas um estágio da comunicação cultural - a distribuição de mídia. De modo semelhante, a introdução da fotografia afetou apenas um tipo de comunicação cultural - as imagens paradas. Em contraste, a revolução computacional das mídias afeta todos os estágios da comunicação, incluindo a aquisição, manipulação, armazenamento e distribuição; ela afeta também todos os tipos de mídia - textos, imagens paradas, imagens em movimento, som e construções espaciais.

As novas mídias representam o encontro de duas trajetórias históricas separadas: o computador (no seu sentido original, enquanto máquina de processar dados numéricos) e as tecnologias de mídia. As duas começaram por volta de 1830, e a síntese dessas duas histórias resultou na tradução de todos os tipos de mídias existentes em dados numéricos acessíveis por computadores. O resultado é a nova mídia - gráficos, imagens em movimento, sons, formas, espaços e textos que se tornaram computáveis; isto é, ela é composta simplesmente de outro conjunto de dados computacionais (MANOVICH, 2001: p.20).

As tecnologias afetam e guiam nossa percepção e o modo como agimos no mundo. Friedrich Nietzsche costumava dizer que a máquina de escrever influenciou profundamente seu modo de pensar e escrever. Einstein dizia que seu lápis fazia cálculos mais rápidos que sua mente. Marshal McLuhan também refletiu sobre o 
impacto das tecnologias no ser humano, afirmando que "nós moldamos as nossas

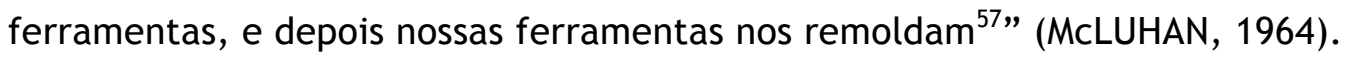

Johnson (2001) defende o mesmo ponto de vista em relação às interfaces de computadores e chama a atenção para o fato de que elas transformam o modo como criamos e nos comunicamos - se a metáfora da interface do computador fosse outra que não uma escrivaninha, provavelmente pensaríamos de outra maneira. Também Pierre Lévy refere-se à grande influência que as tecnologias exercem sobre nosso modo de agir e pensar ao afirmar que

[...] diversos trabalhos desenvolvidos em psicologia cognitiva a partir dos anos sessenta mostraram que a dedução ou a indução formais estão longe de serem praticadas espontaneamente e corretamente por sujeitos reduzidos apenas aos recursos de seus sistemas nervosos (sem papel, nem lápis, nem possibilidade de discussão coletiva). (LÉVY, 1993: p.152).

Assim, toda tecnologia introduzida no ambiente nos afeta e modifica; somando-se a isso a proliferação tecnológica em que vivemos hoje (como apresentado no capítulo 2) e o ritmo vertiginoso em que isso ocorre, podemos afirmar que as transformações humanas nunca aconteceram em um ritmo tão acelerado.

Toda nova tecnologia ou forma de interação homem-computador, portanto, causa consequentes impactos na experimentação artística. No entanto, é importante observar, conforme Machado, que "a multiplicação do aparato tecnológico à nossa volta pode nos dar a falsa impressão de que estamos experimentando algo novo, quando na verdade nós podemos não estar experimentando coisa alguma" (MACHADO, 2001, p.13). A simples introdução de uma nova tecnologia não significa necessariamente uma explosão criativa possibilitada por meios cada vez mais avançados, sendo portanto necessário saber distinguir o trabalho do verdadeiro criador, de um lado, da tarefa do mero funcionário das máquinas, de outro (MACHADO, 2001, p.14).

Além disso, um outro aspecto que deve ser considerado na introdução das novas tecnologias no contexto atual é que toda nova tecnologia traz consigo efeitos colaterais que, em geral, são inicialmente desconsiderados $m$ razão do

\footnotetext{
${ }^{57}$ Frase original em inglês: "We shape our tools and thereafter our tools shape us."
} 
deslumbramento que as novas possibilidades sedutoras promovem. Um exemplo que ilustra bem isso é a lenda que Sócrates contou a Fedro - "O Julgamento de Tamuz":

$\mathrm{Na}$ região de Náucratis, no Egito, houve um dos velhos deuses daquele país [...], chamava-se Thoth. Foi ele que inventou os números e o cálculo, a geometria e a astronomia, o jogo de damas e os dados, e também a escrita. Naquele tempo governava todo o Egito, Tamuz, que residia no sul do país, na grande cidade que os egípcios chamam Tebas do Egito [...]. Thoth foi ter com ele e mostrou-lhe as suas artes, dizendo que elas deviam ser ensinadas aos egípcios. Mas o outro quis saber a utilidade de cada uma, e enquanto o inventor explicava, ele censurava ou elogiava, conforme essas artes the pareciam boas ou más. Dizem que Tamuz fez a Thoth diversas exposições sobre cada arte, condenações ou louvores cuja menção seria por demais extensa. Quando chegaram à escrita, disse Thoth: "Esta arte, caro rei, tornará os egípcios mais sábios e lhes fortalecerá a memória; portanto, com a escrita inventei um grande auxiliar para a memória e sabedoria". Responde Tamuz: "Grande artista Thoth! Não é a mesma coisa inventar uma arte e julgar da utilidade ou prejuízo que advirá aos que a exercerem. Tu, como pai da escrita, esperas dela com o teu entusiasmo precisamente o contrário do que ela pode fazer. Tal coisa tornará os homens esquecidos, pois deixarão de cultivar a memória; confiando apenas nos livros escritos, só se lembrarão de um assunto exteriormente e por meio de sinais, e não em si mesmos. Logo, tu não inventaste um auxiliar para a memória, mas apenas para a recordação. Transmites aos teus alunos uma aparência de sabedoria, e não a verdade, pois eles recebem muitas informações sem instrução e se consideram homens de grande saber, embora sejam ignorantes na maior parte dos assuntos. Em conseqüência, serão desagradáveis companheiros, tornar-se-ão sábios imaginários ao invés de verdadeiros sábios". (SÓCRATES, 2002, p.118-119).

É interessante observar, na história acima, que não é apenas o inventor Thoth que está errado, quando supervaloriza sua invenção, mas também Tamuz, em seu julgamento e crença de que a escrita será um fardo, e nada mais do que um fardo, para a sociedade. Ele falha ao não imaginar quais poderiam ser os benefícios da escrita, que, como sabemos, têm sido consideráveis (POSTMAN, 1992: p.14). A invenção da escrita liberou o homem da tradição oral, separando a voz da presença real, cristalizando palavras e permitindo a propagação do conhecimento para além dos limites de sua encarnação.

Portanto, toda nova tecnologia tanto é uma uma benção como um fardo - o surgimento de novas possibilidades com a introdução das tecnologias e plataformas digitais é inegável, no entanto, estas são apenas novas ferramentas à disposição do artista, a quem cabe a imutável função de explorar novas possibilidades criativas e os limites dos novos meios.

A proliferação tecnológica também amplia as possibilidades de criação de processos de hibridação, convergências e transmidiáticos, como veremos a seguir, e esses processos, por sua vez, dão origem a novas formas tecnológicas que também nos afetam e transformam. 
Veremos a seguir os processos de hibridação, convergência e transmídia.

\section{1 - Hibridação e Convergência}

Existem diversas definições de 'hibridação' e 'convergência', dependendo da área de estudo de origem, mas em muitos casos são tidas como equivalentes. Apesar de na botânica 'hibridação' envolver questões de esterilidade do híbrido gerado, e 'convergência' relacionar-se com a tendência de membros de uma população se tornarem iguais, tanto um termo quanto o outro definem processos em que duas ou mais entidades quaisquer, sejam elas seres, mídias, dados, etc., juntam-se ou misturam-se de algum modo.

Assim, tanto 'hibridação' como 'convergência' têm sido usadas sem distinções, , nas mais diversas áreas, frequentemente para designar combinações. No caso das novas mídias, é comum encontrar menções tanto à 'convergência de mídias' quanto à 'hibridação de mídias'. O mesmo ocorre com hibridação/convergência de dados, de equipamentos, etc. Assim sendo, em razã da interpenetração dos termos, 'hibridação' e 'convergência' serão considerados equivalentes nesta pesquisa, representando processos de junção ou mistura de entidades e/ou códigos.

Na mais básica essência, da recombinação dos códigos atômico, numérico e genético, podemos gerar todos os tipos de hibridizações e convergências possíveis. No entanto, acredita-se que essas recombinações podem ocorrer em diversos níveis. Por um lado, no nível mais intrínseco das recombinações, podemos misturar os elementos formadores dos seres, no plano de seus códigos básicos - quer sejam atômicos, numéricos ou genéticos -, como recombinações de DNA, por exemplo, no código genético, que geram seres com novas características decorrentes da mudança do seu código essencial.

No extremo oposto, no nível mais extrínseco das recombinações, podemos misturar seres inteiros em meios diferentes sem alterar seus códigos básicos formadores, como no caso da convergência digital de mídias, onde entes digitais inteiros, provenientes de diversas mídias distintas, trafegam e são disponibilizados juntos em um outro dispositivo e/ou mídia diferente. Nesse caso, não modificamos o código essencial de cada entidade, apenas as 'transportamos' para outro contexto. 
Segundo IThiel de Sola Pool (JENKINS, 2006, p.37), considerado o pai da convergência dos meios de comunicação:

Um processo chamado "convergência de modos" está tornando imprecisas
as fronteiras entre os meios de comunicaçãoo, mesmo entre as
comunicações ponto a ponto, tais como o correio, o telefone e o
telégrafo, e as comunicação de massa, como a imprensa, o rádio e a
televisão. Um único meio físico - sejam fios, cabos ou ondas - pode
transportar serviços que no passado eram oferecidos separadamente. De
modo inverso, um serviço que no passado era oferecido por um único meio
- seja a radiodifusão, a imprensa ou a telefonia - agora pode ser
oferecido de várias formas físicas diferentes. Assim, a relação um a um
que existia entre um meio de comunicação e seu uso está se corroendo.

Nas convergências de mídia, conforme Zuffo (2005, p.72), “as redes de comunicação de dados, computadores, radiodifusão e televisão difusora, radiocomunicação, telefonia fixa e celular, sistemas de gravação e reprodução de vídeo e som tenderiam, e tendem, a serem combinadas e colocadas em um único, ou mesmo distribuídas, em poucos tipos de equipamentos".

No senso comum, convergência de mídias é o resultado do desenvolvimento de padrões tecnológicos e de comunicação capazes de integrar os padrões de diferentes aparelhos, aplicativos, mídias e ambientes em uma mesma plataforma. Entende-se por convergência de mídias, especificamente, a integração numa mesma plataforma das diferentes formas de mídia, como televisão, computador, telefone, PDA - Personal Digital Assistent - em geral (como palm tops), rádio e Web, entre outras. A convergência é um atributo de padrões de comunicação, a partir de uma plataforma, independentemente de qual plataforma seja. Poderíamos dizer, então, que na convergência de mídias o foco da recombinação está mais nas mídias do que nas entidades em que elas trafegam.

Ainda nas recombinações extrínsecas, poderíamos pensar também em processos de hibridação e convergência que ocorrem entre os códigos básicos formadores atômico, numérico e genético -, ou seja, relacionando os códigos entre si. Nesse processo, podemos ter uma 'tradução' completa de um código em outro ou uma 'colaboração' entre códigos. No primeiro caso - tradução -, podemos citar como exemplo a digitalização de um desenho em papel para arquivo digital, num processo de convergência no qual uma entidade de código atômico passa para o código numérico e pode, a partir daí, recombinar-se com qualquer outra entidade numérica 
ou digital, em outros processos de recombinações. Já no segundo caso - colaboração -, acontece um processo de transmídia, e não mais de convergência, como veremos a seguir. Um exemplo de colaboração transmídia são os cibridismos, em que entidades atômicas e digitais se complementam, existindo por meio de dois códigos. Como visto anteriormente no capítulo 1, segundo Anders:

Cíbridos - híbridos de material e ciberespaço - são entidades que não poderiam existir sem reconciliar a nova classe de símbolos com a materialidade que eles carregam. [...] Cíbridos são mais que simplesmente uma separação completa (entre material e simbólico). Entre esses dois podemos ter componentes compartilhados. (ANDERS, 2001).

Portanto, por meio das recombinações nos códigos formadores essenciais das entidades ocorrem os processos de hibridação e convergência, em diversos níveis - intrínseco e extrínseco (e até tradução).

Nas artes, esses processos de recombinação já ocorriam anteriormente com a imagem, o verbo e mesmo a música. No entanto, eram ainda limitados, pelas restrições tecnológicas, que, conforme vão desaparecendo, ampliam as possibilidades combinatórias.

Analisando as possibilidades de convergências e hibridizações mencionadas, verificamos que podemos gerar tanto intermídias como multimídias, dependendo do tipo de emergência resutante do processo, conforme Júlio Plaza:

No movimento constante de superposição de tecnologias sobre tecnologias, temos vários efeitos, sendo um deles a hibridação de meios, códigos e linguagens, que se superpõem e se combinam em processos chamados intermídia e multimídia [...] Num primeiro caso, a montagem de vários deles pode fazer surgir outro que é a soma qualitativa daqueles que o constituem. Neste caso, a hibridação produz um dado inusitado, que é a criação do novo meio antes inexistente, temos assim processos de coordenação (sinergia) entre linguagens e meios, uma intermídia. Uma segunda possibilidade é superpor diversas tecnologias, sem que a soma resolva o conflito [...] resultando então numa espécie de collage que se conhece como multimídia. (PLAZA, 2000).

O conceito de hibridação, para Plaza, conforme citado, abrangeria também o conceito de metamídia, definido por Manovich (2002): “re-mapear objetos de mídias antigas em novas estruturas através de software computacional, transformando, portanto a mídia em uma meta-mídia". Na metamídia, cada objeto de mídia antiga preserva e mostra suas origens. A peculiaridade das metamídias é que o mapeamento dos objetos da mídia antiga em novas estruturas através de software computacional acrescenta 
funcionalidades de novas mídias aos objetos da mídia antiga, tais como zoom, busca, filtros, múltiplas vistas, etc.

Considerando-se que "A cultura telemática diz respeito à conectividade global das pessoas, dos lugares, mas acima de tudo, da mente. A Internet é a infra-estrutura crua de uma consciência emergente, um cérebro global”, conforme Ascott (1997), poderíamos especular aqui que as tecnologias digitais acrescentam neurônios ao corpo hipertextual do cérebro global.

Poderíamos dizer também que, além de as tecnologias e plataformas digitais ampliarem as possibilidades de convergência e hibridação, elas também acrescentam potencialidades à estética da aparição em emergência no mundo-mente (World-mind) descrito ainda por Ascott (1997).

Em razão da facilidade inerente às mídias digitais de se misturarem, a convergência ocorre principalmente nos dispositivos digitais. 0 exemplo mais comum de convergência de mídia é o telefone celular. Os smartphones convergem vídeo, áudio, voz, imagem, dados e, recentemente, TV. Outro exemplo são os pacotes de TV a cabo, que inicialmente ofereciam apenas o serviço de canais de televisão pagos e, hoje, oferecem uma multiplicidade de novos serviços (tecnologias, mídias), como telefone e acesso à internet por banda larga.

Dessa forma, a convergência permite que a mesma mensagem/conteúdo seja consumida em diversas plataformas diferentes de mídia, tendo, portanto, como característica fundamental, a portabilidade.

Outra consequência da convergência é que o resultado das combinações de tecnologias/mídias convergentes também nos afeta e nos transforma de um modo diferente do que o faz cada tecnologia/mídia individualmente. Assim, cada tecnologia emergente nos modifica, e os processos de combinação entre elas também. Por exemplo, o smartphone, que tem alterado profundamente o modo como vivemos e nos relacionamos uns com os outros, combina várias tecnologias. Individualmente, cada uma dessas tecnologias convergidas em um smartphone nos transforma de algum modo (como a câmera fotográfica embutida neles), no entanto, a combinação de todas as tecnologias/mídias juntas geram um novo impacto tecnológico referente ao conjunto do smartphone, que nos modifica de maneira distinta. 
No livro A Cultura da Convergência (JENKINS,2006), Henry Jenkins afirma que "a convergência está modificando o modo como criamos, consumimos, aprendemos e interagimos uns com os outros". Um exemplo disso é o modo como a convergência das redes sociais digitais no celular tem aumentado o seu uso (tanto das redes quanto do celular), gerando, até mesmo, novas formas de interação, como as baseadas em geolocalização. Outro exemplo é o aumento das vendas de aparelhos de TV que podem ser conectados à internet. Uma pesquisa da agência iSuppli em janeiro/2010 revela que $27,5 \%$ dos consumidores americanos que compraram um aparelho de TV declararam que esses aparelhos conectavam-se à internet. Isso mostra que, além de assistirem aos programas tradicionais da mídia televisiva, os consumidores também estão usando o mesmo aparelho de TV para acessar serviços de redes sociais de vídeo como o YouTube ou serviços online como o Hulu (ISUPPLI, 2010).

\section{III.2. Transmídia}

Transmídia é o termo usado para definir a utilização integrada das mídias de forma que uma estória ou mensagem ultrapasse os limites de um único meio.

Enquanto a convergência ocorre quando tecnologias que eram anteriormente usadas de forma separada (como voz, vídeo, dados etc.) passam a compartilhar o mesmo meio e interagem umas com as outras de forma sinergética, criando novas funcionalidades, a transmídia envolve o processo contrário - ela ocorre quando um conteúdo é distribuído por diversas mídias, de quaisquer naturezas (analógicas ou digitais, on ou off).

Segundo Jenkins (2006),

uma narrativa transmídia é aquela que "se desenrola através de múltiplas plataformas de mídia, com cada novo texto contribuindo de maneira distinta e valiosa para o todo. Na forma ideal de narrativa transmídia, cada meio faz o que faz de melhor, a fim de que uma história possa ser introduzida num filme, ser expandida pela televisão, romances e quadrinhos; seu universo possa ser explorado em games ou experimentado como atração de um parque de diversões. Cada acesso à franquia deve ser autônomo, para que não seja necessário ver o filme para gostar do game, e vice-versa. Cada produto determinado é um ponto de acesso à franquia como um todo. A compreensão obtida por meio de diversas mídias sustenta uma profundidade de experiência que motiva mais consumo.

A definição de narrativas transmídia de Jenkins foca o mercado, em que "franquia" 
refere-se a uma marca, como "The Matrix", por exemplo, envolvendo vários produtos e processos de mídia. O mesmo conceito pode ser usado em artes, engenharia ou quaisquer outras áreas do conhecimento, adaptando-se o significado de "franquia".

$\mathrm{Na}$ engenharia, por exemplo, conforme Lúcia Filgueiras (2008), transmídia ${ }^{58}$ é definida como “o suporte colaborativo de múltiplas mídias para entregar uma única estória ou tema, na qual a narrativa direciona o receptor de um meio para o próximo, conforme a força de cada meio para o diálogo". As características da transmídia requerem que mais de uma mídia seja envolvida para suportar a mensagem/estória/narrativa, e que a distribuição ou suporte da mensagem/estória/narrativa intencionalmente se estenda pelas diferentes mídias (BOUMANS, 2004).

Apesar de ser um termo novo, a transmídia acontece desde a era pré-web. Conforme as mídias foram se desenvolvendo, também foram aumentando as possibilidades transmídia. A Figura 3.1 mostra de forma ilustrativa a evolução das mídias.

${ }^{58} \mathrm{Na}$ engenharia, o termo 'crossmídia' é usado como sinônimo de transmídia. Essa definição usa os termos "transmídia ou crossmídia". No entanto, no contexto do presente trabalho, usaremos apenas o termo transmídia para não causar confusão entre ‘crossmídia' e 'multimídia’, como tratado por Pierre Lévy. 


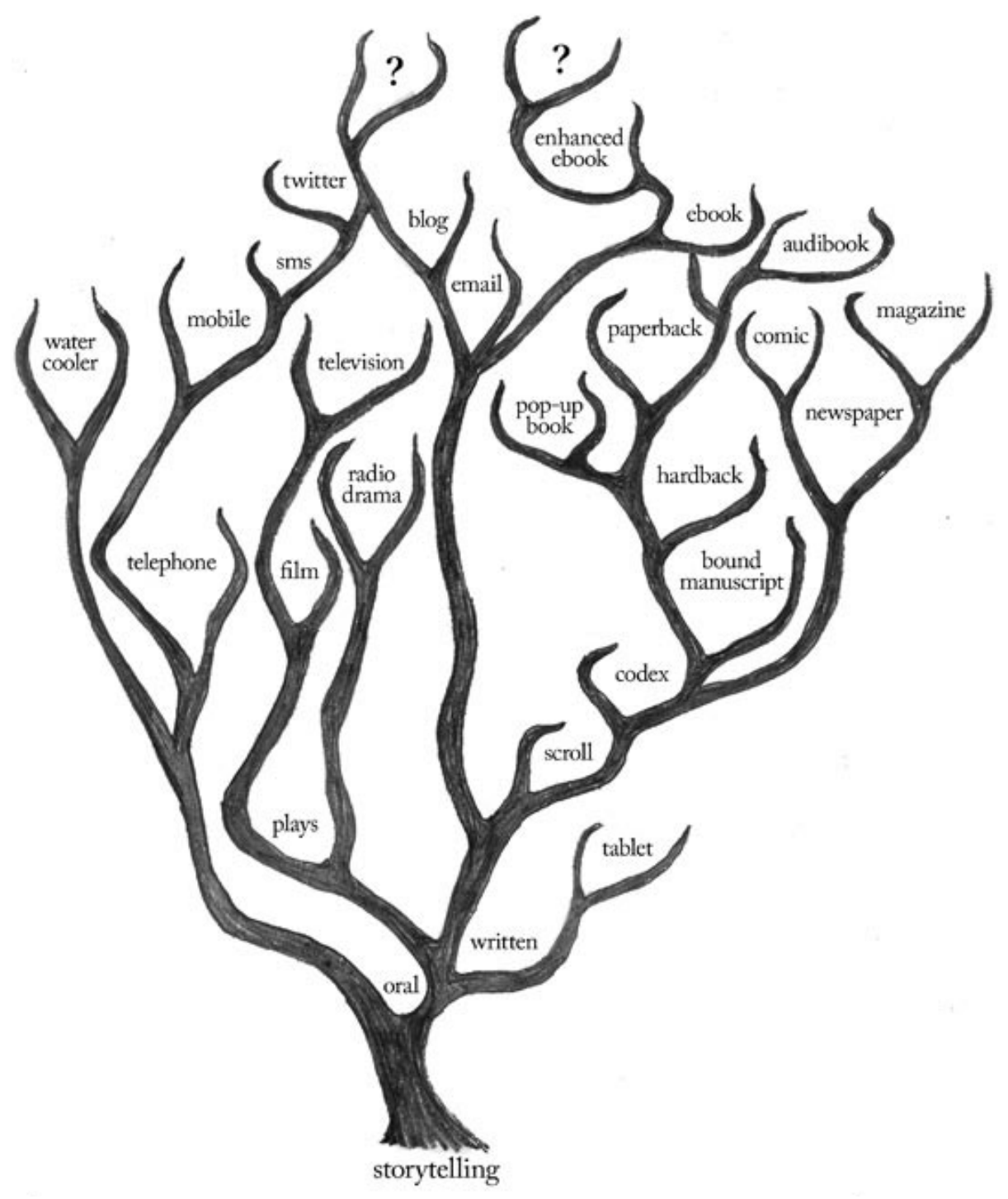

Figura 3.1 - Imagem da imagem Abundance through evolution. Fonte:

<http://www.dare.co.uk/narrative/storytelling-in-abundance/>. Acesso em: 11.jun.2012.

As novelas, antes das mídias digitais, são um exemplo interessante de transmídia. Se pensarmos nos anos 70, por exemplo, cada capítulo de novela que era ou seria veiculado na televisão repercutia também em revistas e rodas de conversas sobre o enredo, os atores, suas vidas, o tangenciamento com os personagens, ramificando-se de forma a criar um contexto maior. Assim, conforme as mídias e tecnologias evoluem, ocorre o mesmo com as possibilidades. Com a explosão das plataformas digitais, há uma explosão de opções para a criação de processos transmidiáticos.

Como o conceito de transmídia envolve a utilização de mais de uma mídia para 
suportar uma mensagem/estória/objetivo, ela pode envolver, no caso das mídias digitais, diversas interfaces (uma em cada mídia) distribuídas pelo processo; por isso, os processos transmidiáticos são 'interfaces distribuídas' por diversos sistemas que as suportem e deem continuidade à estória/mensagem/narrativa. A definição de 'sistemas distribuídos' deixa claro que cada parte do processo deve ser completo e coerente para o usuário:

A distributed system is a piece of software that ensures that: a collection of independent computers that appears to its users as a single coherent system. (GSU, 2003).

Veremos no próximo capítulo as questões referentes à maneira pela qual o conteúdo artístico trafega e utiliza as interfaces distribuídas.

O uso do conceito de transmídia não se restringe aos meios digitais. A conversa entre pessoas, o jornal, a revista, o livro, a fotografia, o cinema, a televisão, as páginas na internet são exemplos de formas que permitem a criação e distribuição de mensagens transmídia. Um exemplo de uso de transmídia no marketing é a campanha da Victoria Secret em 1999 durante a final do Super Bowl (CNN MONEY, 1999), que detém a maior audiência televisiva mundial. Durante o último intervalo do jogo foi veiculado um comercial da Victoria Secret anunciando que, após o jogo, aconteceria na internet o desfile da nova coleção de lingeries. Quando o jogo terminou, uma grande parte da audiência televisiva do Super Bowl migrou para o site da Victoria Secret na internet para ver o desfile. Dessa forma, uma ação que começou numa mídia tradicional, a televisão, continuou por meio de uma mídia digital, um website na internet, ampliando e e dando continuidade à entrega da mensagem/história, pela ação intencional do comercial de chamar a audiência para continuar a interação em outra mídia, com outro conteúdo, característico daquela plataforma.

Analisando-se a utilização de tecnologias de mobile tagging, como os QRcodes, que alavancam o uso de transmídia entre as mídias tradicionais e as digitais, observa-se um exemplo interessante, o do Weather Channel: durante a exibição do programa sobre o clima na TV, eles apresentam um QRcode na tela, que, quando escaneado diretamente da TV, permite a instalação do aplicativo do Weather Channel em smartphones (Figura 3.2). 


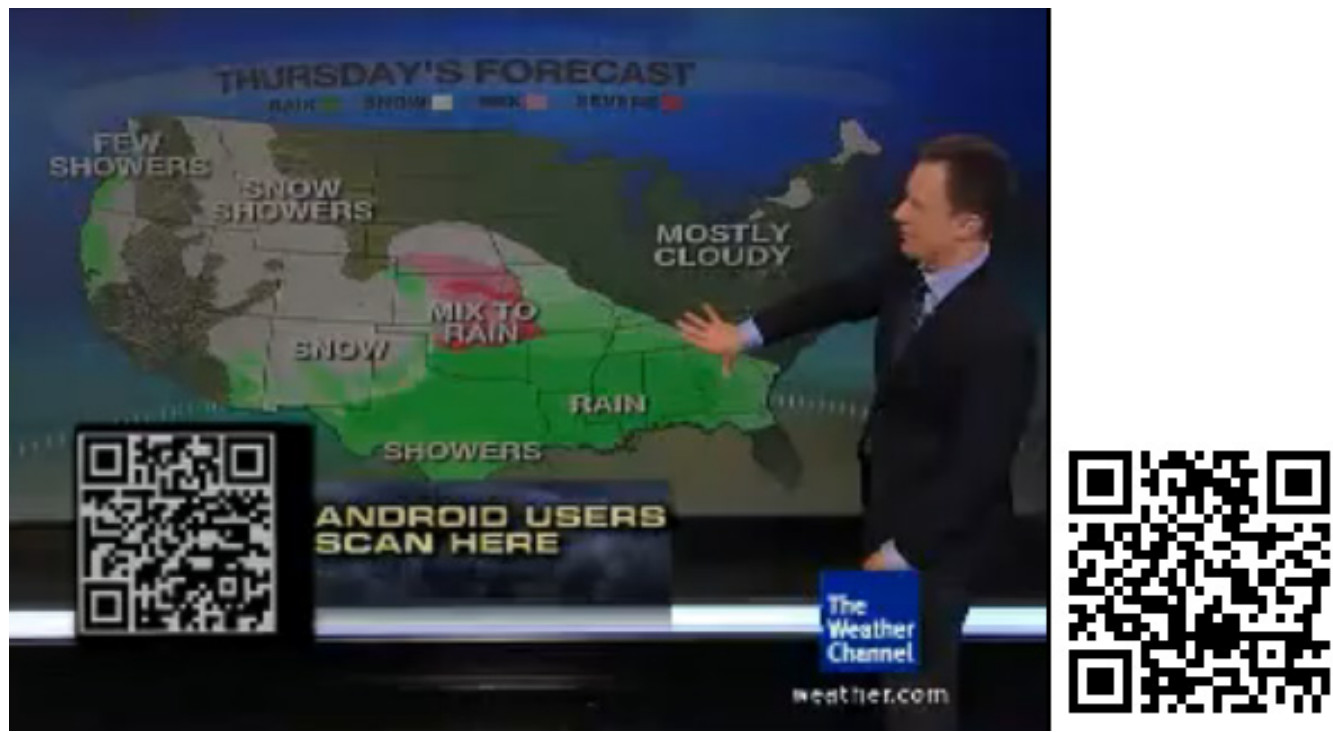

Figura 3.2 - Imagem do programa sobre o clima no Weather Channel, que apresenta um QRcode para download do aplicativo mobile do canal em aparelhos celulares Android. 0 vídeo pode ser acessado pelo QRcode ao lado da imagem. Fonte: <http://www.youtube.com/watch?v=N3e3WwoW9LQ>.

Os cibridismos também são potencializados pelas possibilidades transmídia. Considerando-se que cada nova tecnologia digital acrescenta novas formas de interconexão às redes e sistemas, e permite a 'colaboração' entre on e off line, entre os códigos atômico, genético e digital, e com demais sistemas em rede, todas elas tendem a favorecer o cibridismo de sistemas e objetos, sejam eles artísticos ou não.

Em razão dessas possibilidades cíbridas alavancadas pela disseminação de processos transmidiáticos envolvendo o código genético, alguns cientistas como Ray Kurzweill e Ian Pearson preconizam que, em breve, o ser humano não morrerá mais, pois se tornará cada vez mais viável que o conteúdo formado pelas plataformas distribuídas seja o próprio ser humano. No vídeo da Figura 3.3 pode ser visto o vídeo da entrevista que Ian Pearson concedeu à Rede Globo, na qual declara que em 10 anos os computadores terão a mesma velocidade que o cérebro humano, que em 20 anos terão a mesma inteligência que nós, e que poderemos nos conectar cada vez mais a eles em decorrência da nanotecnologia. 


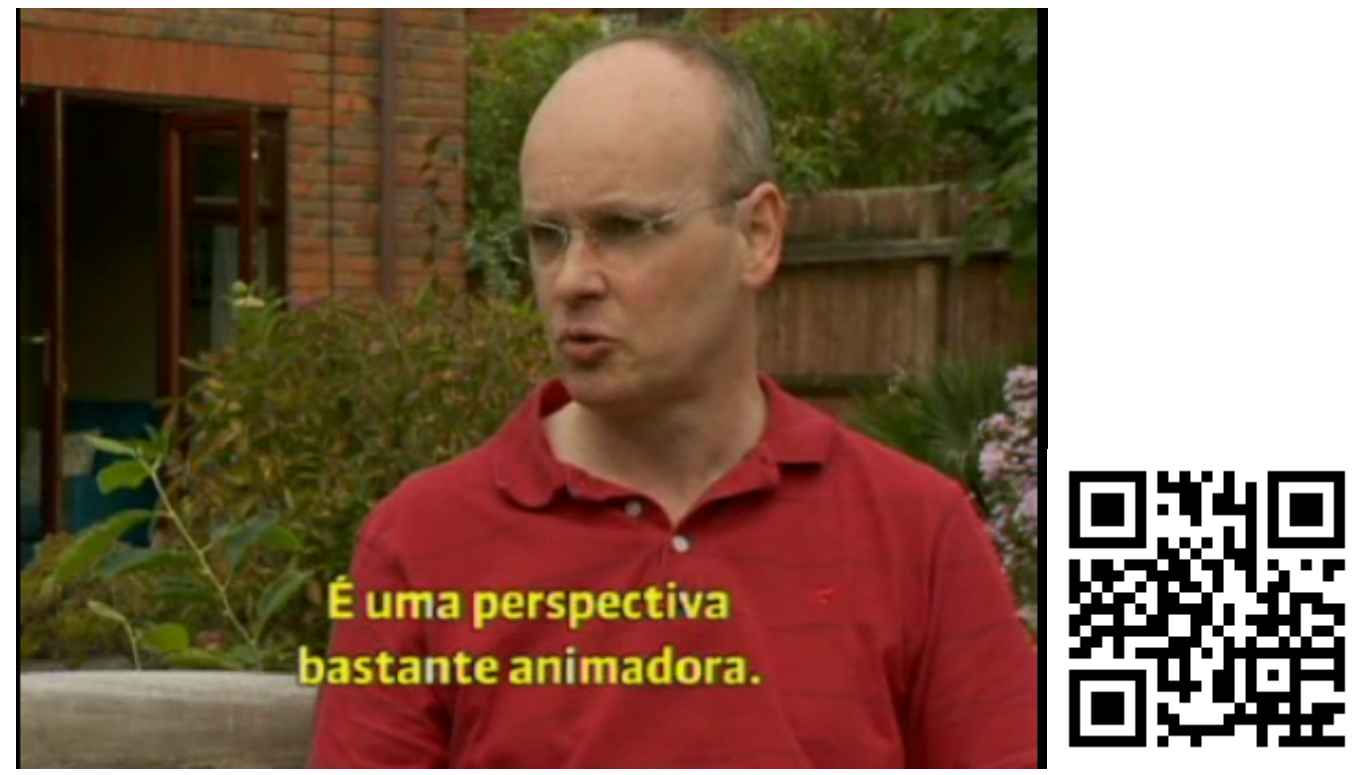

Figura 3.3 - Screenshot da entrevista em que lan Pearson fala sobre as previsões para os próximos 20 anos (GLOBO.COM, 2011).

Assim como nos processos de convergência o resultado da combinação das tecnologias/mídias nos impacta de forma diferente do que faz cada tecnologia/mídia isolada, nos processos transmidiáticos ocorre o mesmo. Ou seja, a distribuição dos conteúdos nas várias mídias requer um pensamento mais fragmentado do que nos processos que envolvem uma única mídia. Além disso, a interação de várias formas de mídias distintas no consumo de um conteúdo distribuído requer habilidades de interação em todas elas. Dessa forma, os processos transmidiáticos nos afetam de maneira diferente do que faz cada mídia/tecnologia individual isolada.

\section{Formas de apropriação transmídia}

Os conteúdos que se propagam em um processo transmidiático podem ser de dois tipos principais: mensagens ou estórias. A diferença fundamental entre um e outro é que no primeiro não existe narrativa, no segundo, sim. Um exemplo do primeiro seria o trabalho de arte moZaico de voSes ${ }^{59}$ (GABRIEL, 2004) e, do segundo, o complexo The Matrix.

59 Esse trabalho será analisado em detalhes no próximo capítulo como exemplo de aplicação de arte transmidia. 
No caso do moZaico de voSes, o trabalho é composto de processos transmidiáticos que envolvem o telefone, gravação de voz analógica e a web. No entanto, as vozes gravadas não fazem parte de um processo narrativo. Elas compõem a poética do trabalho, mas não existe processo narrativo.

Já no caso da série The Matrix, ela forma um complexo narrativo que se iniciou com histórias em quadrinhos (WACHOWSKI, 1999) dos irmãos Andy and Larry Wachowski ( e continuou em paralelo também como histórias em quadrinhos na web ${ }^{60}$ ), virou série de animação $^{61}$, filmes ${ }^{62}$ e jogos de computador $^{63}$, todos acontecendo e atuando em paralelo e cada qual com uma narrativa própria que se soma ao enredo principal. Note-se que as estórias de cada mídia diferente são produzidas de forma diferente e têm enredos diferentes, de forma que cada mídia contribui com suas potencialidades para o todo.

Os Alternate Reality Games (ARG) são ótimos exemplos de narrativas transmídia que envolvem, até mesmo, a realidade física offline como mídia. Nesse tipo de jogo, o jogador participa utilizando informações que podem ser obtidas de qualquer tipo de mídia - online ou offline, analógica ou digital - para solucionar o problema. Um exemplo interessante de ARG é o The Art of the Heist ( $A$ arte do assalto, em português), um jogo produzido pela montadora de carros AUDI para promover o Audi A3. O objetivo do jogo é encontrar o carro Audi A3 que foi roubado de um stand de feira de automóveis. Para tanto, são usadas pistas apresentadas em diversas mídias, incluindo vídeos no Youtube, cartazes no próprio stand da feira de automóveis, notícias em blogs, etc. O detetive da estória é o jogador, que não atua como um avatar ou personagem, mas como ele mesmo, em sua vida real, e quem decifrar o jogo

60 As estórias do Matrix Comic Book on the Web podem ser vistas no WaybackMachine em <http://web.archive.org/web/20061116004846/whatisthematrix.warnerbros.com/cmp/cx_archive2.html >. Acesso em: 11.jun.2012.

${ }^{61}$ Animatrix é uma coleção de 9 contos de curta-metragem sobre o mundo de Matrix, lançada em 2003.

62 A série de filmes é: The Matrix em 1999 e The Matrix Reloaded e The Matrix Revolutions em 2003, produzidos pela Warner.

${ }^{63}$ O primeiro jogo da série, Enter the Matrix foi lançado em 2003, no mesmo dia da estreia do filme The Matrix Reloaded. Mais informações podem ser obtidas em: <http://en.wikipedia.org/wiki/Enter_the_Matrix>. 
e encontrar o carro roubado, ganha o carro como prêmio. A dinâmica do jogo e seu impacto podem ser visualizados no vídeo da Figura 3.4.

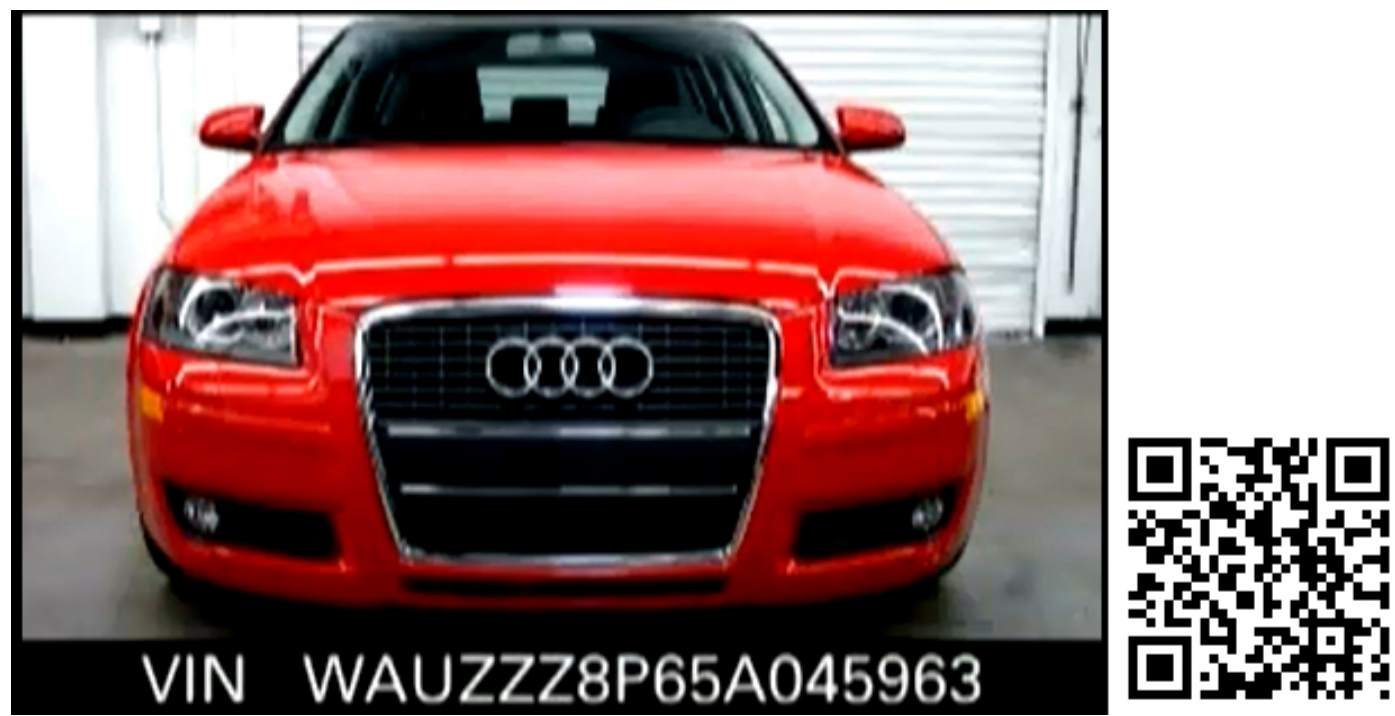

Figura 3.4 - Screenshot do vídeo explicativo do ARG The Art of the Heist que pode ser visto em <http://www.youtube.com/watch? $=z 5 w 2 C N B 9 c l w>$ ou por meio do QRcode da imagem.

\section{Contaminação transmídia}

Outro aspecto importante decorrente da proliferação das mídias digitais é a crescente contaminação de assuntos entre as mídias - tanto as digitais quanto as tradicionais que se alimentam das outras, modificando seus conteúdos mutuamente. A questão aqui está relacionada com a apropriação que uma mídia faz de conteúdos veiculados inicialmente em outra, propagando-o de maneira que, eventualmente, pode até retornar modificado à mídia inicial, retroalimentando-a. O fato de que um assunto surge em uma forma, ou uma mídia, e é propagado por outras formas e mídias sempre aconteceu. O que mudou é a velocidade com que essa propagação ocorre - quanto mais nos aproximamos da informação em real-time, mais rapidamente os assuntos de uma mídia contaminam a outra.

Desde os primórdios da televisão, por exemplo, é muito comum que uma notícia veiculada na TV num dia seja discutida no jornal no outro, modificando-se e ampliando-se. Matérias de revistas já foram várias vezes propagadas à TV, que dá continuidade ao tema, mesmo que com abordagens distintas. Esse fenômeno é particularmente importante porque a conexão entre as mídias e o impacto de uma 
mídia nas outras têm se tornado cada vez maiores, e isso pode afetar as experiências criadas, favorecendo-as ou não. Alguns exemplos que podem ser mencionados de uma mídia digital (Twitter) que se relaciona com mídias tradicionais de forma que uma alimenta a outra e afeta os desdobramentos do acontecimento/assunto/evento são:

- BBB 2010 (Big Brother Brasil) e o Twitter - Por um lado, o programa BBB ${ }^{64} 2010$ incluiu em seu grupo uma participante que ficou notória de forma bastante controversa no Twitter, a Tessalia Serighelli (@tes2alia). Por outro lado, durante os horários em que o programa era exibido na televisão, tudo o que acontecia no BBB era tuitado. $O$ interessante é que, mesmo quem nunca acompanhou o BBB na televisão, como eu, ficava sabendo o que estava se passando nessa edição 2010 por causa dos comentários no Twitter.

- Futebol e Twitter - Do mesmo modo como aconteceu no BBB 2010, é cada vez mais frequente que durante os jogos de futebol, as pessoas que estão assistindo a eles na TV, no rádio, no campo, etc. tuitem e torçam no Twitter, e que esses comentários no Twitter alimentem os programas de televisão sobre os jogos de futebol. A contaminação é tanta, que muitas vezes os próprios técnicos de times de futebol dão notícias diretamente pelos seus perfis no Twitter, sem passar pela imprensa.

- Cala Boca Galvão e a imprensa mundial - Uma brincadeira antiga com um popular narrador de esportes da Rede Globo de Televisão, Galvão Bueno, tomou proporções mundiais em razão da contaminação das mídias e da propagação maliciosa da mensagem. O “cala boca Galvão”, que era usado no âmbito do Brasil durante as transmissões do Galvão Bueno, acabaram alcançando coro nas mensagens no Twitter. Em consequência, o termo “cala boca Galvão” passou a figurar entre os Trending Topics mundiais do Twitter, o que, por sua vez, despertou a curiosidade do mundo sobre o assunto. Em decorrência disso, aproveitando a oportunidade da visibilidade mundial, alguns brasileiros alimentaram a brincadeira criando versões falsas para o termo, incentivando que estrangeiros continuassem a tuitá-lo. Uma das versões falsas era que Galvão era

64 Big Brother Brasil (conhecido como BBB) é um programa de televisão do tipo reality show, que acontece na Rede Globo desde 2002 e teve em 2010 sua $10^{\text {a }}$ edição. Mais informações em: <http://en.wikipedia.org/wiki/Big_Brother_Brasil>. 
uma ave em extinção e que cada tweet com o termo "cala boca Galvão" resultaria em uma doação para prevenir a extinção da ave. Outra versão falsa para o termo envolveu-o numa estória sobre uma canção da pop star Lady Gaga $^{65}$. A repercussão foi tão grande ao redor do mundo, que jornais como o New York Times divulgaram a notícia, além da própria Rede Globo e do Galvão Bueno, que comentaram na televisão os desdobramentos da brincadeira. 0 interessante de observar aqui é que há mais de uma década os brasileiros, de alguma forma, brincam com o narrador televisivo Galvão Bueno. Com as mídias digitais interativas se aproximando do tempo real, as contaminações são tão rápidas entre as mídias, que, pela primeira vez essa brincadeira conseguiu um alcance mundial.

Uma questão importante que deve ser levantada em relação à contaminação intermídia é referente à mutação da mensagem conforme ela se propaga. No caso do "cala boca Galvão", fica clara a facilidade com que a estória foi modificada enquanto se propagava. Esse fenômeno é potencializado pelas redes sociais online e pode afetar consideravelmente o processo, de forma intencional ou não.

Esse processo de assistir à televisão com um dispositivo móvel na mão (tablet ou smartphone) é uma tendência cada vez mais forte, denominado de cross-screen ou navegação em 2a tela. Em 2011, o relatório TV \& Video Consumer Trend Report 2011 (IDGNOW!, 2011), produzido pela empresa de equipamentos para telecom Ericsson revela que $40 \%$ das pessoas já usavam mídias sociais enquanto assistiam à TV. Outro estudo, realizado pela Elife em 2012, revela que, dentre os assuntos mais comentados no Twitter, quatro se referem a eventos televisionados (IDGNOW!, 2012).

Uma pesquisa recente do IAB e do Ipsos MediaCT (EMARKETER, 2012) mostra que o tempo médio que as pessoas gastam assistindo à televisão tem se mantido constante nos últimos três anos. Por outro lado, o uso de computador e de videogames cresceu e as horas de leitura diminuíram. 0 estudo estima que um adulto médio gasta 11,5 horas por dia consumindo conteúdo de mídia. O quadro da Figura 3.5 mostra a evolução do consumo de mídia de 2008 a 2011 nos Estados Unidos.

65 Veja a matéria publicada sobre o "Cala boca Galvão" no New York Times em: <http://schott.blogs.nytimes.com/2010/06/25/cala-boca-galvao/>. 
Daily Time Spent on Select Media Activities by US Internet Users, 2008-2011

hours

\begin{tabular}{lcccc}
\hline & $\mathbf{2 0 0 8}$ & $\mathbf{2 0 0 9}$ & $\mathbf{2 0 1 0}$ & $\mathbf{2 0 1 1}$ \\
\hline Watching TV & 3.4 & 3.4 & 3.2 & 3.4 \\
\hline Going online/using a computer & 2.4 & 2.5 & 3.0 & 3.1 \\
\hline Listening to radio/music & 1.4 & 1.3 & 1.6 & 1.5 \\
\hline Reading & 1.0 & 0.8 & 0.7 & 0.7 \\
\hline Playing video games & 0.5 & 0.6 & 0.7 & 0.7 \\
\hline Other & 0.4 & 0.4 & 0.4 & 0.3 \\
\hline Total & $\mathbf{9 . 1}$ & $\mathbf{9 . 0}$ & $\mathbf{9 . 5}$ & $\mathbf{9 . 6}$ \\
\hline
\end{tabular}

Note: ages 13-74; total of all tasks adds up to more than 24 hours due to inclusion of multitasking, i.e., media activities conducted in addition to primary activities

Source: ipsos MediaCT as cited by interactive Advertising Bureau ( $I A B)$, "Screens": What Are People Doing... and Why?" May 16, 2012

141145 www.eMarketer.com

Figura 3.5 - Evolução do tempo gasto no consumo de mídia por usuários de internet de 2008 a 2011 (EMARKETER, 2012).

Outro dado interessante é apresentado na Figura 3.6: 63\% dos usuários de internet assistem à televisão ao vivo usando algum dispositivo móvel. Esse número cresce para 66\% quando eles assistem a um vídeo. Ou seja, se em 2011 40\% das pessoas usavam um device móvel enquanto assistiam à televisão, esse número cresceu em mais de $50 \%$ em 2012, aumentando, portanto, a contaminação entre as mídias online e offline. 


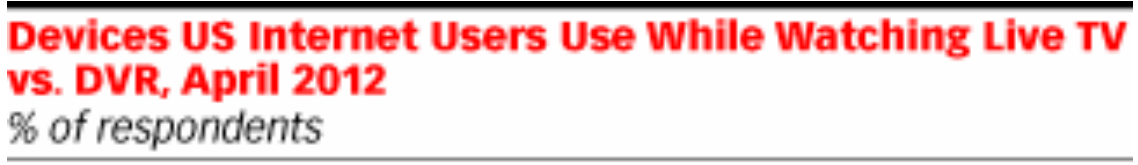

\section{Computer}

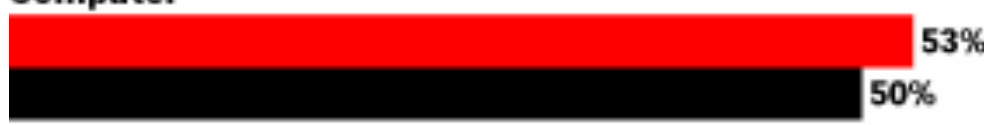

\section{Smartphone}

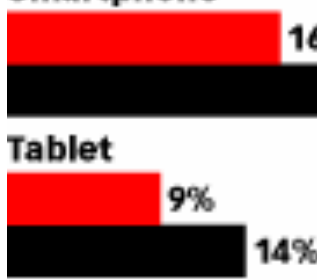

Any

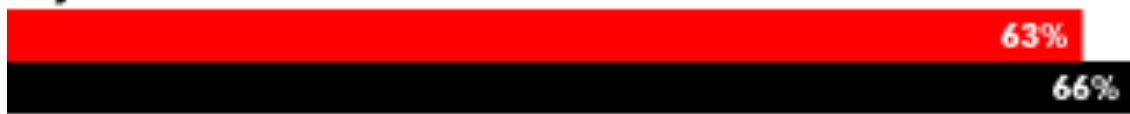

\section{Live TV DVR}

Source: ipsos MediaCT as cited by interactive Advertising Bureau (IAB), "Screens" What Are People Doing... and Why?" May 16, 2012

141133 wwweMarketer.com

Figura 3.6 - Dispositivos usados enquanto se assiste à TV ou a vídeos dados de abril/2012 (EMARKETER, 2012).

O mesmo estudo (EMARKETER, 2012) revela os modos como as pessoas usam os seus dispositivos móveis enquanto assistem à televisão. Os dados podem ser observados na Figura 3.7 . 


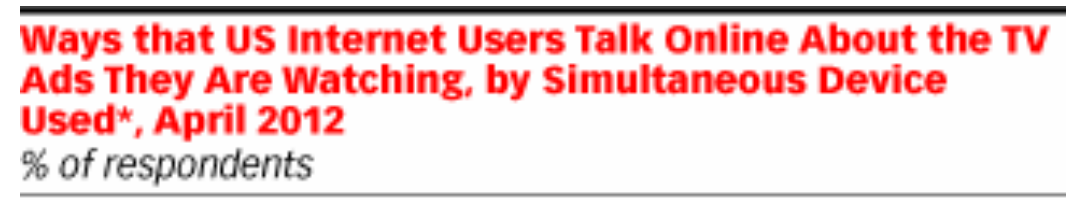

\section{Text/email/IM with friends about ads}

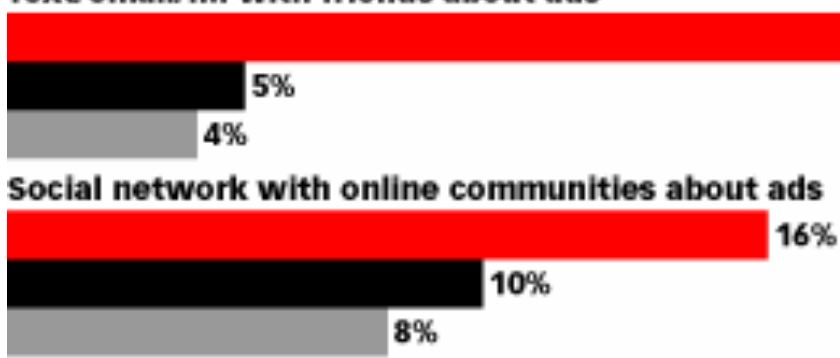

Voice chat with friends about ads

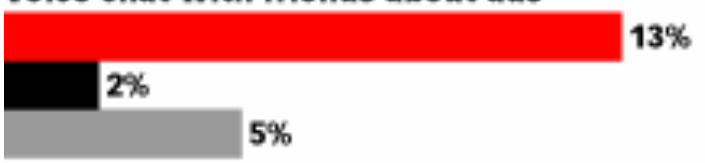

Social network with friends about ads

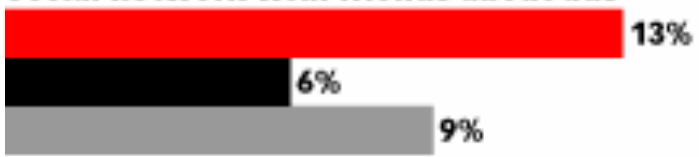

Forums, blogs or ads' website about ads

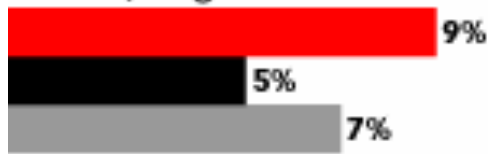

Smartphone

Computer

Tablet

Note: $n=454$ who use their smartphone, tablet or computer while watching $T V$; *device being used while watching TV

Source: Ipsos MediaCT as cited by interactive Advertising Bureau (IAB),

"Screens": What Are People Doing... and Why?" May 16, 2012

141136

wwweMarketer.com

Figura 3.7 - Dados de como as pessoas usam seus dispositivos móveis enquanto assistem à televisão (EMARKETER, 2012).

$* * *$

Este capítulo apresentou e discutiu a transmídia e os diversos processos a ela relacionados, tais como a convergência/hibridação, a contaminação midiática, etc. Os modos como a transmídia se desenvolve também foram analisados para que se possa relacioná-los com a Arte no próximo capítulo. 


\section{CAPÍTULO IV. ARTE TRANSMÍDIA NA ERA DIGITAL}

Arte transmídia é aquela que se utiliza de processos transmidiáticos. Como visto anteriormente, esses processos podem propagar conteúdos narrativos ou não. Da mesma forma que os processos transmidiáticos, a arte transmídia existia muito antes das mídias digitais.

No entanto, como discutido no capítulo 3, a proliferação de plataformas e tecnologias favorece os processos transmidiáticos, que, por sua vez, oferecem mais possibilidades de criação transmídia na arte. Todas as plataformas e tecnologias apresentadas no capítulo 2 podem ser exploradas e combinadas de infinitas maneiras para a criação transmídia.

Nesse contexto, apresentaremos a seguir, como exemplos de aplicação, quatro trabalhos de arte transmídia que se apropriam de tecnologias e plataformas digitais:

- moZaico de voSes (2004)

- Locative Painting (2007)

- SENSITIVE ROSE (2008)

- Crystal Ball (2009)

Esses trabalhos são exemplos de arte que só se tornam possíveis por meio das tecnologias e mídias digitais, possibilitando processos transmidiáticos inusitados que permitem extrair poéticas distribuídas, impossíveis na era pré-web. 


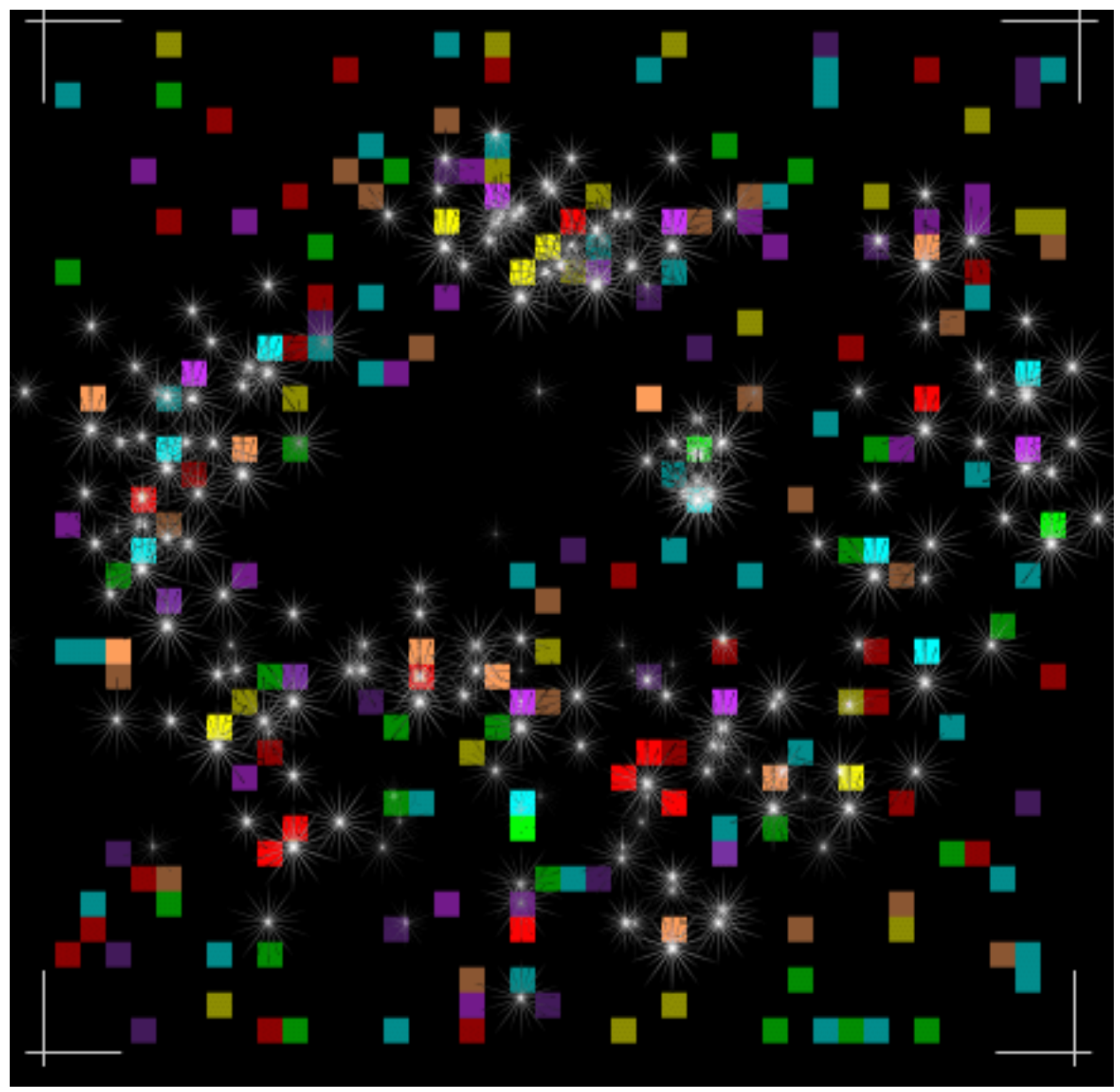

Figura 4.1 - Screenshot do trabalho de arte moZaico de voSes. Fonte: <http://www.voicemosaic.com.br/>. Acesso em: 1.jul.2012.

moZaico de voSes é um trabalho de arte interativa que tem o intuito de causar reflexão sobre a convergência e hibridação de tecnologias e mídias, e principalmente sobre nossa humanidade dentro da nova estrutura sociotecnológica que vivenciamos. Para tanto, a obra expõe várias dualidades, que não se contrapõem, mas se hibridizam e se completam, tais como - oral/visual, simples/complexo, arte/ciência, velho/novo, lowtech/high-tech, tempo/espaço, homem/computador, individual/comunidade, passivo/ativo, causalidade/casualidade, entre outras.

A obra converge voz e imagem em um mosaico visual/sonoro na web usando as cores escolhidas e vozes gravadas por pessoas que interagem por telefone de qualquer lugar no mundo. 
A interface de voz utiliza síntese e reconhecimento de fala, e funciona por meio de ligações telefônicas feitas a partir de qualquer telefone - fixo ou móvel. O mosaico é visto e ouvido na web. Desse modo ocorre uma dissolução de fronteiras e a hibridação da mais antiga rede de comunicação global, o telefone, e da maior rede computacional existente, $a$ internet.

A voz humana carrega em si parte de quem fala, portanto, ao se gravarem as vozes das pessoas no mosaico, elas estão sendo inseridas nele, gerando-se assim uma comunidade visual/sonora na qual cada pastilha com as informações individuais das pessoas participantes (cor e gravação de voz) forma e participa do todo, criando um diálogo comunidade/individual. A obra foi desenvolvida em três línguas - português, inglês e espanhol -, para permitir participação global.

Em razão da liberdade de escolha das cores e da livre gravação de voz das pessoas que participam do mosaico, sua estética em evolução e seu resultado final são imprevisíveis, colocando lado a lado o casual e o causal.

Nesse contexto, o moZaico de voSes causa um colapso tempo/espaço, pois mapeia em uma única tela participações que vêm de diferentes localizações geográficas, em diferentes línguas e em diferentes momentos.

Este trabalho é uma obra transmídia alavancada pelo telefone e pela web, duas interfaces de interação - uma visual (na web) e uma aural (via telefone). Cada mídia e sua respectiva interface contribuem com uma parte do trabalho, utilizando suas potencialidades e formando a obra. 


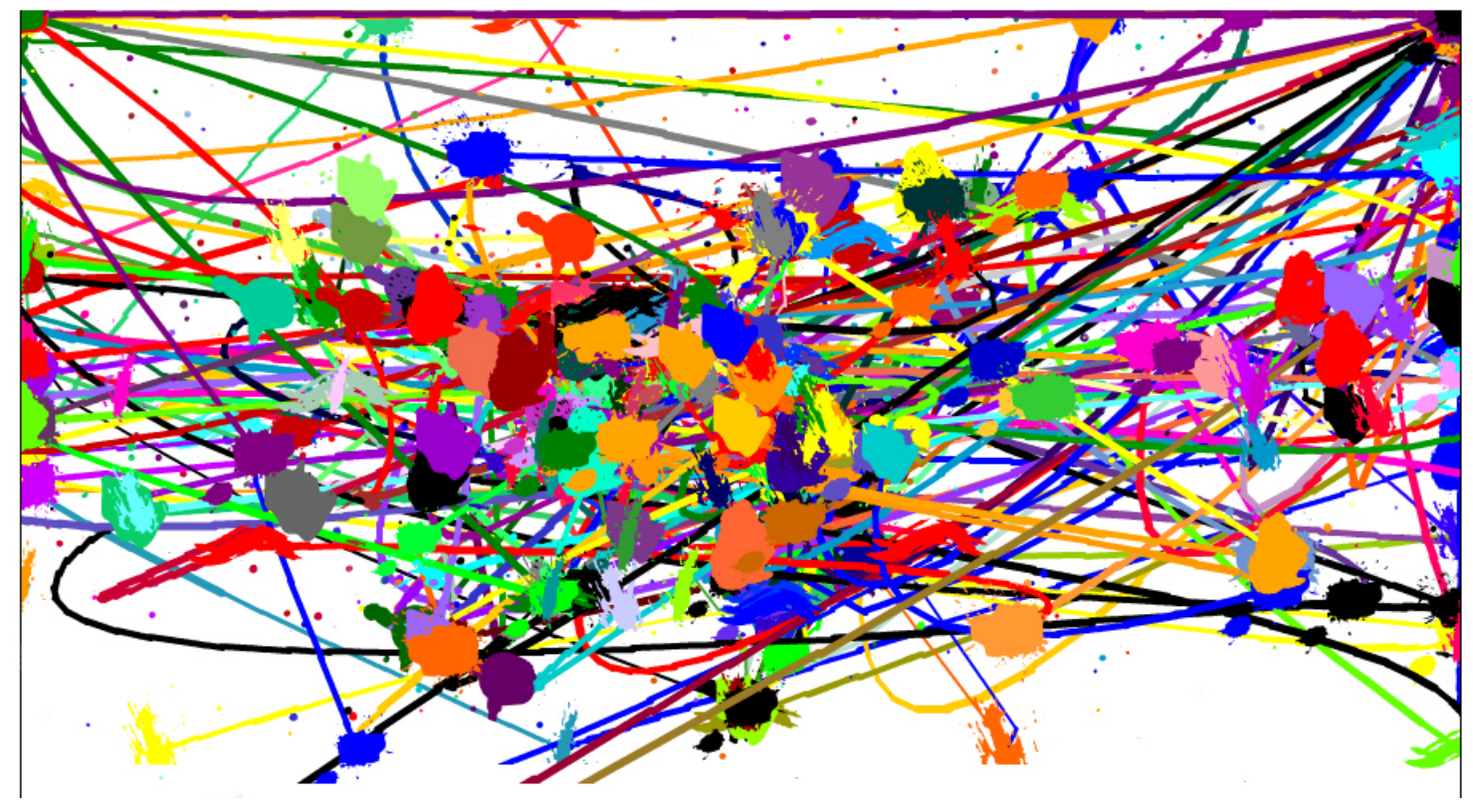

Figura 4.2 - Screenshot do trabalho de arte Locative Painting. Fonte: <http://www.locativepainting.com.br/flash.html>. Acesso em: 1.jul.2012.

Locative Painting é um trabalho de arte interativa que forma uma pintura na tela de projeção (ver Figura 4.2), na qual as pinceladas são criadas pelos participantes de acordo com suas posições geográficas (CEP), gerando, assim, uma mídia locativa.

O participante escolhe a cor da pincelada e ela é pintada a partir do local da participação anterior até a posição do participante na tela. Depois de interagir, a pessoa recebe a imagem da pintura por e-mail, incluindo sua pincelada em destaque, com seu nome escrito.

Permitindo que cada participante crie uma pincelada baseada em sua localização geográfica, o trabalho possibilita que cada pessoa tenha seu momento único na pintura. Por outro lado, como todas as pinceladas conectam as localizações das pessoas e permitem assim uma multitude de caminhos cruzados, o Locative Painting cria uma pintura comunitária intercambiando e cruzando caminhos que talvez nunca se cruzassem na vida. 
As intenções artísticas deste trabalho são: a) criar reflexão sobre a localização; e b) extrair de algumas maneiras a poética revelada pelas localizações e suas conexões digitais emergentes.

Este trabalho é uma obra transmídia alavancada pelo celular e pela web, duas interfaces de interação - uma interativa/contemplativa visual (na web) e uma interativa, em que acontece a entrada de dados na obra (via telefone celular). Cada mídia e respectiva interface contribuem com uma parte do trabalho, utilizando suas potencialidades e formando a obra.

\section{IV.3 - Exemplo de aplicação 3: SENSITIVE ROSE}

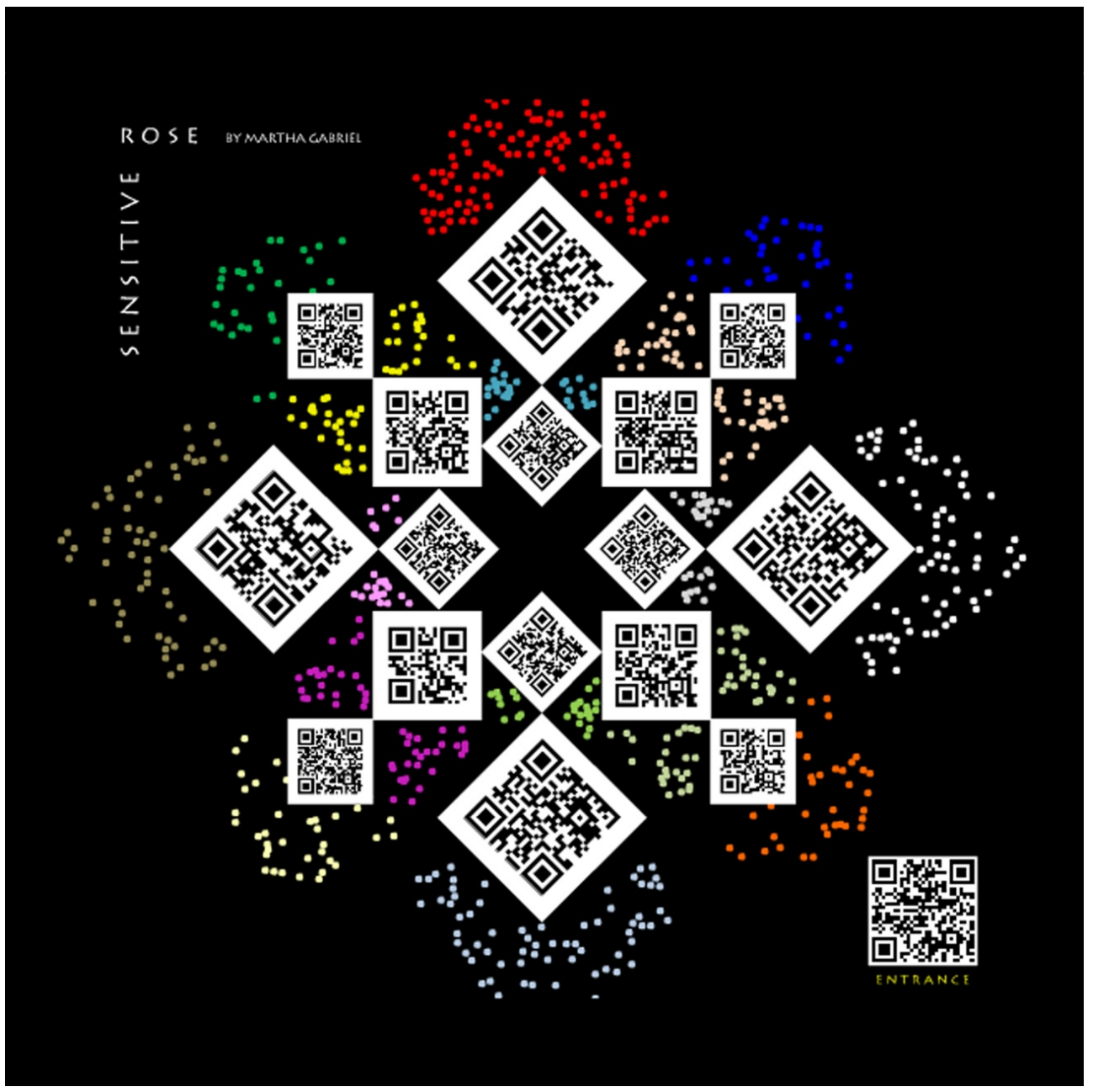

Figura 4.3 - Screenshot do trabalho de arte SENSITIVE ROSE. Fonte: <http://www.sensitiverose.com.br/rose.php>. Acesso em: 1.jul.2012. 
SENSITIVE ROSE é uma rosa dos ventos interativa formada por mobile tags (QRcodes) que mapeia os desejos das pessoas.

O trabalho é uma grande projeção $(3 \mathrm{~m} \times 3 \mathrm{~m})$ na qual as interações acontecem escaneando-se a tag de entrada na projeção por meio do uso de telefones celulares ou dispositivos móveis,. O interator, então, entrará em um formulário (no celular) e responderá à questão “O que você quer da vida?" Cada interação é mapeada por uma nova bolinha colorida colocada ao redor da tag relacionada com a resposta - se a pessoa escolhe amor, isso faz aparecer uma bolinha apareça ao redor da tag 'amor', com a cor que o trabalho associa a amor (neste caso, vermelho). Uma mobile tag é criptografada em QRcode com o texto "Fulano quer Amor", e essa tag vai para a rosa dos ventos de desejos, substituindo a tag anterior relacionada a amor.

O desejo mais escolhido é sempre posicionado no Norte,e de acordo com a ordem de relevância das escolhas dos desejos, todos o trabalho se reconfigura quando uma relevância muda. Nesse sentido, o trabalho funciona como uma rosa dos ventos que navega no desejo das pessoas. A navegação, no entanto, deve ser feita por meio de uma poética codificada de mobile tags (QRCodes), pois os textos associados a cada tag não podem ser decifrados a olho nu, mas apenas com o uso de um aparelho que permita ver além da superfície (neste caso, o telefone celular). Outra intenção do trabalho é extrair a poética de QRCodes na forma de uma poesia visual.

Do mesmo modo que a Poesia Concreta usava códigos alfabéticos - letras e palavras utilizando suas características visuais para criar significado, o SENSITIVE ROSE cria uma poesia concreta interativa, formada de mobile tags (códigos visuais de informação), de modo que a entrada e saída de dados seja feita completamente por meio do trabalho (na projeção).

Este trabalho foi lançado no Nokia Trends São Paulo 2008, exposto em vários países, premiado na Bienal de Florença 2009 e convidado para o Technarte (Bilbao) 2010. A imagem do trabalho e o link para assistir ao vídeo de demonstração estão na Figura 4.4. 

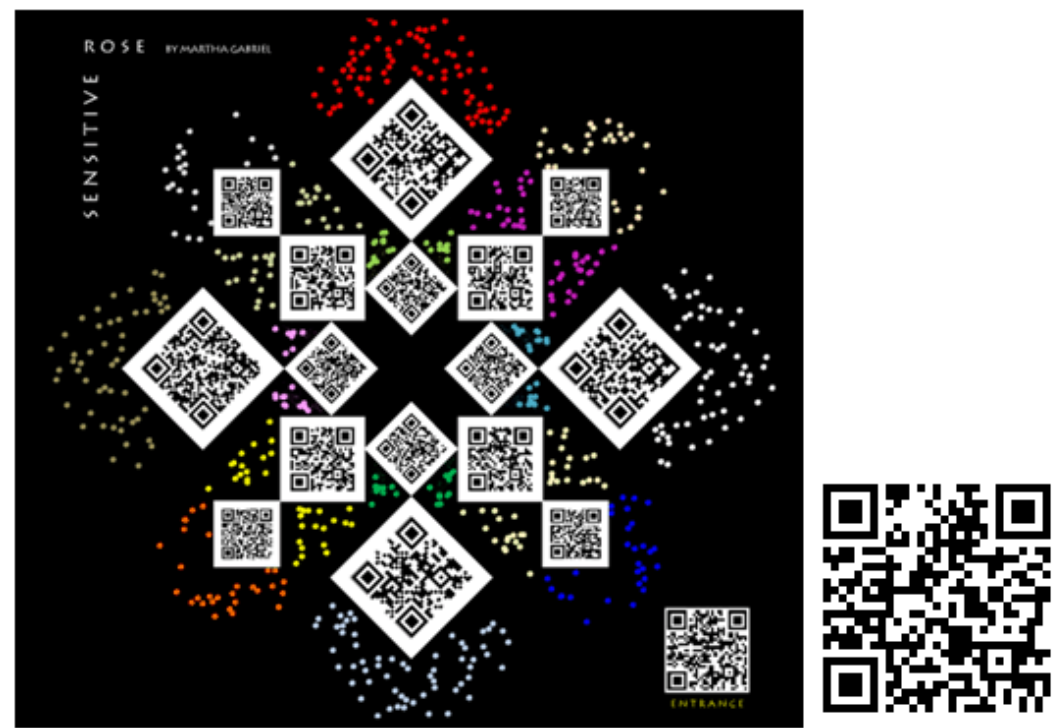

Figura 4.4 - Tela do vídeo de demonstração do trabalho de arte SENSITIVE ROSE, disponível em: <http://www.youtube.com/watch?v=EwOf80TWYSg>. Acesso em 1/jul/2012.

Para participar do trabalho: a) acesse o endereço <www.sensitiverose.com.br/rose.php em uma tela ou projeção grande (para que seja possível escanear e ler as tags) e depois interaja com o trabalho via celular, escaneando o QRcode da Figura 4.5 (ou o QRcode que fica no canto inferior direito da tela do trabalho, que é a tag de entrada do mesmo). Após a interação no celular, você verá o trabalho se transformar na tela do computador em função de sua interação.

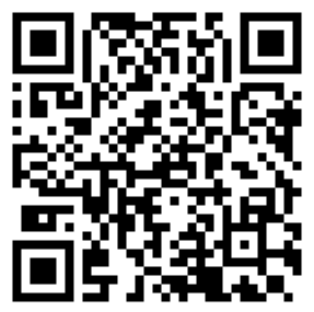

SENSITIVE ROSE

Figura 4.5 - Imagem do QR code com link para a página mobile de interação com o trabalho de arte SENSITIVE ROSE <www.sensitiverose.com.br/m>.

Este trabalho é uma obra transmídia alavancada pelo celular e pela web, que se utilizam de duas interfaces de interação - uma projeção contemplativa/reativa visual (na web) e uma interativa (via telefone celular). Cada mídia e sua respectiva interface contribui 
com uma parte do trabalho, utilizando suas potencialidades e formando a obra.

IV.4 - Exemplo de aplicação 4: Crystal Ball

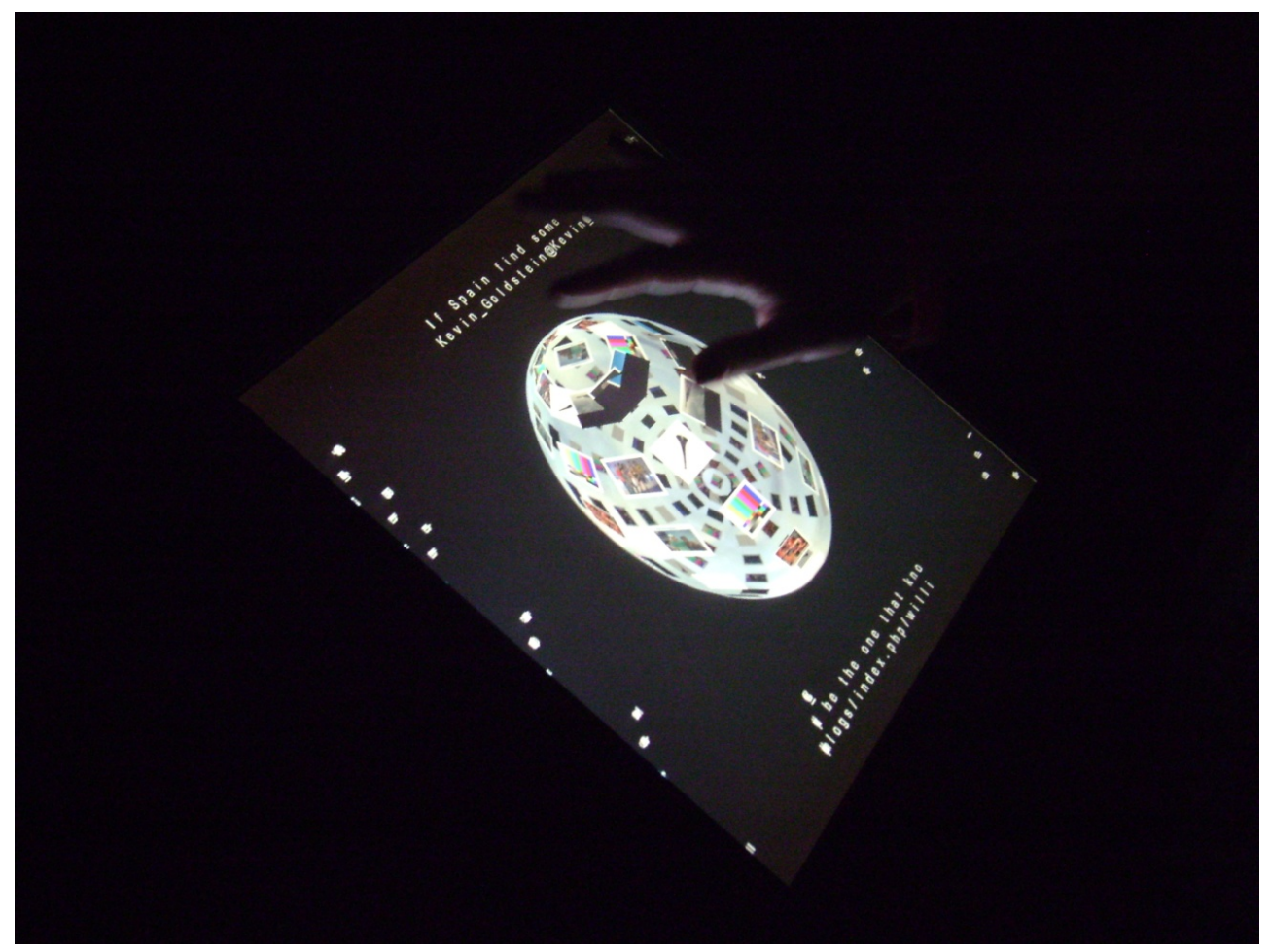

Figura 4.6 - Foto do trabalho de arte Crystal Ball na exposição da Dinamize, Porto Alegre, jun.2010. Fonte: Martha Gabriel.

Crystal Ball é um trabalho de arte mobile interativo que funciona como uma bola de cristal (ver Figura 4.6), a qual mostra o que está acontecendo no mundo em tempo real baseando-se nas Trending Topics (TT) mundiais do Twitter a cada momento. As Trending Topics são os assuntos (tópicos) que representam as inquietações e acontecimentos que emergem no mundo a cada instante. As tendências são alimentadas pelo mundo offline e também o alimentam, em um processo contínuo de retroalimentação de tendências e acontecimentos.

No Crystal Ball, as 10 trending topics do momento são traduzidas em imagens via o Google Images, ou seja, a própria rede se interpreta e resulta nas imagens que 
aparecem na bola de cristal. Assim, a obra não é apenas uma ferramenta de visualização conceitual das micro-trends em tempo real, mas também a rede interpretando-se a si mesma. Existem duas formas de interagir com a bola de cristal: 1) Tuitar incluindo a hashtag \#crystalball - essas mensagens aparecerem ao redor da bola de cristal; 2) Interagir com a bola tocando nas imagens associadas às trending topics (TT). Quando clicada, a imagem é mostrada centralizada na bola e, ao seu redor, começam a aparecer as mensagens trocadas no Twitter, em tempo real, sobre aquela TT.

Este trabalho tem como objetivos: 1) Visualizar como o ato individual (de tuitar, por exemplo), que em um primeiro momento parece banal e isolado, cria, revela e afeta o que acontece no mundo, no todo; 2) Investigar como o que se apresenta nas trending topics (e que está acontecendo em tempo real) é traduzido ou perdido na tradução para imagens (conexão entre textos coletivos de micro-blogging e repertório imagético da rede); 3) Causar reflexão sobre a atuação das pessoas nas redes sociais, mostrando que: a) mesmo inconscientemente, elas estão atuando e afetando as tendências, ou seja, quer se queira ou não, se perceba ou não, cada ação na rede afeta o todo e tem consequências; e b) intencionalmente, todos podem participar e afetar a rede (por meio da hashtag \#crystalball).

Este trabalho é uma obra transmídia alavancada pelo celular, pela web, pelo Google Images e pelo Twitter (mídia social), que se utiliza de duas interfaces de interação uma reativa 'touch' visual (na web) e uma interativa (via telefone celular). Cada mídia e sua respectiva interface contribuem com uma parte do trabalho, utilizando suas potencialidades e formando a obra.

Este capítulo apresentou a transmídia na Arte por meio da análise de quatro trabalhos de arte desenvolvido pela autora, mostrando funcionalidades viabilizadas pelo ambiente tecnológico emergente, que fornece inúmeras possibilidades de plataformas conectadas e interativas.

O intuito aqui foi mostrar que a arte é afetada pelos processos transmidiáticos, que lhe conferem novas funcionalidades e possibilidades de experimentação e interação, expandindo o conceito de obra em si - que pode se desenvolver por cada vez mais plataformas que se integram (tanto online quanto offline, tanto analógicas quanto 
digitais) - e as formas de contato com o público. A mesma pessoa pode experimentar a mesma obra de vários modos, participando de partes distintas do trabalho. Por exemplo, uma pessoa que gravou uma mensagem no moZaico de voSes, experimentando a entrada na obra por um processo aural via telefone, pode posteriormente interagir com a interface visual na web, vendo o mosaico e ouvindo as gravações de outros interatores. 


\section{CONCLUSÕES}

Retomando nossas premissas e dúvida inicial: uma vez que a proliferação de tecnologias e plataformas digitais de comunicação e informação acrescentam novas possibilidades e complexidades à web, gerando novas formas de interatividade, hibridação e convergências entre arte e tecnologia, possibilitando criações artísticas que antes não eram possíveis; e, sendo diferente o modo de interação humano por meio das plataformas digitais emergentes do modo de interação nas mídias tradicionais, requerendo um tratamento diferenciado para se explorar suas plenas possibilidades potenciais; consequentemente, o cenário transmídia digital modifica o universo das criações artísticas, e vice-versa. De onde lançamos a dúvida inicial: Com a emergência e disseminação de plataformas e tecnologias digitais quais são as novas formas de criação e interação artísticas que ampliam o cenário de possibilidades criativas? Com a emergência e disseminação de plataformas e tecnologias digitais novas formas de criação e interação artísticas ampliam o cenário de possibilidades criativas. Há uma contribuição importante produzida pelas transmídias digitais, que criam poéticas e estéticas particulares somente possíveis no ambiente tecnológico atual, e que pode ser observada principalmente no desenvolvimento dos trabalhos práticos desta tese, que podem ser considerados como uma síntese desta proposição.

No capítulo 1 vimos que inúmeras transformações sociais e tecnológicas modificam a relação das pessoas com o mundo, mediadas cada vez mais por tecnologias digitais. A proliferação tecnológica e de conteúdos, a disseminação da conexão e mobilidade, alavancando o cibridismo, o tempo-real, o nowism, o big data e a 'internet das coisas ', desenvolvem um ambiente cada vez mais propício para processos transmídia interconectados e múltiplos.

O Big data, por exemplo, tem um potencial inusitado para exploração de processos de visualização de dados e e isto repercutirá nas práticas poéticas. Trabalhos de arte que usam o Google, como o Digital Oracles (GABRIEL, 2006), resultam do fenômeno do big data e suas consequências. As funcionalidades de sistemas computacionais que o ambiente digital oferece - zoom, busca, filtros, etc. - passam a fazer parte das mídias interativas, e dos trabalhos de arte, permitindo que o público não apenas participe, mas também altere e transforme as obras. Esta dimensão de participação do público em termos estruturais das obras de arte é uma característica favorecida pelo ambiente 
digital, no qual bits se misturam de modo muito mais fluido e dinâmico do que em qualquer meio atômico. As potencialidades poéticas em decorrência disso são inétidas e incontáveis.

A cultura das telas interativas e da participação que se forma em função da evolução tecnológica também contribui para a propagação da transmídia, na arte ou em qualquer outra área do conhecimento. E, já que se tornou procedimento comum as pessoas 'serem' online, ou seja, estarem o tempo todo simultaneamente online e off-line ( $p$. 24), elas em si geram processos transmídia. Pessoas usando os seus dispositivos móveis enquanto assistem à televisão demonstram este diferencial (p.181) provocado pelo fenômeno cross-screen.

As inúmeras plataformas e tecnologias digitais, atuais e emergentes, apresentadas e analisadas no capítulo 2 - mobile, redes sociais, buscadores, display, etc. - mostram a ampliação de opções midiáticas, de interação, de comunicação, de integração, etc., acrescentando diversidade e complexidade ao cenário tecnológico que emerge e se dissemina na vida cotidiana das pessoas. Os processos transmidiáticos utilizam as plataformas e mídias disponíveis - digitais ou não - e, assim, a miríade de possibilidades tecnológicas que emerge e sua inerente complexidade oferecem novas formas de experimentação e desenvolvimento.

Trabalhos como Crystal Ball são possíveis apenas no ambiente tecnológico atual - ele utiliza a busca (Google Images), as redes sociais (Twitter) e o mobile (para comunicação com o trabalho) de forma a criar uma poética participativa que depende tanto do interator quanto do big data e demais atores que fornecem o tsunami de dados usados para a formação do trabalho.

Os processos transmidiáticos, portanto, potencializados pelo ambiente hiperconectado e hiperinformacional em que estamos imersos, possibilitam a criação de trabalhos artísticos que não poderiam existir em outro cenário na era pré-digital. Dessa forma, a transmídia afeta a Arte, tanto nos processos de criação quanto em sua distribuição e consumo, em que a fragmentação de interações e significações é potencializada.

Assim, a arte é afetada pelos processos transmidiáticos, que the conferem novas funcionalidades e possibilidades de experimentação e interação, expandindo o conceito de obra em si - que pode se desenvolver por cada vez mais plataformas que se integram 
(tanto online quanto offline, tanto analógicas quanto digitais) - e as formas de contato com o público.

Limitações inerentes a plataformas analógicas são superadas no ambiente digital. Por exemplo, a fala analógica tem por características a transiência, a invisibilidade e a assincronicidade (GABRIEL, 2012). No ambiente digital, essas limitações da fala são vencidas pelas tecnologias que gravam, processam e apresentam o som, criando poéticas como as desenvolvidas no trabalho moZaico de voSes. Além disso, a voz pode ser comparada por amostragem, ser filtrada; podemos extrair certas características; aplicar processos de afinamento, retirada de ruídos e inconsistências; reconhecer padrões; ou seja, trabalhamos no digital com dados estruturados que nos sistemas analógicos estavam não-estruturados.

Se por um lado, os processos transmidiáticos afetam a arte, como argumentado anteriormente, a arte também afeta esses processos. Muitas vezes, a arte utiliza e experimenta tecnologias de ponta, e este será um processo precursor para que essas tecnologias se desenvolvam e ganhem espaço no cenário tecnológico contemporâneo, e passem a configurar mais opções transmídia. Trabalhos como SENSITIVE ROSE, por exemplo, permitiu que as pessoas conhecessem e utilizassem QRcodes e processos mobile em 2008, muito antes dessas tecnologias se tornarem populares no Brasil, o que está ocorrendo hoje. O trabalho moZaico de voSes se apropriou de tecnologias de VoiceXML no seu desenvolvimento em 2004. Essas tecnologias começaram a ser utilizadas de forma mais ampla a partir de 2010. Locative Painting utilizava tecnologias locativas já em 2007. Muitos trabalhos de arte começaram a explorar a realidade aumentada e suas possibilidades antes que as aplicações comerciais se tornassem disponíveis. 0 artista quando explora poeticamente uma tecnologia transcende sua funcionalidade e usos apresentando novas formas de utilização e linguagem. Assim, a arte afeta o ambiente transmídia também, tanto quanto é afetada por ele.

Temos vivenciado por apenas uma década ainda a revolução digital alavancada pela conexão. A maior parte das transformações aqui descritas ocorreram nos últimos 5 anos. Desta forma, estamos experimentando ainda a aurora desta revolução. A quantidade de plataformas, tecnologias, processos interativos e possibilidades de conexão entre as coisas e pessoas, provavelmente crescerão e se tornarão mais complexas. Portanto, as possibilidades de desenvolvimento de processos transmidiáticos e as formas de 
exploração das suas potencialidades na arte também devem aumentar consideravelmente nos próximos anos.

A complexidade crescente do ambiente possivelmente tornará os processos transmidiáticos não apenas possíveis, como, principalmente, necessários. A transmídia funciona como uma 'cola', uma 'costura' que permite extrair sentido, narrativa, poéticas maiores de um conjunto fragmentado e distribuído. A presente tese mostra como a transmídia afeta e transforma a arte e vice-versa, demonstrando sua contribuição no cenário contemporâneo. A próxima etapa seria investigar as estruturas de narrativas e conteúdos que se desenvolvem nos processos transmidiáticos. 


\section{BIBLIOGRAFIA}

ABRÃO, B. S.; COSCODAI, M. U. (Orgs.). Dicionário de Mitologia. São Paulo: Best Seller, 2000.

ANDERS, Peter. Toward an architecture of mind. In: CAiiA-STAR SYMPOSIUM: 'Extreme parameters. New dimensions of interactivity' (july.2001). Disponível em:

<http://www.uoc.edu/artnodes/eng/art/anders0302/anders0302.html>. Acesso em:

10.mai.2006.

ASCOTT, Roy. Cultivando o Hipercórtex. In: DOMINGUES, Diana (Org.). A Arte no Século XXI: a humanização das tecnologias. São Paulo: Editora Unesp, 1997.

BAKER, Stephen. The Numerati. USA: Houghton Mifflin Harcourt, 2008.

BASU, S. 10 Search Engines to Explore the Invisible Web. 2010. Disponível em: <http://www.makeuseof.com/tag/10-search-engines-explore-deep-invisible-web/>. Acesso em: 18 nov.2010.

BATTELLE, J. Busca: Como o Google e seus Competidores Reinventaram os Negócios. Rio de Janeiro: Campus, 2005.

BAUMAN, Zygmunt. Modernidade Líquida. São Paulo: Zahar, 2001.

BEIGUELMAN, G. Admirável Mundo Cíbrido. In: BRASIL, André; ALZAMORA, Geane; FALCI, Carlos Henrique; JESUS, Eduardo de (Org.). Cultura em Fluxo: novas mediações em rede. 1. ed. Belo Horizonte: PucMinas, 2004, v. 1, p. 264-282.

BOUMANS, J. e-Content Report - Anticipating Content Technology Needs. 2004. Disponível em: <http://www.springerlink.com/content/j623205v0t160h85/>. Acesso em: 15.ago.2010.

BRUST, Andrew. Big Data: Defining its definition. Disponível em: <http://www.zdnet.com/blog/big-data/big-data-defining-its-definition/109> acessado em 18.jun.2012.

BUSINESS WEEK. My Virtual Life. 2006. Disponível em: <http://www.businessweek.com/magazine/content/06_18/b3982001.htm>. Acesso em: 1 dez.2009.

CNN Money. Victoria's 'Net Secret is out. 1999. Disponível em: <http://money.cnn.com/1999/02/02/bizbuzz/victoria/>. Acesso em 10.jun.2012.

CHRISTAKIS, N \& FOWLER, J. Connected: the Surprising Power of our Social Networks and How They Shape Our Lives. London: Little, Brown and Company, 2009.

DE LUCA, Cristina. 2010. E o SMS faz 25 anos. Acredite!. 2010. Disponível em: <http://idgnow.uol.com.br/blog/circuito/2010/08/03/e-o-sms-comemora-hoje-25-anosacredite/>. Acesso em: 8 dez.2010. 
DEBORD, Guy. A Sociedade do Espetáculo. E-Books Brasil. Disponível em: <http://goo.gl/AoLcT>. acesso em: 5.jul.2010.

DENSO-WAVE. Bar code to 2D Code. 2009. Disponível em: <http://www.densowave.com/qrcode/aboutqr-e.html>. Acesso em: 7 dez.2010.

EMARKETER. TV Watchers Use Digital Devices to Multitask Online. 2012. Disponível em: <http://www.emarketer.com/Article.aspx?R=1009102>. Acesso em: 10.jun.2012.

FARBER, D. 2014: Magic Software, Free Hardware. In ZDNet.com, 2004. Disponível em: <http://techupdate.zdnet.com/techupdate/stories/main/Gates_gives_magical_software _tour.html>. Acesso em: 3.abr.2004.

FARBER, D. 2015: Sensors Everywhere, Computers Invisible. In: ZDNet.com, 2004. Disponível em:

<http://techupdate.zdnet.com/techupdate/stories/main/Gartner_senses_a_world_sans _computers.html>. Acesso em 3.abr.2004.

FILGUEIRAS, L.; CORREA, D.; OLIVEIRA NETO, J.; FACIS, R. X-gov planning: how to apply cross media to government services. In: ICDS 2008, p. 140-145. IEEE, Los Alamitos, 2008.

FOGG, B. J. Persuasive Technology: Using Computers to Change What We Think and Do, 2002. San Francisco: Morgan Kaufmann. Disponível em:

<http: / / books.google.com.br/books?id=aSfvNuUJNoUC\&dq=fogg+persuasive+technology \&printsec $=$ frontcover\&source $=$ bn\&hl=pt-

BR\&sa=X\&oi=book_result\&resnum=4\&ct=result\#PPP1,M1>. Acesso em: 24.out.2008.

FOLHA. Electronic Arts Alerta para Mudanças no Universo de Videogames. 2010. Disponível em: <http://www1.folha.uol.com.br/tec/783659-electronic-arts-alerta-paramudancas-no-universo-de-videogames.shtml>. Acesso em: 17 set.2010.

GABRIEL, Martha. moZaico de voSes. 2004. Disponível em:

<http://www.mozaicodevoses.com.br/>. Acesso em: 1.mar.2012.

GABRIEL, Martha. Digital Oracles. 2006. Disponível em:

<http://www.digitaloracles.com.br/>. Acesso em: 1.mar.2012.

GABRIEL, Martha. Locative Painting. 2007. Disponível em:

<http://www.locativepainting.com.br>. Acesso em: 1.mar.2012.

GABRIEL, Martha. SENSITIVE ROSE. 2008. Disponível em:

<http://www.sensitiverose.com.br>. Acesso em: 1.mar.2012.

GABRIEL, Martha. Crystal Ball. 2009. Disponível em: <http://www.crystalball.art.br>. Acesso em: 1.mar.2012.

GABRIEL, Martha. Conversando com Computadores: interfaces de voz na web. São José dos Pinhais: Editora Melo, 2012. 
GLADWELL, Malcolm. The Tipping Point: How Little Things Can Make a Big Difference. USA: Back Bay Books, 2002.

GLOBO.COM. 'Em 20 anos, um PC poderá ter a mesma inteligência que a nossa', prevê lan Pearson. 2011. Disponível em: <http://g1.globo.com/videos/globonews/milenio/t/programas/v/em-20-anos-um-pc-podera-ter-a-mesma-inteligencia-quea-nossa-preve-ian-pearson/1752756>. Acesso em 10.jun.2012.

GOURLAY; C. OMG: Brains Can't Handle all our Facebook Friends. 2010. Disponível em:

<http://technology.timesonline.co.uk/tol/news/tech_and_web/the_web/article6999879 .ece>. Acesso em: 10 mai.2011.

GRANOVETTER; M. The Strength of Weak Ties. In: American Journal of Sociology. 1973 May; 6:1360-80. Disponível em: <http://www.stanford.edu/dept/soc/people/ mgranovetter/documents/granstrengthweakties.pdf>. Acesso em: 8 jul.2010.

GREENFIELD, A. Everyware: The Dawning Age of Ubiquitous Computing (Voices That Matter). Indianapolis: New Riders Publishing, 2006.

GSU. Distributed System: Definition. 2003. Disponível em:

<http://www.cs.gsu.edu/ cscskp/DistSystems/chap01-prasad.pdf>. Acesso em: 10.ago.2010.

HAYES, G. Top 16 Augmented Reality Business Model. 2009. Disponível em: <http://www.personalizemedia.com/16-top-augmented-reality-business-models/>. Acesso em: 1 out.2010.

HOBSBAWM, E. J. A era das revoluções: Europa 1789-1848. Rio de Janeiro: Paz e Terra, 1994.

IBOPE. Games Sociais Mudam Rotina em Sites de Relacionamento . 2010. Disponível em: <http://bit.ly/92JZhA>. Acesso em: 19 nov.2010.

IDGNOW! Realidade Aumentada vai girar US\$ 700 Milhões em 2014, Prevê Estudo. 2010. Disponível em: <http://idgnow.uol.com.br/internet/2010/01/05/realidadeaumentada-vai-girar-us-700-milhoes-em-2014-preve-estudo/>. Acesso em 17 ago.2010.

IDGNOW!. Pesquisa: Mais de 40\% das pessoas usam mídias sociais diante da TV. 2011. Disponível em: <http://idgnow.uol.com.br/internet/2011/09/02/pesquisa-mais-de-40das-pessoas-usam-midias-sociais-diante-da-tv/>. Acesso: em 10.jun.2012.

IDGNOW!. No Brasil, a moda agora é assistir TV e comentar nas redes sociais. 2012. Disponível em: <http://idgnow.uol.com.br/internet/2012/04/13/no-brasil-a-modaagora-e-assistir-tv-e-comentar-nas-redes-sociais/>. Acesso em: 10.jun.2012.

IPROSPECT. iProspect Search Engine User Behavior Study. 2006. Disponível em: <http://www.iprospect.com/premiumPDFs/WhitePaper_2006_SearchEngineUserBehavior .pdf>. Acesso em 12 set.2010.

ISUPPLI. iSuppli Market Intelligence. 2010. Disponível em: <http://www.isuppli.com/>. 
Acesso em: 10.mai.2010.

JENKINS, H. A Cultura da Convergência. São Paulo: Aleph, 2006.

JOHNSON, Steven. A Cultura da Interface: como o computador transforma nossa maneira de criar e comunicar. Tradução Maria Luiza X. de A. Borges. Rio de Janeiro: J. Zahar, 2001.

KERCKHOVE, Derrick. A Realidade Virtual Pode Mudar a Vida?. In: DOMINGUES, Diana (Org.). A Arte no Século XXI: a humanização das tecnologias. São Paulo: Editora Unesp, 1997, p. 49-51.

KERCKHOVE, Derrick. A Arquitetura da Inteligência: Interfaces do corpo, da mente e do mundo, In: DOMINGUES, Diana (Org.). Arte e Vida no Século XXI. São Paulo: Editora Unesp, 2003, p. 15-26.

LAMANTIA, J. Inside Out: Interaction Design for Augmented Reality. 2009. Disponível em: <http://www.uxmatters.com/mt/archives/2009/08/inside-out-interaction- designfor-augmented-reality.php>. Acesso em: 8 fev.2010.

LAURENTIZ, Silvia (2004). Padrões Emergentes e/ou Valores Estéticos. In: ENCONTRO NACIONAL DA ANPAP - Arte em Pesquisa: especificidades, 13., 2004, Brasília. Anais... Brasília: Editora da Pós-graduação em Artes da UnB, Brasília. V.2, p. 381-387.

LEVITT, Steve \& DUBNER, Stephen. Freakonomics. USA: William Morrow, 2005.

LÉVY, Pierre. As Tecnologias da Inteligência: o futuro do pensamento na era da informática. Tradução Carlos Irineu da Costa. São Paulo: Ed. 34, 1993.

LÉVY, Pierre. 0 que é o virtual. São Paulo: Ed. 34, 1996.

MACHADO, Arlindo. Máquina e Imaginário. 3.ed. São Paulo: EDUSP, 2001.

MANEY, K. The King of Alter Egos is Surprisingly Humble Guy - Creator of Second Life's Goal? Just to Reach People. In: USA Today, 2007. Disponível em: <http:// www.usatoday.com/printedition/money/20070205/secondlife_cover.art.htm>. Acesso em 3 ago.2008.

MANOVICH, Lev. The Language of New Media. Cambridge: MIT Press, 2001.

MANOVICH, Lev. The Anti-Sublime Ideal in Data Art. Berlim, 2002.

MARKETING VOX. Married to RFID, What Can AR Do for Marketers?. 2010. Disponível em: <http: / / www.marketingvox.com/married-to-rfid-what-can-ar-do-for-marketers-046365/>. Acesso em: 10.dez.2010.

McCullagh D. FAQ: When Google is not your Friend. 2006. Disponível em: <http://news.zdnet.com/2100-9588_22-6034666.html?tag=nl.e539>. Acesso em: 15 dez.2006. 
MCLUHAN, Marshall. Understanding Media: The Extensions of Man. $1^{\text {st }}$ Ed., New York: McGraw Hil, 1964.

MIKE 2.0. Big data definition. 2012. Disponível em:

<http://mike2.openmethodology.org/wiki/Big_Data_Definition>. Acesso em:

18.jun.2012.

MILGRAM, P. \& KISHINO, F. A Taxonomy of Mixed Reality Visual Displays. In: IEICE Transactions on Information Systems. Vol. E77-D, No. 12. Dec.1994.

MURRAY, Janet H. Hamlet no Holodeck: o futuro da narrativa no ciberespaço.

Tradução Elissa Khoury Daher e Marcelo Fernandez Cuzziol. São Paulo: Itaú Cultural, 2003.

NAISBITT J.; NAISBITT N. \& PHILIPS D. High Tech High Touch: Technology and Our Search for Meaning. 1. Ed. USA: Broadway, 1999.

NEGROPONTE, N. A vida digital. São Paulo: Companhia das Letras, 1995.

O GLOBO. De “Moneyball a Davos: o Big Data se abre para o mundo. 2012. Disponível em: <http://oglobo.globo.com/tecnologia/de-moneyball-davos-big-data-se-abre-paramundo-4460918>. Acesso em: 18.jun.2012.

O GLOBO. Como funciona o Big Data. 2012. Disponível em:

<http://oglobo.globo.com/infograficos/bigdata/>. Acesso em 18.jun.2012.

PERKOWITZ, S. Digital People: From Bionic Humans to Androids. Washington: Joseph Henry Press, 2004.

PEW INTERNET \& AMERICAN LIFE PROJECT. How Media Habits have Changed Since 2000. 2010. Disponível em: <http: / /www.reportr.net/2010/06/25/pew-internet-onhow-media-habits-have-changed-since-2000/>. Acesso em: 3 out.2010.

PEW INTERNET \& AMERICAN LIFE PROJECT. Searching for Ourselves. 2010. Disponível em: <http://pewinternet.org/Reports/2010/Reputation-Management/Part-1/ Searchingfor-ourselves-online.aspx?r=1>. Acesso em 3 out. 2010.

PEW RESEARCH. Search Soars, Challenging Email as a Favorite Internet Activity. 2008. Disponível em: <http://pewresearch.org/pubs/921/internet-search>. Acesso em 3 out.2010.

PICTUREPHONING. Ultimatum For MMS \& Picture Recognition. 2007. Disponível em: <http://www.textually.org/picturephoning/archives/2007/08/016953.htm>. Acesso em 7.dez.2010.

PINKER, Steven. O Instinto da Linguagem - Como a mente cria a linguagem. São Paulo: Martins Fontes, 2002.

PINKER, Steven. Como a Mente Funciona. São Paulo: Companhia das Letras, 2004. 
PLAZA, Julio; TAVARES, Mônica. Processos Criativos com Meios Eletrônicos: Poéticas Digitais. São Paulo, Hucitec, 1998.

PLAZA, Julio. Arte e Interatividade: Autor-Obra-Recepção. In: Cadernos da PósGraduação, Campinas: Instituto de Artes da Unicamp, a.4, v.4, n.1, p. 23-39, 2000.

POOL, Ithiel de Sola. Technologies of Freedom. Boston: Belknap Press of Harvard University Press, 1984.

POPPER, Frank. Art of Electronic Age. Tradução Bernard Hemingway. New York: Harry N. Abrams, 1993.

POSTMAN, Neil. Tecnopólio: a rendição da cultura à tecnologia. Tradução Reinaldo Guarany. São Paulo: Nobel, 1992.

PRADO, Gilbertto. Arte Telemática: dos intercâmbios pontuais aos ambientes virtuais multiusuário. São Paulo, Itaú Cultural, 2003.

RECUERO; R. Redes Sociais na Internet. Rio de Janeiro: Mauad, 2009.

RECUERO, Raquel. As Redes Sociais na Internet e a Conversação em Rede. 2012. Disponível em: <http://www. pontomidia.com.br/raquel/ciseco.pdf>. Acesso em: 18.jun.2012.

RITZER, George; STEPNISKY, Jeffrey. The New Blackwell Companion to Major Social Theorists. Hoboken, USA: Wiley-Blackwell, 2011.

RWW. Augmented Reality: 5 Barriers to a Web That's Everywhere. 2010. Disponível em:

<http://www.readwriteweb.com/archives/augmented_reality_five_barriers_to_a_web_thats_eve. php>. Acesso em: 15 dez.2010.

RWW. Second Life Economy At Record High. 2010. Disponível em:

<http://www.readwriteweb.com/archives/second_life_economy_at_record_high.php>. Acesso em: 15.dez.2010.

RWW. 2010-2. 100 Uses of RFID. 2010. Disponível em:

<http://www.readwriteweb.com/archives/100_uses_of_rfid.php>. Acesso em: 15 dez.2010.

SANTAELLA, Lucia. Matrizes da Linguagem e Pensamento - Sonora, Visual, Verbal. São Paulo: Iluminuras, 2001.

SANTAELLA, Lucia. Linguagens Líquidas na Era da Mobilidade. São Paulo: Paulus, 2007.

SANTAELA, Lucia. A Semiose da Arte nas Mídias, Ciência e Tecnologia. In DOMINGUES, Diana (Org.). Arte, Ciência e Tecnologia. São Paulo: UNESP, 2009.

SCHOFIELD, Jack. In Japan, you can get a barcode for your tomb. 2008. Disponível em: <http://www.guardian.co.uk/technology/blog/2008/apr/05/injapanyoucangetabarcode>. Acessado em: 15.out.2010. 
SOCIAL MEDIA TODAY. Twitter Topic Searches, a New Way to Search. 2010. Disponível em: <http://www.socialmediatoday.com/johncass/146658/twitter-topic- searches-newway-search>. Acesso em 7 jun.2010.

SPIVACK; N. A New Layer of the Brain is Evolving: the Metacortex. 2010. Disponível em: <http: / /www.novaspivack.com/web-3-0/a-new-layer-of-the-brain-is-evolving-themetacortex>. Acesso em 15 abr.2011.

STANLEY, Morgan. Internet Trends. 2010. Disponível em:

<http://pt.scribd.com/doc/31350540/Morgan-Stanley-Internet-Trends-Analysis>. Acesso em: 5 mar.2012.

Tapscott D. Grown up Digital: How the Net Generation is Changing Your World. New York: McGraw-Hill, 2008.

TECHCRUNCH. Opera: Facebook Largest Mobile Social Network, Twitter Fastestgrowing. 2010. Disponível em: <http://eu.techcrunch.com/2010/01/26/opera-facebooklargest-mobile-social-network-twitter-fastest-growing/>. Acesso em: 8 dez.2010.

THOMPSON, C. Clive Thompson in Praise of Online Obscurity. 2010. Disponível em: <http://www.wired.com/magazine/2010/01/st_thompson_obscurity/>. Acesso em 8 abr.2011.

WACHOWSKI, Larry \& Andy. The Matrix: Comic Book Preview "The Matrix Has You". New York: Warner Brothers, 1999.

WIKIPEDIA. Dunbar's Number. 2010. Disponível em: <http://en.wikipedia. org/wiki/Dunbar\%27s_number>. Acesso em: 7 nov.2010.

WIKIPEDIA. Six Degrees of Separation. 2010. Disponível em: <http:// en.wikipedia.org/wiki/Six_degrees_of_separation>. Acesso: 7 nov.2010.

Wikipedia. Social Network. Disponível em: <http://en.wikipedia.org/ wiki/Social_network>. Acesso em 15 abr.2010.

WIKIPEDIA. Technological Convergence. 2010. Disponível em:

<http://en.wikipedia.org/wiki/Technological_convergence>. Acesso em: 1 out.2010.

WIKIPEDIA. Technology. 2012. Disponível em:

<http://en.wikipedia.org/wiki/Technology\#Definition_and_usage>. Acesso em: 1 mai.2012.

WILSON, S. Information Arts. Boston: MIT Press, 2002.

WILSON, S. Intersections of Art, Technology, Science \& Culture - Links. 2005. Disponível em: <http://userwww.sfsu.edu/ infoarts/links/wilson.artlinks2.html>. Acesso em: 10 jan.2006.

XAVIER, L. Johnnie Walker Black Label Investe em TV Móvel. 2010. Disponível em: <http://leonardoxavier.typepad.com/mobilizado/2010/01/johnnie-walker-black-labelinveste-em-tv-m\%C3\%B3vel.html>. Acesso em: 8.nov.2010. 
ZUFFO, J. A. A Convergência Digital e a Interpenetração de Mercados nas Tecnologias da Informação. Revista Fonte: Convergência Digital, Minas Gerais: Prodemge, a.2, n.3, p. 72-78, jul/dez. 2005. 
APÊNDICE A - Tabela de exemplos de Realidade Aumentada

\begin{tabular}{|c|c|c|c|}
\hline $\begin{array}{l}\text { Empresa/ } \\
\text { Produto }\end{array}$ & Descrição & URL & QRcode \\
\hline $\begin{array}{l}\text { A\&E Television } \\
\text { (game) }\end{array}$ & $\begin{array}{l}\text { Jogo de RA Five Lives of Criss } \\
\text { Angel. }\end{array}$ & $\begin{array}{l}\text { Demo: } \\
\text { <http://www.youtube.com/wa } \\
\text { tch?v=dIGnu4BEZKw> } \\
\text { Game: } \\
\text { <http://www.youtube.com/wa } \\
\text { tch?v=tb0pMeg1UN0> }\end{array}$ & \\
\hline $\begin{array}{l}\text { Acrossair } \\
\text { (navegador } \\
\text { localizador) }\end{array}$ & $\begin{array}{l}\text { Browser em RA para o iPhone } \\
\text { que permite localizar } \\
\text { informações nas redondezas, } \\
\text { além de possuir outras } \\
\text { funcionalidades. }\end{array}$ & $\begin{array}{l}\text { <http://www.youtube.com/wa } \\
\text { tch?v=0_mUFS992Cw> }\end{array}$ & \\
\hline $\begin{array}{l}\text { Adidas } \\
\text { (game) }\end{array}$ & $\begin{array}{l}\text { Jogo de RA presente na língua } \\
\text { do tênis. O jogo aparece no } \\
\text { computador, via webcam, e é } \\
\text { jogado com o próprio tênis. }\end{array}$ & $\begin{array}{l}<\text { http://www.youtube.com/watch? } \\
\text { v=ZsvorkhVCmg> }\end{array}$ & \\
\hline $\begin{array}{l}\text { Arcane } \\
\text { Technologies } \\
\text { (medicina) }\end{array}$ & $\begin{array}{l}\text { Aplicativo de RA que permite a } \\
\text { um estudante de medicina, ou } \\
\text { médico, visualizar internamente } \\
\text { o cérebro, em qualquer seção. }\end{array}$ & $\begin{array}{l}<\text { http: / / www.youtube.com/wa } \\
\text { tch?v=9qqUrhGQEiE> }\end{array}$ & \\
\hline
\end{tabular}




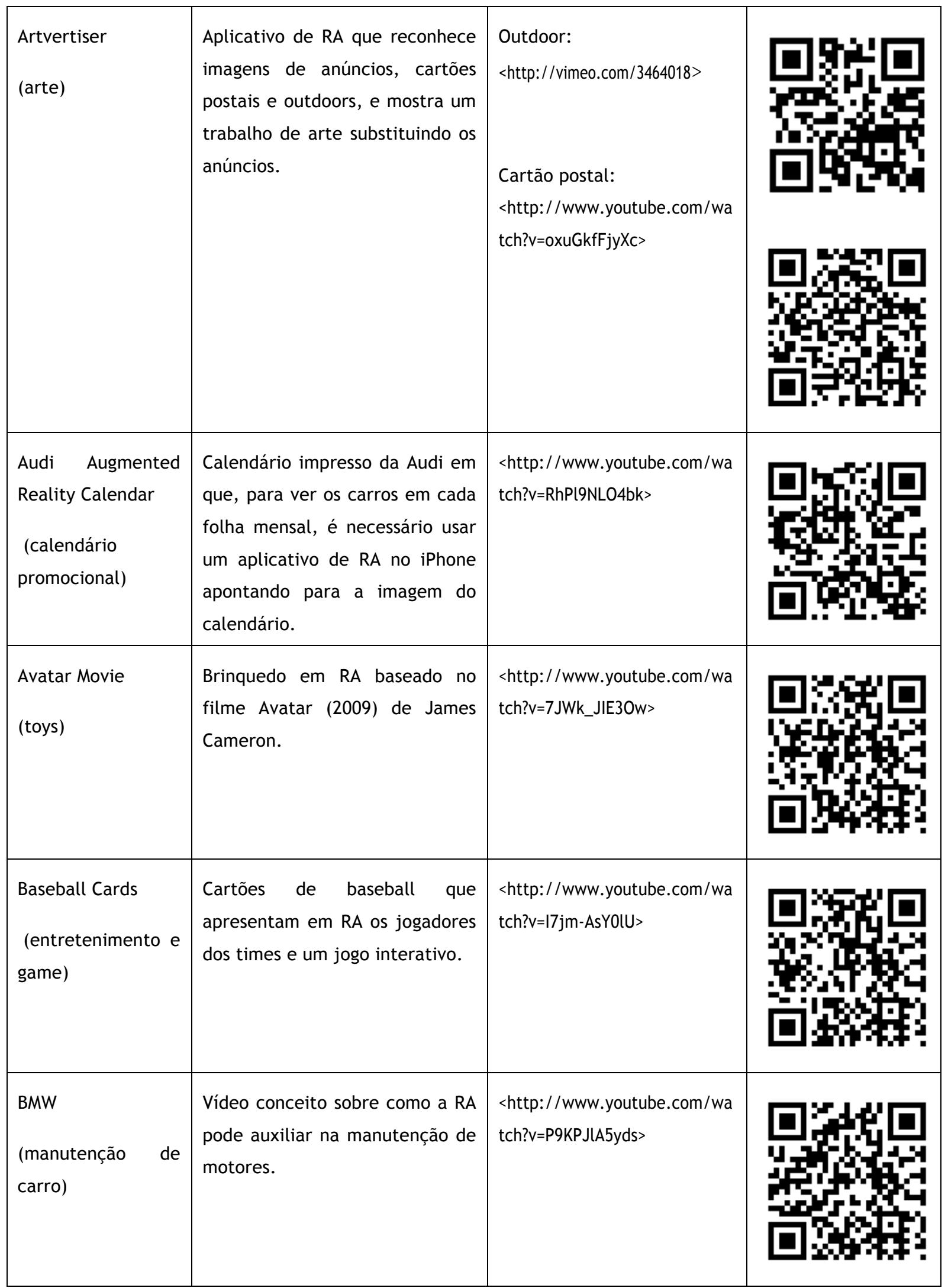




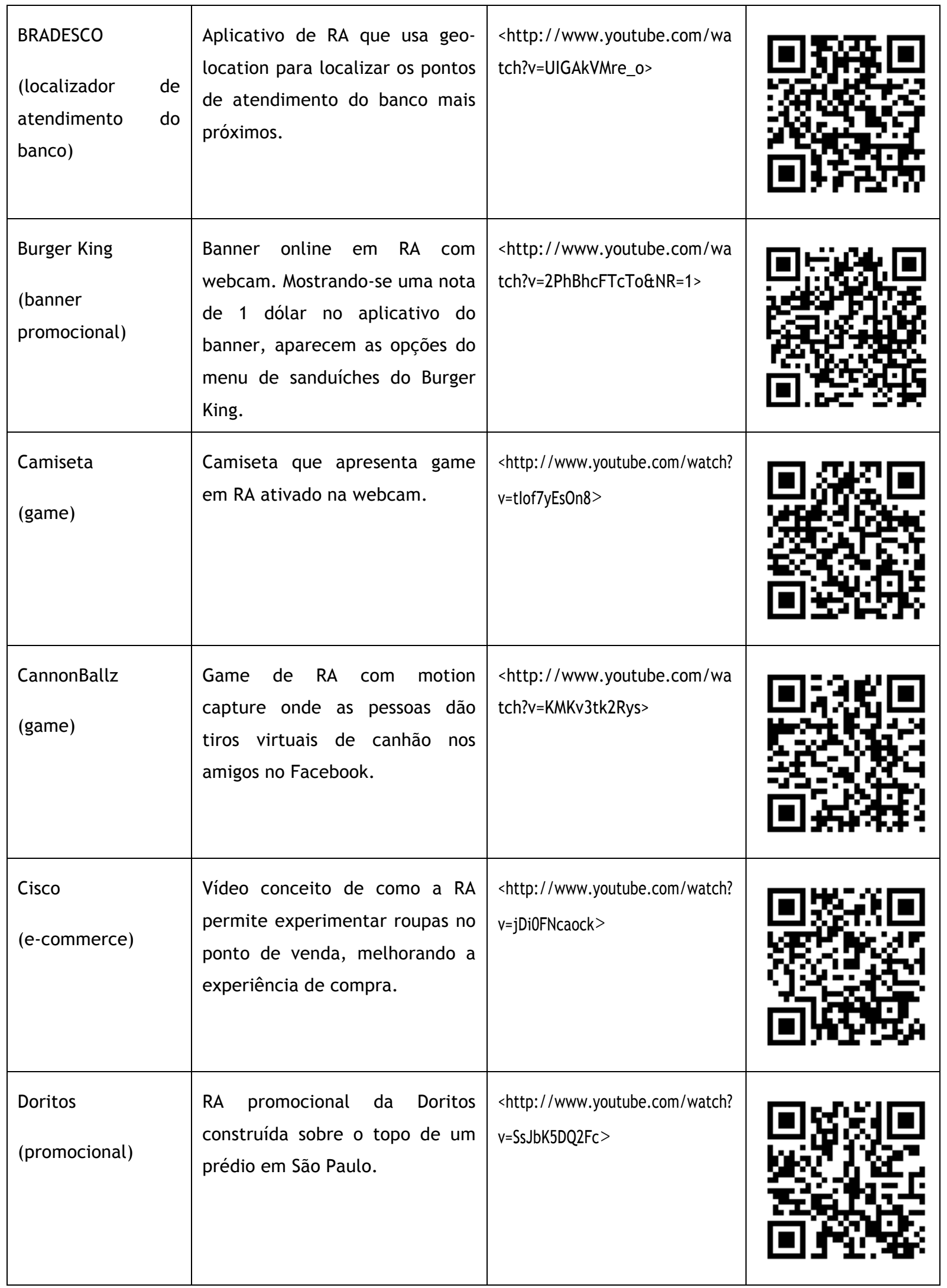




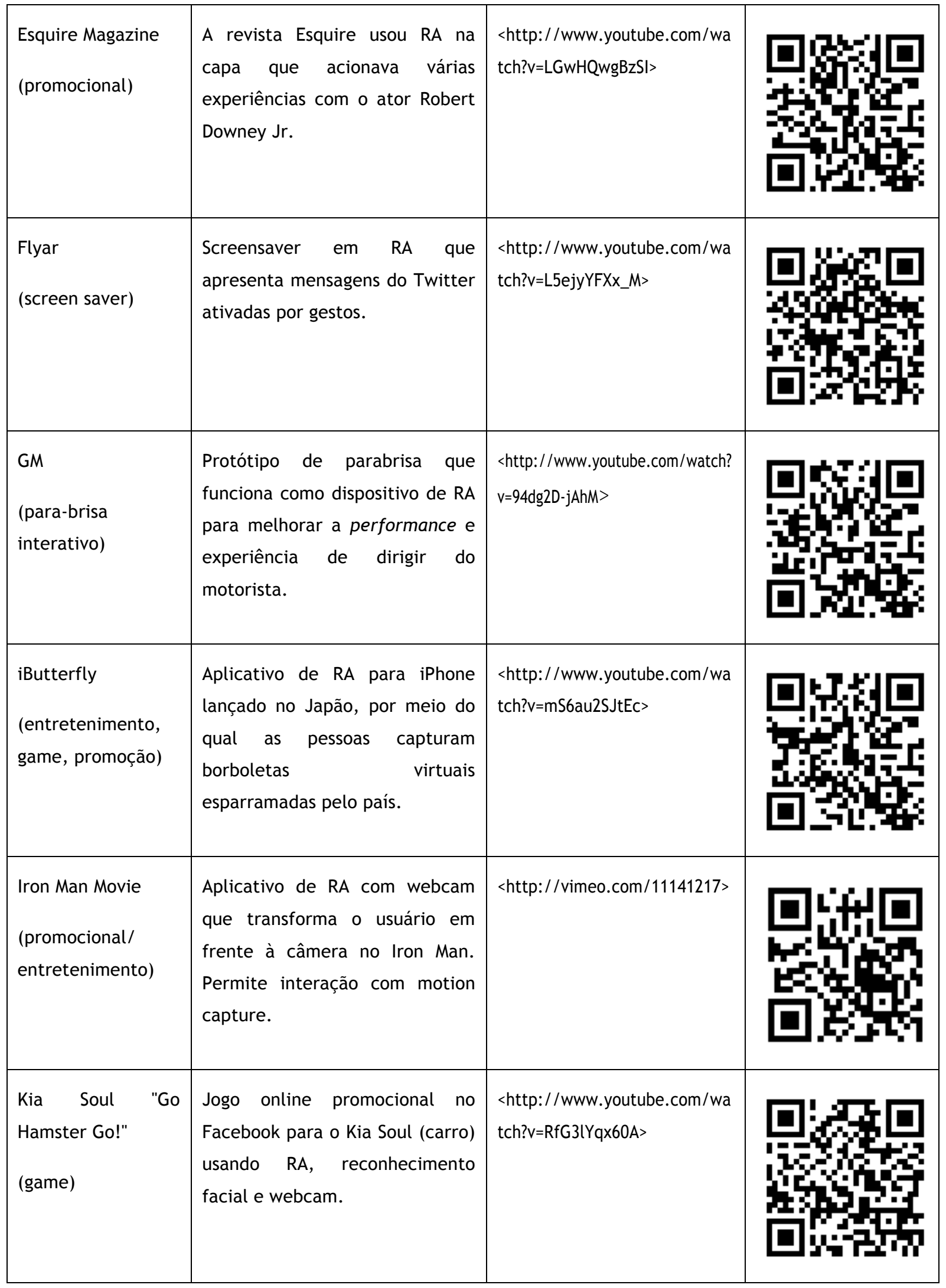




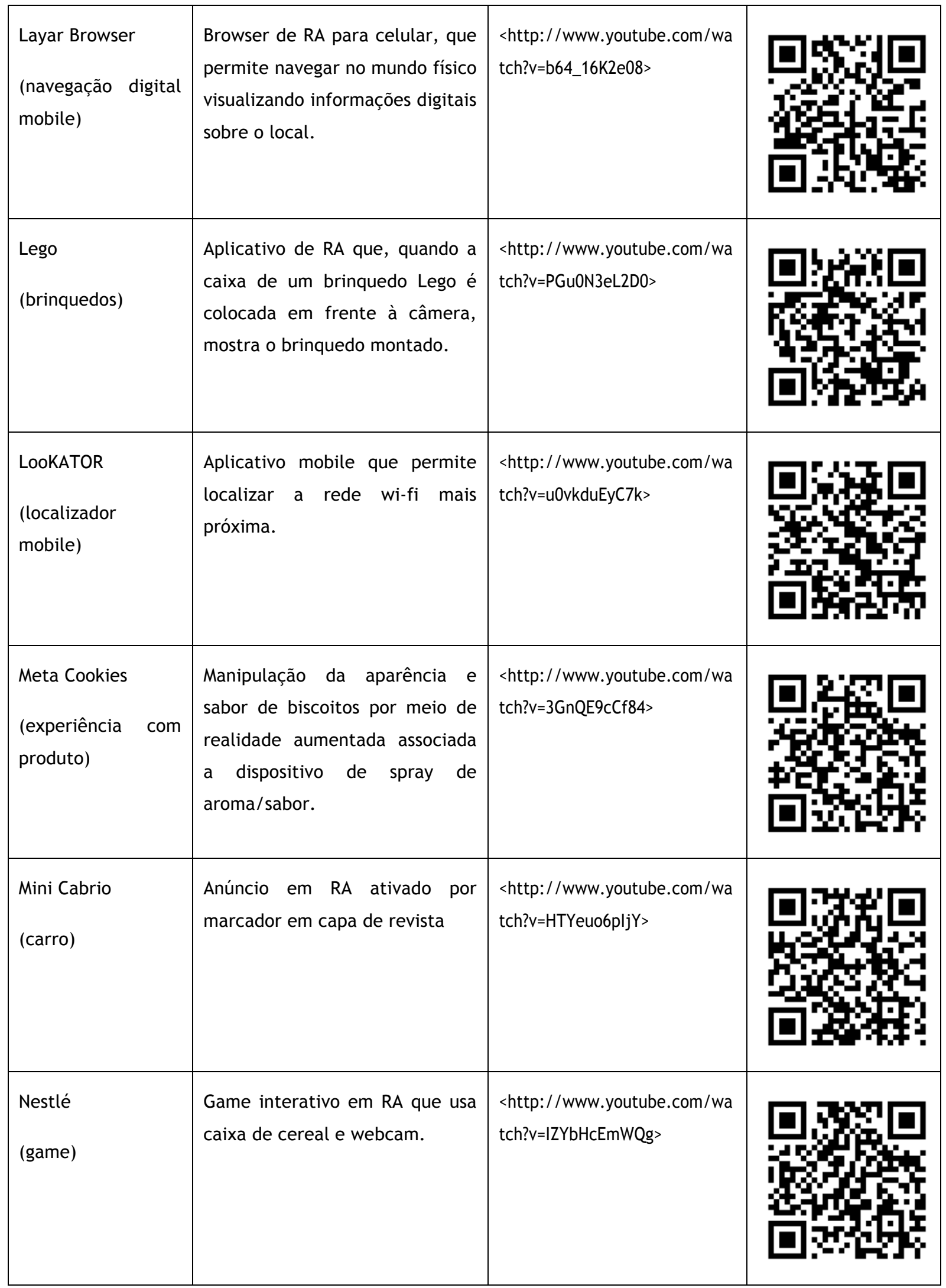




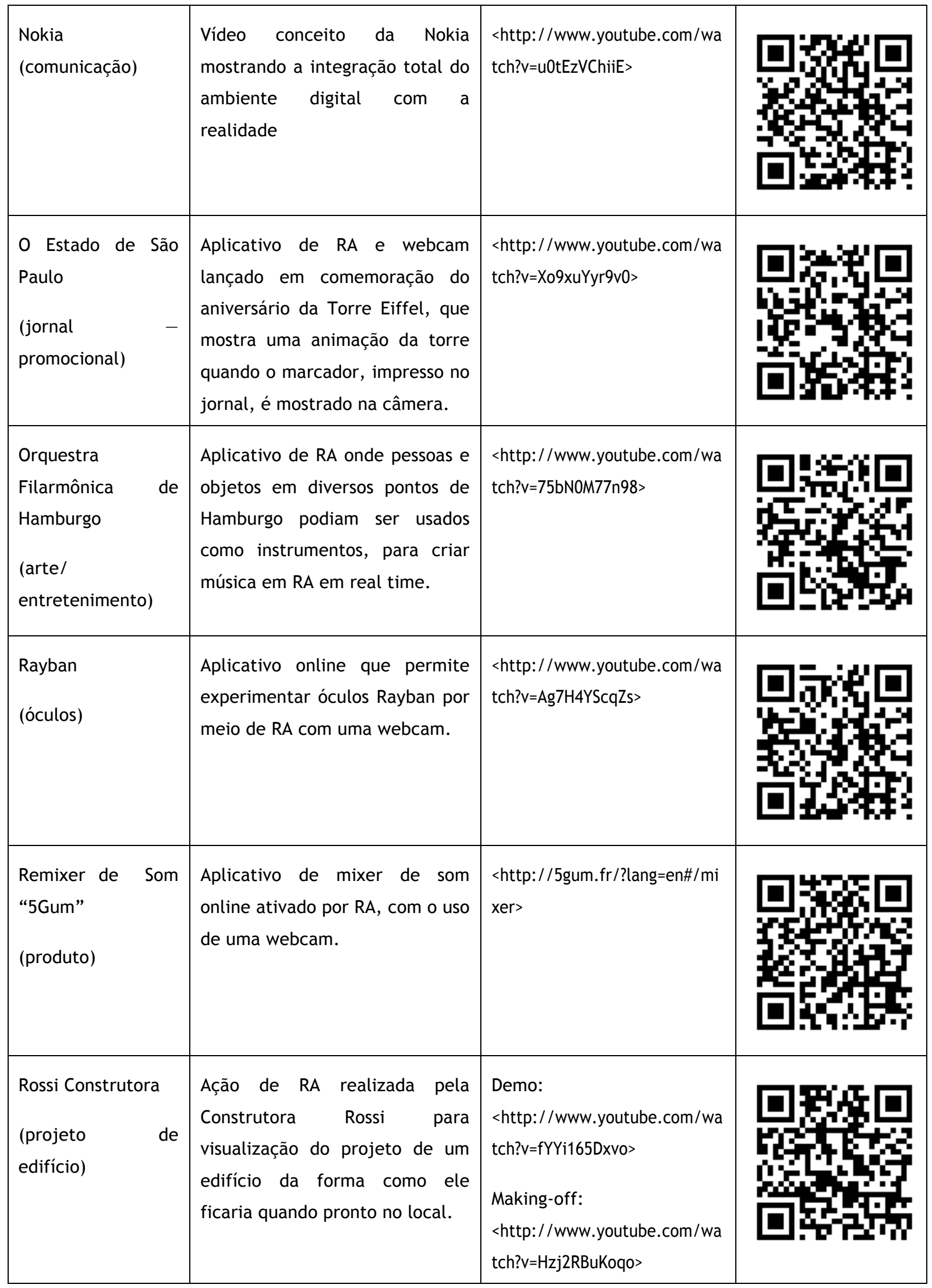




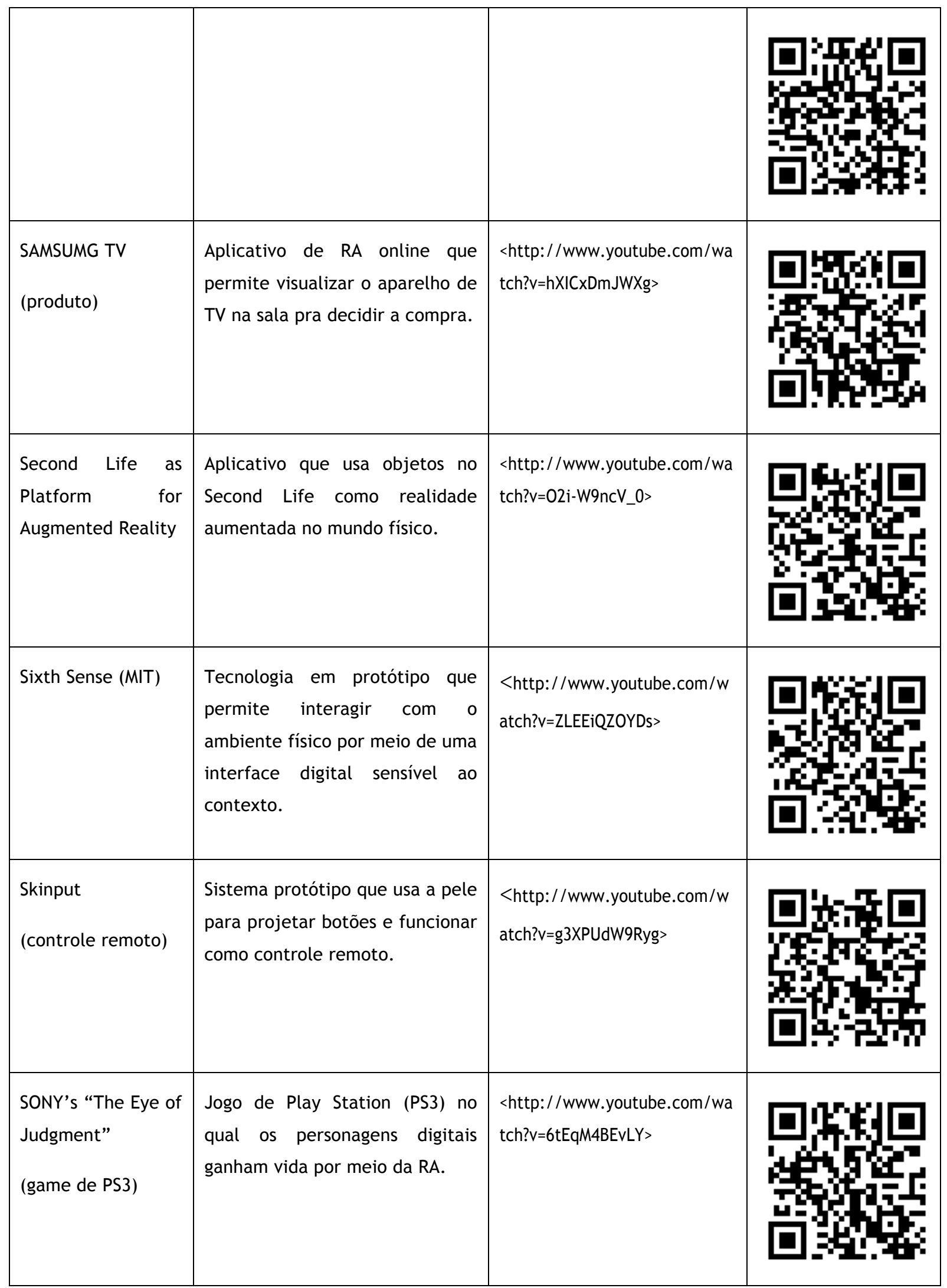




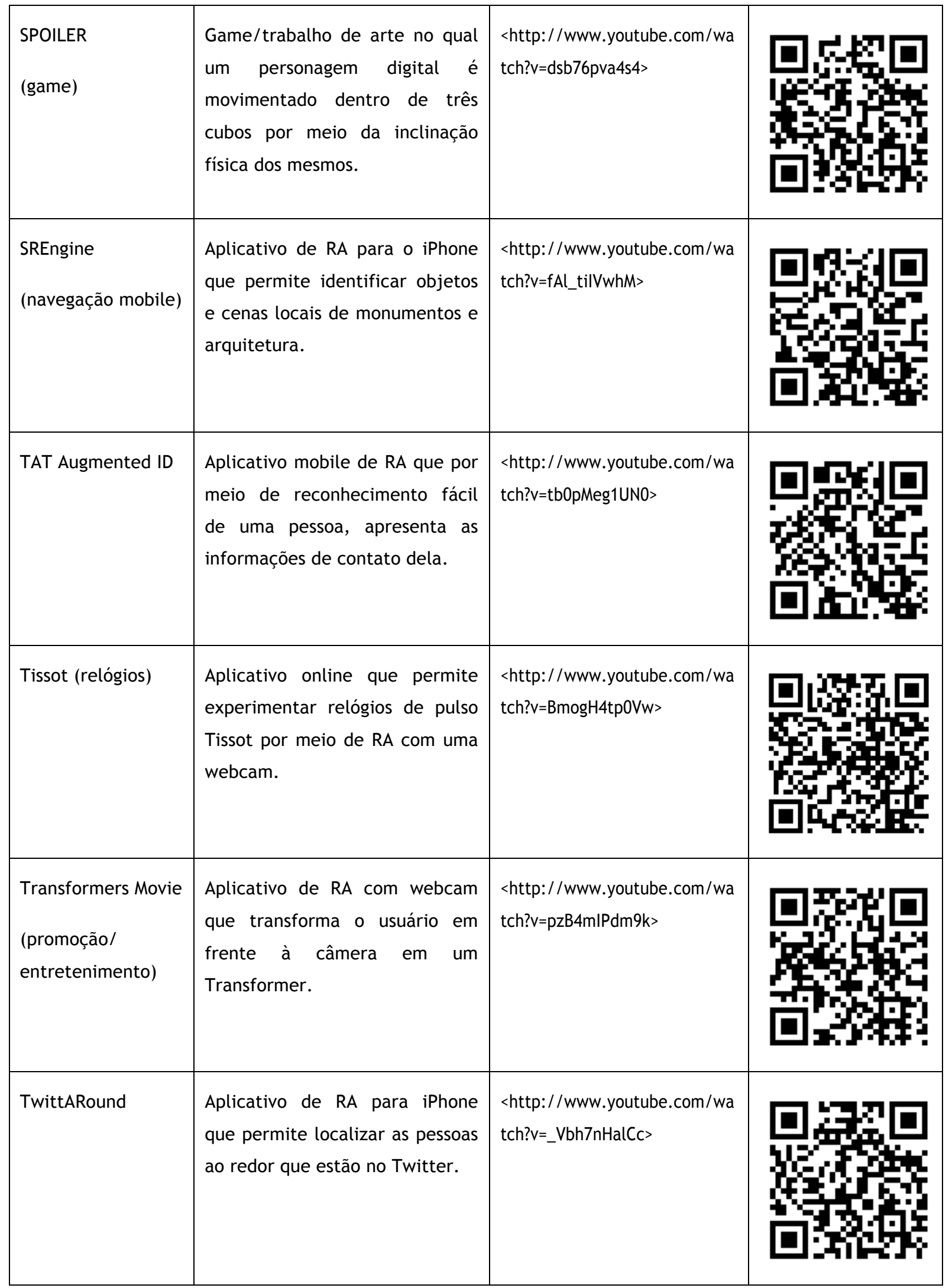




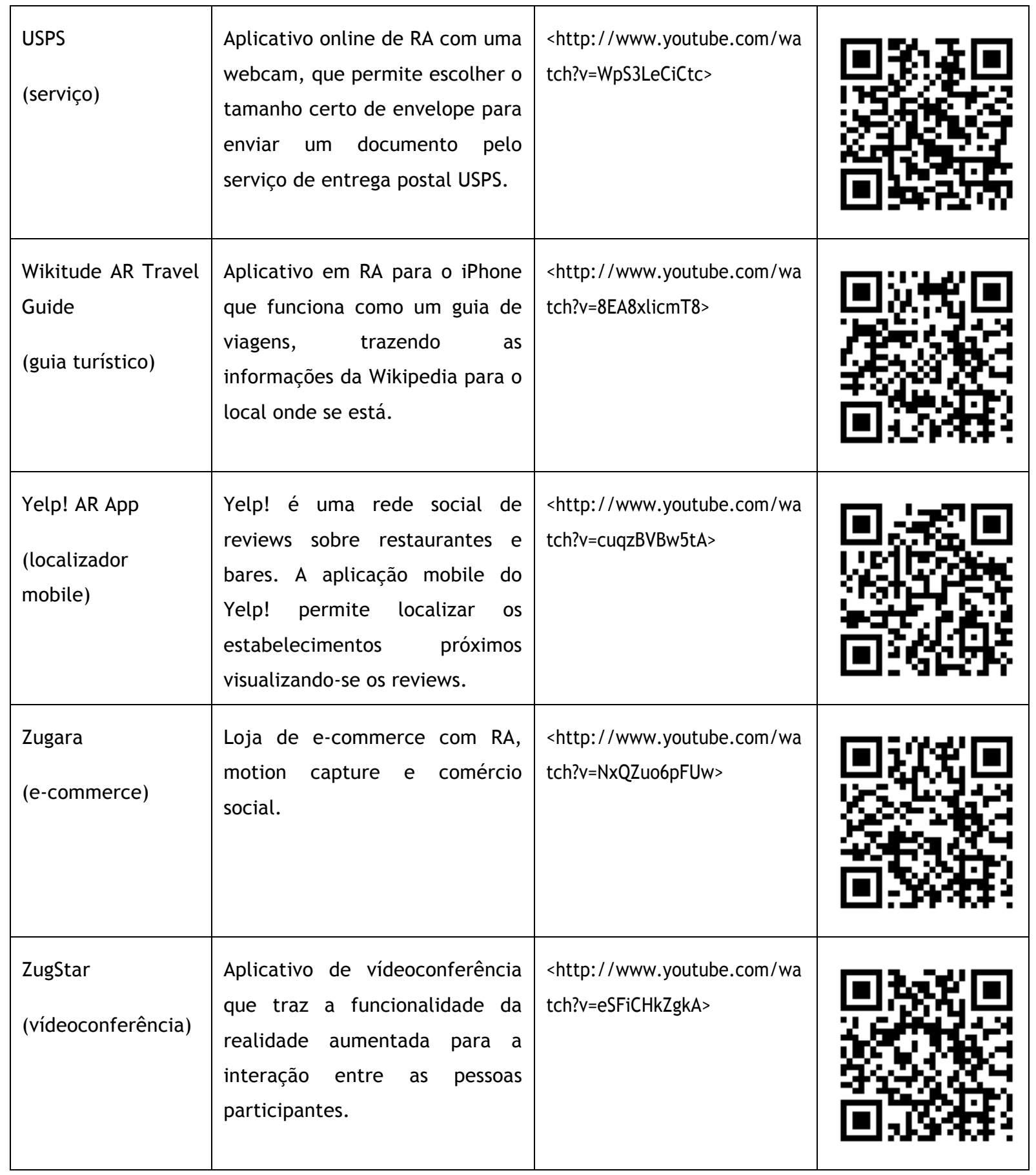

Tabela A.1 - Exemplos de Realidade Aumentada (fonte: Martha Gabriel) 